\title{
Tape Calendering Manufacturing Process for Multilayer Thin-Film Solid Oxide Fuel Cells
}

Final Report - Phases I and II September 2000 - April 2004

Dr. Nguyen Minh, Kurt Montgomery

October, 2004

DE-AC26-00NT40705

Hybrid Power Generation Systems, LLC

19310 Pacific Gateway Drive

Torrance, CA 90502 


\section{DISCLAIMER}

"This report was prepared as an account of work sponsored by an agency of the United States Government. Neither the United States Government nor any agency thereof, nor any of their employees, makes any warranty, expressed or implied, or assumes any legal liability or responsibility for the accuracy, completeness, or usefulness of any information, apparatus, product, or process disclosed, or represents that its use would not infringe privately owned rights. Reference herein to any specific commercial product, process, or service by trade name, trademark, manufacturer, or otherwise, does not necessarily constitute or imply its endorsement, recommendation, or favoring by the United States Government or any agency thereof. The views and opinions of authors expressed herein do not necessarily state or reflect those of the United States Government or any agency thereof." 


\begin{abstract}
This report summarizes the work performed by Hybrid Power Generation Systems, LLC during the Phases I and II under Contract DE-AC26-00NT40705 for the U. S. Department of Energy, National Energy Technology Laboratory (DOE/NETL) entitled "Tape Calendering Manufacturing Process For Multilayer Thin-Film Solid Oxide Fuel Cells". The main objective of this project was to develop the manufacturing process based on tape calendering for multilayer solid oxide fuel cells (SOFC's) using the unitized cell design concept and to demonstrate cell performance under specified operating conditions.

Summarized in this report is the development and improvements to multilayer SOFC cells and the unitized cell design. Improvements to the multilayer SOFC cell were made in electrochemical performance, in both the anode and cathode, with cells demonstrating power densities of nearly $0.9 \mathrm{~W} / \mathrm{cm}^{2}$ for $650^{\circ} \mathrm{C}$ operation and other cell configurations showing greater than $1.0 \mathrm{~W} / \mathrm{cm}^{2}$ at $75 \%$ fuel utilization and $800^{\circ} \mathrm{C}$. The unitized cell design was matured through design, analysis and development testing to a point that cell operation at greater than $70 \%$ fuel utilization was demonstrated at $800^{\circ} \mathrm{C}$. The manufacturing process for both the multilayer cell and unitized cell design were assessed and refined, process maps were developed, forming approaches explored, and nondestructive evaluation (NDE) techniques examined.
\end{abstract}




\section{TABLE OF CONTENTS}

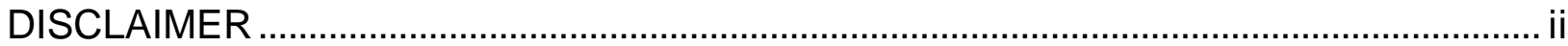

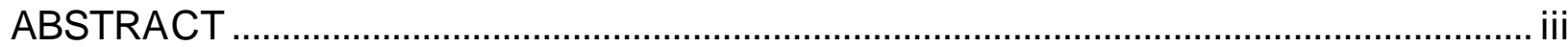

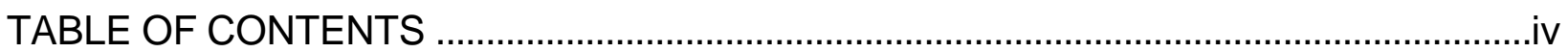

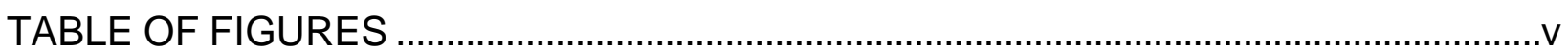

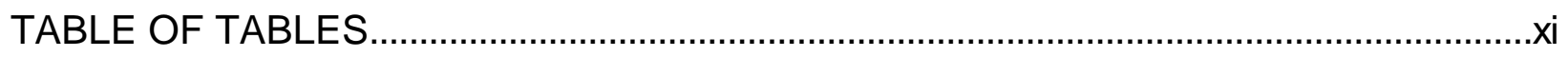

EXECUTIVE SUMMARY ..........................................................................................

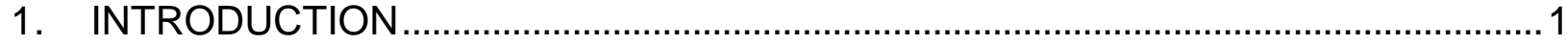

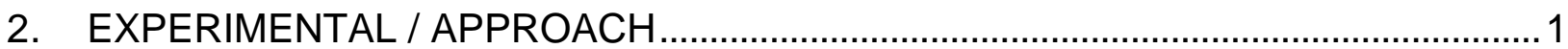

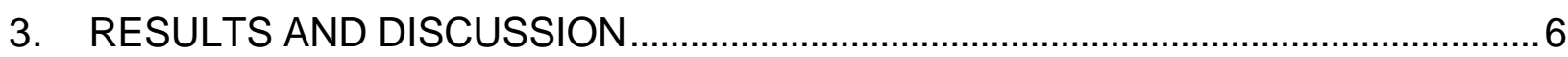

3.1 Multilayer Cell Fabrication and Improvement 6

3.1.1 Cathode Improvements 6

3.1.2 Anode Improvements 25

3.1.3 Cell Mechanical Properties Improvements 31

3.2 Unitized Cell fabrication and design 43

3.2.1 Unitized Cell Design Development 43

3.2.2 Improved Flow Distribution Validation Testing 49

3.3 Manufacturing Process Development 53

3.3.1 Cell Fabrication Process 53

3.3.1.1 Baseline Cell Fabrication Process Verification \& Validation 53

3.3.1.2 Non-Destructive Evaluation (NDE) 64

3.3.2 Interconnect Fabrication Process 83

3.3.2.1 Formability of sheet metal interconnects 83

3.3.2.2 Flatness and Variability in Sheet Metal Interconnects 95

3.3.2.3 Metallic Interconnect Assembly Methods 99

3.3.3 Unitized Cell Module Fabrication 109

3.3.3.1 Assembly of Unitized Cell Modules 109

3.3.3.2 Performance Testing 116

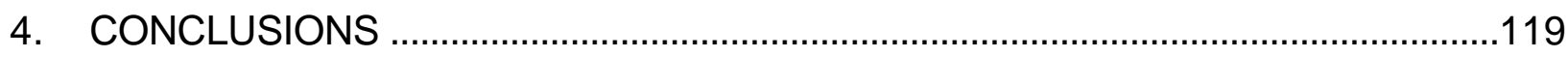

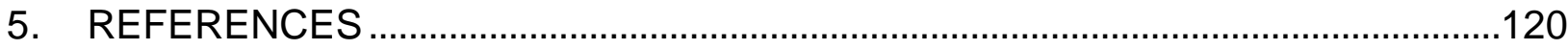

DE-AC26-00NT40705 IV 


\section{TABLE OF FIGURES}

Figure 1. Fabrication sequence for fabrication of cells. .................................................

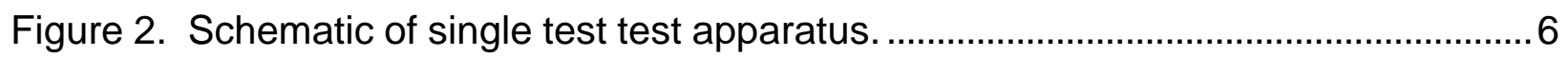

Figure 3. Cell (NJ003-1) performance at $800^{\circ} \mathrm{C}$ in $\mathrm{H}_{2} / \mathrm{N}_{2}$ fuel with a fixed fuel flow rate of $67 \mathrm{cc} / \mathrm{min}$ and non-flowing air. ......................................................................................

Figure 4. Performance of cell NJ003-1 at different temperatures under hydrogen fuel with a fixed fuel flow rate of $67 \mathrm{cc} / \mathrm{min}$ and non-flowing air. ....................................... 8

Figure 5. Typical impedance spectra at $800^{\circ} \mathrm{C}$ at OCV (SPC-3 cathode) ........................ 9

Figure 6. Effects of DC bias on cathode polarization at $700^{\circ} \mathrm{C}$ (SPC-3 cathode). .........10

Figure 7. Performance of cell NJ009-2 with a conductive layer on the cathode with a fixed fuel flow rate of $67 \mathrm{cc} / \mathrm{min}$ and non-flowing air. 11

Figure 8. Cathode impedance of NJ003-1 (no conductive layer) and NJ009-2 (with

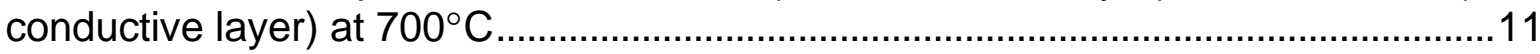

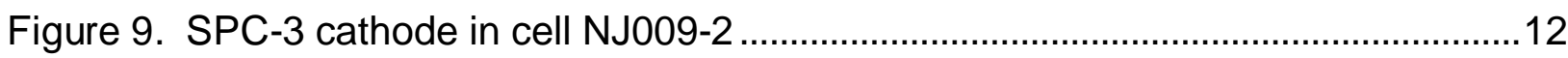

Figure 10. SPC-4 cathode in cell NN33 ................................................................... 12

Figure 11. Polarization of cell NJ59-1 under hydrogen with a fixed fuel flow rate of 67

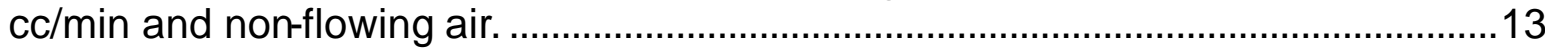

Figure 12. Cell performance at $0.826 \mathrm{~A} / \mathrm{cm}^{2}$ and $70 \%$ fuel utilization .............................15

Figure 13. Polarization of cell NP105 under hydrogen with a fixed fuel flow rate of 67

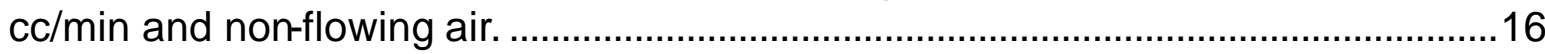

Figure 14. Microstructure of the SPEX-5 cathode in cell NJ097 .................................17

Figure 15. Cell NJ097 with experimental cathode, SPCEX-5 with pure hydrogen fuel and a fixed fuel flow rate of $67 \mathrm{cc} / \mathrm{min}$ and non-flowing air........................................18

Figure 16. Cathode Microstructure with Graded Porosity (Cell NJ128) .........................19

Figure 17. Performance losses in Cell NJ128 and NJ59-1 at $700^{\circ} \mathrm{C}$............................19

Figure 18. Polarization of Cell NP117 with hydrogen as fuel and air as oxidant............20

Figure 19. SEM Micrograph of a polished cross section of the cathode of cell NP112-1, electrolyte surface at the bottom of the micrograph. 21

Figure 20. Polarization of Cell NP126-1 with hydrogen as fuel and air as oxidant. .......22

Figure 21. SEM micrograph of a polished cross section of cathode in cell NP126-1 ...22

Figure 22. Micrograph of anode with graphite fiber pore former (NN33) ........................26

Figure 23. Micrograph of a bilayer made with anode "N" (NJ009) …...............................28

DE-AC26-00NT40705 v 
Figure 24. Anode "B" cell performance under different fuel utilization at $800 \mathrm{C}$, and hydrogen as the fuel and air as oxidant.

Figure 25. Cell Performance of NJ205-1 with porous anode "C" and SPC-4 Cathode, hydrogen as fuel and air as oxidant. 30

Figure 26. Performance of cell NJ205-1 at $1.72 \mathrm{~A} / \mathrm{cm}^{2}$ load and $75 \%, 80 \%, 85 \%$ fuel utilizations at $800^{\circ} \mathrm{C}$, hydrogen as fuel and air as oxidant. 30

Figure 27. Polarization curve for a cell with anode " $\mathrm{C}$ " and an improved cathode SPCEX5 at $800^{\circ} \mathrm{C}(\mathrm{NJ} 208)$. 31

Figure 28. (a) Testing set-up with (b) details of the ring-on-ring loading fixture. A high temperature controlled gas enclosure surrounded the fixture during high temperature testing.

Figure 29. Characteristic strength of the tested samples. …………..............................35

Figure 30. Tested bilayer samples (a) air, $800^{\circ} \mathrm{C}$ and (b) reduced, $800^{\circ} \mathrm{C}$...................36

Figure 31. Measured residual stress in the electrolyte for the bilayer samples. The effect of the mismatch in the coefficient of thermal expansion (CTE) is clearly seen in the results. Where the inverted triangles are for the reduced samples and the circles are for the unreduced sample. 37

Figure 32. SEM image of the surface of the anode with YSZ powders which are present during sintering. 38

Figure 33. Fracture surfaces of reduced bilayers at (a) $25^{\circ} \mathrm{C}$ and (b) $800^{\circ} \mathrm{C}$. The anode surface is at the top and the arrows indicate the location of dense YSZ possibly originating from the powder on the surface shown in Figure 32 39

Figure 34. (a) Fracture surface of a reduced bilayer with (b) magnified image of the interface showing zones of local high porosity.

Figure 35. Biaxial flexure strength data for the various mechanical properties improvement stratagies. 41

Figure 36. Performance of a cell with a 3Y-anode composition with pure hydrogen fuel and a fixed fuel flow rate of $67 \mathrm{cc} / \mathrm{min}$ and non-flowing air.

Figure 37. Polarization curve for 3Y-20A baseline anode cell. Cathode was SPC-4 ...42

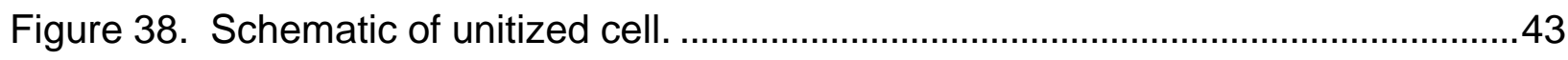

Figure 39. Typical fabrication sequence for unitized cell fabrication and stacking.........44

Figure 40. Diagram of the interconnect structure for cell NO023...................................45

Figure 41. Split Flow design. .................................................................................

Figure 42. Effect of total gas flow rate on the gas flow rate at individual exit holes ( 1 is nearest the inlet).................................................................................................... 48

DE-AC26-00NT40705 vi 
Figure 43. Percentage of total mass flow versus axial distance for various design iterations.

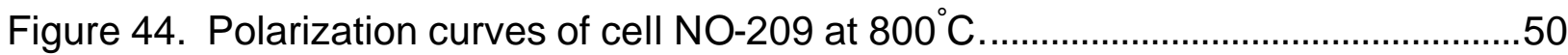

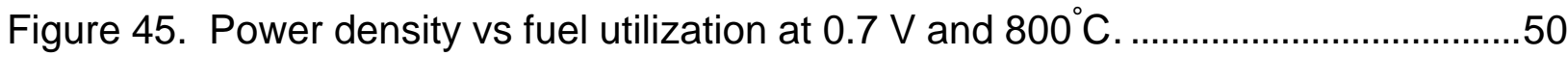

Figure 46. Cell NO-215 polarization curves at $800^{\circ} \mathrm{C}$ under different fuel flow rates. ....51

Figure 47. Cell NO-215 power density vs. fuel utilization at different temperatures. .....52

Figure 48. Pareto chart of key manufacturing parameters. ...........................................54

Figure 49. Fishbone of the baseline process variation in SOFC manufacturing. Impact was assigned based on expert judgment, and was used to guide prioritization of areas to be investigated.

Figure 50. A small section of the data sheet collected on bilayer tape manufacturing..56

Figure 51. Descriptive statistics of bilayer tape thickness for 118 bilayer cell tapes that remained from the manufacture of 126 cells.

61

Figure 52. Descriptive statistics on the bilayer cell tape weight based on 118 bilayer cell tapes that remained from the manufacture of 126 cells.

Figure 53. Flatness run chart for the first 30 fired bilayers. The red line denotes the mean flatness. 63

Figure 54 X-ray digital radiography of three tapes in various stages of processing, TN4719 = electrolyte tape, TN 4758 = bilayer tape (electrolyte, anode 1, and anode 2) with the electrolyte surface up, and TN4782 = anode 2 tape. The electrolyte tape and anode 2 tapes are representative of the tapes used to fabrication the bilayer tape shown.

66

Figure 55. IR and X-ray images of the sintered bilayer sample NDE-9 are shown. The upper left panel is an IR image of the front surface whereas the lower left panel is the back surface. The X-ray image is shown in the right panel. Note: this cell was broken and only half of the cell is seen in the image and the sample was imaged with the electrolyte surface up. 67

Figure 56. SOFC sample NDE-5 is shown under IR (left) and X-ray (right). 68

Figure 57: The flatness and surface smoothness of the sample NDE-5 is shown as a function of the position on a diameter.

Figure 58 X-ray images of the SOFC plate (NDE-3) are shown in reverse video (i.e. white is low density, and black indicates high density). The right panels where taken at higher magnification. 70

Figure 59. Two ultra-sonic images of sample NDE-3 are shown in the panels above. The left panel shows a surface wave image while the right panel shows an impulse reverberation image. 70 
Figure 60. SEM image is of the defect cross - section with a higher magnification image shown on the right.

Figure 61. Two images of SOFC (NDE-7) are shown. The left panel is an IR-image and the right panel is an $\mathrm{X}$-ray radiograph.

72

Figure 62. X-ray radiograph of bilayer tape (NDE-S2) with the calibration standards in the left side of the frame (left). The right panel shows a enlarged region of the cell (NDE-S2) illustrating defects or non-uniformities at the $600 \mu \mathrm{m}$ (15 mil) level. Black points, (circled in red) identify voids, while white points (circled in green), indicates regions of high density. .74

Figure 63. X-ray radiograph of bilayer tape (NDE-S5) with the aluminum calibration standards in the left side of the frame .75

Figure 64. X-ray radiographs of bilayers NDE-S2 (left) and NDE-S5 (right) after sintering. Both images are shown rendered in the identical gray scale. Shown on the inset of each image is a re-normalized gray scale image of the apparent "missing" edges of the bilayers. .76

Figure 65. X-ray radiographs of NDE-S2 before (left) and after (right) cathode application. Two circles creating an annulus have been drawn on the fired bilayer image to give an approximate indication of where the cathode was deposited.......77

Figure 66. X-ray images of sample NDE-S2 before (left) and after (right) cathode firing. .78

Figure 67. Photograph and wide latitude X-ray radiograph (right) of the sample NDE-S5 after the cathode has been fired. 79

Figure 68. Radiographs of samples NDE-S2 (left) and NDE-S5 (right) are shown above.

Figure 69. Fixed flow polarization curve for NDE cells S4, S7 and S9. Tests were performed with $64 \%$ hydrogen and balance nitrogen for fuel and at $800^{\circ} \mathrm{C}$. .80

Figure 70. Polarization curves for 3 NDE cells S4, S7 and S9 under fixed fuel utilizations. All data was taken at $800^{\circ} \mathrm{C}$ under $64 \%$ hydrogen balance nitrogen for fuel and $20 \%$ air utilization. 81

Figure 71. Engineering stress strain curves from 0.025 " thick stainless sheets. .84

Figure 72. Sample dimensions used for forming limit curve generation. .86

Figure 73. Samples prior to testing. .86

Figure 74. Limiting strains measured on 0.025 " thick stainless steel. .87

Figure 75. Method to shift forming limit curves between various sheet thicknesses. ....88

Figure 76. Forming limit curves for (a) 0.025" thick stock; (b) 0.010" thick stock; (c) 0.005 " thick stock. .88 
Figure 77. Typical corner dimensions that may pose limits on stamped interconnect

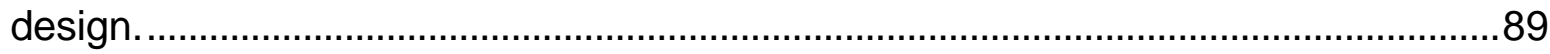

Figure 78. Flow/current collector features that may be stamped in sheet metal

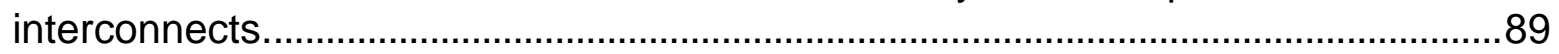

Figure 79. Axisymmetric finite element simulations for determination of $\mathrm{R}_{\mathrm{ROOT}}$..............90

Figure 80. Calculated major strains for (a) draw depth of $1 \mathrm{~mm}$ and (b) draw depth of $2 \mathrm{~mm}$. 91

Figure 81. Forming limit diagrams of strains in inside (left) and outside (right) corners for 0.025 " sheet. Draw depth $=0.250$ ".

Figure 82. Forming limit diagrams of strains in inside (left) and outside (right) corners for 0.010 " sheet. For Draw depth $=0.250$ ". .92

Figure 83. Deformed element plot for forming of 0.005 " thick stock into a corner with radius of $0.050 "$. .93

Figure 84. Schematic of the 1.5" stamped cup test vehicle. .94

Figure 85. Photograph of a 1.5" stamped cup test vehicle, 0.025 " thick metal sheet....94

Figure 86. Components of 6" test vehicle, from left to right: Stamped interconnect "pan"; manifold spacer sheet; anode current collector perforated sheet; cathode current collector support sheet; cathode current collector perforated sheet; 4" tape calendared cell. .95

Figure 87. Schematic representation of interconnect non-flatness. (a) Ideal situation; cell and interconnect are flat. (b) Local non-uniformity in current collector surface (c) Global curvature in current collector. Contact resistance varies with bond paste thickness and contact pressure. 96

Figure 88 . $115 \mathrm{~mm}(4.53$ ") square sheet of $0.127 \mathrm{~mm}(0.005$ ") thick stainless steel sheet was stamped with an array of dimples. Dimple diameter $=3.5 \mathrm{~mm}(0.138$ "); spacing $=4 \mathrm{~mm}(0.154 ")$; height $=0.5 \mathrm{~mm}(0.197 ")$. .97

Figure 89. Flatness measurements on prototype interconnect. 97

Figure 90. Height profiles for four 6" interconnects. .98

Figure 91. Spring back simulation in cup drawing of a 2" ID cup, to a depth of 0.2 ". ..98

Figure 92. Springback in 1.5" cups .99

Figure 93. Resistance projection welding process schematic. 101

Figure 94. Laser edge weld (small spot) of two 0.025 " thick sheets 103

Figure 95. Laser edge weld (large spot). 103

Figure 96. Laser lap weld of two 0.025 " thick sheets. 104 
Figure 97. Laser lap weld of two 0.025 " thick sheets that resulted in a full penetration

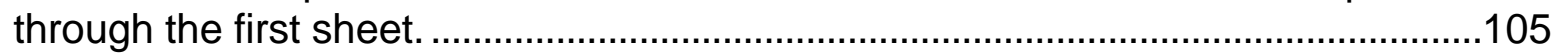

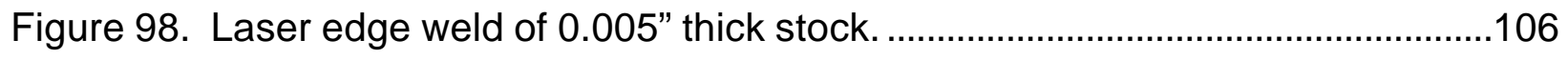

Figure 99. E-beam edge weld of 0.025 " thick sheets...................................................106

Figure 100. E-beam lap weld of 0.025 " thick sheets. ................................................107

Figure 101. Photograph of samples after laser edge welding of 0.025 " material with glass sealed cell. 108

Figure 102. Photograph of samples after E-beam welding of 0.025 " material with glass sealed cell. 108

Figure 103. Schematic of planar SOFC stack, cell module, and components. 111

Figure 104. Design choices that govern stack assembly pathways. 112

Figure 105. Assembly operations in building a stack. 112

Figure 106. Sequence \#1 All at once - pre-assemble all metallic interconnect components along with cell support. 114

Figure 107. Sequence \#2a: Close anode side interconnect, seal cell before stack, assemble and manifold.

Figure 108. Sequence \#2b: Preseal cell, close interconnect, assemble and manifold. 115

Figure 109. Six inch test vehicle cross-section schematic. 116

Figure 110. Stamped, laser welded 6" interconnects. Cathode interconnect (left); Anode interconnect (right).

Figure 111. Curvature measurements on cell and interconnects used in test Oly001. 117

Figure 112. Performance curve from test Oly001 118

Figure 113. Performance curve from test Oly002. 119 


\section{TABLE OF TABLES}

Table 1. Characterization of Starting Materials ....................................................................

Table 2. Characterization of Green Tapes …………..................................................... 4

Table 3. Characterization of Fired Components ................................................................

Table 4. Observed Peak Power $\left(\mathrm{W} / \mathrm{cm}^{2}\right)$ of Cell NJ003-1 at Different Temperatures and Hydrogen Concentrations.

Table 5. Peak Power Densities for Cells SPC-3 and SPC-4 Cathodes at Different Temperatures....................................................................................................14

Table 6. Peak Power Densities for Cells NP105, NJ059-1, and NJ003-1 at Different Temperatures .......................................................................................................16

Table 7. Cathode Grading Layers. .............................................................................20

Table 8. Cathode Electrode Powder Descriptions .............................................................23

Table 9. Summary of Test Results of Cells with Different Cathode Designs ..................24

Table 10. Compositions Evaluated for Anode Engineering ${ }^{*}$..........................................27

Table 11. Test Matrix for Mechanical Testing. The number of samples tested at each

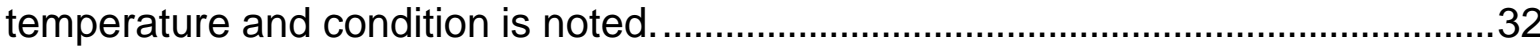

Table 12. The Characteristic Flexural Strength (MPa) and the Weibull Modulus for the Tested Samples...................................................................................................34

Table 13. Performance Summary for Unitized Cells .....................................................52

Table 14. Description of Data Categories and the Amount and Types of Data

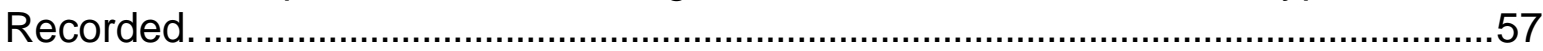

Table 15. Manufacturing Yields for Tape Calendared SOFC's. .....................................58

Table 16. Firing Yields of 4 inch Bilayers in 7 Different Furnaces. .................................59

Table 17. Summary of Cell Examined by NDE ............................................................73

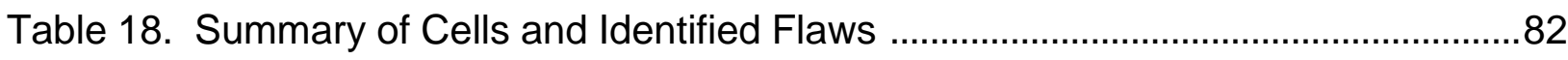

Table 19. Summary of Tensile Tests on Stainless Steel Sheets. ..................................... 85

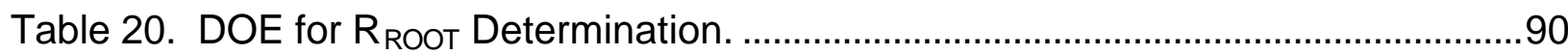

Table 21. Inside/Outside Corner Radius DOE ...............................................................

Table 22. Comparitive Assessment of Sheet Metal Joining Processes .........................101

Table 23. Desgin of Experiment on Sheet Metal Weld Configurations ..........................102

Table 24. Interactions Between Components and Assembly Operations ......................113

DE-AC26-00NT40705 Xi 


\section{EXECUTIVE SUMMARY}

This report summarizes the work performed by Hybrid Power Generation Systems, LLC during the Phases I and II under Contract DE-AC26-00NT40705 for the U. S. Department of Energy, National Energy Technology Laboratory (DOE/NETL) entitled "Tape Calendering Manufacturing Process For Multilayer Thin-Film Solid Oxide Fuel Cells". The main objective of this project was to develop the manufacturing process based on tape calendering for multilayer solid oxide fuel cells (SOFC's) using the unitized cell design concept and to demonstrate cell performance under specified operating conditions.

The work done under this program has advanced the understanding and engineering knowledge in a number of areas. The key accomplishments are summarized below:

- Cathode and anode improvements, such as modifications to powder morphologies and compositions, processing improvements and formulation changes, have lead to significantly improved SOFC performance especially in the 650 to $700^{\circ} \mathrm{C}$ range

- Cell power density was increased from $0.243 \mathrm{~W} / \mathrm{cm}^{2}$ to $0.892 \mathrm{~W} / \mathrm{cm}^{2}$ for $650^{\circ} \mathrm{C}$ operation. This performance was world leading at the time of reporting.

- Cells were operated at $85 \%$ fuel utilization

- Cells were fabricated that exhibited a $3 x$ improvement in flexure strength, while maintaining a peak power density of $0.914 \mathrm{~W} / \mathrm{cm}^{2}$.

- Flow fields designs for unitized cells were analyzed and optimized for improved flow uniformity across the active area

- $70 \%$ fuel utilization with at a power density of greater than $0.2 \mathrm{~W} / \mathrm{cm}^{2}$ was demonstrated on a unitized cell operating on dilute hydrogen (64\%)

- Several NDE techniques for flaw detection in multilayer cells were evaluated; digital radiography was selected for further evaluation

- Manufacturing baseline process maps were created

- Baseline process capability data gathered

- Tools for gather and analyzing capability data developed

- The process maps have been used to identity key areas for improvements

- Developed forming models and investigated advanced joining methods, such as laser, e-beam and micro TIG welding, for fabricating complex interconnect structures 


\section{INTRODUCTION}

The main objective of this project is to develop the manufacturing process based on tape calendering for multilayer solid oxide fuel cells (SOFC's) using the unitized cell design concept and to demonstrate cell performance under specified operating conditions.

The tape calendering process involves the formation of a continuous sheet of tape of controlled size by squeezing of a softened ceramic filled thermoplastic material between two rolls. The process can be used to produce multilayer tapes by laminating and rolling individual layers. The multilayer tapes are sintered to form multilayer cells.

The unitized cell concept places a multilayer ceramic cell in a metallic housing with its own gas manifolds to form a complete cell package. Thus, unitized cells can be operated as a single unit and can be easily stacked. The multilayer cell contains a thin electrolyte for reduced temperature $\left(<800^{\circ} \mathrm{C}\right)$ operation and each cell component may consist of multiple layers for performance enhancements. This work involves cost analysis of unitized cell production, development and definition of the tape calendering fabrication process, and characterization of fabricated cells, including electrochemical performance testing to demonstrate efficient operation under desired conditions.

The fabrication process and cell configuration examined have all the characteristics required for low-cost production of high-performance cell packages that can be easily used for stack build:

- The tape-calendering process is most suitable for cost-effective manufacturing of multilayer cells proposed in this program. The process has several important advantages: scaleability, simplicity, and robustness. In addition, the process is material independent, thus providing fabrication flexibility. Furthermore, the process can be designed for high-volume production and automation using available commercial equipment.

- The unitized cell configuration has the potential to enhance cell robustness, life, reliability, and maintainability. The unitized cell design simplifies cell quality control (QC), sealing, stacking procedures, stack repair/overhaul, and improves cell handling and robustness.

\section{EXPERIMENTAL / APPROACH}

The experimental work for this program can be grouped into three categories; cell fabrication \& characterization, interconnect structure fabrication \& characterization, and electrochemical evaluation. For cell fabrication, tape calendering (as described below) was used for creating bilayers (bodies with electrolyte and anode electrode) and screenprinting (typical process found in literature) for cathode electrode application. 
Figure 1 shows the basic tape-calendering sequence for producing a thin electrolyte supported on an anode support. In this process, the starting materials (yttria-stabilized zirconia (YSZ) electrolyte, NiO/YSZ anode support electrode, organic binders, and plasticizers) are mixed in a high-shear mixer. The heat generated by the mixing process softens the organics to form a homogeneous plastic mass.

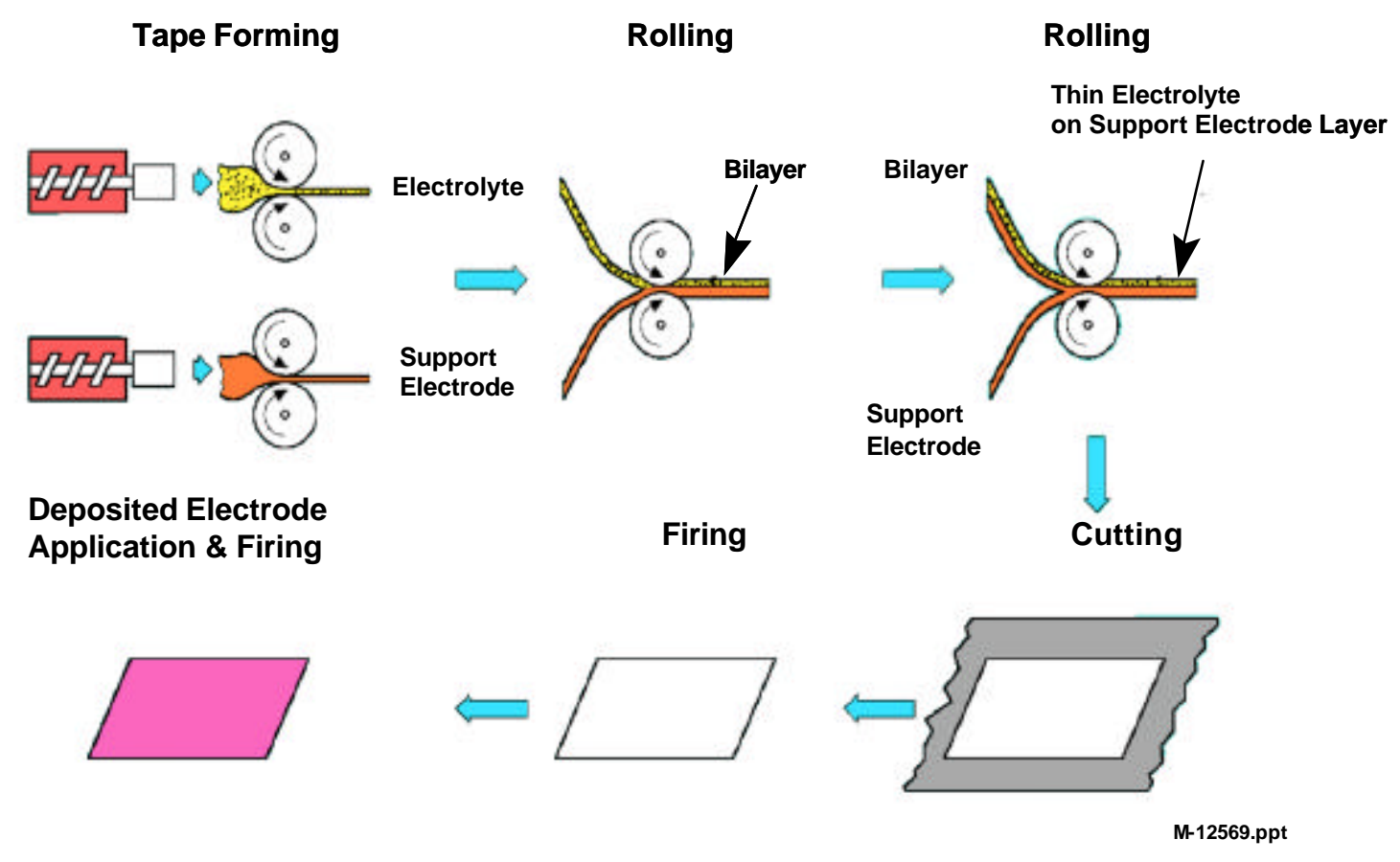

Figure 1. Fabrication sequence for fabrication of cells.

Each plastic mass is then rolled to produce a flexible sheet on the order of 0.25 to $2.5 \mathrm{~mm}$ thick. The electrolyte and anode tapes are then laminated together to form a bilayer and subsequently rolled to reduce the thickness of each layer. Another anode tape is added to the bilayer and again rolled to a thin tape. The addition of anode tapes has the effect of reducing the electrolyte thickness while keeping the bilayer at a handleable thickness. Such process is repeated until the desired thickness of electrolyte is reached. At this point, the bilayer is cut to the desired shape and size. The green tape is then fired at elevated temperatures in an air atmosphere to sinter the bilayer tape. The cathode, a mixture of YSZ and strontium doped lanthanum manganite (LSM), is then screen printed and fired on the electrolyte surface of the sintered bilayer to produce a complete cell. Characterization of the cells was done using standard 
approaches, techniques, and equipment from the ceramic and polymer fields. Starting materials were examined to understand and quantify particle morphology and processing characteristics of the materials, properties examined included:

- Specific surface area

- Particle size distribution

- Particle morphology

- Chemical impurities

- Crystal phase

- Loss on ignition

Many of the same items need examination after the powder processing steps also. In addition, thermal and chemical analyses are also required for the organic constituents. Table 1 lists the methods used for starting material characterization.

Table 1. Characterization of Starting Materials

\begin{tabular}{|l|l|l|}
\hline \multicolumn{1}{|c|}{ Property } & \multicolumn{1}{|c|}{ Method } & \multicolumn{1}{|c|}{ Typical Output } \\
\hline $\begin{array}{l}\text { Particle } \\
\text { morphology }\end{array}$ & $\begin{array}{l}\text { Surface adsorption/deadsorption surface } \\
\text { area analysis (BET), sedimentary and light } \\
\text { diffraction particle size techniques, and } \\
\text { scanning electron microscope (SEM) }\end{array}$ & $\begin{array}{l}\text { Specific surface area, } \\
\text { particle size distribution } \\
\text { and particle morphology }\end{array}$ \\
\hline Chemical & $\begin{array}{l}\text { X-ray difraction (XRD), inductive coupled } \\
\text { plasma mass spectroscopy (ICP-MS), } \\
\text { energy dispersive spectroscopy (EDS) }\end{array}$ & $\begin{array}{l}\text { Crystal phase, chemical } \\
\text { composition, and impurity } \\
\text { level }\end{array}$ \\
\hline Thermochemical & $\begin{array}{l}\text { Thermogravimetric analysis (TGA), differ } \\
\text { ential thermal analysis (DTA), and } \\
\text { differential scanning calorimetry (DSC) }\end{array}$ & $\begin{array}{l}\text { Decomposition products, } \\
\text { temperatures, and } \\
\text { thermodynamic properties }\end{array}$ \\
\hline
\end{tabular}

After the starting materials have been combined into green tapes and laminated into layered green tapes specific characteristics were measured. The key measurements for the unfired tapes are:

- Tape weight loss (solids loading)

- Binder burnout temperatures

- Shrinkage 
- Thickness and thickness ratios

Table 2 lists the properties and measurement methods that were used for green tapes.

Table 2. Characterization of Green Tapes

\begin{tabular}{|l|l|l|}
\hline \multicolumn{1}{|c|}{ Property } & \multicolumn{1}{|c|}{ Method } & \multicolumn{1}{c|}{ Typical Output } \\
\hline Thermochemical & TGA, DTA, DSC, and dilatometry & $\begin{array}{l}\text { Solids loading, binder } \\
\text { decomposition products, } \\
\text { temperatures and } \\
\text { thermodynamic properties }\end{array}$ \\
\hline Thermomechanical & Dilatometry & Firing shrinkage \\
\hline Dimensional & $\begin{array}{l}\text { Precision micrometers, } \\
\text { microscopy (optical and SEM) }\end{array}$ & $\begin{array}{l}\text { Tape thickness, functional layer } \\
\text { thickness and thickness ratios }\end{array}$ \\
\hline
\end{tabular}

After tapes are sintered characterization focused on the microstructure of the fired ceramic, which could be characterized by these measurements:

- Density

- Flatness

- Thickness

- Porosity

- Electrical properties

- Mechanical properties

- Elemental migration/interaction

- Coefficient of thermal expansion (CTE)

Table 3 describes the characterization methods and outputs for fired components. 
Table 3. Characterization of Fired Components

\begin{tabular}{|l|l|l|}
\hline \multicolumn{1}{|c|}{ Property } & \multicolumn{1}{|c|}{ Method } & \multicolumn{1}{c|}{ Typical Output } \\
\hline Microstructure & $\begin{array}{l}\text { Archimedes density, mercury } \\
\text { porosimetry, and SEM }\end{array}$ & $\begin{array}{l}\text { Density, porosity size } \\
\text { distribution, and pore } \\
\text { morphology }\end{array}$ \\
\hline Thermomechanical & Dilatometry & CTE \\
\hline Electrical & $\begin{array}{l}\text { 2- and 4-point conductivity and AC } \\
\text { impedance }\end{array}$ & $\begin{array}{l}\text { lonic and electronic } \\
\text { conductivity }\end{array}$ \\
\hline Chemical & $\begin{array}{l}\text { EDS and wavelength dispersive } \\
\text { spectroscopy (WDS) }\end{array}$ & $\begin{array}{l}\text { Elemental distribution/ } \\
\text { migration and impurities }\end{array}$ \\
\hline Dimensional & $\begin{array}{l}\text { Precision micrometers, acoustic } \\
\text { emission analysis, optical micros } \\
\text { copy, SEM, microfocus X-ray, and } \\
\text { optical comparator }\end{array}$ & $\begin{array}{l}\text { Thickness, thickness ratios, } \\
\text { flatness, delaminations and } \\
\text { other defects }\end{array}$ \\
\hline Mechanical & $\begin{array}{l}\text { Ring on ring biaxial flexure } \\
\text { Ting }\end{array}$ & $\begin{array}{l}\text { Characteristic strength and } \\
\text { Weibull modulus }\end{array}$ \\
\hline
\end{tabular}

Interconnect structures were fabricated using typical metal forming techniques including, simple sheet metal forming, machining, and stamping, which are described in metal forming texts. The interconnect materials were characterized for formability by measuring the mechanical properties of the metals in their processed conditions. Tensile strength, elastic modulus, and yield strength were determined using accepted testing techniques and equipment.

Electrochemical testing of the cell encompassed collecting a polarization curve under different operating conditions, and determining performance as a function of fuel utilization. For cell testing, gas connections were made to the appropriate manifold tube, and the gases were introduced into the cell. A schematic of a single cell test apparatus is presented in Figure 2. This test fixture is placed in a furnace to heat and control the temperature of the cell. Mass flow controllers in the test stand control flow rates for the fuel gases, while air is provided by natural convection with in the furnace. DC polarization testing was performed on the cells under constant current with the voltage change being monitored or with constant voltage and varying current. The open circuit voltage (OCV) observed during the tests gave a good indication of the leak tightness of the unitized cell, since gas leaking across the cell would reduce the OCV at a given temperature. The resistance of the cell was determined from the slope of 
the voltage vs. current polarization curve. Typically, this resistance is normalized for area to give an area specific resistance (ASR), which is useful for comparing various cells with different active areas. Cells with smaller ASR's have better cell performance. Power densities $\left(\mathrm{W} / \mathrm{cm}^{2}\right)$ were also determined from polarization curves. These tests in some cases were also carried out at various temperatures and fuel flow rates to create performance maps. AC impedance spectroscopy was also used to determine resistances of specific components in the unitized cells, including ohmic resistance from the electrolyte.

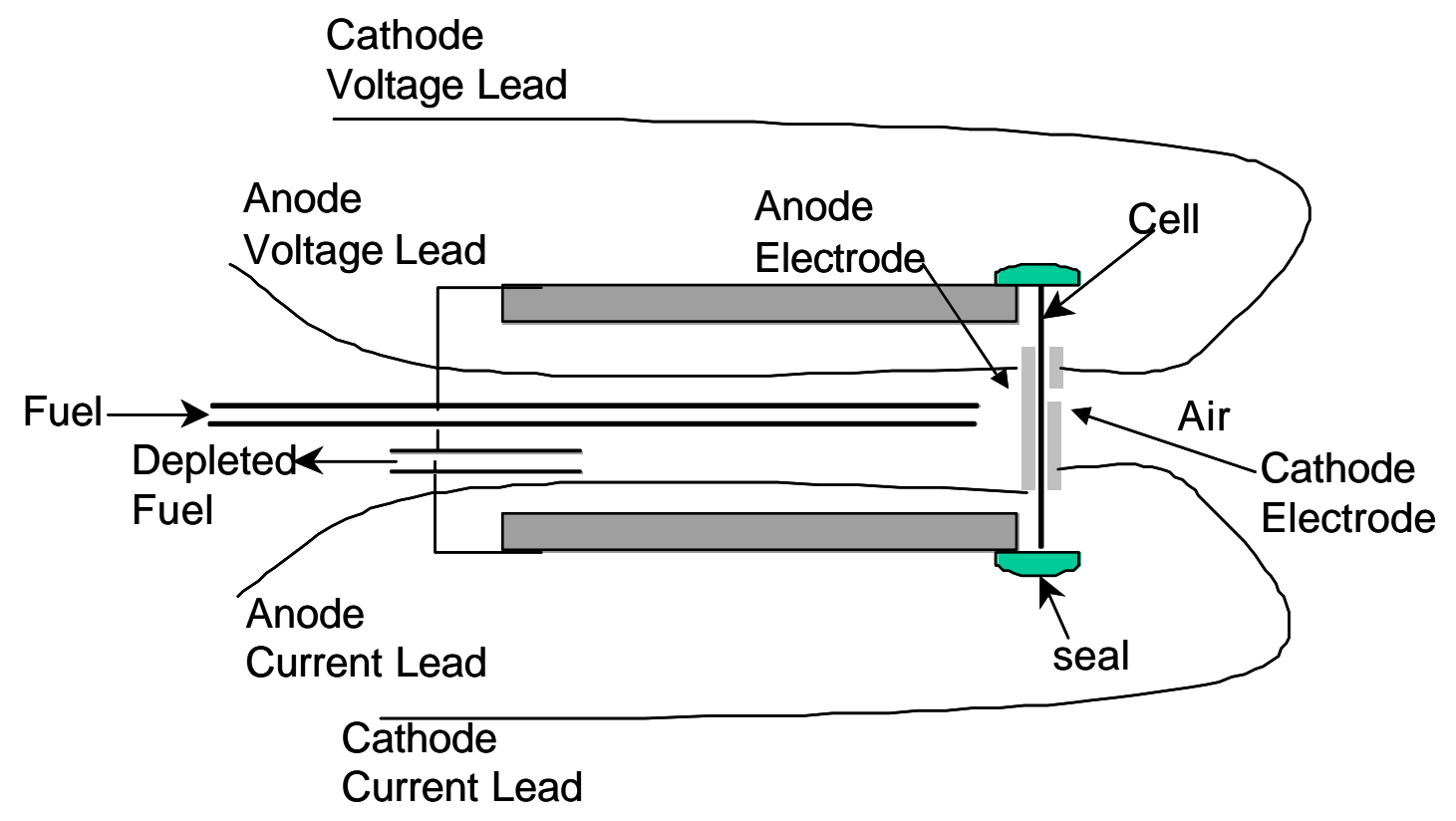

Figure 2. Schematic of single test test apparatus.

\section{RESULTS AND DISCUSSION}

The development efforts under this program focused on three key areas to advance SOFC technology towards commercialization. The first area was Multilayer Cell Fabrication and Improvement; the second was Unitized Cell Fabrication and Design; and third Manufacturing Process Development.

\subsection{MULTILAYER CELL FABRICATION AND IMPROVEMENT}

\subsubsection{Cathode Improvements}

In order to focus the work on certain aspects of cell fabrication cell performance loss at different temperatures was characterized with $2.54 \mathrm{~cm}$ diameter single cells. Cells were fabricated with "baseline" materials and processes. For the cathode the "baseline" was 5 layers of a LSM/YSZ mix designated as SPC-3. The single cells were tested in single cell test stand that was described in Figure 2 above. Results at $800^{\circ} \mathrm{C}$ with different fuel compositions are shown in Figure 3. The effect of operating temperature is 
shown in Figure 4. As expected, the performance decreased as the hydrogen concentration in the fuel or the operating temperature is reduced. Observed peak power densities at different temperatures and fuel contents are summarized in Table 4.

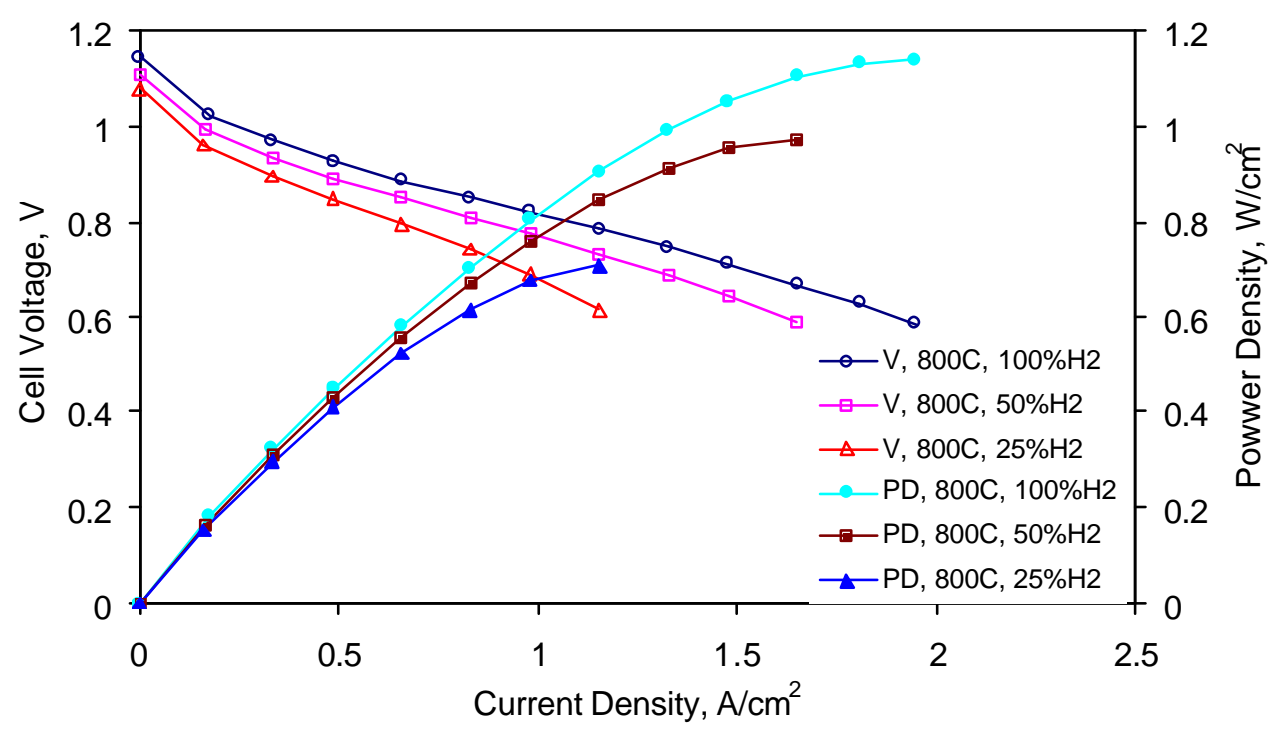

Figure 3. Cell (NJ003-1) performance at $800^{\circ} \mathrm{C}$ in $\mathrm{H}_{2} / \mathrm{N}_{2}$ fuel with a fixed fuel flow rate of $67 \mathrm{cc} / \mathrm{min}$ and non-flowing air. 


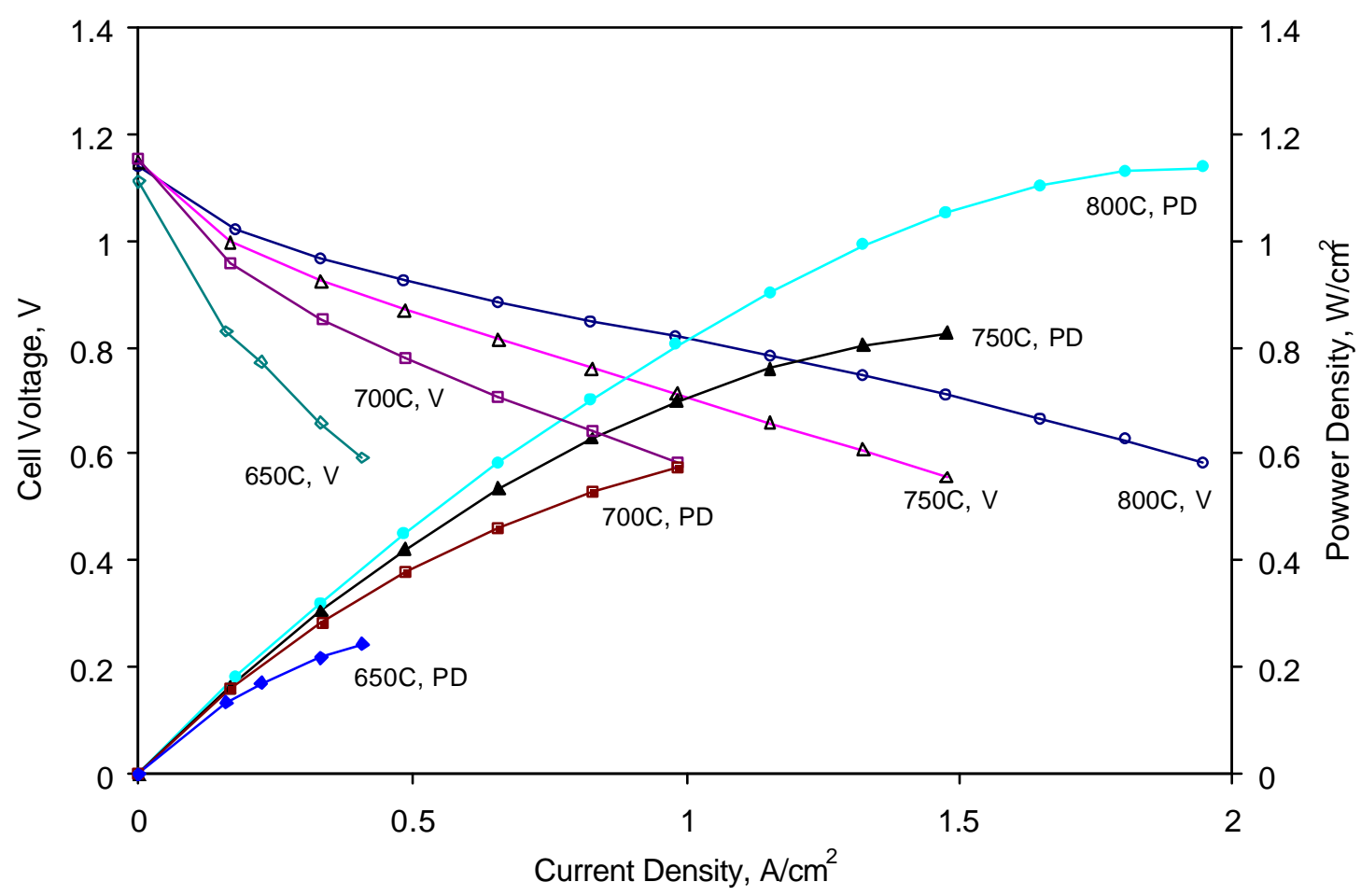

Figure 4. Performance of cell NJ003-1 at different temperatures under hydrogen fuel with a fixed fuel flow rate of $67 \mathrm{cc} / \mathrm{min}$ and non-flowing air.

Table 4. Observed Peak Power $\left(\mathrm{W} / \mathrm{cm}^{2}\right)$ of Cell NJ003-1 at Different Temperatures and Hydrogen Concentrations.

\begin{tabular}{|c|c|c|c|}
\hline Temperature, ${ }^{\circ} \mathrm{C}$ & $\begin{array}{c}100 \% \mathrm{H}_{2}, \\
\mathrm{~W} / \mathrm{cm}^{2}\end{array}$ & $\begin{array}{c}50 \% \mathrm{H}_{2}, \\
\mathrm{~W} / \mathrm{cm}^{2}\end{array}$ & $\begin{array}{c}25 \% \mathrm{H}_{2}, \\
\mathrm{~W} / \mathrm{cm}^{2}\end{array}$ \\
\hline 800 & 1.14 & 0.974 & 0.708 \\
\hline 750 & 0.826 & 0.769 & 0.590 \\
\hline 700 & 0.575 & 0.463 & 0.373 \\
\hline 650 & 0.243 & 0.197 & 0.177 \\
\hline
\end{tabular}

AC impedance was used to analyze the performance loss from cell components. Figure 5 is an example of the impedance spectra obtained. It shows the results for the complete cell (anode, electrolyte, and cathode) and the cathode (that includes ohmic contribution from the electrolyte). From this figure, it can be seen that the cathode impedance $\left(Z_{\mathrm{re}}\right)$ is much larger than that from the anode and the electrolyte. Cathode polarization was further analyzed with dc 
bias to determine if cathode polarization could be reduced by activation. As seen in Figure 6, the cathode polarization was significantly reduced when a dc bias was applied, suggesting cathode activation is required for improved performance. Both polarization and impedance analysis indicate that the major cell performance loss came from the cathode.

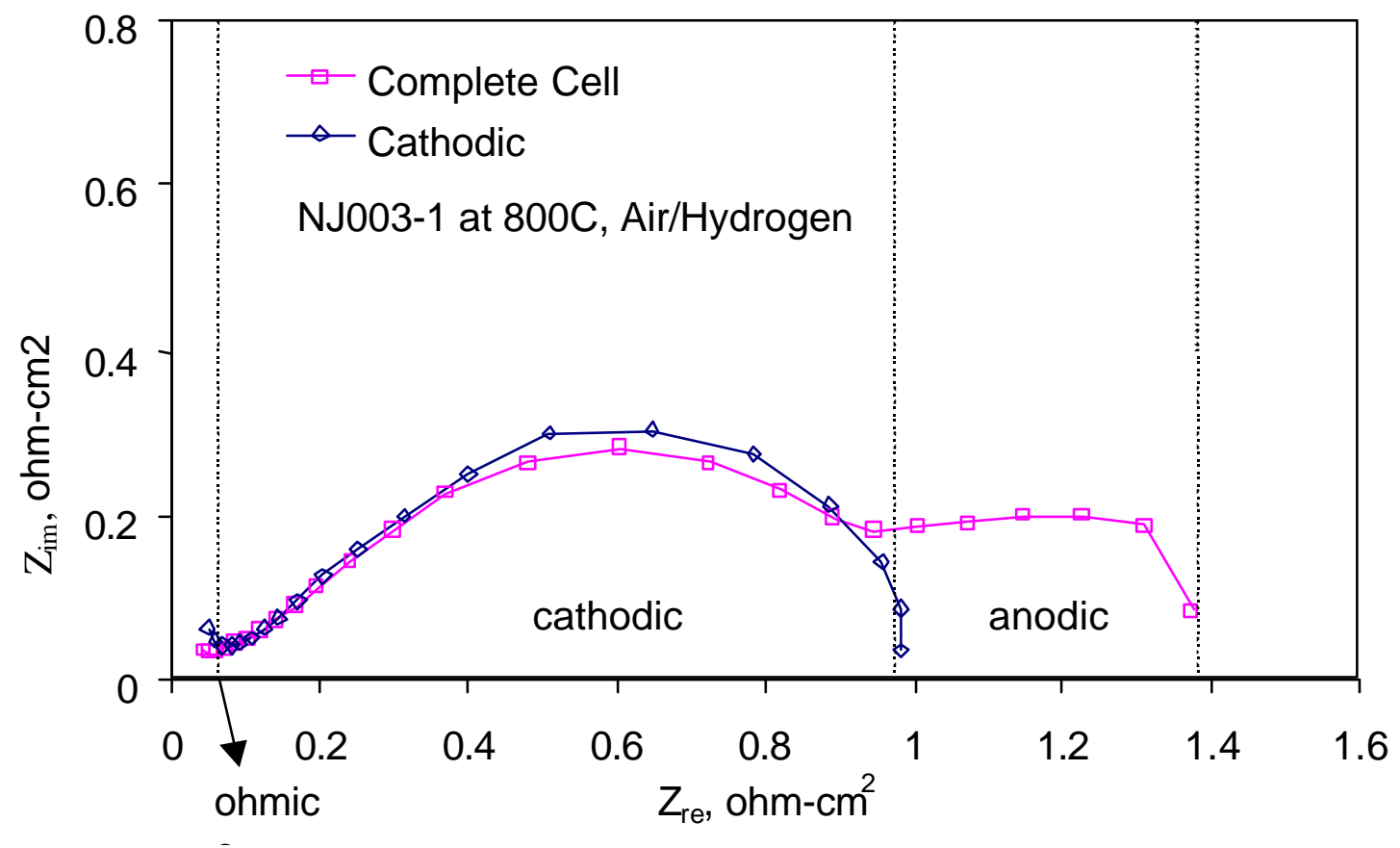

Figure 5. Typical impedance spectra at $800^{\circ} \mathrm{C}$ at OCV (SPC-3 cathode). 


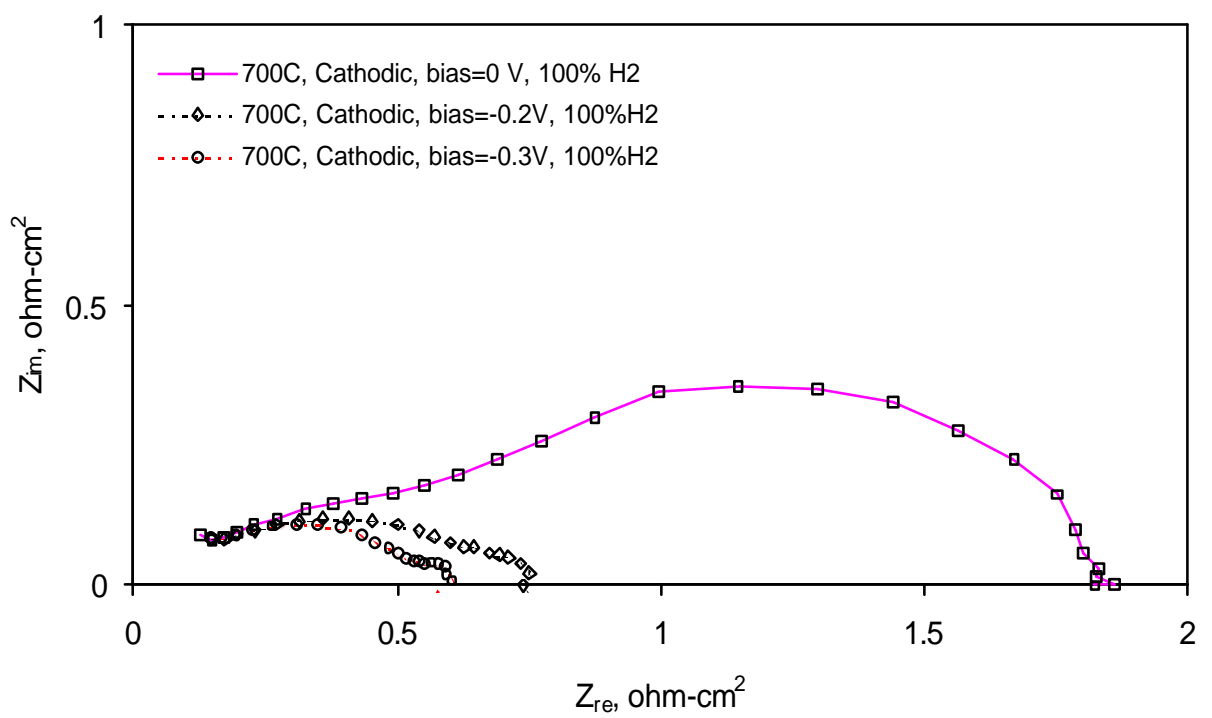

Figure 6. Effects of DC bias on cathode polarization at $700^{\circ} \mathrm{C}$ (SPC-3 cathode).

This work identified a need to improve the cathode electrode to increase cell performance. To improve the single cell performance at reduced temperature, a conductive layer of pure lanthanum strontium manganese oxide or LSM paste was screen-printed on the top of LSM/YSZ cathode in an effort to improve cathode sheet conductivity and thus minimize the contact resistance. A single cell (NJ009-2) with 4 layers of cathode-electrode SPC-3 (cathodeelectrode SPC-3 was the standard cathode-electrode at the beginning of the program) and 1 layer of LSM was tested between 800 and $650^{\circ} \mathrm{C}$. Cell performance is shown in Figure 7 with peak power density of $448 \mathrm{~mW} / \mathrm{cm}^{2}$ at $650^{\circ} \mathrm{C}$. This is much higher than the $243 \mathrm{~mW} / \mathrm{cm}^{2}$ observed in Cell NJ003-1, which had SPC-3 but did not have a conductive layer. The higher performance at reduced temperature of the cell with conductive layer, according to impedance analysis, was due to a better cathode performance as shown in Figure 8. 


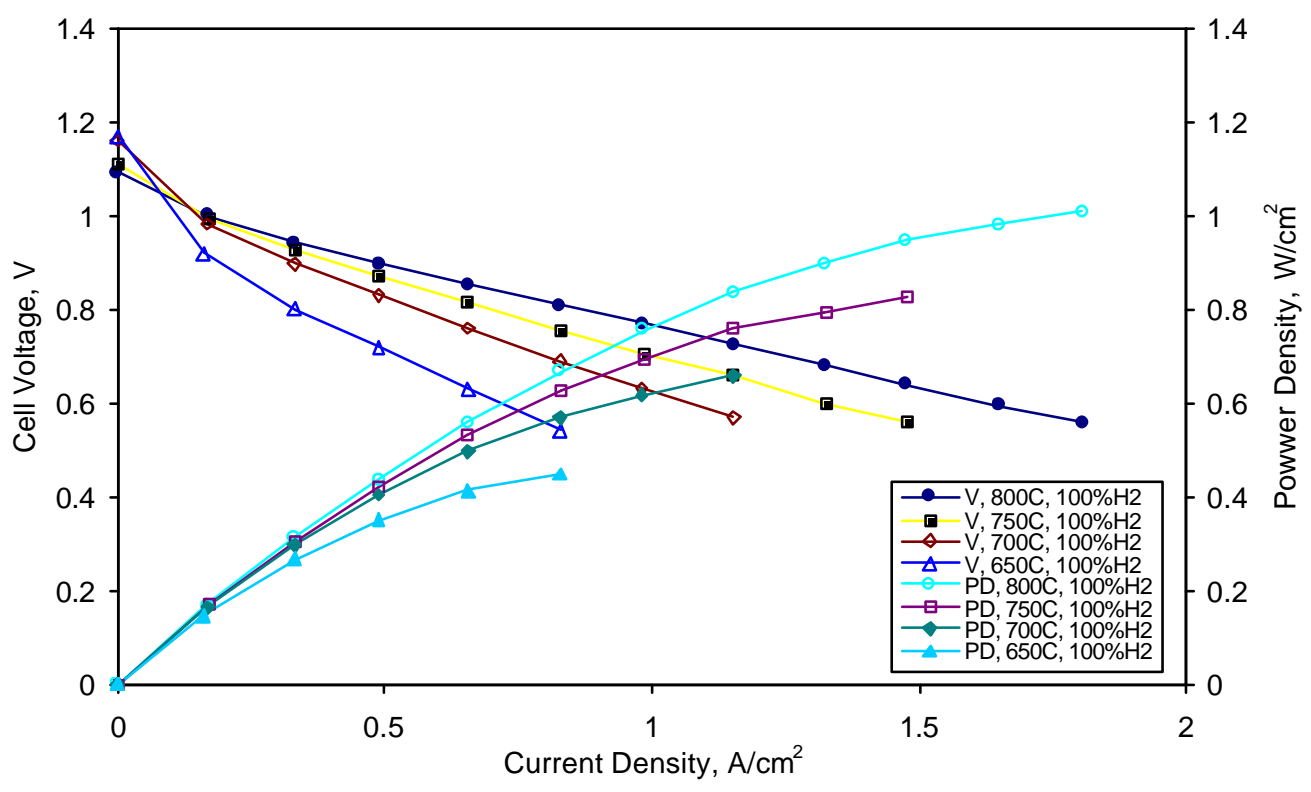

Figure 7. Performance of cell NJ009-2 with a conductive layer on the cathode with a fixed fuel flow rate of $67 \mathrm{cc} / \mathrm{min}$ and non-flowing air.

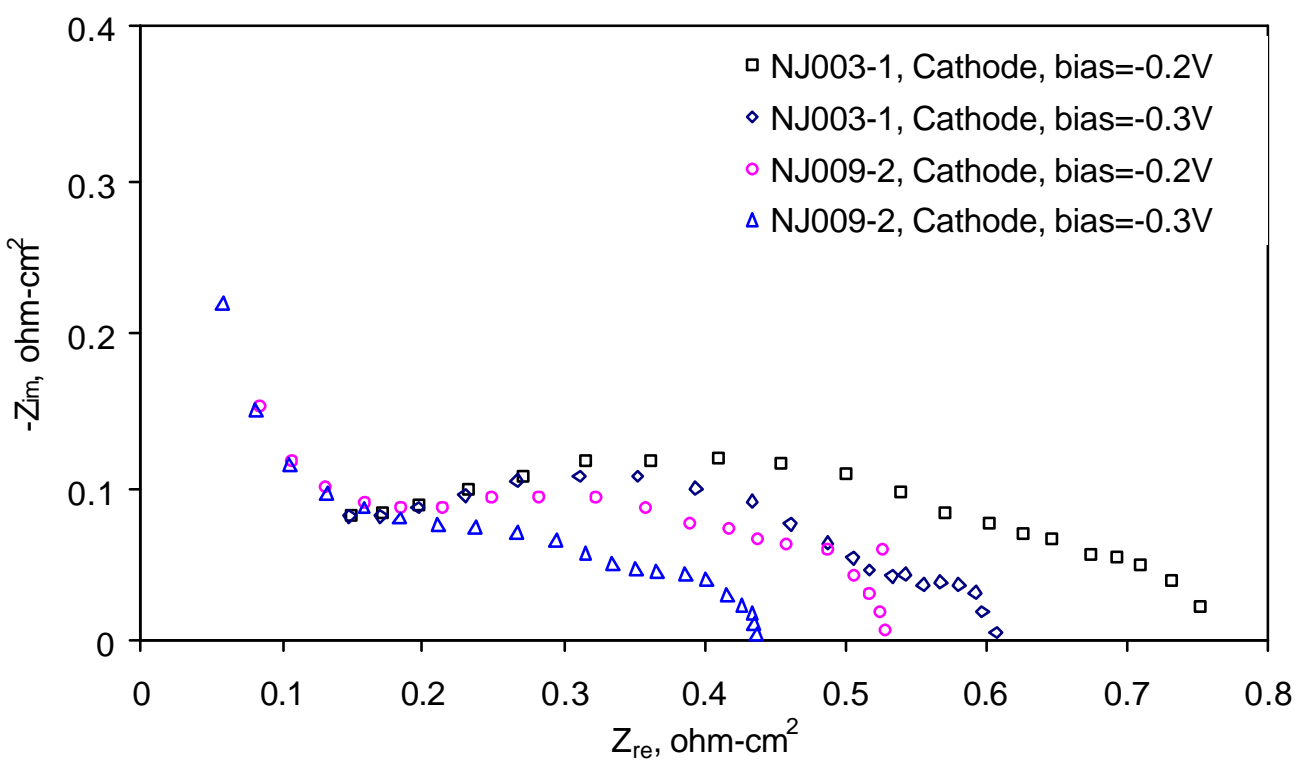

Figure 8. Cathode impedance of NJ003-1 (no conductive layer) and NJ009-2 (with conductive layer) at $700^{\circ} \mathrm{C}$.

To improve cathode performance, a new batch of cathode formulation, SPC-4, was formed. The main difference between SPC-3 and SPC-4 was in the YSZ powder used in cathode formulation. The YSZ for the former had a higher surface area, $12 \mathrm{~m}^{2} / \mathrm{gm}$ for SPC-3 and $8 \mathrm{~m}^{2} / \mathrm{gm}$ for SPC-4. Microstructures for SPC-3 and SPC-4 are presented in Figure 9 and Figure 10, showing that lower 
surface area YSZ powder in SPC-4 cathode resulted in a more open microstructure than that in SPC-3. A cell (cell NJ59) with the layered cathode structure consisting of 4 layers SPC- 4 and one layer LSM bonding material was fabricated and tested to compare the cells of similar configurations, but using SPC-3 (NJ009-2). This œll showed excellent performance as shown in Figure 11. The peak power density of cells with different cathode formulations (SPC-3, SPC-4) and configurations (with or w/o a LSM conductive layer) at different temperatures are summarized in Table 5, Cells NN33 (5 layer SPC-4 cathode, $\mathrm{Ni}$ coated graphite fiber in anode) and NJ59-1 have comparable performance, and both of them performed better than NJ009-2 and NJ003-1 with SPC-3 cathode.

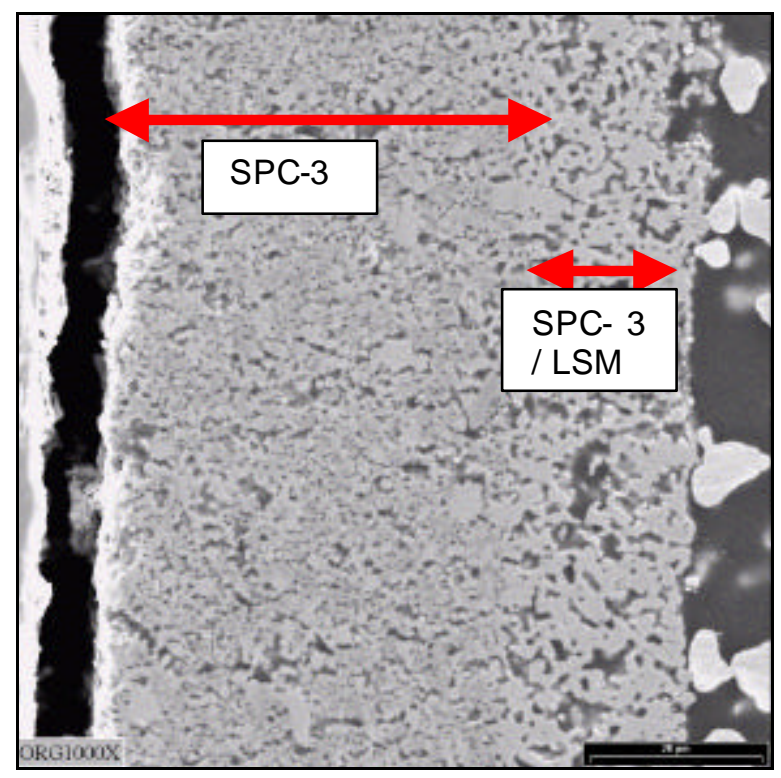

Figure 9. SPC-3 cathode in cell NJ009-2

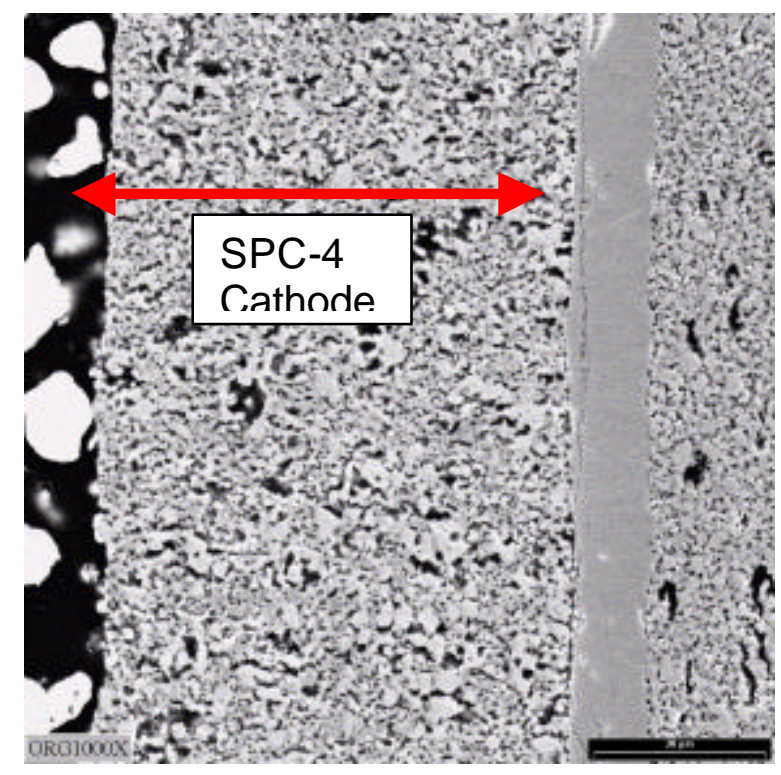

Figure 10. SPC-4 cathode in cell NN33 


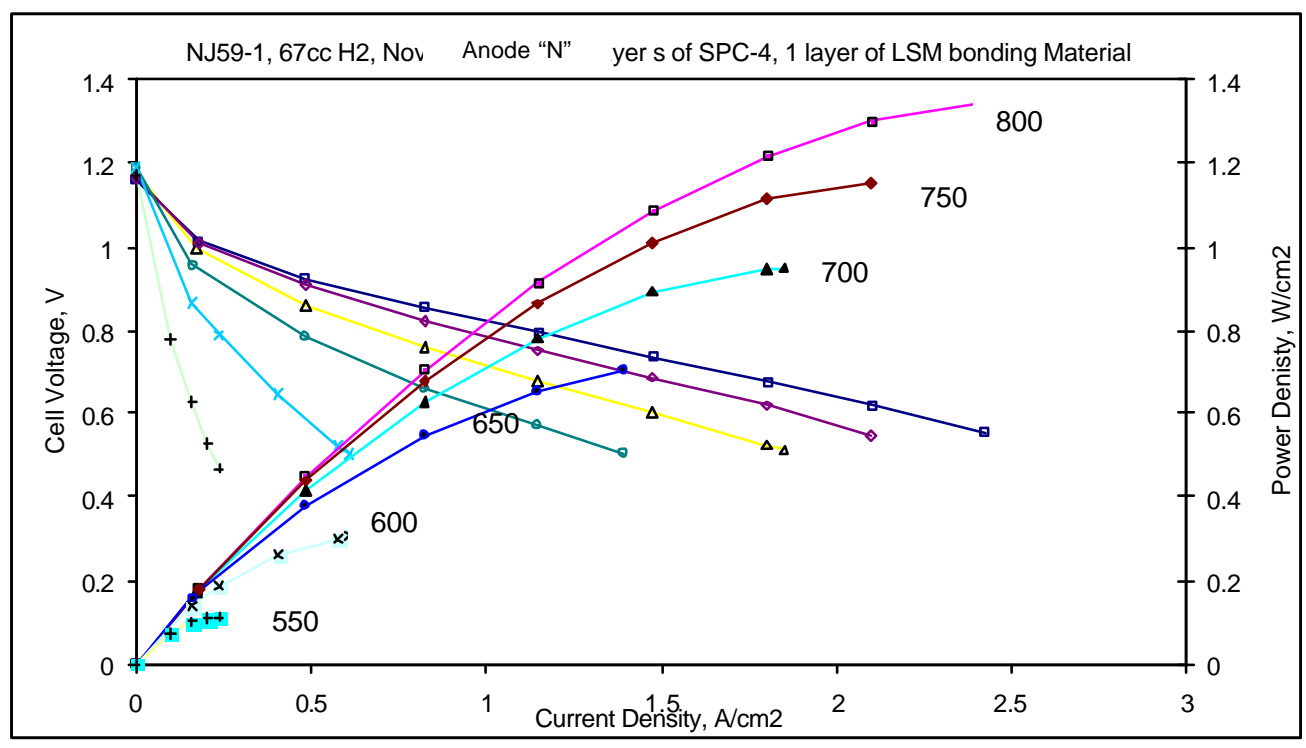

Figure 11. Polarization of cell NJ59-1 under hydrogen with a fixed fuel flow rate of $67 \mathrm{cc} / \mathrm{min}$ and non-flowing air. 
Table 5. Peak Power Densities for Cells SPC-3 and SPC-4 Cathodes at Different Temperatures

\begin{tabular}{|c|c|c|c|c|c|c|}
\hline Cell & $\begin{array}{l}800^{\circ} \mathrm{C}, \\
\mathrm{W} / \mathrm{cm}^{2}\end{array}$ & $\begin{array}{l}750^{\circ} \mathrm{C}, \\
W / \mathrm{cm}^{2}\end{array}$ & $\begin{array}{l}700^{\circ} \mathrm{C}, \\
\mathrm{W} / \mathrm{cm}^{2}\end{array}$ & $\begin{array}{l}650^{\circ} \mathrm{C}, \\
\mathrm{W} / \mathrm{cm}^{2}\end{array}$ & $\begin{array}{l}600^{\circ} \mathrm{C}, \\
\mathrm{W} / \mathrm{cm}^{2}\end{array}$ & $\begin{array}{l}550^{\circ} \mathrm{C}, \\
\mathrm{W} / \mathrm{cm}^{2}\end{array}$ \\
\hline $\begin{array}{l}\text { NJ59-1 } \\
(\text { SPC-4+LSM) } \\
1250^{\circ} \mathrm{C}\end{array}$ & 1.34 & 1.15 & 0.949 & 0.704 & 0.306 & 0.112 \\
\hline $\begin{array}{l}\text { NJ59-2 } \\
\left(\text { SPC-4+LSM) } 1150^{\circ} \mathrm{C}\right.\end{array}$ & 1.31 & 1.15 & 0.939 & 0.700 & 0.285 & $\mathrm{~N} / \mathrm{A}$ \\
\hline $\begin{array}{l}\text { NN33 } \\
\text { (SPC-4) Ni coated } \\
\text { graphite fiber in } \\
\text { anode }\end{array}$ & 1.36 & N.A. & 0.96 & 0.661 & 0.257 & 0.094 \\
\hline $\begin{array}{l}\text { NJ009-2 } \\
\text { (SPC-3+ LSM) }\end{array}$ & $1.007^{*}$ & $0.826^{*}$ & 0.656 & 0.448 & $\mathrm{~N} / \mathrm{A}$ & $\mathrm{N} / \mathrm{A}$ \\
\hline $\begin{array}{l}\text { NJ003-1 } \\
\text { (SPC-3) }\end{array}$ & 1.14 & 0.826 & 0.575 & 0.243 & $\mathrm{~N} / \mathrm{A}$ & $\mathrm{N} / \mathrm{A}$ \\
\hline $\begin{array}{l}{ }^{* *} \text { Slightly lower OC } \\
\text { uncontrolled humidific }\end{array}$ & $\begin{array}{l}\text { wer } \\
\text { h) }\end{array}$ & & $\overline{\text { ost }}$ & ly & to & ions \\
\hline
\end{tabular}

Cell NJ59-1 showed no decay in performance at $650^{\circ} \mathrm{C}$ under $0.826 \mathrm{~A} / \mathrm{cm}^{2}$ load at $70 \%$ fuel utilization as shown in Figure 12. In fact, over a period of 101 hours, the cell voltage slowly increased from 594 to $650 \mathrm{mV}$, which corresponds to a gain from 491 to $537 \mathrm{~mW} / \mathrm{cm}^{2}$ in power density. The noise in voltage data was probably caused by water removal from the cold end of the test fixture for this low temperature test. In a attempt to optimize this cathode configuration, cells with SPC-4 cathode and LSM functional layer was fired at $1150^{\circ} \mathrm{C}$ rather than the baseline temperature of $1250^{\circ} \mathrm{C}$ to minimize reaction between LSM and YSZ, to increase cathode porosity, and to obtain flatter cells. The cell (NJ59-2) performance (see Table 5) was nearly identical to the best cell (NJ59-1) tested earlier. 


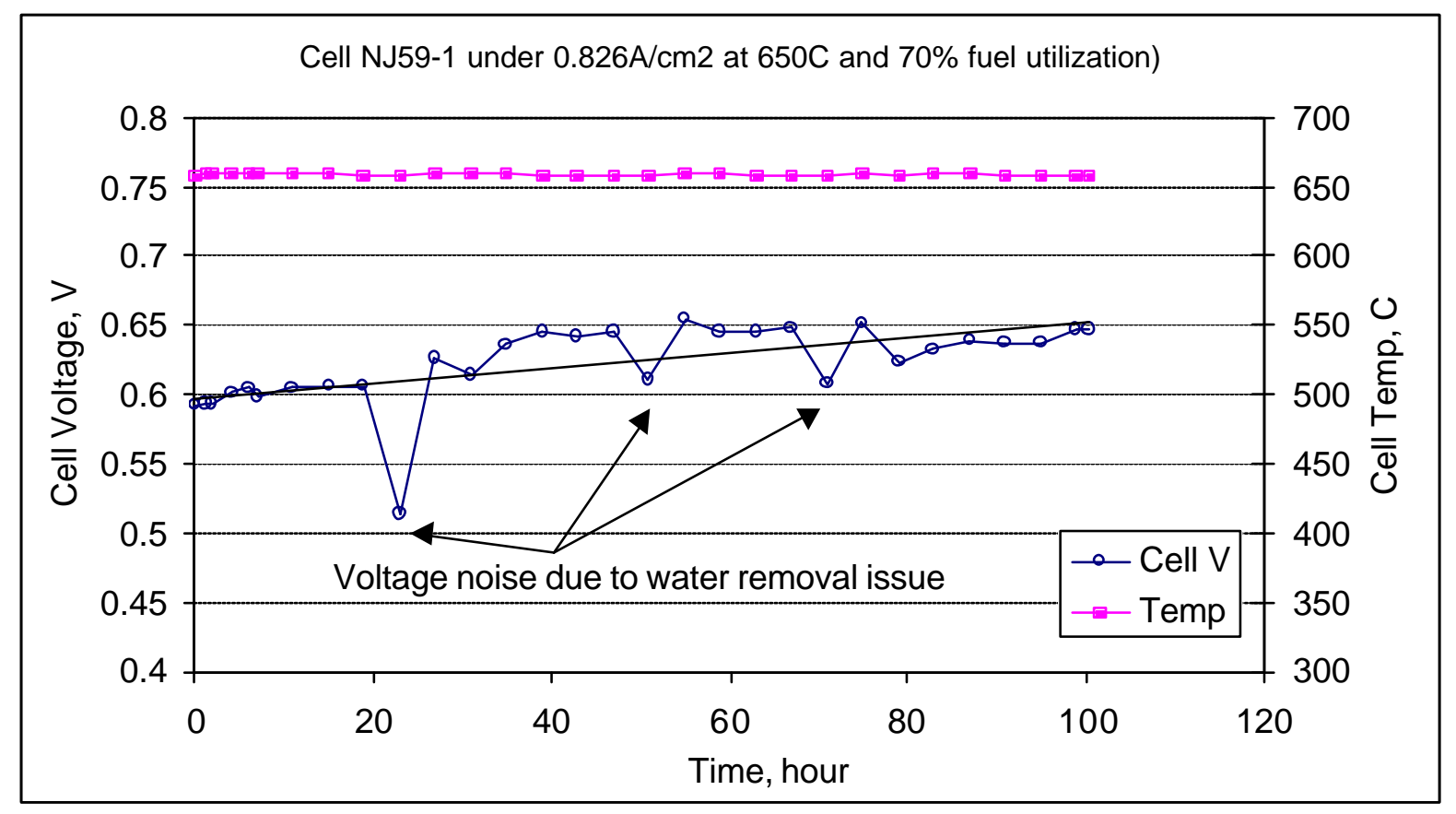

Figure 12. Cell performance at $0.826 \mathrm{~A} / \mathrm{cm}^{2}$ and $70 \%$ fuel utilization

A cell, NP105, with five layers of the SPC-4 (the same structure as cell NN33) cathode was prepared and tested to duplicate the high performance previously obtained from similar cathode configuration. After reduction at $800^{\circ} \mathrm{C}$ in $67 \mathrm{sccm}$ of hydrogen, the cell showed an OCV of over $1.1 \mathrm{~V}$. After the cell was conditioned under a high current load, a polarization run was made, presented in Figure 13. The peak power density for the cell was $1.44 \mathrm{~W} / \mathrm{cm}^{2}$, the highest performance achieved in this study at $800^{\circ} \mathrm{C}$. Polarization runs were further taken at lower temperatures and the data are shown in Table 6. Cell NP105 out performed the SPC-3 baseline cathode (NJ003) at every temperature and its performance was only slightly below NJ059-1 (the previously tested cell) at $700^{\circ} \mathrm{C}$, and $650^{\circ} \mathrm{C}$. 


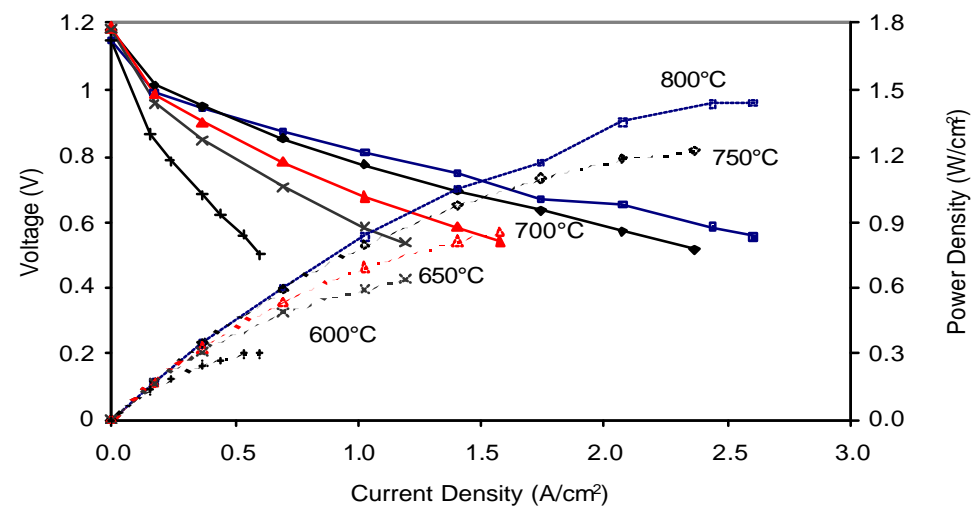

Figure 13. Polarization of cell NP105 under hydrogen with a fixed fuel flow rate of $67 \mathrm{cc} / \mathrm{min}$ and non-flowing air.

Table 6. Peak Power Densities for Cells NP105, NJ059-1, and NJ003-1 at Different Temperatures

\begin{tabular}{|c|c|c|c|c|c|}
\hline & $\begin{array}{l}800^{\circ} \mathrm{C}, \\
\mathrm{W} / \mathrm{cm}^{2}\end{array}$ & $\begin{array}{c}750^{\circ} \mathrm{C}, \\
\mathrm{W} / \mathrm{cm}^{2}\end{array}$ & $\begin{array}{l}700^{\circ} \mathrm{C}, \\
\mathrm{W} / \mathrm{cm}^{2}\end{array}$ & $\begin{array}{l}650^{\circ} \mathrm{C}, \\
\mathrm{W} / \mathrm{cm}^{2}\end{array}$ & $\begin{array}{l}600^{\circ} \mathrm{C}, \\
\mathrm{W} / \mathrm{cm}^{2}\end{array}$ \\
\hline NP105 & 1.44 & 1.22 & 0.855 & 0.637 & 0.306 \\
\hline NJ59-1 & 1.34 & 1.15 & 0.949 & 0.704 & 0.306 \\
\hline NJ003-1 & 1.14 & 0.826 & 0.574 & 0.243 & $\begin{array}{c}\text { not } \\
\text { available }\end{array}$ \\
\hline
\end{tabular}

To further improve the cathode electrode the effects of pre-calcining the starting LSM and YSZ cathode powders were also investigated. In one experimental cathode (denoted as SPCEX-5), the LSM $\left(\left(\mathrm{La}_{0.85} \mathrm{Sr}_{0.15}\right)_{0.98} \mathrm{MnO}_{3}\right)$ was calcined at $1000^{\circ} \mathrm{C}$ for 1 hour while half of the $\mathrm{YSZ}$ was calcined at $1000^{\circ} \mathrm{C}$ for 1 hour and the other half at $1200^{\circ} \mathrm{C}$ for 1 hour. A micrograph of the resulting cathode is shown in Figure 14. Peak power densities of a cell (NJ097) with this cathode were $1.36,1.16,0.964,0.892,0.3 \mathrm{~W} / \mathrm{cm}^{2}$ at $800,750,700,650$, and $600^{\circ} \mathrm{C}$, respectively (see Figure 15). The peak power of $0.892 \mathrm{~W} / \mathrm{cm}^{2}$ at $650^{\circ} \mathrm{C}$ has been the best obtained at this temperature. While it normally takes a cell a few hours for 
performance to stabilize at each new temperature after the initial conditioning (done at $800^{\circ} \mathrm{C}$ ), this cell took a much longer time to condition at $650^{\circ} \mathrm{C}$. Cell voltage rose from 531 to $591 \mathrm{mV}$ over night at $1.2 \mathrm{~A} / \mathrm{cm}^{2}$. The trend of $650^{\circ} \mathrm{C}$ polarization curve as shown in Figure 15 may be due to this long conditioning time. At this time the conditioning mechanism is unknown, thus it is difficult to assign a cause for this observed behavior.

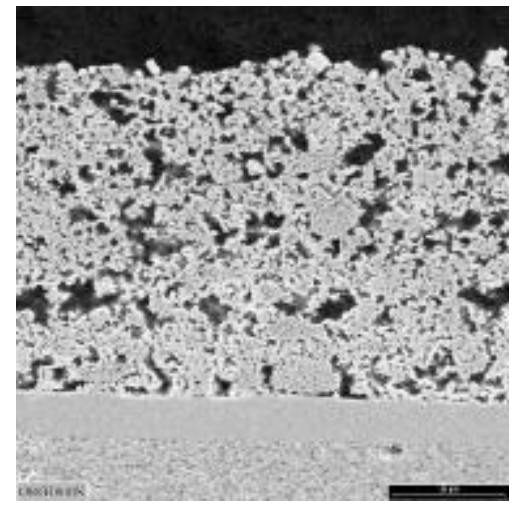

Figure 14. Microstructure of the SPEX-5 cathode in cell NJ097. 


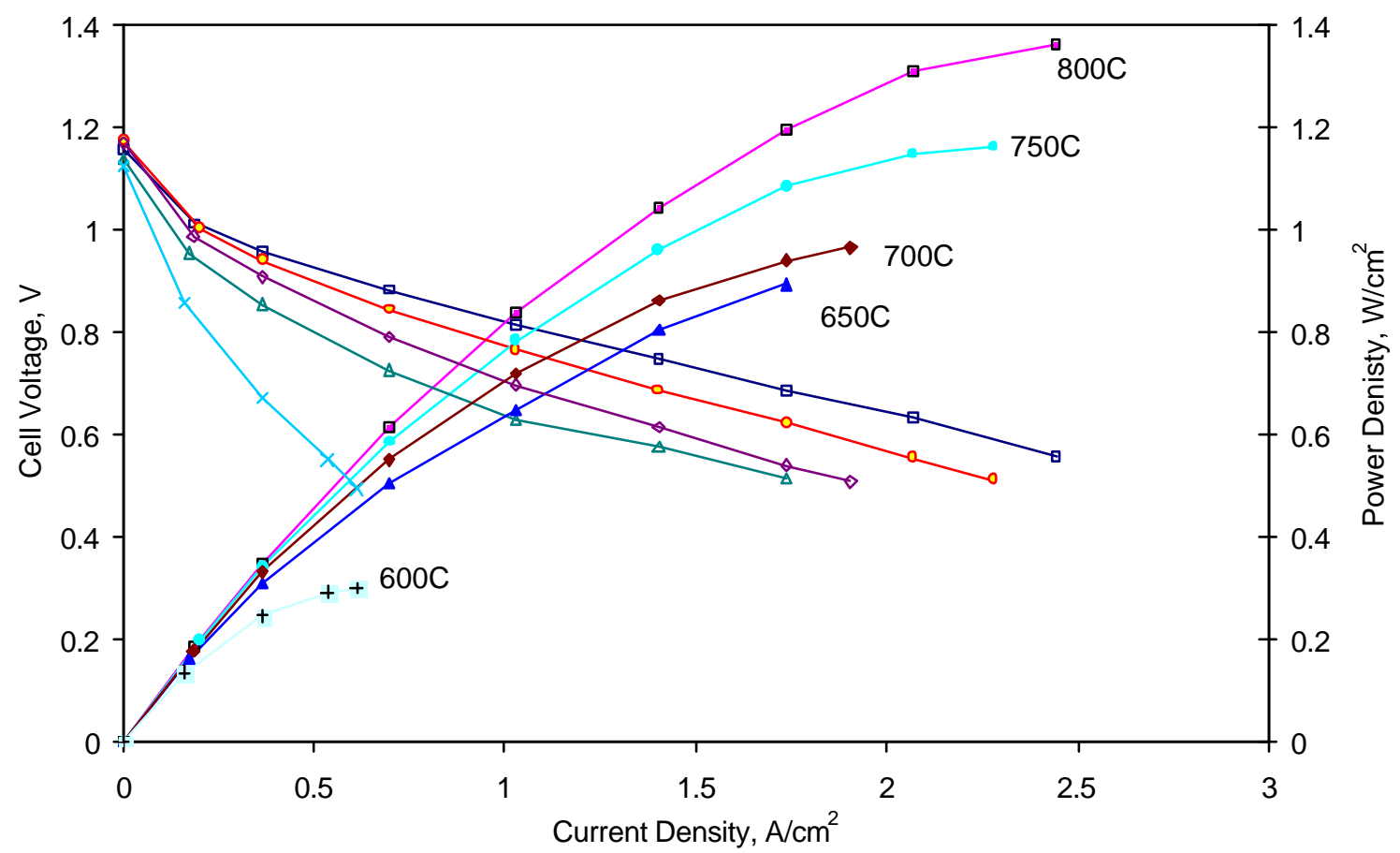

Figure 15. Cell NJ097 with experimental cathode, SPCEX-5 with pure hydrogen fuel and a fixed fuel flow rate of $67 \mathrm{cc} / \mathrm{min}$ and non-flowing air.

Another approach to improve cathode performance that was evaluated was cathode porosity gradient. In general, a higher porosity is desirable for the outer cathode layer to improve gas access. The porosity gradient was created using different cathode paste compositions. In Cell NJ128, the cathode consisted of one layer of SPC-4 next to the electrolyte, then 3 layers of SPCEX-5, and one layer of LSM-1000 (LSM powder calcined at $1000^{\circ} \mathrm{C}$ ) as the outermost layer. The LSM used in SPCEX-5 and LSM-1000 was $\left(\mathrm{La}_{0.85} \mathrm{Sr}_{0.15}\right)_{0.98} \mathrm{MnO}_{3}$ while that in SPC-4 was $\left(\mathrm{La}_{0.80} \mathrm{Sr}_{0.20}\right)_{0.98} \mathrm{MnO}_{3}$. Cathode microstructure for this cell is shown in Figure 16. Cell NJ128 did not perform as well as cells with pure SPC-4 cathode (NP105), SPCEX-5 cathode (NJ097), or SPC-4 with LSM outer layer (NJ059-1). The lower performance of NJ128 was more pronounced at lower temperatures as shown in Table 8. The relatively low performance of NJ128 was mainly due to a low cathode performance. Figure 17 compared the cell voltage, reference-to-cathode and reference-to-anode voltages observed in cell NJ128 and cell NJ59-1 (4 SPC-4 layers $+1 \mathrm{LSM}$ layer) at $700^{\circ} \mathrm{C}$. Reference-to-anode voltages in these two cells are nearly identical while reference-to-cathode voltage for NJ128 was much higher than that of NJ59-1. 


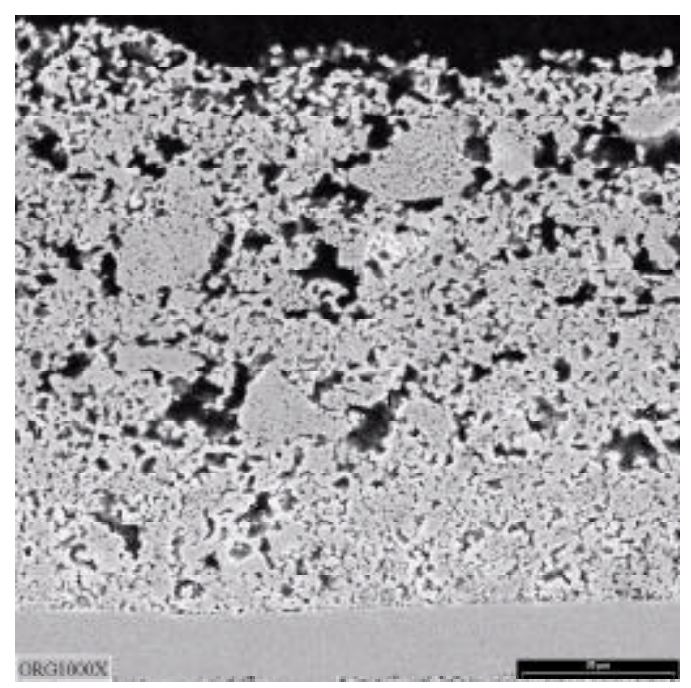

Figure 16. Cathode Microstructure with Graded Porosity (Cell NJ128).

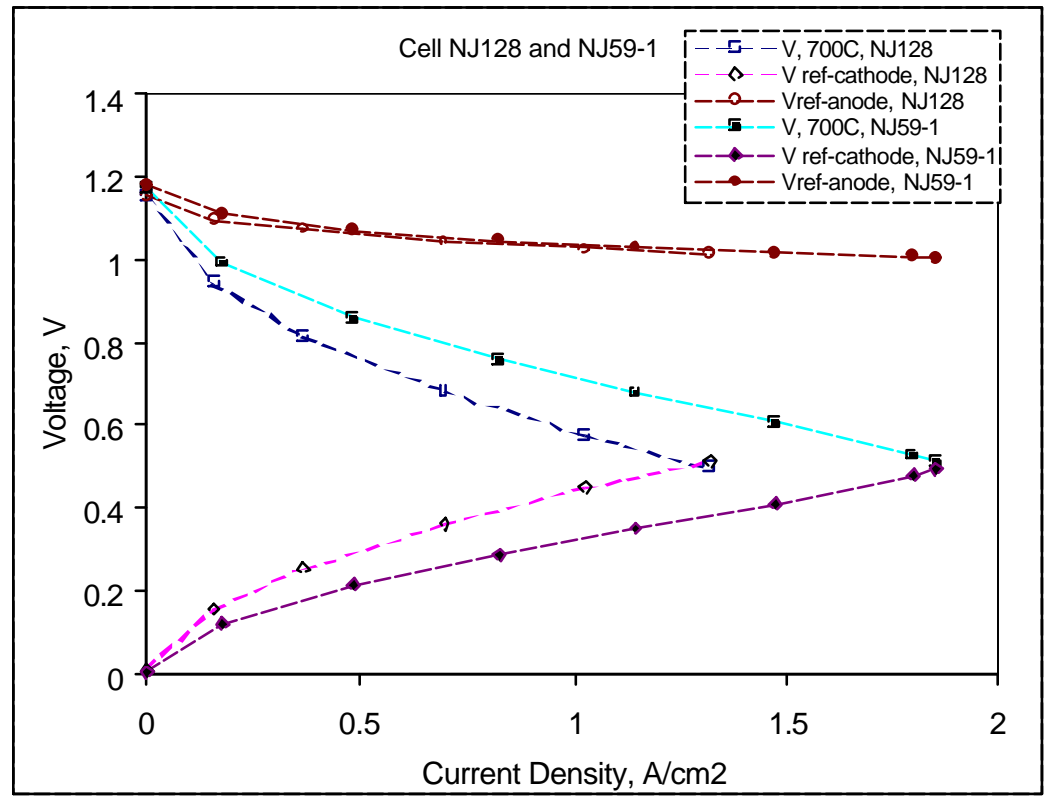

Figure 17. Performance losses in Cell NJ128 and NJ59-1 at $700^{\circ} \mathrm{C}$.

In addition to porosity gradient, the effect of grading the YSZ/LSM ratio in the cathode was also investigated. The standard cathode composition is $50 \% \mathrm{LSM} /$ $50 \%$ YSZ by weight. It was hypothesized that grading this ratio to a higher LSM content further away from the electrolyte would increase the conductivity of the electrode and reduce the charge transfer and ohmic polarizations, especially at 
temperatures lower than $800^{\circ} \mathrm{C}$. Cell NP117 had a cathode with a five-layer graded LSM/YSZ ratio. The layers were applied by screen-printing and had the compositions given in the table below (Table 7).

Table 7. Cathode Grading Layers.

\begin{tabular}{|c|c|c|}
\hline & YSZ & $\left(\mathrm{La}_{0.8} \mathrm{Sr}_{0.2}\right)_{0.98} \mathrm{MnO}_{3}$ \\
\hline Layer 1 & $60 \mathrm{wt} \%$ & $40 \mathrm{wt} \%$ \\
\hline Layer 2 & $50 \mathrm{wt} \%$ & $50 \mathrm{wt} \%$ \\
\hline Layer 3 & $40 \mathrm{wt} \%$ & $60 \mathrm{wt} \%$ \\
\hline Layer 4 & $20 \mathrm{wt} \%$ & $80 \mathrm{wt} \%$ \\
\hline Layer 5 & $0 \mathrm{wt} \%$ & $100 \mathrm{wt} \%$ \\
\hline
\end{tabular}

The OCV of Cell NP117 at $800^{\circ} \mathrm{C}$ was $1.1 \mathrm{~V}$ and the peak performance was $1.18 \mathrm{~W} / \mathrm{cm}^{2}$. The polarization curves at lower temperatures are plotted in Figure 18. Performance at all temperatures was higher when compared to the baseline SPC-3 (NJ003-1) cathode (see Table 9). However, the performance is lower when compared with the SPC-4 (NP105) composition, which has the same LSM and YSZ materials but without the grading. The cathode microstructure is shown in Figure 19.

NP117; Graded YSZ/LSM Ratio in Cathode Layers

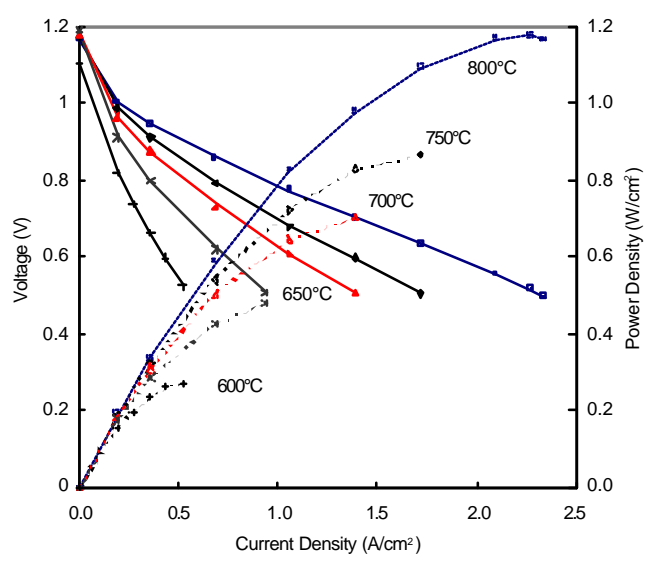

Figure 18. Polarization of Cell NP117 with hydrogen as fuel and air as oxidant. 


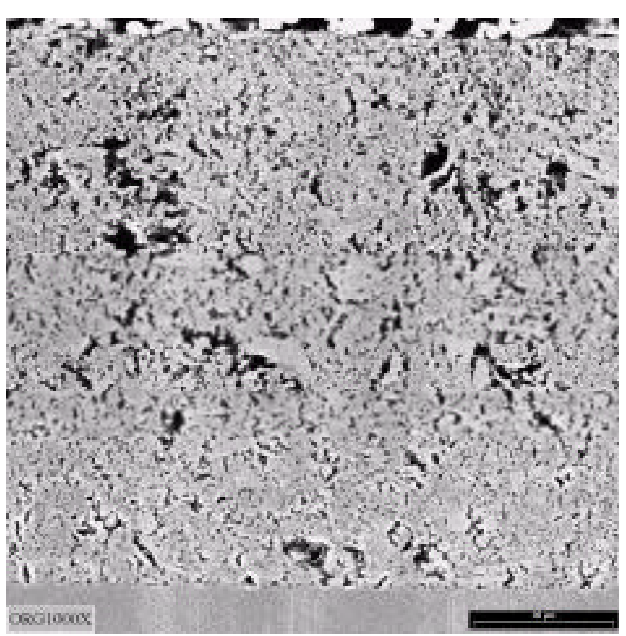

Figure 19. SEM Micrograph of a polished cross section of the cathode of cell NP112-1, electrolyte surface at the bottom of the micrograph.

To obtain a more open porosity, a 25 volume percent pore former was added to the SPC-4 cathode composition (50\% ( $\left.\mathrm{La}_{0.8} \mathrm{Sr}_{0.2}\right)_{0.98} \mathrm{MnO}_{3} / 50 \%$ Y YSZ). Cell NP126-1 with this cathode was tested and results are shown in Figure 20. Peak power at each temperature was better than the cell with SPC-3 baseline cathode but lower than the cell with similar cathode but made without pore former (NP105). Figure 21 shows the SEM micrograph of the polished cross-section of the tested cathode. The cathode is $60-80$ microns thick and the porosity is visible with some connectivity. One possible explanation for the lower performance is excessive porosity at the electrolyte interface, which reduces triple phase boundary areas, thus the effective charge transfer area. 
NP126-1; 25 vol\% Poreformer in SPC-4 Cathode

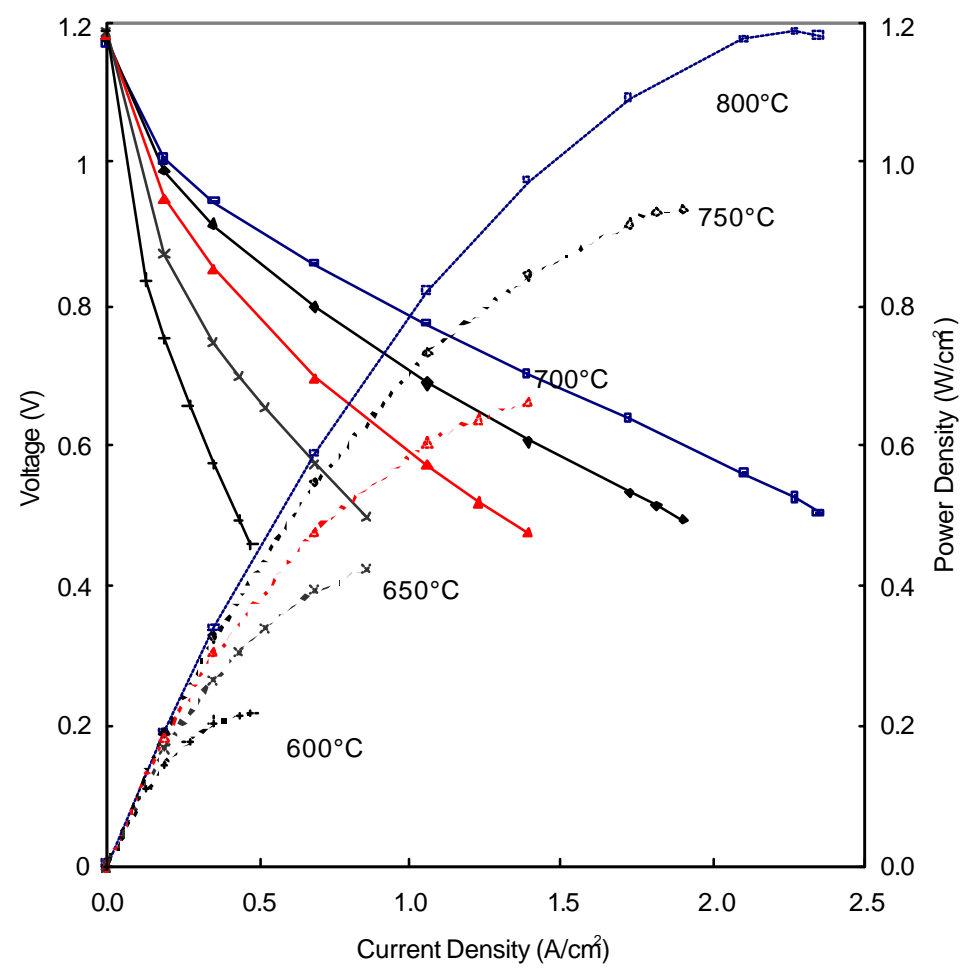

Figure 20. Polarization of Cell NP126-1 with hydrogen as fuel and air as oxidant.

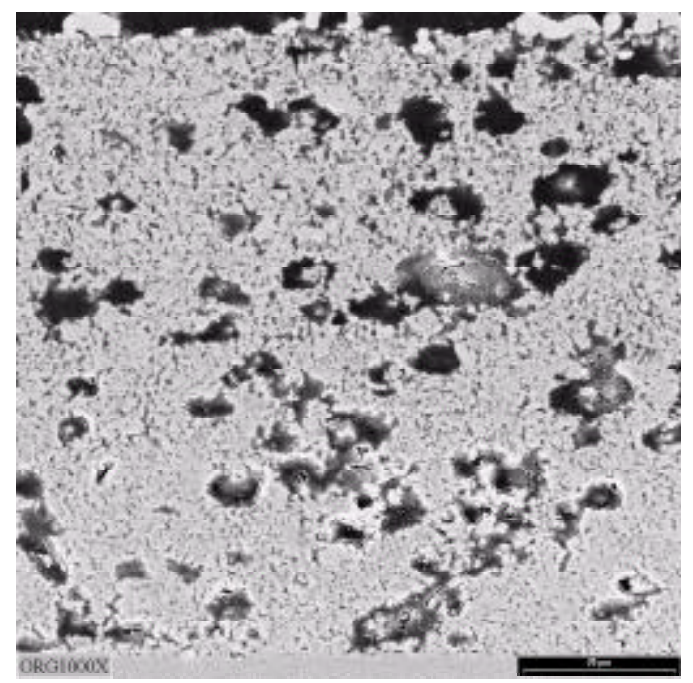

Figure 21. SEM micrograph of a polished cross section of cathode in cell NP126-1 
A summary of the significant cathode tests done on the program is presented in Table 8 and Table 9 . Table 9 compares power density at 5 different temperatures for a number of cathode tests.

Table 8. Cathode Electrode Powder Descriptions

\begin{tabular}{|c|c|c|}
\hline $\begin{array}{c}\text { Cathode } \\
\text { Designation }\end{array}$ & LSM Powder & YSZ Powder \\
\hline SPCEX-4 & $\begin{array}{l}\mathrm{La}_{0.84} \mathrm{Sr}_{0.15} \mathrm{MnO}_{3} \text { calcined } \\
\text { at } 1150^{\circ} \mathrm{C}\end{array}$ & $\begin{array}{l}50 \% \text { YSZ calcined at } 1000^{\circ} \mathrm{C} \\
50 \% \text { YSZ calcined at } 1200^{\circ} \mathrm{C}\end{array}$ \\
\hline SPCEX-5 & $\begin{array}{l}\left(\mathrm{La}_{0.85} \mathrm{Sr}_{0.15}\right)_{0.98} \mathrm{MnO}_{3} \text { calcined } \\
\text { at } 1000^{\circ} \mathrm{C}\end{array}$ & $\begin{array}{l}50 \% \text { YSZ calcined at } 1000^{\circ} \mathrm{C} \\
50 \% \text { YSZ calcined at } 1200^{\circ} \mathrm{C}\end{array}$ \\
\hline SPC-1 & As received $\mathrm{La}_{0.84} \mathrm{Sr}_{0.15} \mathrm{MnO}_{3}$ & As received $Y S Z$, \\
\hline SPC-2 & $\begin{array}{l}\text { As received } \\
\left(\mathrm{La}_{0.85} \mathrm{Sr}_{0.15}\right)_{0.98} \mathrm{MnO}_{3}\end{array}$ & As received YSZ \\
\hline $\begin{array}{l}\text { SPC-3 } \\
\text { (baseline) }\end{array}$ & $\begin{array}{l}\text { As received } \\
\left(\mathrm{La}_{0.85} \mathrm{Sr}_{0.15}\right)_{0.98} \mathrm{MnO}_{3}\end{array}$ & As received YSZ \\
\hline SPC-4 & $\begin{array}{l}\text { As received } \\
\left(\mathrm{La}_{0.85} \mathrm{Sr}_{0.15}\right)_{0.98} \mathrm{MnO}_{3}\end{array}$ & $\begin{array}{l}\text { As received higher surface area } \\
\text { YSZ }\end{array}$ \\
\hline
\end{tabular}


Table 9. Summary of Test Results of Cells with Different Cathode Designs

\begin{tabular}{|c|c|c|c|c|c|}
\hline \multirow{2}{*}{$\begin{array}{c}\text { Cell ID } \\
\text { Cathode Composition }\end{array}$} & \multicolumn{5}{|c|}{ Peak Performance $\left(\mathrm{W} / \mathrm{cm}^{2}\right)$} \\
\hline & $800^{\circ} \mathrm{C}$ & $750^{\circ} \mathrm{C}$ & $700^{\circ} \mathrm{C}$ & $650^{\circ} \mathrm{C}$ & $600^{\circ} \mathrm{C}$ \\
\hline $\begin{array}{c}\text { NJ003-1 } \\
\text { Baseline cathode (SPC-3) }\end{array}$ & 1.14 & 0.826 & 0.574 & 0.243 & N. A. \\
\hline $\begin{array}{c}\text { NN33 } \\
\text { Higher surface are YSZ in } \\
\text { cathode (SPC-4) } \\
\text { Ni coated graphite fiber in anode }\end{array}$ & 1.36 & N.A. & 0.96 & 0.661 & 0.257 \\
\hline $\begin{array}{c}\text { NJ059-1 } \\
\text { Functional layer over the } \\
\text { cathode (SPC-4) }\end{array}$ & 1.34 & 1.15 & 0.949 & 0.704 & 0.306 \\
\hline $\begin{array}{c}\text { NJ059-2 } \\
\text { Functional layer over the } \\
\text { cathode (SPC-4) processed } \\
\text { at low T }\end{array}$ & 1.31 & 1.15 & .939 & 0.700 & 0.285 \\
\hline $\begin{array}{c}\text { NJ097 } \\
\text { Cathode from calcined } \\
\text { powders (SPCEX-5) }\end{array}$ & 1.36 & 1.16 & 0.964 & 0.892 & 0.300 \\
\hline $\begin{array}{c}\text { NP105 } \\
\text { New cathode batch (SPC-4) }\end{array}$ & 1.44 & 1.22 & 0.855 & 0.637 & 0.306 \\
\hline $\begin{array}{c}\text { NP117 } \\
\text { Graded cathode composition }\end{array}$ & 1.18 & 0.868 & 0.708 & 0.478 & 0.275 \\
\hline $\begin{array}{c}\text { NP112-1 } \\
\text { Alternative LSM source }\end{array}$ & 0.839 & 0.622 & 0.399 & 0.221 & 0.120 \\
\hline $\begin{array}{c}\text { NP126-1 } \\
\text { Open pore cathode }\end{array}$ & 1.19 & 0.935 & 0.672 & 0.423 & 0.219 \\
\hline $\begin{array}{c}\mathbf{N J 1 2 8} \\
\text { Layered cathode } \\
\text { composition }\end{array}$ & 1.19 & 0.856 & 0.660 & 0.412 & N. A. \\
\hline
\end{tabular}




\subsubsection{Anode Improvements}

One advantage of tape calendering is the fact that a multilayer anode structure can be made from the calendering process. As mentioned in the discussion of the process in the Experimental section multiple anode layers are added to achieve the desired thin electrolyte. Since the multiple layers were a part of the current process, it was seen to be an excellent means to improve the cell. In an anode supported cell the anode has three roles, electrochemical, structural and gas delivery to and from the electrochemical reaction sites, and typically the optimum for one is opposed to the other. For example an optimum anode from an electrochemical standpoint would be relatively thin, on the order of 50 micrometers, and have a large number of fine pores for a large surface area for reactions to occur, where as an optimum structural anode would be relatively thick, greater than 300 micrometers, and pore free, but from the gas delivery standpoint an optimum structure would be thin with very large pores for easy gas flow. With a monolithic anode, optimizing for all of these functions would be very difficult, but with a multilayer anode the difficulty of the task is reduced since it is possible to create different anode layers with different compositions, microstructures and thicknesses to match many of the requirements. Optimum electrochemical properties are only needed near the anode/electrolyte interface, thus a thin layer with these properties can be designed into fabrication process to meet these requirements. The structural and gas transport requirements can be met again through a multilayer anode approach, by incorporating layers of increasing pore size on top the electrochemical layer the structural needs can be traded off with the gas transport need to create an improved multilayer anode. In order to create this anode structure, work was done to develop tape formulations that would meet the requirements and still be compatible with the tape calendering process. For improved performance, the more porous outer anode layer was investigated by making modifications with pore formers or additives such as a) fiber pore formers to create highly connected porosity and b) nickel-coated graphite powder to increase the effectiveness of porosity and of nickel anode catalyst.

In this work, graphite fibers of $120 \mu \mathrm{m}$ average length and $8 \mu \mathrm{m}$ diameter have been incorporated in the outer anode layer, a micrograph of the cross section is shown in Figure 22. Cells of 1 -in diameter with this anode reached a peak power density of $1.36 \mathrm{~W} / \mathrm{cm}^{2}$ at a fuel utilization of $31 \%$ and $630 \mathrm{~W} / \mathrm{cm}^{2}$ at a fuel utilization of $81 \%$. For comparison, cells with the standard anode achieved power densities ranging from 300 and $460 \mathrm{~mW} / \mathrm{cm}^{2}$ at similar utilizations. Because of the encouraging results, fabrication of full size bilayers with the graphite fiber pore formers was initiated. Initial results showed parallel cracks on the electrolyte surface, indicating alignment of the fibers and possible migration of the fibers through the anode layer to the anode/electrolyte surface during rolling. Adjusting the solids content in the tape, and thus the viscosity, reduced the cracks but did not eliminate them. On the other hand, partial (instead of full) substitution of the original pore former by the graphite fiber resulted in significant reduction of cracks. 
With $80 \%$ of the pore former substituted by graphite fiber, only one crack in a 4-inch diameter bilayer was observed. With $60 \%$ pore former substitution, a crack-free 4inch diameter bilayer was finally obtained, but the overall yield was poor and other approaches were investigated. It was postulated that the burnout characteristics/profile of the graphite fibers was not compatible the other organics in the green tape, that lead to increased stresses in the tape during binder-burnout phase of the firing process, thus resulting in the poor overall yield.

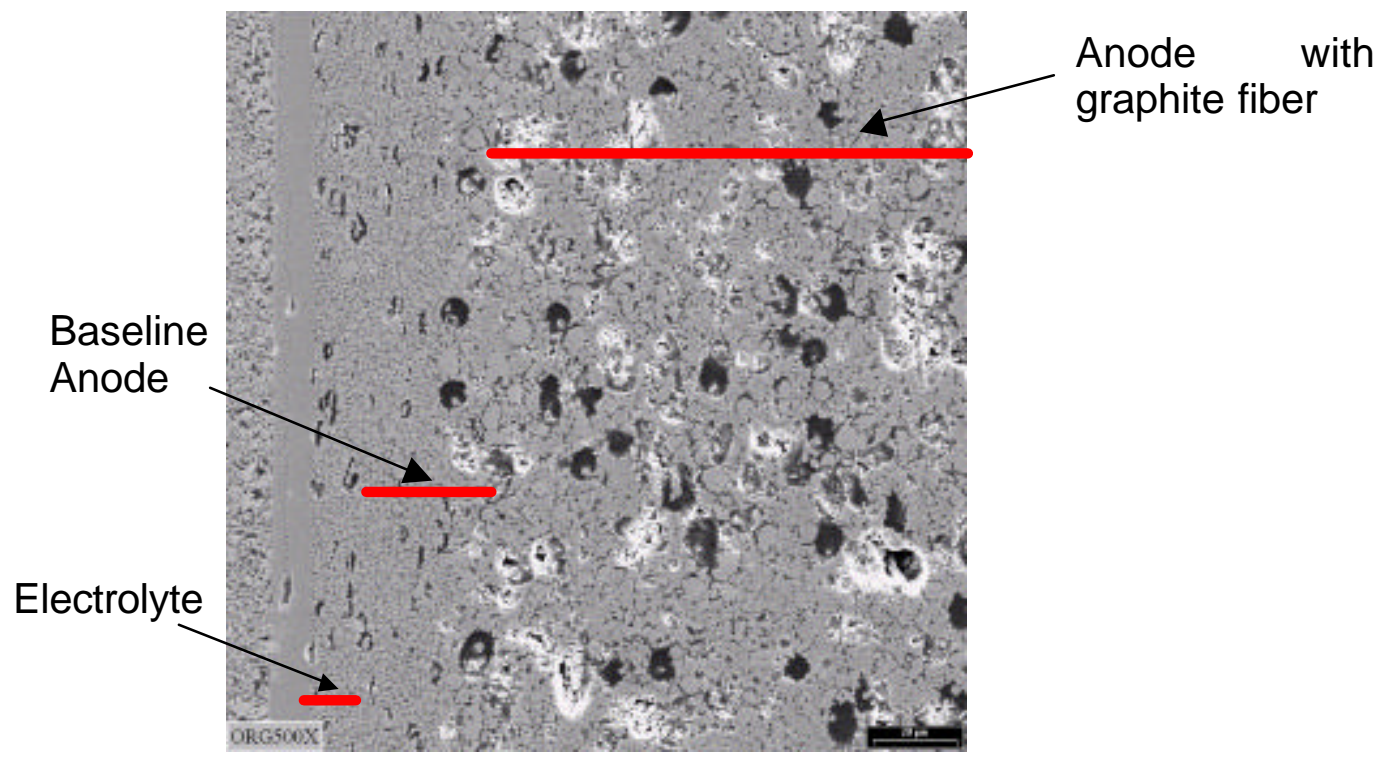

Figure 22. Micrograph of anode with graphite fiber pore former (NN33)

A Ni-coated graphite powder was investigated as an anode pore modifier. It contains $60 \mathrm{wt} \% \mathrm{Ni}$ and has a 90 micron average diameter. Anode batches were prepared and bilayer tapes were fabricated. However, because the graphite content of the powder was low, only $10 \%$ of the pore former can be substituted. With this substitution, the effect on anode pore structure is insignificant. Ni-coated graphite fiber tows were also looked at as pore modifiers. A tow of several feet in length was chopped into about $1 \mathrm{~mm}$ lengths, which was then milled and sieved to about 150 micrometers length. The yield of usable fiber to be used as pore former from this very labor intensive process was very low and thus this approach was also stopped. Due to the poor yields from the graphite fiber and coated particle approaches, improvements to the existing anode constituents were examined.

The pore former amount in the standard anode was near the limit that would allow bilayers to be successfully fabricated, so modifications of the other anode constituents, namely the $\mathrm{NiO}$ and $\mathrm{YSZ}$, were required to increase the porosity and to allow for the addition of additional amounts of poreformer in the green tapes. Various anode modifications were evaluated, and five of the more promising modified anode and layer compositions are described in Table 10. The anode 
structures are denoted as $\mathrm{N}, \mathrm{A}, \mathrm{B}, \mathrm{C}$, and $\mathrm{D}$, each with expected increasing porosity going from baseline to $N$ to $A$ to $B$ to $C$ and to $D$.

Table 10. Compositions Evaluated for Anode Engineering*

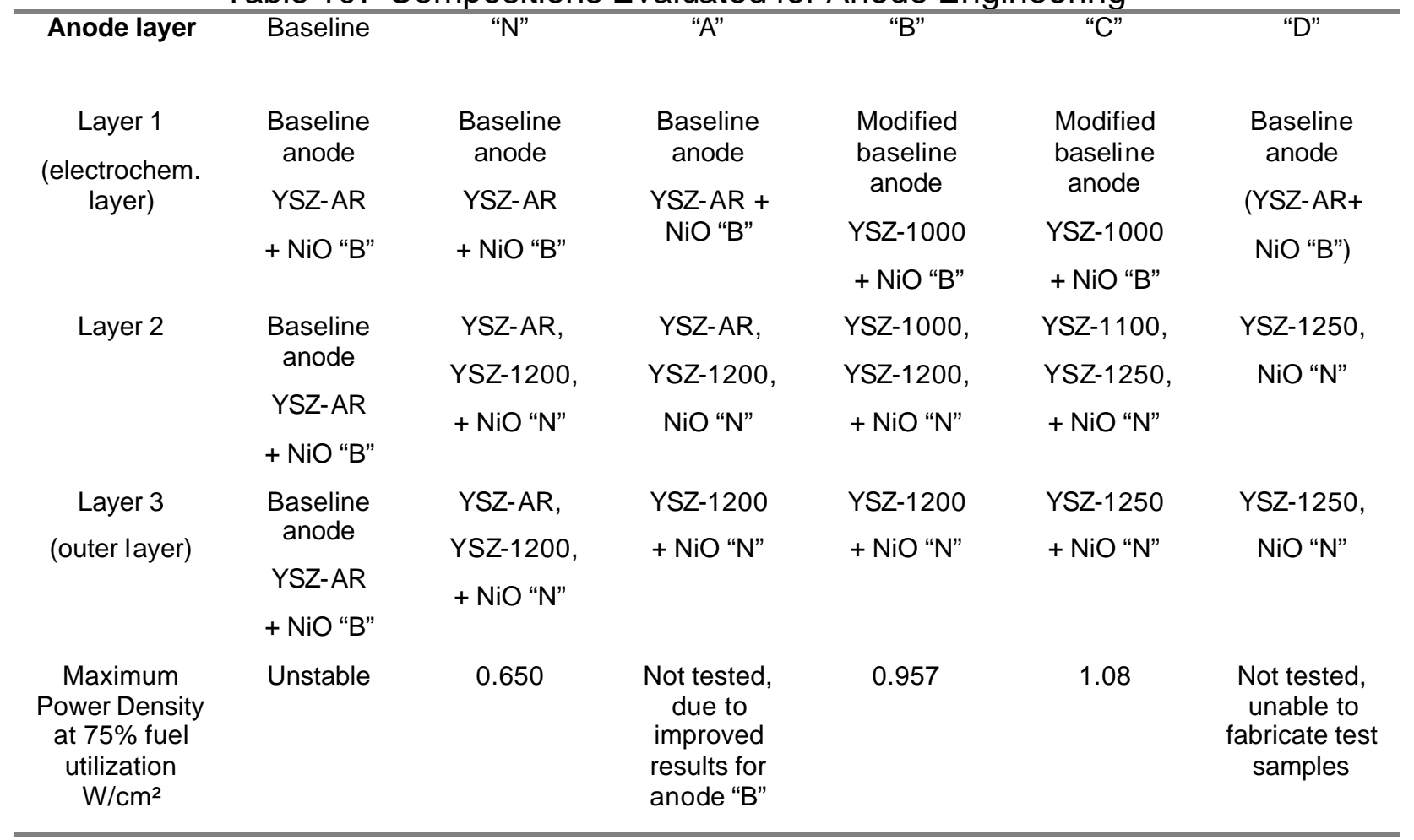

*YSZ-AR = as-received, YSZ-1000 $=$ YSZ-AR calcined at $1000^{\circ} \mathrm{C}, \mathrm{YSZ}-1200$ $=$ YSZ-AR calcined at $1200^{\circ} \mathrm{C}, \mathrm{YSZ}-1250=\mathrm{YSZ}-\mathrm{AR}$ calcined at $1250^{\circ} \mathrm{C}, \mathrm{NiO}$ "B" = as received $\mathrm{NiO}$ grade "B", and $\mathrm{NiO}$ "N" = as received $\mathrm{NiO}$ grade "N"

The first improvement on the standard anode was to reduce the sintering of the YSZ in the outer layers by reducing the surface area and in turn reducing the driving force for sintering. To reduce the surface area of the as received materials, the powders were calcined at elevated temperatures to partially sinter the particles before incorporation into the calendering process. A second effect was achieved in that by reducing the surface area of the ceramic materials in the tape additional pore formers can be added without having to modify the binder system of the tape. This anode structure had a thin layer $(1.5 \mathrm{mil})$ of baseline anode next to the electrolyte and a more porous and thicker layer $(12$ mils) on the gas side. The denser baseline layer was made from a finer $\mathrm{NiO}$ powder while the more porous layer was made from the coarser $\mathrm{NiO}$ and had 2.5 times more pore former. A microstructure of a bilayer with anode "N" is shown in Figure 23. Cells with this anode showed up to $250 \mathrm{~mW} / \mathrm{cm}^{2}$ power density at $50 \%$ fuel utilization in simulated 
steam reformed natural gas fuel composition in a 4-in diameter radial cell stack module. At $75 \%$ fuel utilization, the performance drops off to about $150 \mathrm{~mW} / \mathrm{cm}^{2}$.

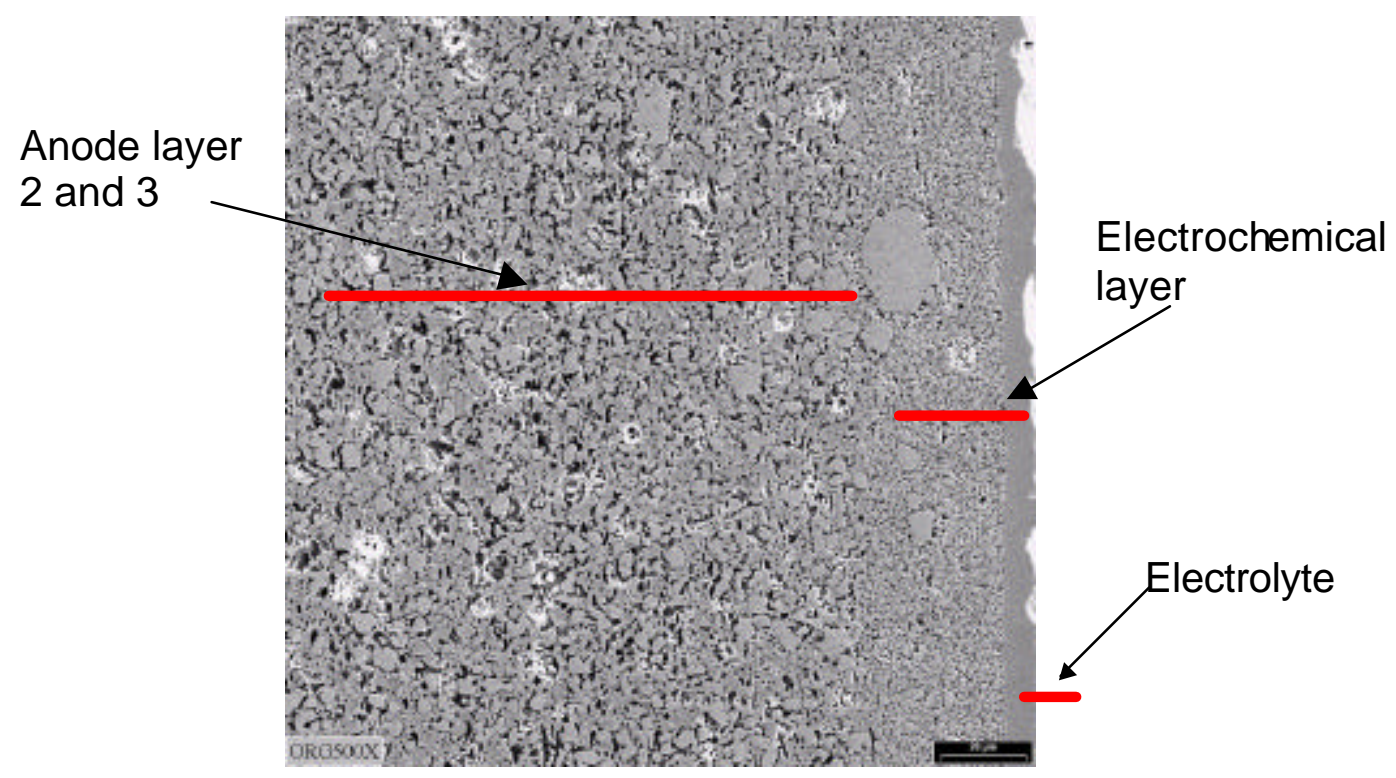

Figure 23. Micrograph of a bilayer made with anode "N" (NJ009).

Anode "B" cells were fabricated and tested, and example was single cell (Cell NJ200-1) which had an SPC-4 cathode. The cell had a very good OCV of $1.19 \mathrm{~V}$ at $800^{\circ} \mathrm{C}$. Peak power density was $1.23 \mathrm{~W} / \mathrm{cm} 2$ at $800^{\circ} \mathrm{C}$ with $67 \mathrm{cc} / \mathrm{min}$ hydrogen flow. Fuel utilization was varied using different current densities and hydrogen flows. As seen in the data shown in Figure 24, that the maximum sustainable fuel utilization was $75 \%$ in pure hydrogen with this anode structure. 


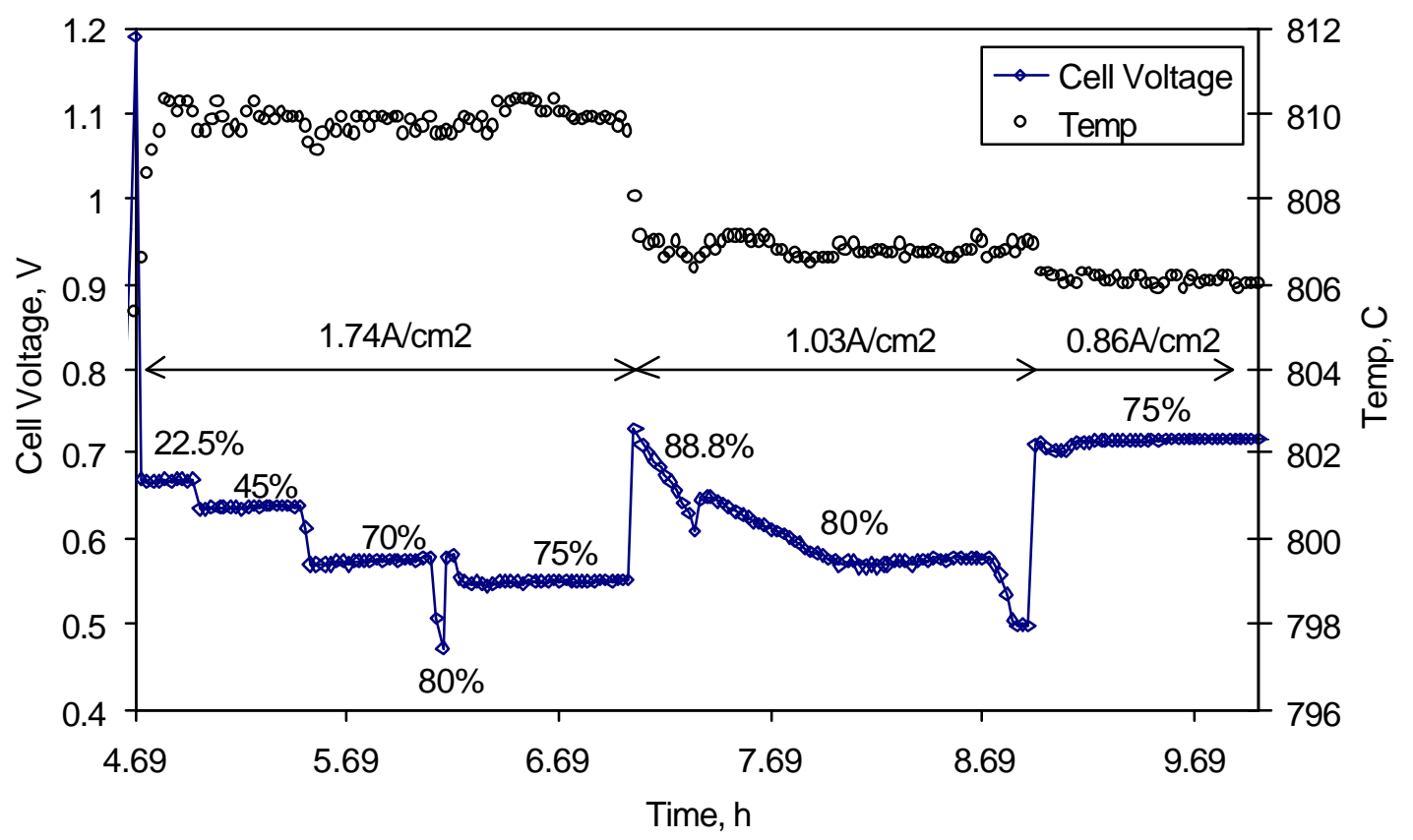

Figure 24. Anode "B" cell performance under different fuel utilization at $800 \mathrm{C}$, and hydrogen as the fuel and air as oxidant.

Cells with anode " $\mathrm{C}$ " were also fabricated and tested. Anode $\mathrm{C}$ was a further extension of anode "B", where the YSZ in the outer layers was calcined at even higher temperatures, thus decreasing the surface area more, and further reducing the sintering in those layers. One consequence of modifying the sintering of any layer in a multilayer ceramic is the risk of decreased sintering yields due to stresses from differential sintering of the layers. Fabrication of 1" diameter bilayers with anode "C" was achieved with good yield $(>80 \%)$, but as the diameter of the bilayer was increased the yield dropped off precipitously to less than $40 \%$ for 4 " diameter bilayers, where the typical yield for bilayers with baseline anode was greater the $80 \%$. For this yield calculation, a rejected cell was a cell with a crack anywhere within the bilayer. A single cell NJ205-1, made of anode "C" and SPC-4 cathode, was tested and a peak power density of about $1.41 \mathrm{~W} / \mathrm{cm}^{2}$ at $800^{\circ} \mathrm{C}$ (Figure 25) in $\mathrm{H}_{2}$ was observed. After a polarization curve was generated, the cell was placed under a constant current load while the fuel flow rate was varied to characterize cell performance under different fuel utilization. As shown in Figure 26, the cell performed very well for more than 100 hours at $75 \%$ fuel utilization and $1.72 \mathrm{~A} / \mathrm{cm}^{2}$ with a power density greater than $1 \mathrm{~W} / \mathrm{cm}^{2}$. It also shows that fuel utilization as high as $85 \%$ is feasible with this cell. 


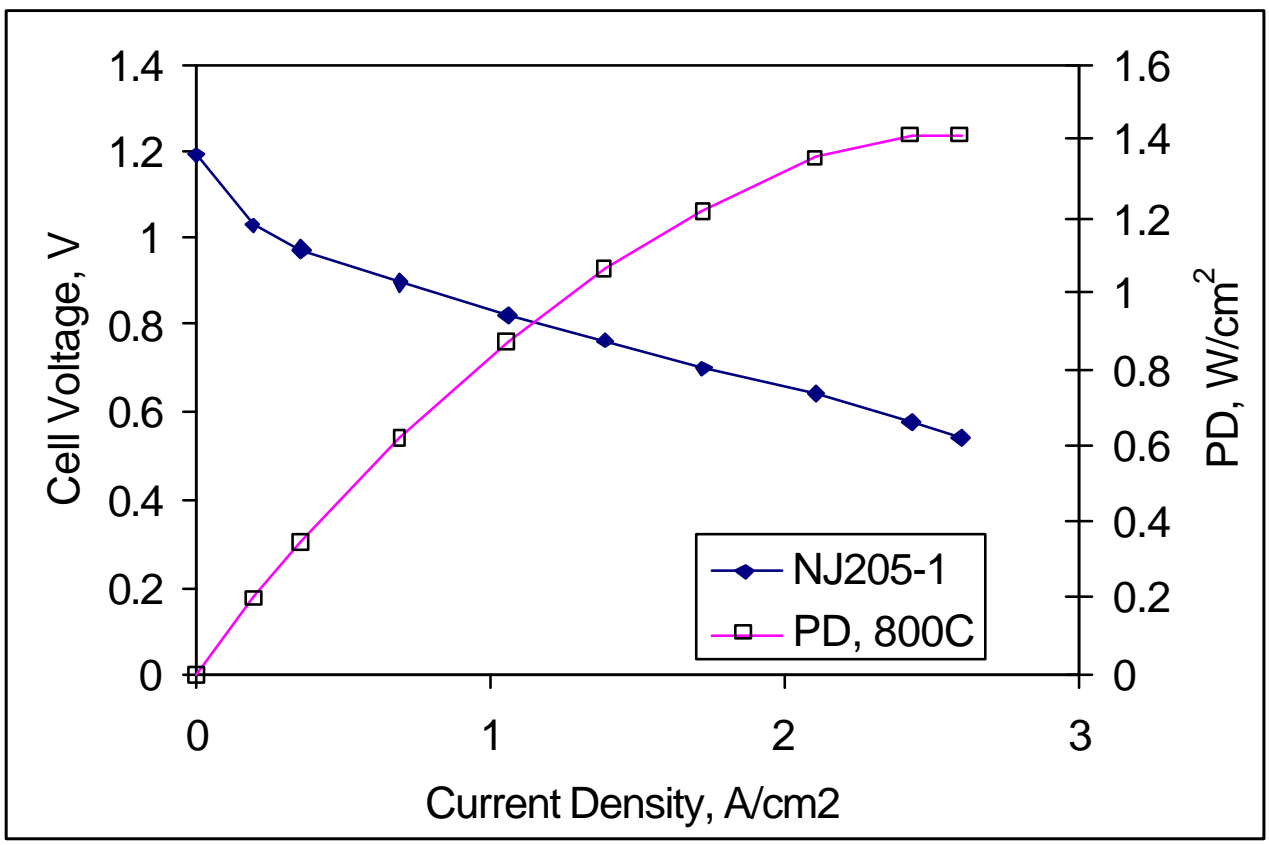

Figure 25. Cell Performance of NJ205-1 with porous anode "C" and SPC-4 Cathode, hydrogen as fuel and air as oxidant.

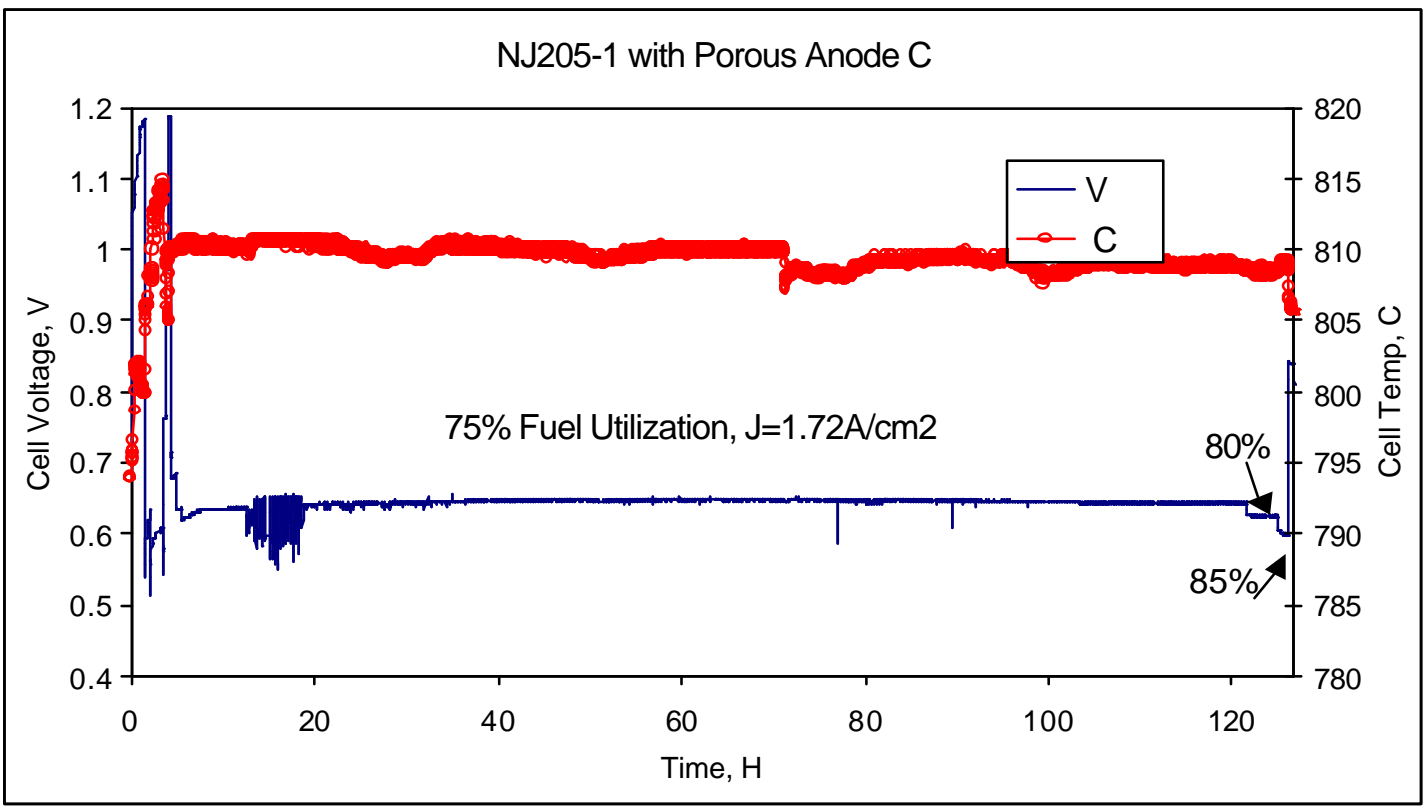

Figure 26. Performance of cell NJ205-1 at $1.72 \mathrm{~A} / \mathrm{cm}^{2}$ load and $75 \%$, $80 \%, 85 \%$ fuel utilizations at $800^{\circ} \mathrm{C}$, hydrogen as fuel and air as oxidant. 
A 1" single cell NJ208 with anode "C" and high performing SPC-EX5 cathode was assembled and tested to evaluate effects on performance of $\mathrm{H}_{2}$ flow and $\mathrm{N} 2$ dilution. Figure 27 shows the cell performance at $800^{\circ} \mathrm{C}$. The cell had an OCV of greater than $1.2 \mathrm{~V}$. With a $\mathrm{H}_{2}$ flow rate of $67 \mathrm{cc} / \mathrm{min}$, the performance was slightly reduced when diluted with $37 \mathrm{cc} / \mathrm{min} \mathrm{N}_{2}$. With a flow rate of $104 \mathrm{cc} / \mathrm{min}$, the performance was higher with pure $\mathrm{H}_{2}$ than with $\mathrm{N}_{2}$ diluted fuel as expected. Further testing of cells with anode "C" was limited by the low yield in the bilayer firing step mentioned above. The excellent electrochemical performance indicates promise for this cell composition and further development and testing of this anode may be done on the DOE- NETL SECA program.

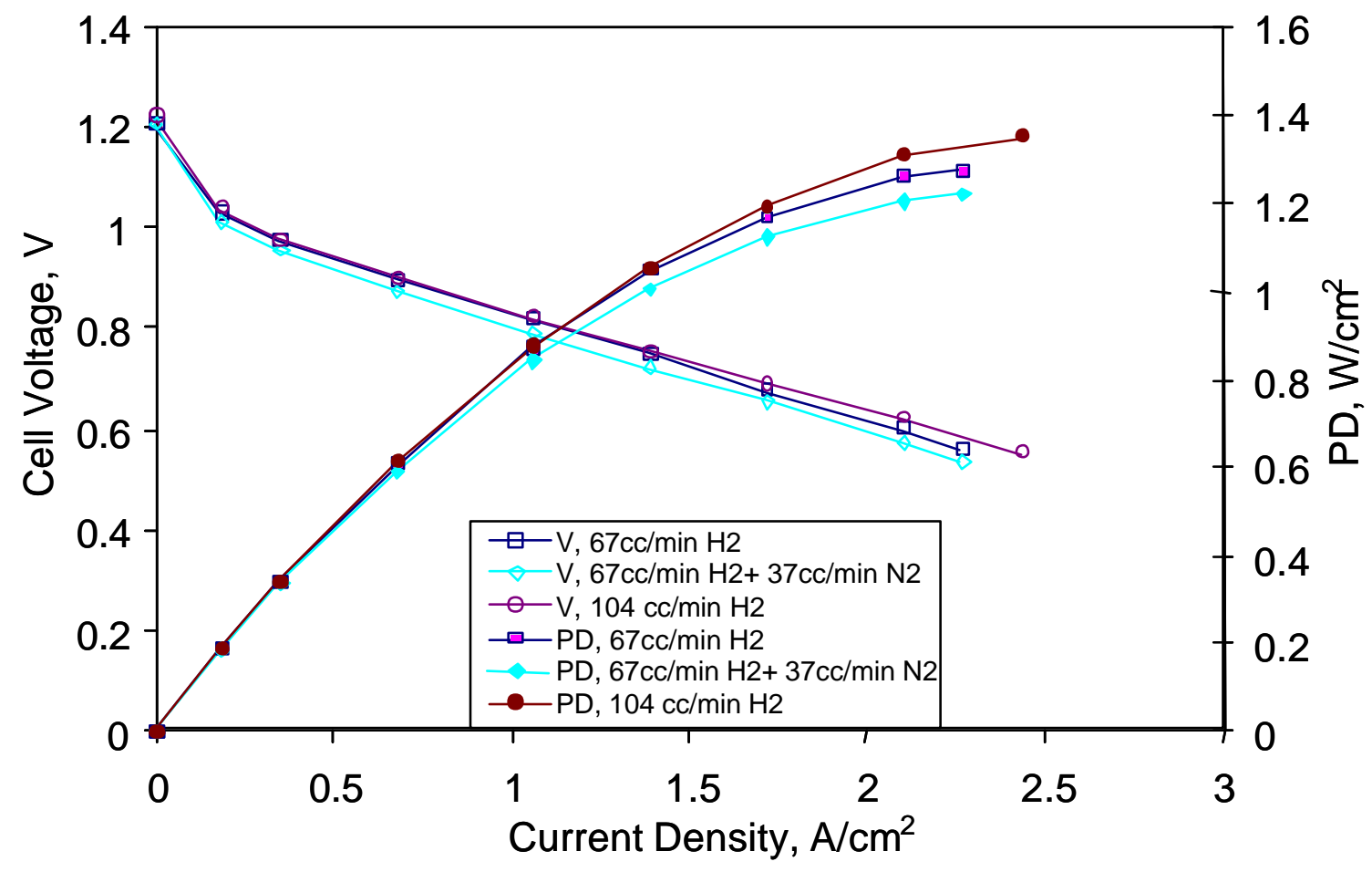

Figure 27. Polarization curve for a cell with anode " $\mathrm{C}$ " and an improved cathode SPC-EX5 at $800^{\circ} \mathrm{C}(\mathrm{NJ} 208)$.

\subsubsection{Cell Mechanical Properties Improvements}

Improving the reliability of solid oxide fuel cell (SOFC) stacks is a significant issue facing development of SOFC's. A typical mode of failure observed in stacks is cell fracture. These cracks occur during stacking and during operation. Stresses 
leading to failure of these multilayer ceramic cells are a combination of residual and applied stresses. Residual stresses in the sintered multilayers would likely change the effective mechanical properties of the individual component in the multilayer form. Stress analysis of ceramics involves probabilistic models to predict failure because of the scatter in mechanical strength of ceramics. The mechanical properties of the SOFC components from room temperature to the operating temperature are required as input for these models.

The flexural strength of anodes, electrolytes, and bilayers was measured at $25^{\circ} \mathrm{C}, 550,700$, and $800^{\circ} \mathrm{C}$ under both oxidizing and reducing atmospheres. Table 11 shows the test matrix for the flexural testing conducted. The samples were prepared by the tape calendering, laminating and sintering method. The electrolyte was $8 \mathrm{~mol} \%$ Yttria Stabilized Zirconia (YSZ) while the anodes were a mixture of Nickel Oxide (NiO) and YSZ. Two different types of $\mathrm{NiO}$ are used in the anode formulations.

Table 11. Test Matrix for Mechanical Testing.

The number of samples tested at each temperature and condition is noted.

\begin{tabular}{|l|c|c|c|c|c|c|c|}
\hline $\begin{array}{l}\text { All samples were nominally 0.014" } \\
\text { thick }\end{array}$ & $\begin{array}{c}25^{\circ} \mathrm{C} \\
\text { (Reduced) }\end{array}$ & $\mathbf{5 5 0 ^ { \circ } \mathrm { C }}$ & $\begin{array}{c}550^{\circ} \mathrm{C} \\
\text { (Reduced) }\end{array}$ & $\mathbf{7 0 0 ^ { \circ } \mathrm { C }}$ & $\begin{array}{c}700^{\circ} \mathrm{C} \\
\text { (Reduced) }\end{array}$ & $\mathbf{8 0 0}{ }^{\circ} \mathrm{C}$ & $\begin{array}{c}800^{\circ} \mathrm{C} \\
(\text { Reduced) }\end{array}$ \\
\hline Anode Layer 1 ("Baseline") & 0 & 0 & 8 & 0 & 8 & 8 & 8 \\
\hline Anode Layer 2 (Anode "N") & 0 & 0 & 3 & 0 & 6 & 7 & 7 \\
\hline Electrolyte & 0 & 0 & 6 & 0 & 7 & 8 & 7 \\
\hline $\begin{array}{l}\text { Bilayer } \\
\text { (electrolyte/anode 1 "Baseline") } \\
\text { anode 2 "N") }\end{array}$ & 7 & 8 & 10 & 9 & 7 & 90 & 9 \\
\hline
\end{tabular}

Samples were reduced at $1000^{\circ} \mathrm{C}$ for 2 hrs using a mixture of $4 \%-\mathrm{H}_{2}$ and $\mathrm{Ar}$. The testing was conducted in ring-on-ring configuration with circular samples of approximately $25 \mathrm{~mm}$ diameter (Figure 28). The loading had an outside diameter of $20 \mathrm{~mm}$ and an inside diameter of $5 \mathrm{~mm}$ and the loading rate was $1 \mathrm{~mm} / \mathrm{minute}$. The bilayer samples were tested with the anode side in tension. The heating rate for the high temperature samples was $20^{\circ} \mathrm{C} /$ minute to the test temperature followed by 15 minutes dwell time. For the reduced samples the testing was conducted in an environment of a flowing gas mixture of $4 \%-\mathrm{H}_{2}$ and $\mathrm{Ar}$. The fracture surfaces of a few of the samples were then examined using a scanning electron microscope (SEM) to detect the failure origin. 


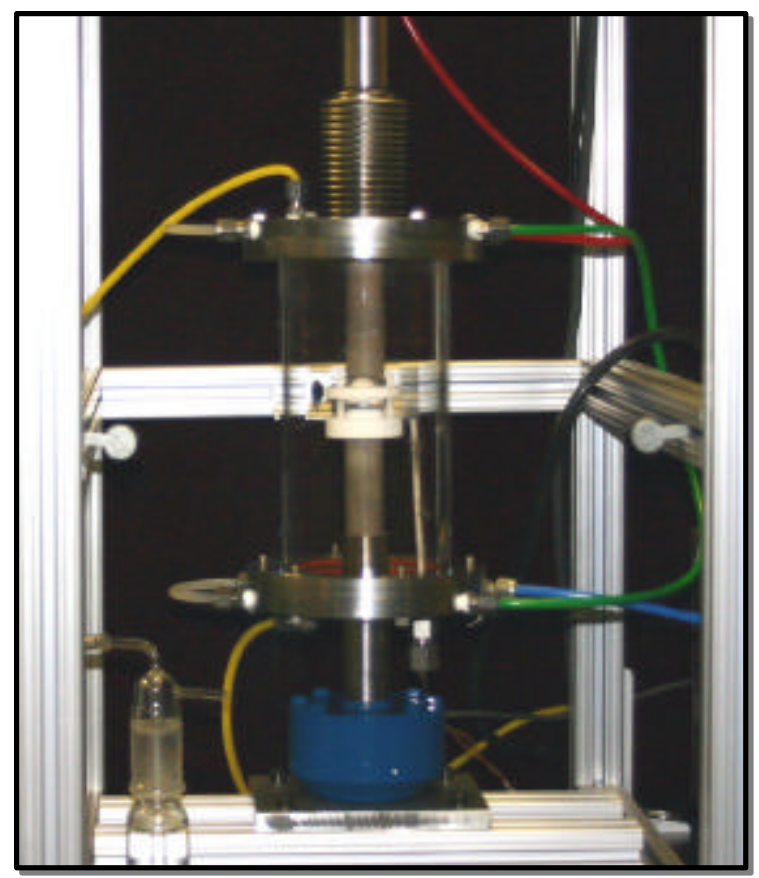

a)

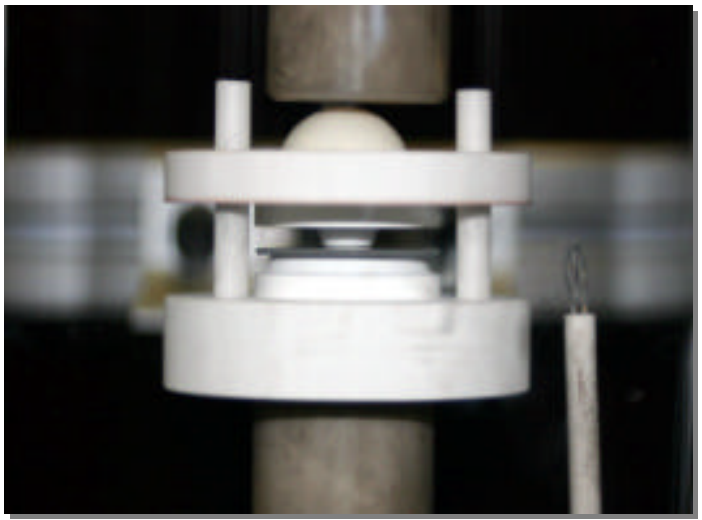

b)

Figure 28. (a) Testing set-up with (b) details of the ring-on-ring loading fixture. A high temperature controlled gas enclosure surrounded the fixture during high temperature testing.

The electrolyte in a few bilayer samples of size $5 \mathrm{~mm} \times 5 \mathrm{~mm}$ of NiO-YSZ and reduced Ni-YSZ were measured for residual stresses by a high temperature $X-$ ray diffractometer. The samples were reduced at $800^{\circ} \mathrm{C}$ for 3 hours using a gas mixture of $4 \% \mathrm{H}_{2}$ and $96 \%$ Ar. Scans were made between $140^{\circ}$ and $146^{\circ} 2 \theta$ at $20^{\circ} \mathrm{C}, 200^{\circ} \mathrm{C}, 400^{\circ} \mathrm{C}, 600^{\circ} \mathrm{C}, 800^{\circ} \mathrm{C}$ and $900^{\circ} \mathrm{C}$. The unreduced samples were scanned in air and the reduced samples were scanned in N2. The flexural strength data is shown in Table 12 and it is plotted in Figure 29 with the error bars associated with it. 
Table 12. The Characteristic Flexural Strength (MPa) and the Weibull Modulus for the Tested Samples.

\begin{tabular}{|c|c|c|c|}
\hline \begin{tabular}{|l} 
Sample type - Atmosphere \\
Note: "Baseline" (fine particle size) \\
Anode "N" (coarse particle size)
\end{tabular} & $\begin{array}{c}\text { Temperature } \\
\left({ }^{\circ} \mathrm{C}\right)\end{array}$ & $\begin{array}{c}\text { Characteristic Strength } \\
(\mathrm{MPa})\end{array}$ & Weibull Modulus \\
\hline \multicolumn{4}{|c|}{ BILAYER (electrolyte/anode 1 "Baseline"/ anode 2 "N") } \\
\hline $\mathrm{H}_{2}$ & 25 & 166.4 & 7.0 \\
\hline $\mathrm{H}_{2}$ & 550 & 150.1 & 4.0 \\
\hline $\mathrm{H}_{2}$ & 700 & 110.8 & 3.6 \\
\hline $\mathrm{H}_{2}$ & 800 & 122.2 & 13.7 \\
\hline BILAYER (electrolyte/anode 1 "Baseline" & & & \\
\hline Air & 25 & & \\
\hline Air & 550 & 175.2 & 4.7 \\
\hline Air & 700 & 184.7 & 2.8 \\
\hline Air & 800 & 183.6 & 4.3 \\
\hline \multicolumn{4}{|l|}{ ANODE 1(“Baseline”) } \\
\hline $\mathrm{H}_{2}$ & 25 & & \\
\hline $\mathrm{H}_{2}$ & 550 & 158.6 & 3.4 \\
\hline $\mathrm{H}_{2}$ & 700 & 149.5 & 5.2 \\
\hline $\mathrm{H}_{2}$ & 800 & 122.4 & 5.3 \\
\hline \multicolumn{4}{|l|}{ ANODE 2 (anode "N") } \\
\hline $\mathrm{H}_{2}$ & 25 & & \\
\hline $\mathrm{H}_{2}$ & 550 & 123.1 & 4.5 \\
\hline $\mathrm{H}_{2}$ & 700 & 104.7 & 9.0 \\
\hline $\mathrm{H}_{2}$ & 800 & 94.2 & 5.7 \\
\hline \multicolumn{4}{|l|}{ ANODE 2 (anode "N") } \\
\hline Air & 25 & & \\
\hline Air & 550 & & \\
\hline Air & 700 & & \\
\hline Air & 800 & 169.5 & 4.7 \\
\hline \multicolumn{4}{|l|}{ ANODE 1 ("Baseline") } \\
\hline Air & 25 & & \\
\hline Air & 550 & & \\
\hline Air & 700 & & \\
\hline Air & 800 & 149.5 & 3.0 \\
\hline \multicolumn{4}{|l|}{ ELECTROLYTE } \\
\hline Air & 25 & & \\
\hline Air & 550 & & \\
\hline Air & 700 & & \\
\hline Air & 800 & 123.7 & 3.5 \\
\hline \multicolumn{4}{|l|}{ ELECTROLYTE } \\
\hline $\mathrm{H}_{2}$ & 25 & & \\
\hline $\mathrm{H}_{2}$ & 550 & 140.1 & 7.6 \\
\hline $\mathrm{H}_{2}$ & 700 & 151.8 & 5.6 \\
\hline $\mathrm{H}_{2}$ & 800 & 151.5 & 3.1 \\
\hline
\end{tabular}




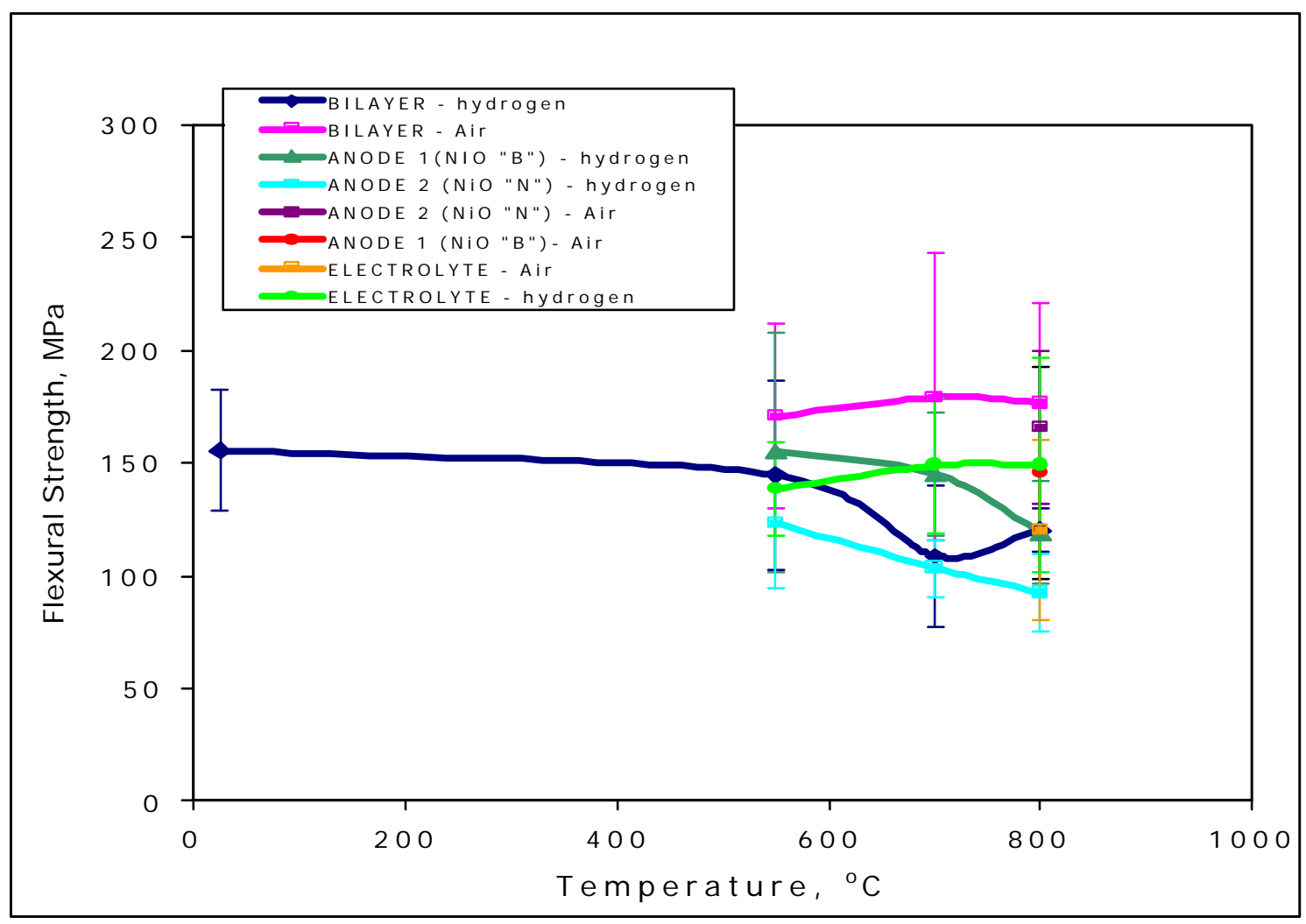

Figure 29. Characteristic strength of the tested samples.

The electrolyte strength in the reduced condition in hydrogen is relatively independent of temperature. The values reported are a little lower than those found in literature [1]. The strength of the both the anode 1 (with finer $\mathrm{NiO}$ powder) and the anode 2 (with coarser $\mathrm{NiO}$ ) decrease with temperature in the reduced condition in hydrogen atmosphere. The strength of both these anode materials is higher at $800^{\circ} \mathrm{C}$ in air to the corresponding strengths in the reduced condition. The bilayer (Anode/Electrolyte) strength in air is also relatively independent of temperature. The strength of the reduced bilayers in hydrogen decreases with temperature with an uncharacteristic increase in strength from $700^{\circ} \mathrm{C}$ to $800^{\circ} \mathrm{C}$. It should be noted that the data at $800^{\circ} \mathrm{C}$ has very little scatter as compared to the data at $700^{\circ} \mathrm{C}$. The data at $700^{\circ} \mathrm{C}$ could be skewed on the lower side because of the relatively low values of a few outliers. Further the low number of samples shows a trend of the strength rather than complete statistical reliability for ceramic samples.

A few representative tested samples are shown in Figure 30. Most of the samples had fracture origins inside the inner ring of the specimens indicating even 
loading and no discernable concentrated effect of the pin loading. A lot of the specimens were high-energy fractures from the number of bifurcations emanating from the failure origin.

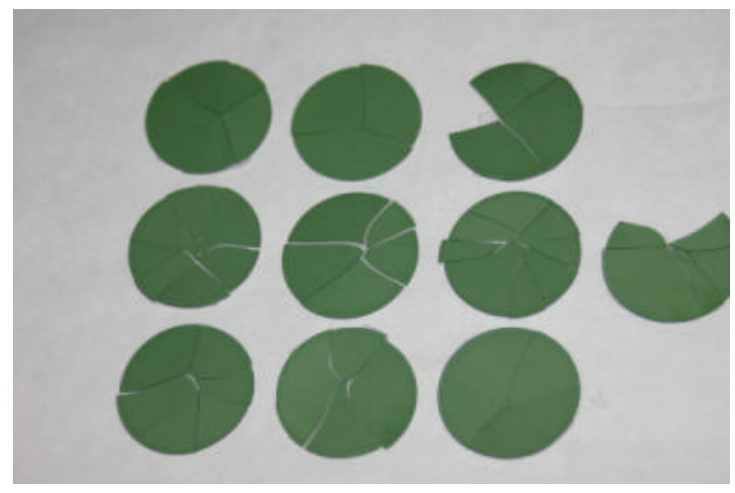

a)

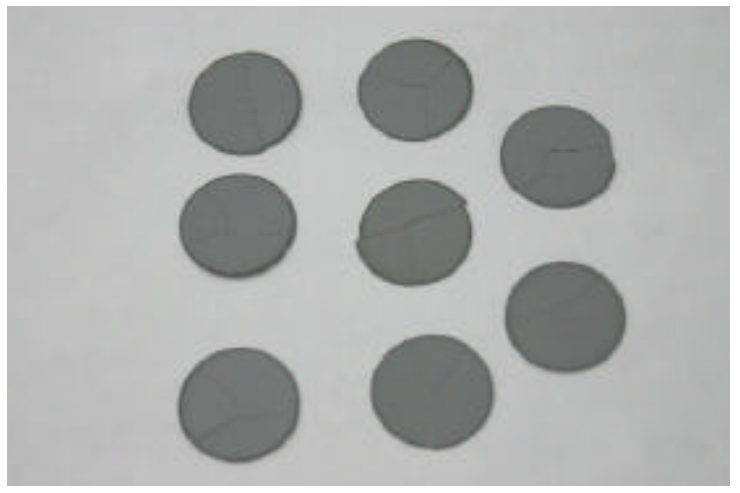

b)

Figure 30. Tested bilayer samples (a) air, $800^{\circ} \mathrm{C}$ and (b) reduced, $800^{\circ} \mathrm{C}$.

The results of the x-ray scans on one bilayer sample to measure the residual stress in the electrolyte is shown in Figure 31. The electrolyte, with the lower coefficient of thermal expansion (CTE) as compared to the anode, is in high compression at room temperature showing the effect of the mismatch in the CTE between the anode and the electrolyte. The layers can be assumed to be in the elastic regime for the whole temperature range for which the data is taken.(0$900^{\circ} \mathrm{C}$ ). The compression values do not change much after anode reduction, though the cross over of the regression line at around $600^{\circ} \mathrm{C}$ would indicate a change in properties at that temperature. It is also possible that the reduction could alter the integrity of the anode/electrolyte interface changing the residual stresses generated. 


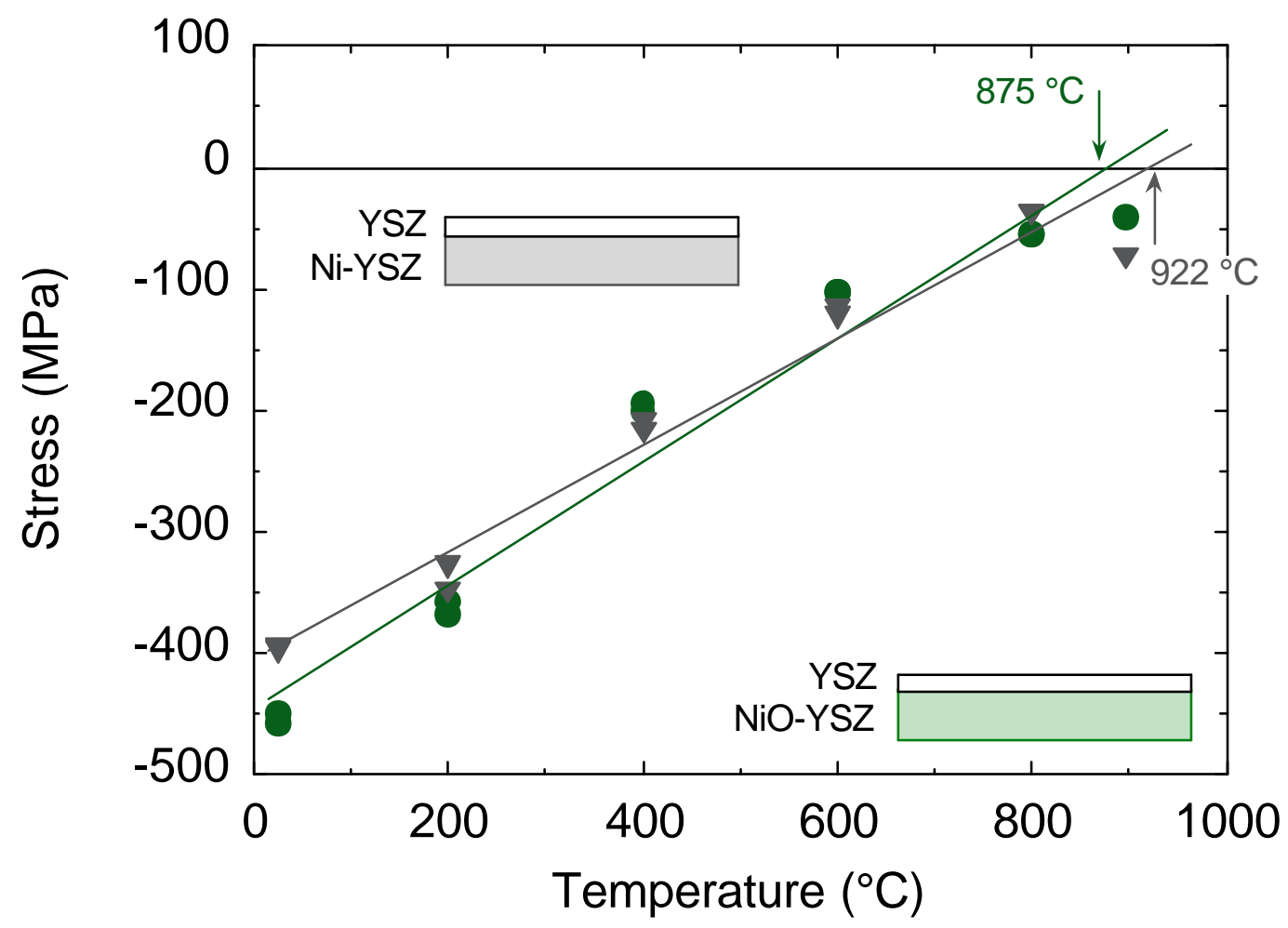

Figure 31. Measured residual stress in the electrolyte for the bilayer samples. The effect of the mismatch in the coefficient of thermal expansion (CTE) is clearly seen in the results. Where the inverted triangles are for the reduced samples and the circles are for the unreduced sample.

For the individual component samples, except for the electrolyte samples at $800^{\circ} \mathrm{C}$, all the data indicate that the strength in air is greater than the strength of the reduced samples. The reduced electrolyte samples in our tests did not show any significant change in strength with temperature. The strength of the anode 1 (finer $\mathrm{NiO}$ ) is higher than that of anode 2 (coarser $\mathrm{NiO}$ ) indicating a denser and stronger microstructure for the former. Both the reduced anode samples show a decrease in strength with temperature indicating that the reduction phenomenon alters the anode microstructure making it sensitive to temperature.

The bilayers also show the trend of the strength of the unreduced samples being more than the reduced samples. Also, the strength of the unreduced bilayers is relatively same at 550,700 and $800^{\circ} \mathrm{C}$, while there is a 14,40 and $33 \%$ reduction in characteristic strength at those respective temperatures in the reduced samples. Anode reduction will result in increased porosity, which could explain the reduction in strength for the reduced anode and bilayer samples. The decrease in strength 
for the reduced bilayers would need further investigation. This is further complicated by the increase in strength of the reduced bilayers in hydrogen from $700^{\circ} \mathrm{C}$ to $800^{\circ} \mathrm{C}$.

An SEM image of the surface of the anode is shown in Figure 32. The circular particles are YSZ powder that is in contact with the surface of the anode during the sintering process.

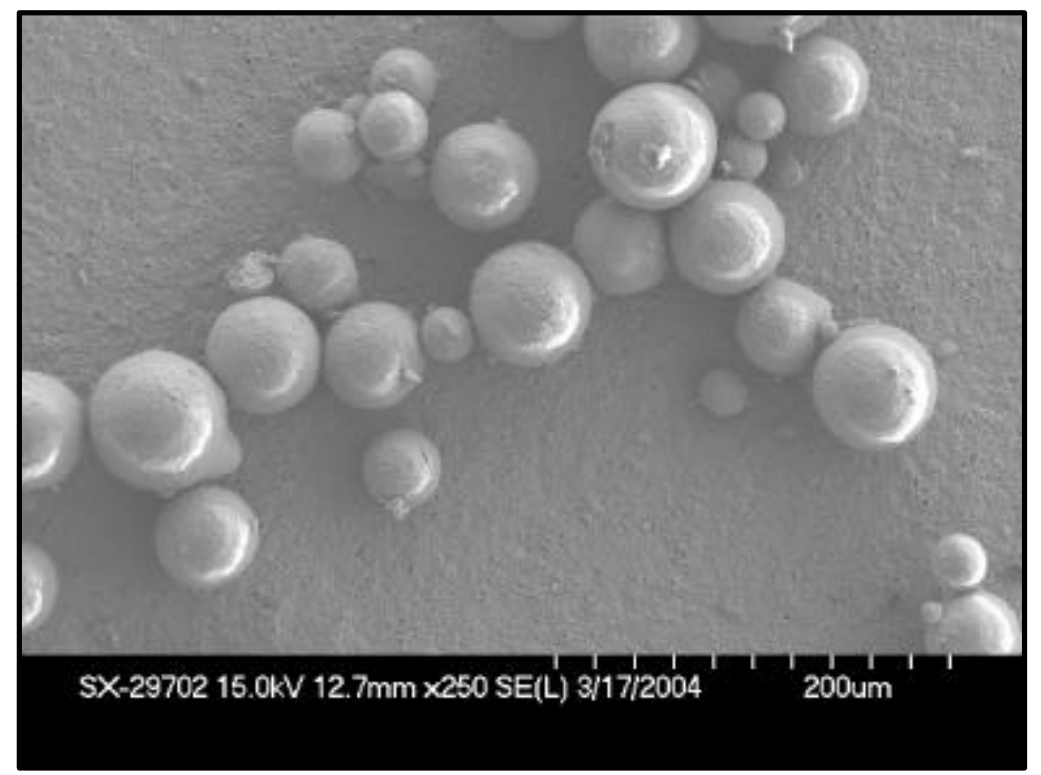

Figure 32. SEM image of the surface of the anode with YSZ powders which are present during sintering.

Figure 33 shows SEM images of fracture surfaces of reduced bilayer samples at $25^{\circ} \mathrm{C}$ and $800^{\circ} \mathrm{C}$. There are dense YSZ agglomerates embedded inside the surface of the anode. The fracture surface of those agglomerates indicates very good adhesion of the agglomerates to the surrounding anode material. During cool-down it is possible that the mismatch in the CTE between the YSZ and the anode material will lead to local zones of tension on the anode surface which could likely turn into a failure origin during testing. The high compression in the electrolyte from the residual stress measurements would translate into residual tension of the anode near the interface with the electrolyte. But, the bending or curvature development of the bilayer due to this CTE mismatch or differential sintering would put the outer ligament i.e. the external anode surface into slight compression. This could possibly explain the slightly higher values of strength of 
the bilayers compared to the individual anode samples, which do not have any residual compression on the tensile surface.

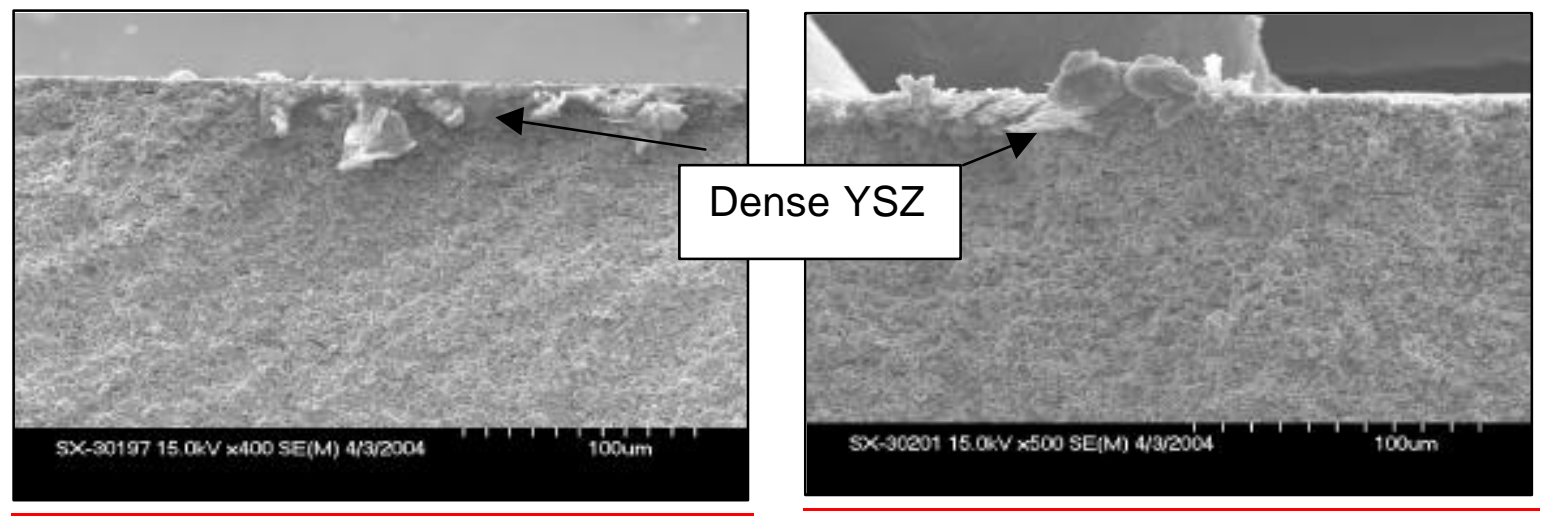

a)

b)

Figure 33. Fracture surfaces of reduced bilayers at (a) $25^{\circ} \mathrm{C}$ and (b) $800^{\circ} \mathrm{C}$. The anode surface is at the top and the arrows indicate the location of dense YSZ possibly originating from the powder on the surface shown in Figure 32

Figure 34 shows the fracture surface of a reduced bilayer along with a magnified image of the interface. In these bilayer tests, the anode surface was in tension, which would lead to the strength-limiting flaws being on the anode surface. The latter are of concern during stack loading and heat-up. The local voids seen in Figure 34 (b) might serve as crack initiation sites during operation and thermal cycling leading to delamination of the interface. This delamination would cause performance losses as also eventual failure of the cell.. As is evident, the stresses generated in the cell during various stages act upon different flaw populations. The optimization of the manufacturing processes to reduce the range of these flaws must take into account the severity of the conditions where surface or bulk flaws are seen as critical. 


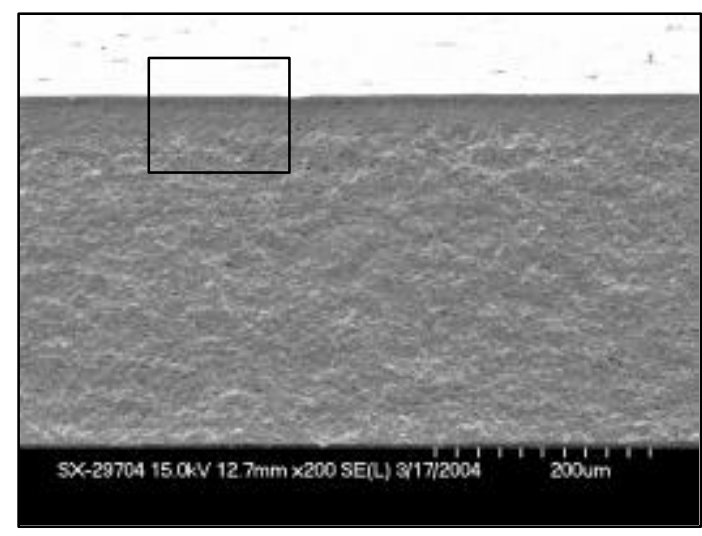

a)

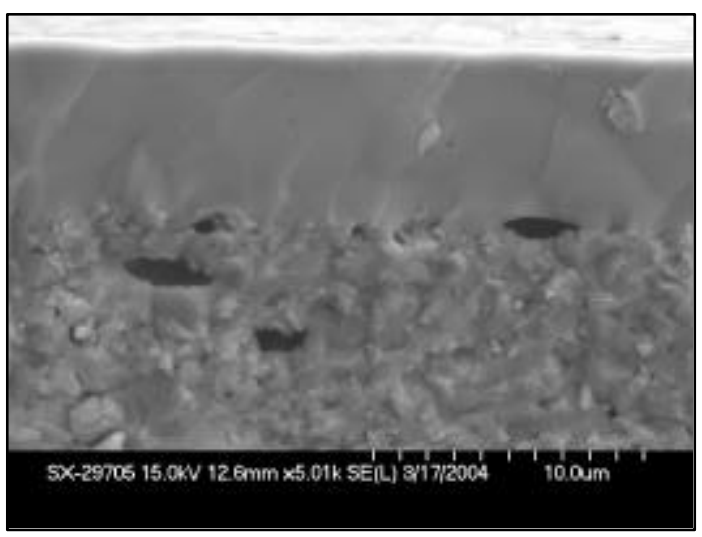

b)

Figure 34. (a) Fracture surface of a reduced bilayer with (b) magnified image of the interface showing zones of local high porosity.

Modification to the cell cons tituents and layer structures were looked at for improvements in cell mechanical properties. Yttria stabilized zirconia containing 3 mole percent yttria (3Y YSZ) is known to be stronger than that containing 8 mole percent yttria (8Y-YSZ) and is and ideal candidate for substitution into a multilayer SOFC cell. 3Y YSZ was substituted for the electrolyte as well as for the zirconia in the support anode layers of the cell. A second material, A 3 mol percent yttria stabilized zirconia with 20 weight percent alumina addition (designated as 3Y20A zirconia), was investigated for strength improvement, but only substituted in the support anode layer. To maintain a high ionic conductivity, however, a thin layer of baseline $8 \mathrm{Y}$ anode next to the electrolyte was retained in all of the bilayers. Bilayers were fabricated for mechanical strength measurements and electrochemical cell performance testing.

Using a specially designed testing rig, independent of the data reported above, biaxial flexure strength measurements (modulus of rupture or MOR) were performed on a series of 1 -in bilayer disks of the $8 Y$ electrolyte/8Y-baseline anodes (denoted as typical bilayers), 8Y electrolyte/3Y_baseline anodes, 3Y electrolyte/8Y baseline anodes, and 8Y electrolyte/3Y-20A baseline anode compositions as well as on two dense zirconia disks. The data is shown in Figure 35 below. For each of the bilayer compositions, 10 disks were broken and two standard deviations from the mean are shown in the error bars. Values for the dense zirconia specimens (172 and $176 \mathrm{MPa}$ ) fall within the range of biaxial flexure strength measurements for sintered zirconia given in the literature $i$. The results in Figure 35 show mean modulus of rupture (MOR) values of $111.4,98.4$ and $131.4 \mathrm{MPa}$ for the $8 \mathrm{Y}$ electrolyte/8Y baseline anode, $3 \mathrm{Y}$ electrolyte/8Y baseline anode, and the $8 \mathrm{Y}$ electrolyte/3Y+20A baseline anode compositions, respectively. These values are 
significantly lower than the strongest bilayer material, 8Y electrolyte/3Y-baseline anode structure, whose MOR is $325 \mathrm{MPa}$.

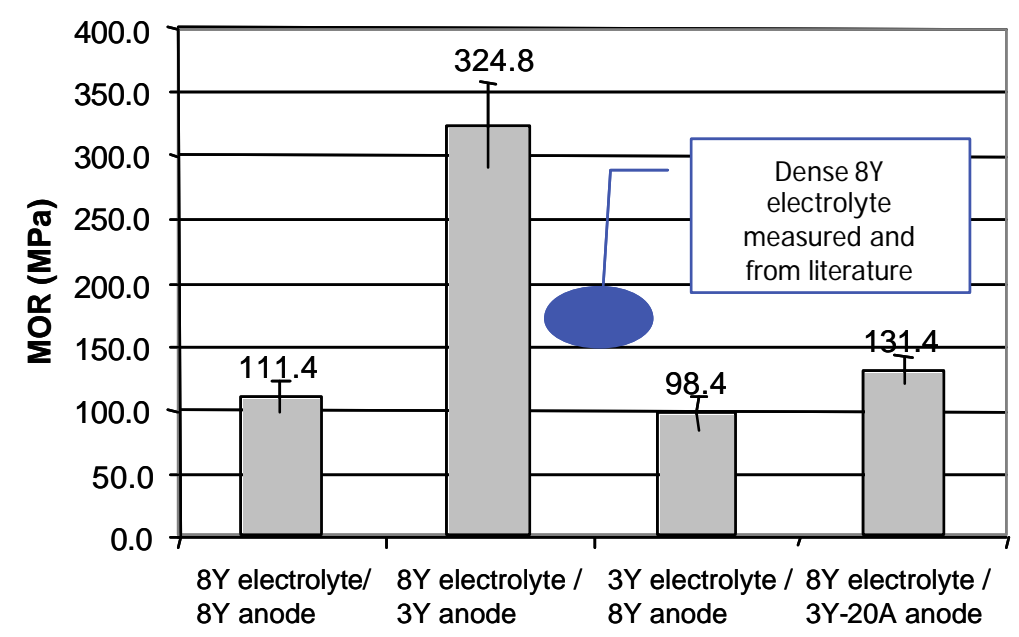

Figure 35. Biaxial flexure strength data for the various mechanical properties improvement stratagies

The electrochemical performance of the 3Y-anode composition was tested using a 1 -in cell with SPC-3 cathode. The polarization curve is shown in Figure 36 below. At $825^{\circ} \mathrm{C}$, the measured peak power of $941 \mathrm{~mW} / \mathrm{cm}^{2}$ is slightly lower than that achieved by the typical 8 Y-anode composition at $815^{\circ} \mathrm{C}$. However, it is possible that in some stack design cases that this performance may be an acceptable given the increase in mechanical strength.

One other interesting outcome of this study to improve strength was that while the bilayers fabricated with 3Y-20A baseline anodes did not show significantly improved mechanical strength they exhibit significant improvement in bilayer and cell flatness, greater then 5 times flatter then the baseline cells (8Y electrolyte/8Y baseline anode). It is thought that the 3Y-20A materials sintering properties, in conjunction with the shrinkage behavior of the pore formers and binders, more closely matches that of the electrolyte layer resulting in lower differential shrinkage rates and thus flatter sintered cells. Cell performance of this anode composition, as shown in Figure 37, is comparable to that of standard 8Y anode based cells (refer to Table 9). 


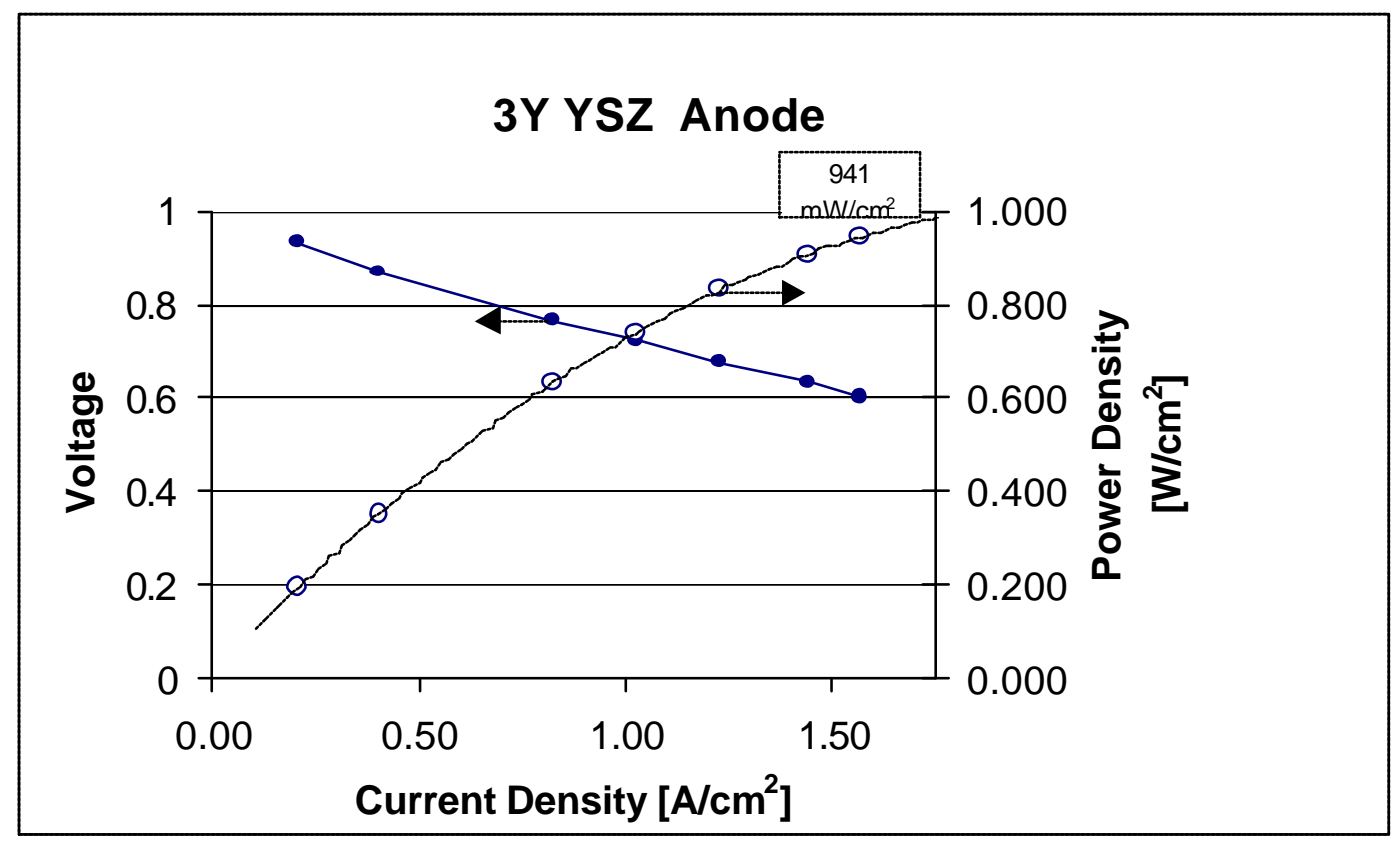

Figure 36. Performance of a cell with a 3Y-anode composition with pure hydrogen fuel and a fixed fuel flow rate of $67 \mathrm{cc} / \mathrm{min}$ and non-flowing air.

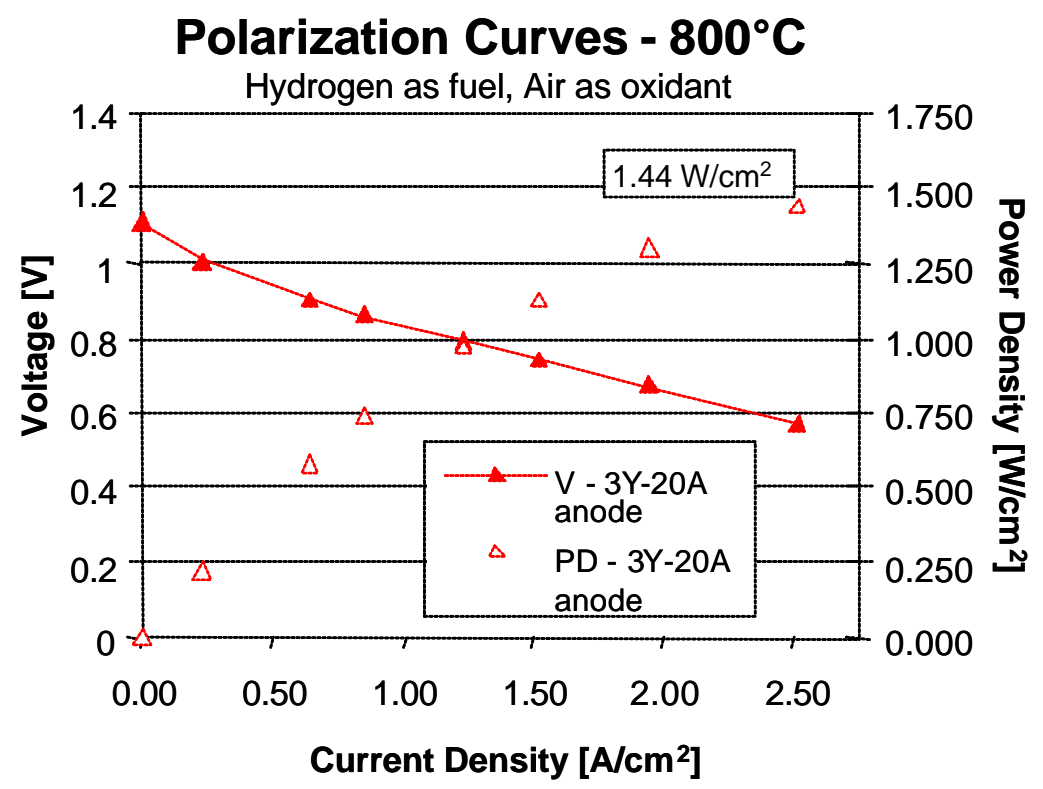

Figure 37. Polarization curve for 3Y-20A baseline anode cell. Cathode was SPC-4. 


\subsection{UNITIZED CELL FABRIC ATION AND DESIGN}

Work was done to 1) down-select a design, 2) design flow fields, 3) fabricate and test parts, and 4) test unitized cell assemblies. A unitized cell is schematically illustrated in Figure 38. In the early part of this program, cell design was narrowed down to focus on seal evaluation. Based on this approach, different cell geometry and flow field options were considered. Unitized cell assemblies were configured and constructed using baseline cells with metallic interconnects and tested to evaluate the designs.

\subsubsection{Unitized Cell Design Development}

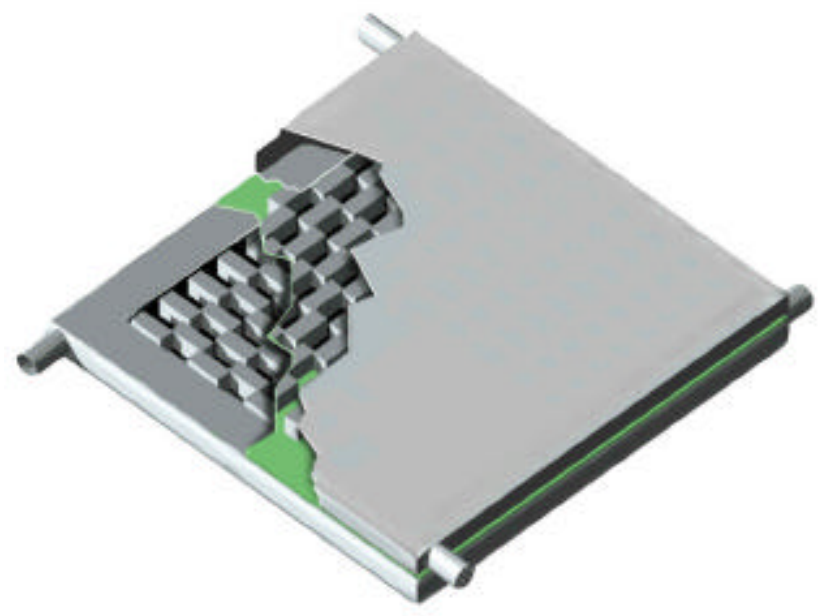

Figure 38. Schematic of unitized cell.

Figure 38 shows the baseline design approach going into this program. In this design the flow is introduced to the cell via one of the tubes on the tubes on the corners, which extend along the whole edge of the cell. The flow is then distributed to the cell through a series of orifices milled into the wall of the tube. The gases then flow across the cell and are collected at the opposite edge of the cell and exhausted out through the tube positioned diagonally from the inlet tube. In order to simplify the manifolding the exhaust can be allowed to exhaust directly out of the cell, instead of being collected by the tube, and the fuel and air are then combusted at the cell edge. This approach was adopted early in the program and was further refined. A generic fabrication sequence for fabricating unitized cells and cell stacking is shown in Figure 39. From the initial tests of this design the need to control the pressure drop at the exhaust edge of the cell was identified. This was evident from the low open circuit voltage during testing (an indication of back flow of air or fuel into the opposite electrode) and by the post-test observations the areas of the cell were not reduced during the testing (an indication that the fuel was not evenly distributed across the cell surface). Both of these issues can be improved 
with the addition of a permeable barrier at the exit edge of the cell. A number of cells were tested to improve the cell design to improve the flow control. Cell NO023A was tested to explore a cell configuration having an interconnect structure shown in Figure 40. The wavy lines on the active area correspond to the fin structure that was brazed onto the interconnect. The arrows represent the flow direction of the gas. The four sides of the interconnect sheet were folded towards the cell to form a frame around the perimeter. The gas outlet side fold was perforated for gas exhaust. A one-end sealed perforated tube was inserted through a slot in a corner along the gas inlet side of the interconnect. This tube was connected to the main gas line to supply and distribute the gas to the cell area through its perforation. For the cell assembly, the anode and cathode gases were co-flow in direction. Thus, the cathode inlet and the anode inlet (or outlet sides) were on the same side. There were 16 perforations of 0.037 -in diameter on each of the anode inlet and outlet and 24 perforations of 0.024 -in diameter on each of the cathode inlet and outlet. The cell assembly consisted of a 4.375 -in by 4.375 -in trilayer ceramic cell sandwiched between two interconnect structures. Strips of zirconia felt served as gaskets and were placed between all folds of both anode and cathode interconnects and the ceramic cell. A holding force of $6.2 \mathrm{~kg}$ was applied on the top plate.

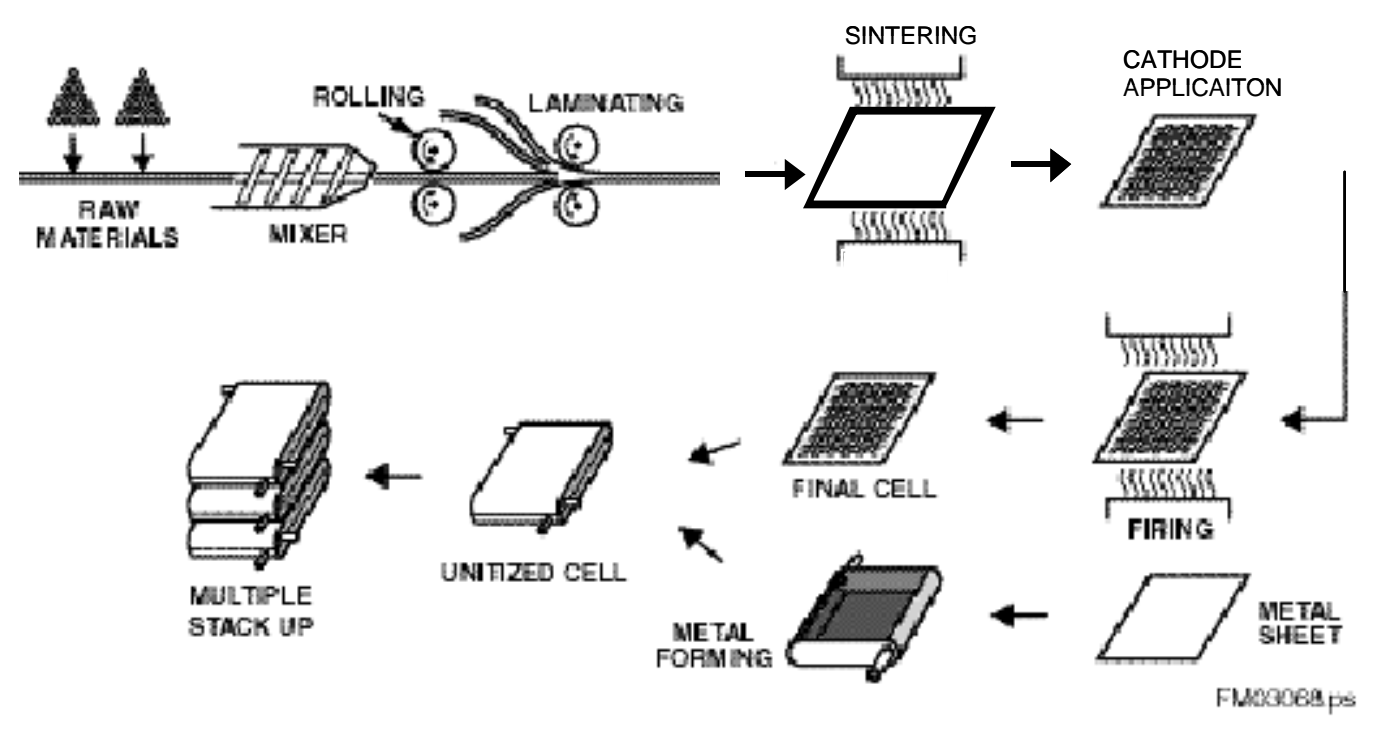

Figure 39. Typical fabrication sequence for unitized cell fabrication and stacking. 


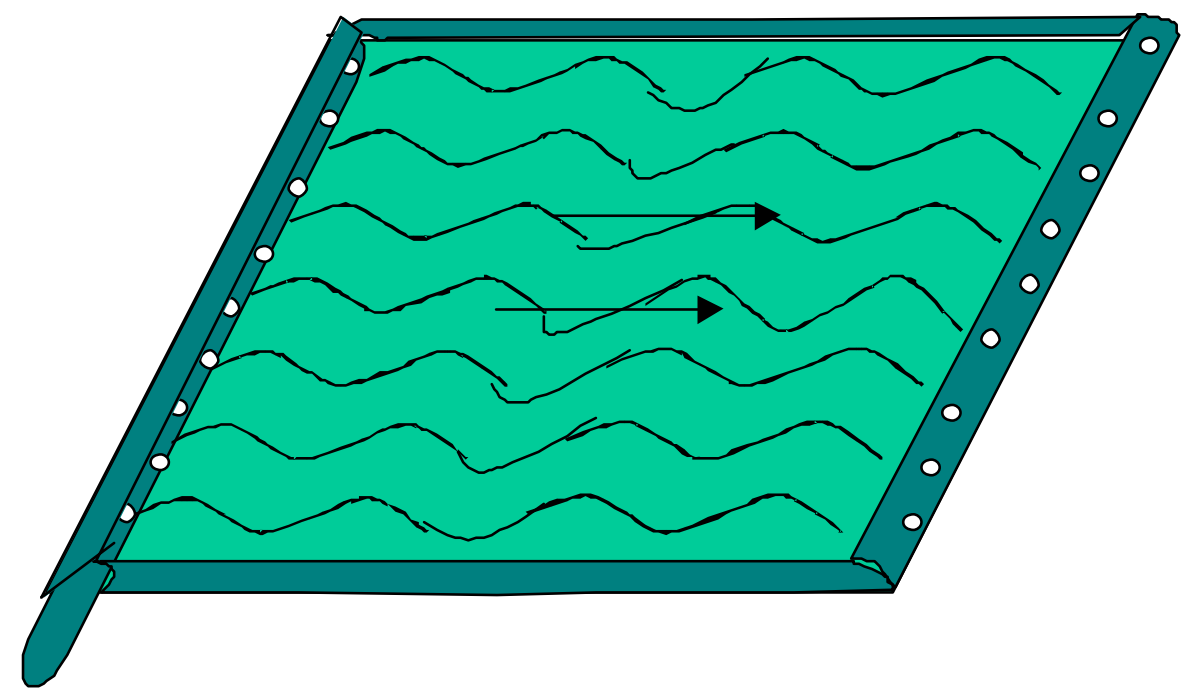

Figure 40. Diagram of the interconnect structure for cell NO023.

Cell NO023 achieved an OCV of $1.009 \mathrm{~V}$ at $800^{\circ} \mathrm{C}$ with 1 slpm $64 \% \mathrm{H}_{2} / 36 \%$ $\mathrm{N}_{2}$ fuel and $3 \mathrm{slpm}$ air. This fuel simulated the fuel value of a steam-reformed natural gas. The peak power under this gas was only $220 \mathrm{~mW} / \mathrm{cm}^{2}$. Cell OCV and performance degraded with time and the cell test was ended after just $20 \mathrm{hrs}$ at temperature. Posttest cell examination showed an unreduced anode area corresponding to the section with the fuel supplied by the far end of the fuel supply tube. A closer examination of the fuel supply tube indicated that the hand-drilled perforations were not perfectly aligned. Towards the far end, the perforations were facing more towards the interconnect plate and away from the fins. Gas flow to the corresponding section, therefore was restricted.

Cell test $\mathrm{NO} 013 \mathrm{C}$ was a test to address some to the issues identified in other tests, such as NO023. The cell was built with a slightly modified design referred to as the "Split Flow" design. This design, shown in Figure 41, introduces the gas at the middle of the cell through a slotted gas supply tube. The gas stream splits and flows towards the two opposite sides of the cell. The exhaust fuel and air react and combust outside the cell along the two exit sides. The flow field for this cell is relatively easy to configure for uniform gas flow distribution. However, an edge seal is needed along the two sides that are parallel to the gas flow. 


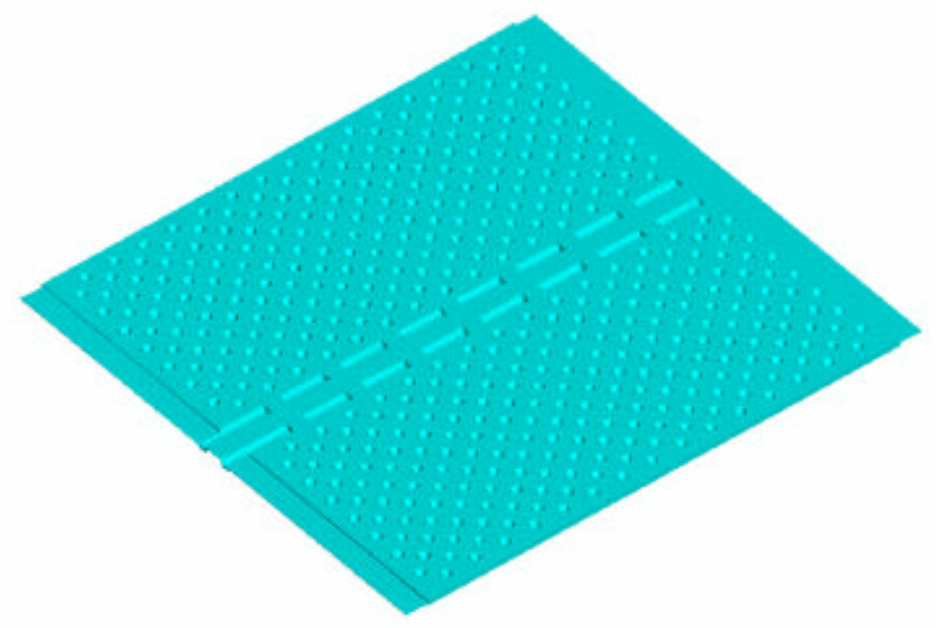

Figure 41. Split Flow design.

In this cell the permeable barrier consisted of a perforated metal sheet. The perforation on the outlet edges consisted of 16 holes of 0.062 -in diameter for both anode and cathode interconnects. The fuel gas supply tube had two rows of perforation, each having 23 holes of 0.030 -in diameter. The air gas supply tube had also two rows of perforation, each having 21 holes of 0.062 -in diameter. The edge seals for this test were a zirconia felt placed under a compressive load. The zirconia felt creates a "leaky" seal that relies on creating a higher pressure drop through the felt than through the exhaust barrier to insure that the gasses stay within the cell and do not escape before the cell exit.

Cell NO013C was heated to $800^{\circ} \mathrm{C}$ and conditioned accordingly. The main events that took place for this cell are listed below.

- Initially, the cell was operated with $1.5 \mathrm{slpm}$ fuel of the composition $64 \mathrm{H}_{2} / 36 \mathrm{~N}_{2}$ and $3 \mathrm{slpm}$ air. The OCV was $1.010 \mathrm{~V}$ and a polarization run yielded a peak power of $262 \mathrm{~mW} / \mathrm{cm}^{2}$ at $450 \mathrm{~mA} / \mathrm{cm}^{2}$. The cell was left under this fuel at a load of $300 \mathrm{~mA} / \mathrm{cm}^{2}$ overnight. Voltage improved from $0.756 \mathrm{~V}$ to $0.762 \mathrm{~V}$ in $16 \mathrm{hrs}$.

a Polarization run on the second day $\left(19^{\text {th }} \mathrm{hr}\right.$ of operation) showed an improvement in peak power to $285 \mathrm{~mW} / \mathrm{cm}^{2}$ at $500 \mathrm{~mA} / \mathrm{cm} 2$. The fuel flow rate was then reduced to $1.25 \mathrm{~s} / \mathrm{pm}$. Under a constant load of $300 \mathrm{~mA} / \mathrm{cm} 2$, the voltage dropped from $0.757 \mathrm{~V}$ to $0.752 \mathrm{~V}$ over $13 \mathrm{hrs}$.

a On the third day, a polarization run $\left(43^{\text {rd }} \mathrm{hr}\right)$ was conducted with $50 \%$ constant fuel utilization and $25 \%$ constant $\mathrm{O}_{2}$ utilization. Peak power of $273 \mathrm{~mW} / \mathrm{cm}^{2}$ was DE-AC26-00NT40705 
achieved at $500 \mathrm{~mA} / \mathrm{cm}^{2}$. The cell was then left at a fuel flow of $1 \mathrm{slpm}$. The voltage remained steady at $0.735 \mathrm{~V}$ over a $14 \mathrm{hr}$ hold.

a On the fourth day, the fuel flow was reduced to $0.65 \mathrm{slpm}$. This flow corresponds to a fuel utilization of $50 \%$ at $300 \mathrm{~mA} / \mathrm{cm}^{2}$. Under this operating condition, the voltage dropped from $0.677 \mathrm{~V}$ to $0.656 \mathrm{~V}$ over a period of $10 \mathrm{hrs}$ and then remained stable at $0.656 \mathrm{~V}$ over the next $10 \mathrm{hrs}$.

a On the $5^{\text {th }}$ day of operation, further attempt was made to reduce the fuel flow rate for operation at greater that $50 \%$ utilization. For example, a flow rate of $0.44 \mathrm{slpm}$ at a current of $25 \mathrm{~A}$ yield a fuel utilization of $60 \%$. Under this condition, however, voltage was initially about $0.610 \mathrm{~V}$ and but decreased rapidly. This testing condition caused irreversible cell damage that resulted in OCV degradation even at high fuel flows. The test was therefore ended.

Post test analysis showed normal looking components and good cell-to-fins contact on both electrodes. However, anode reoxidation at the four corners of the cell are evident and there were indications of hot spots on the interconnect edges that are likely due to gas leakage. Nevertheless, this test was very encouraging for it demonstrated continuous operation at $50 \%$ fuel utilization with the interconnect structures similar to that shown in Figure 41, but with only a perforated metal barrier at the exhaust side. Also porous materials, such as the zirconia felt, may be able to form "leaky" seals to contain the gases within fuel cells. These "leaky" seals were also attractive since the gas barrier is not bonded to the ceramic cell, it will not impose thermal stresses that can fracture the cell.

Concurrent with the testing of these cell modules efforts were under way to design an improved flow field. These early cell module were built using a flow field that was created with heat exchanger fin similar to that shown in Figure 38. This fin materials is good for easy of fabrication, but due to its fabrication method the pattern contact patches and flow barriers are regular and not easily modified to create custom flow fields. Computational fluid dynamics (CFD) modeling of the gas flow within the cell module was used to develop an engineered flow field for the cells. In order to create a modifiable flow field the fin materials was replaces with ribs and posts. The evenly spaced orifices from the initial design were also maintained in the initial iterations. The goal of these improved flow fields were to promote even flow distribution with in the cell. CFD analysis was done on the baseline configuration and it was observed that the flow path lines were not very evenly distributed at the gas flow required for high fuel utilization (for cell NO013C discussed above, $0.5 \mathrm{slpm}$ corresponds to approximately $53 \%$ fuel utilization). Also, as seen in Figure 42, as the flow rate is decreased the amount of flow maldistribution increases. So in order for higher fuel utilizations to be achieved further modification were required to the flow field design. 


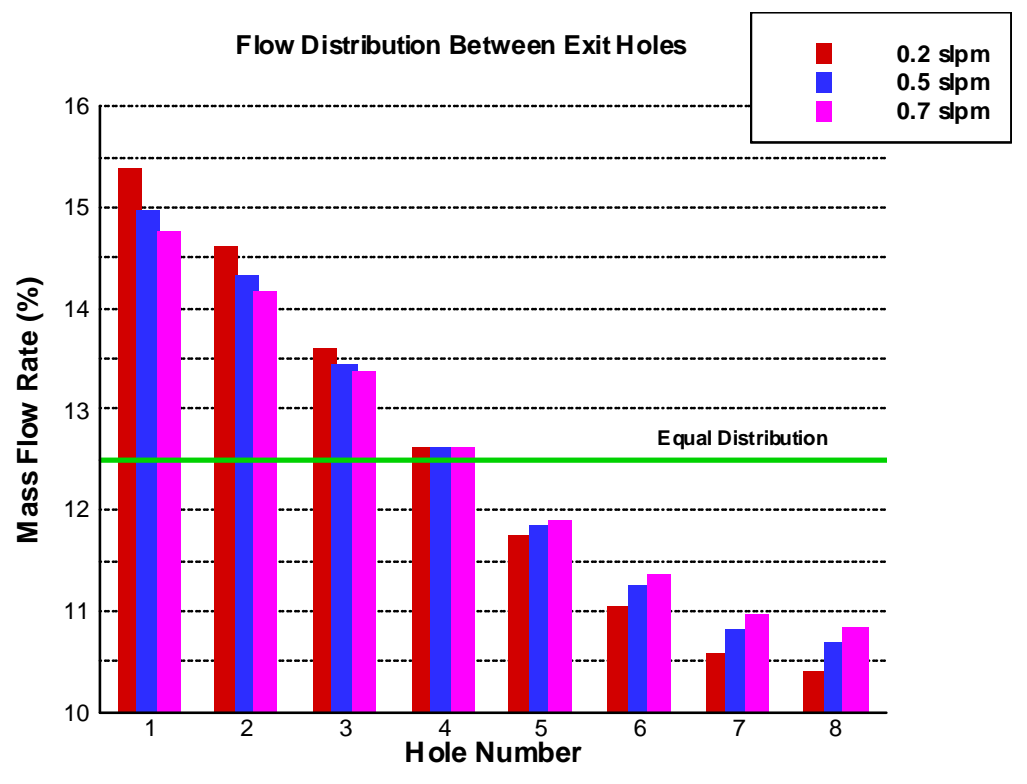

Figure 42. Effect of total gas flow rate on the gas flow rate at individual exit holes ( 1 is nearest the inlet).

A number of design iterations were done to improve the flow distribution. Variables considered were post/rib spacing and number, as well as other features modifications with in the interconnect. A combination of all of the aforementioned variables was combined to create a flow field (configuration 10) with the good flow distribution within the cell active area. CFD analysis was done on this configuration as well and the flow distribution was observed to be significantly better. This improved flow distribution is presented in Figure 43, which plots the percent of total mass flow versus axial length (essentially the same presentation as Figure 42, but with respect to length and not individual holes). The plot in Figure 43 also contains the curve for the baseline case shown in Figure 42. 


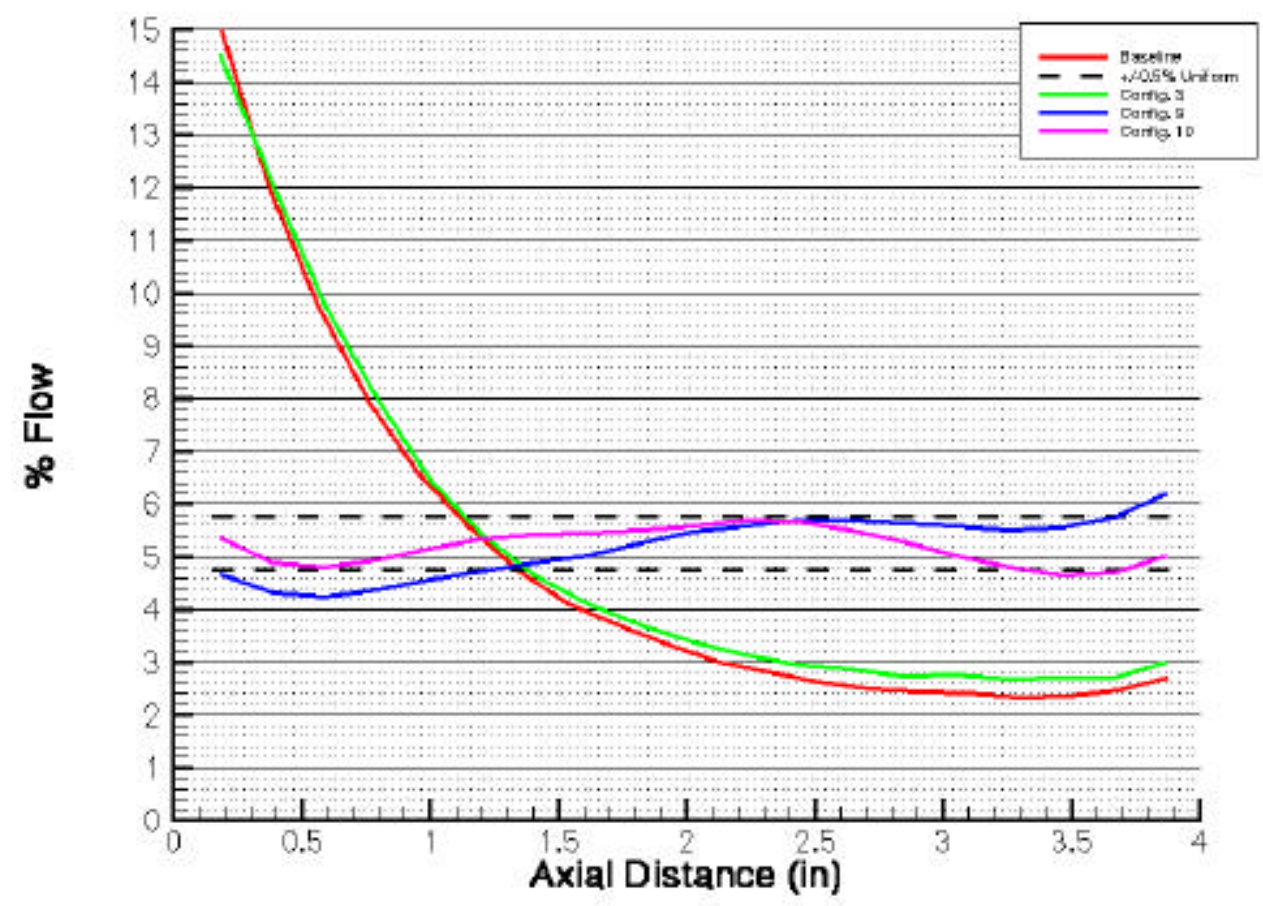

Figure 43. Percentage of total mass flow versus axial distance for various design iterations.

\subsubsection{Improved Flow Distribution Validation Testing}

The design and modeling indicated that very uniform flow distribution in the split flow design are possible and that uniformity should lead to higher fuel utilizations if the gas channels and gas supply mechanisms are properly sized. To validate the effect of the improved orifice sizing, configuration 10 was simulated using brazed interconnects and perforated distribution tubes. Two cells, NO-209 and NO-215, were tested with these interconnects. The fin heights were 0.050 -in in the anode and 0.100 -in in the cathode. The fin density was 6 fins per inch. These cells are described below.

\section{$\underline{\text { Cell NO209 }}$}

Polarization curves were obtained at $800^{\circ} \mathrm{C}$ with $1,0.75$ and $0.5 \mathrm{slpm}$ of $64 \mathrm{H}_{2} / 36 \mathrm{~N}_{2}$ (this composition mimics that of a steam reformed natural gas). Results are presented in Figure 44. The 1.0 and $0.75 \mathrm{slpm}$ curves are close to each other but with the $0.5 \mathrm{slpm}$ flow rate, voltage starts to decline significantly above 200 $\mathrm{mA} / \mathrm{cm}^{2}$ current density. From the polarization data, power density at $0.7 \mathrm{~V}$ was plotted against fuel utilization in Figure 45. As shown, power density drops significantly when fuel utilization was increased from 40 to $50 \%$. Posttest analysis 
shows oxidation cracks towards the far exhaust corners of the cell, indicating poor flow in those areas, which might have limited the extent of fuel utilization.

Cell NO209 Performance with $64 \mathrm{H}_{2} / 36 \mathrm{~N}_{2}$ at $800 \mathrm{C}$

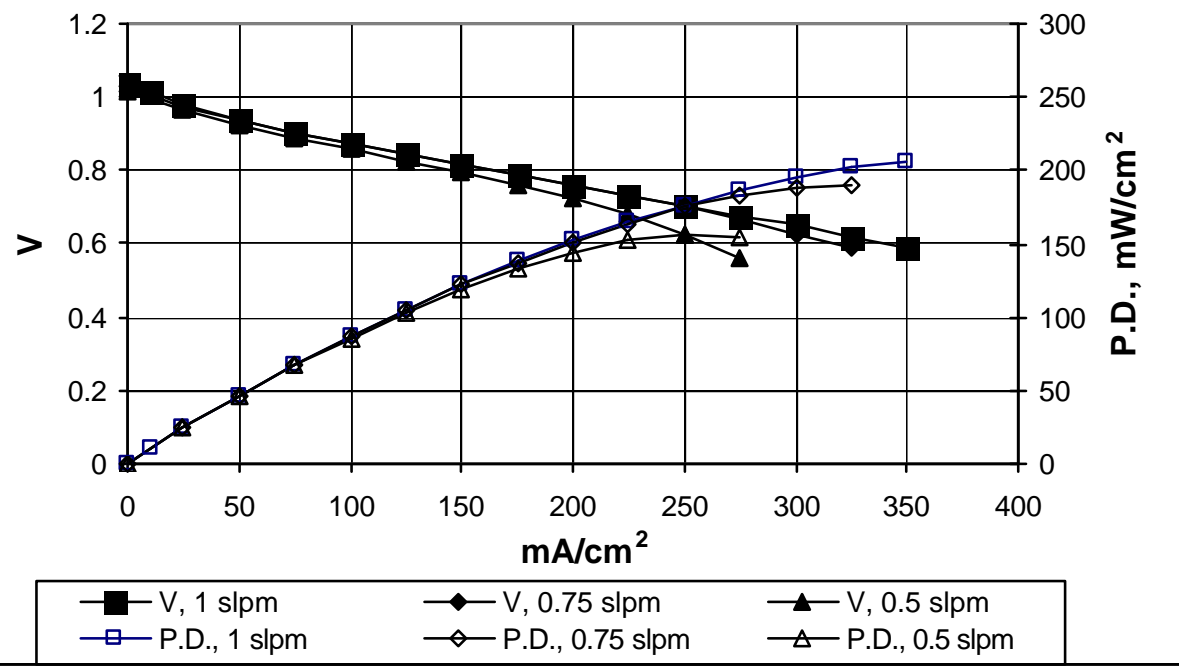

Figure 44. Polarization curves of cell NO-209 at $800^{\circ} \mathrm{C}$.

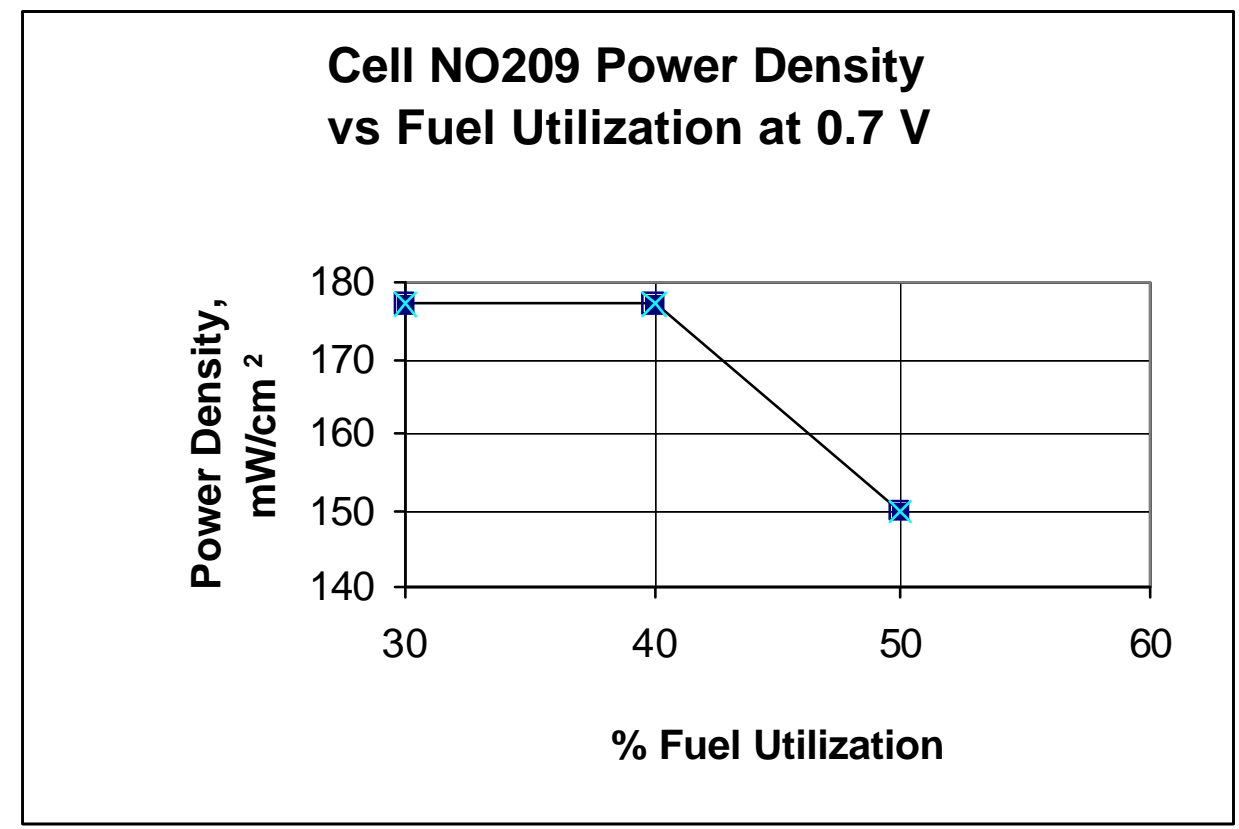

Figure 45 . Power density vs fuel utilization at $0.7 \mathrm{~V}$ and $800^{\circ} \mathrm{C}$. 


\section{Cell NO215}

Cell NO215 was a repeat test of Cell NO209. Performance data were obtained at $800^{\circ} \mathrm{C}$ using different flow rates of the gas composition $64 \mathrm{H}_{2} / 36 \mathrm{~N}_{2}$. Results are presented in Figure 46. The performance data for this cell was the best obtained for a unitized cell at that point in the program. As with Cell NO209, the 1.0 and $0.75 \mathrm{slpm}$ curves are close to each other but with the $0.5 \mathrm{slpm}$ flow rate, voltage started to decline significantly above $200 \mathrm{~mA} / \mathrm{cm}^{2}$ current density. The cell was later tested at different temperatures using a flow rate of $0.75 \mathrm{slpm} 64 \mathrm{H}_{2} / 36 \mathrm{~N}_{2}$. The test results for both cells, NO209 and NO215 are tabulated in Table 13. At 0.7 $\mathrm{V}$, the power densities were 175,240 , and $280 \mathrm{~mW} / \mathrm{cm}^{2}$ at 700,750 and $80^{\circ} \mathrm{C}$. The corresponding fuel utilizations were 39,53 and $63 \%$. Power density at $0.7 \mathrm{~V}$ at different temperatures was plotted against fuel utilization in Figure 47 . The maximum fuel utilizations were 50,65 , and $70 \%$ at 700,750 , and $800^{\circ} \mathrm{C}$, respectively, with corresponding power densities of 150,195 , and $210 \mathrm{~mW} / \mathrm{cm}^{2}$. Posttest analysis showed that the cell was intact and that there was no indication of gas leak. $k$.

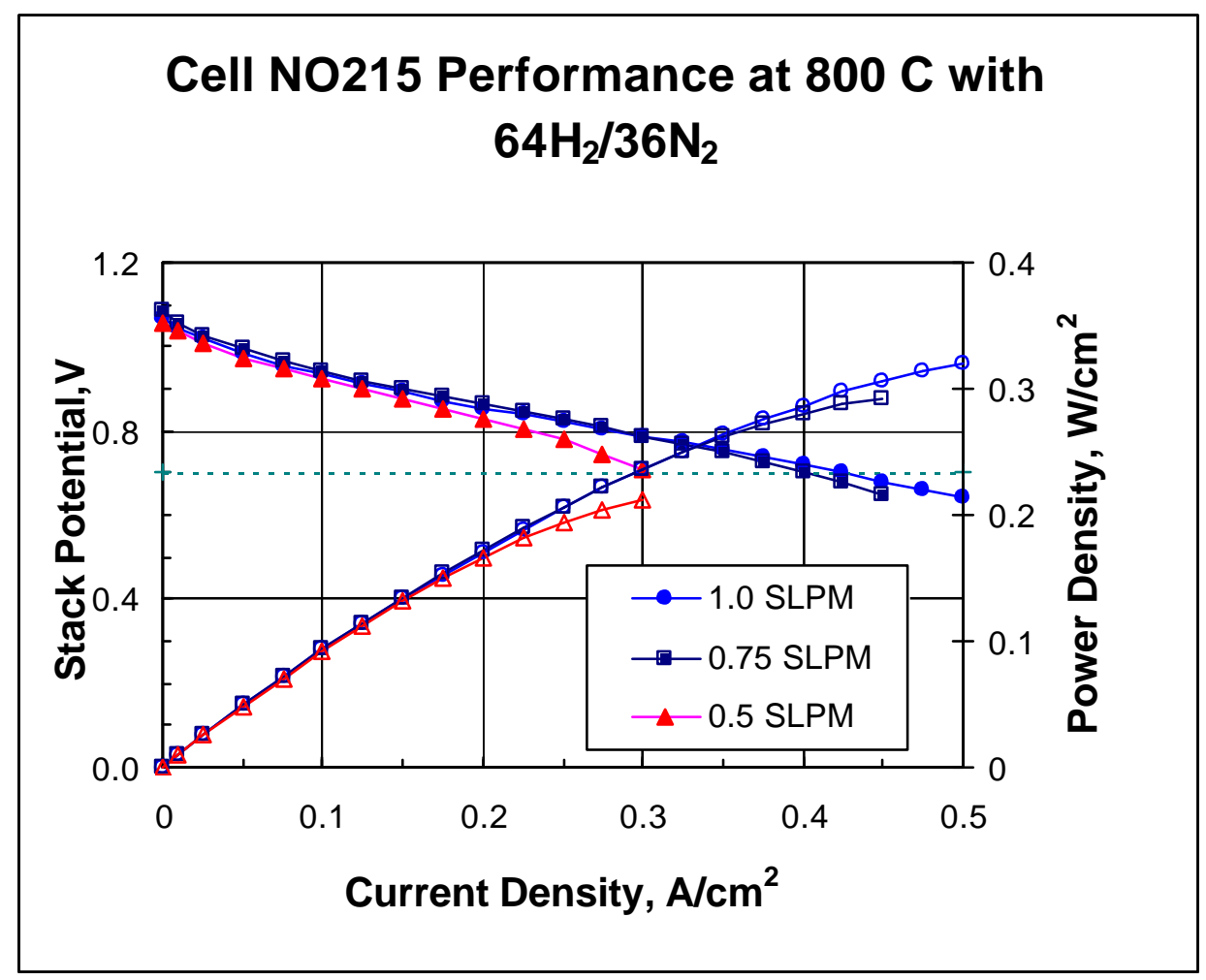

Figure 46. Cell NO-215 polarization curves at $800^{\circ} \mathrm{C}$ under different fuel flow rates. 


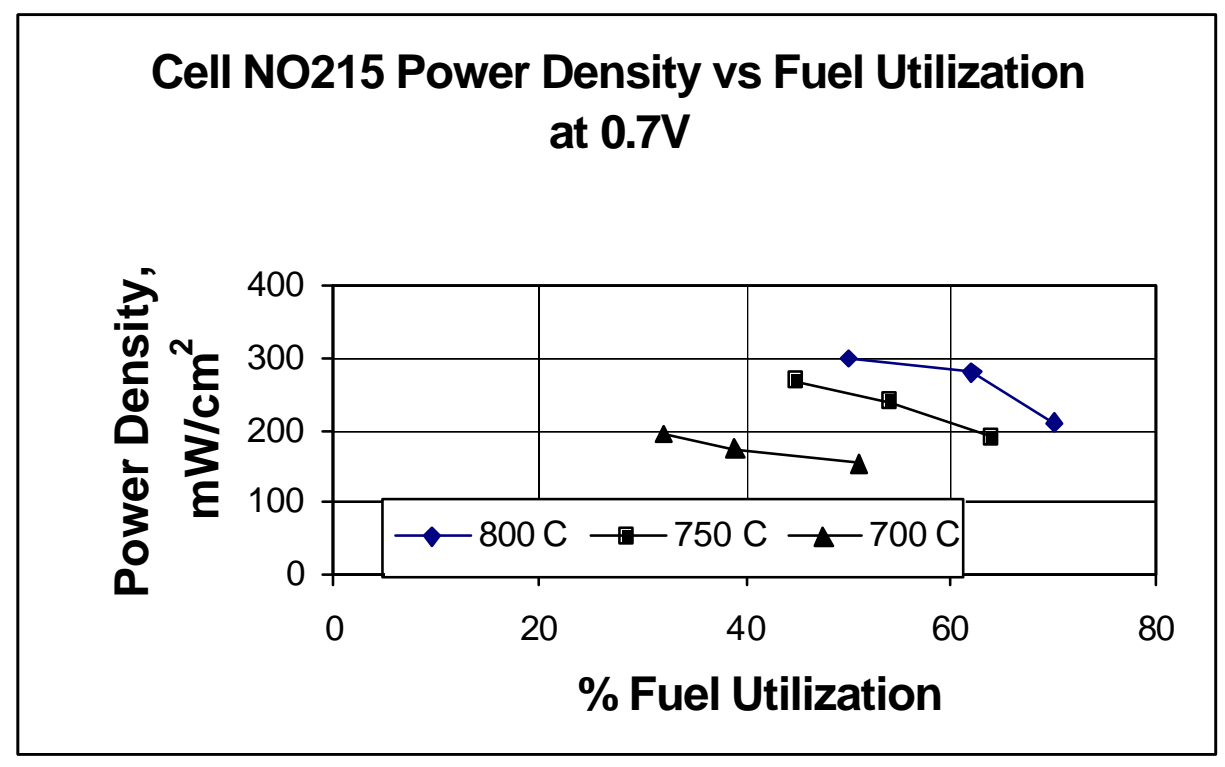

Figure 47. Cell NO-215 power density vs. fuel utilization at different temperatures.

Table 13. Performance Summary for Unitized Cells

\begin{tabular}{|c|c|c|c|c|}
\hline Cell ID & $\begin{array}{c}\text { Temperature, } \\
{ }^{\circ} \mathrm{C}\end{array}$ & $\begin{array}{c}\text { Flow rate, } \\
\text { slpm }\end{array}$ & $\begin{array}{c}\text { Power Density, } \\
\mathrm{mW} / \mathrm{cm}^{2} \text { at } 0.7 \\
\text { V }\end{array}$ & $\begin{array}{c}\text { \% Fuel } \\
\text { Utilization }\end{array}$ \\
\hline NO-209 & 800 & 0.75 & 177 & 40 \\
\hline NO-209 & 800 & $\begin{array}{c}0.6 \\
\text { (estimated) }\end{array}$ & 150 & 50 \\
\hline NO-215 & 800 & 1.0 & 295 & 49 \\
\hline NO-215 & 800 & 0.75 & 280 & 63 \\
\hline NO-215 & 800 & 0.5 & 210 & 71 \\
\hline NO-215 & 700 & 0.75 & 175 & 39 \\
\hline NO-215 & 750 & 0.75 & 240 & 53 \\
\hline
\end{tabular}

Given the flow distribution characteristics shown by CFD analysis and the significant performance improvement demonstrated by the brazed interconnect, configuration 10 was selected as the flow field design. 


\subsection{MANUFACTURING PROCESS DEVELOPMENT}

Establishing a preliminary definition of the fabrication process for the cell design and identification of critical process parameters were the primary focus in this area. The effects of selected parameters on fabricability and performance were studied. Non-destructive evaluation (NDE) approaches were evaluated and some preliminary screening test done. The cell manufacturing process is shown schematically in Figure 1. Metal forming techniques for interconnect fabrication were investigated and forming trials executed. Unitized cell module assembly options were summarized and example modules were fabricated and tested. These results of these studies were used to develop the final definition of the tapecalendering manufacturing process for unitized cells.

\subsubsection{Cell Fabrication Process}

\subsubsection{Baseline Cell Fabrication Process Verification \& Validation}

Manufacturing solid oxide fuel cells by tape calendering is a process with many steps and numerous opportunities for variation to occur. In an effort to identify the variation that occurs in the baseline cell fabrication process a manufacturing study was performed. As part of a company funded program prior to this program the baseline cell fabrication process was documented in a procedure and process maps were created to delineate how the fuel cells were made and to have a reference point from which to improve. This current project, however, took this one step further as it looked into how closely the fabrication followed the baseline procedure as well as tracked the parts to verify whether or not they were within the baseline specifications. The benefits to this approach is an improved understanding of the current manufacturing process capability and of where the source of variation is so that future work can focus on reducing process variability and defects. In addition as a part of this study, the foundations of a database was determined in which manufacturing parameters will be stored so that when the fuel cells are eventually tested the manufacturing history can be linked with performance data.

\section{Manufacturing Parameters}

At the beginning of this study the key requirements were determined for manufacturing which are reproducibility, cost, and high volume. In order to determine how the process was doing with respect to these goals, it was decided that additional manufacturing data needed to be recorded than was performed previously. To guide the determination of those new manufacturing parameters, the team went through a process of brainstorming and ranking traceable manufacturing factors, ultimately yielding a prioritized list based on expert judgment. Figure 48 shows a Pareto chart of these parameters where rework, labor time and defects were determined as the highest impact areas to address reproducibility, cost and 
high volume manufacturing. With respect to yield, the amount of scrap material, recycle material, and breakage due to firing or handling are also important. Other parameters specific to tape calendering such as the number of passes through the rolls, temperature of the rolls, and which pieces of equipment were used were also identified as candidate items to track. With respect to firing the fuel cells, furnace identification, furnace location, and flatness after firing were also determined as important information to record. Environmental factors such as temperature and humidity were also noted to understand their influence. All of these factors were considered when determining the approach on how to pinpoint the variation.

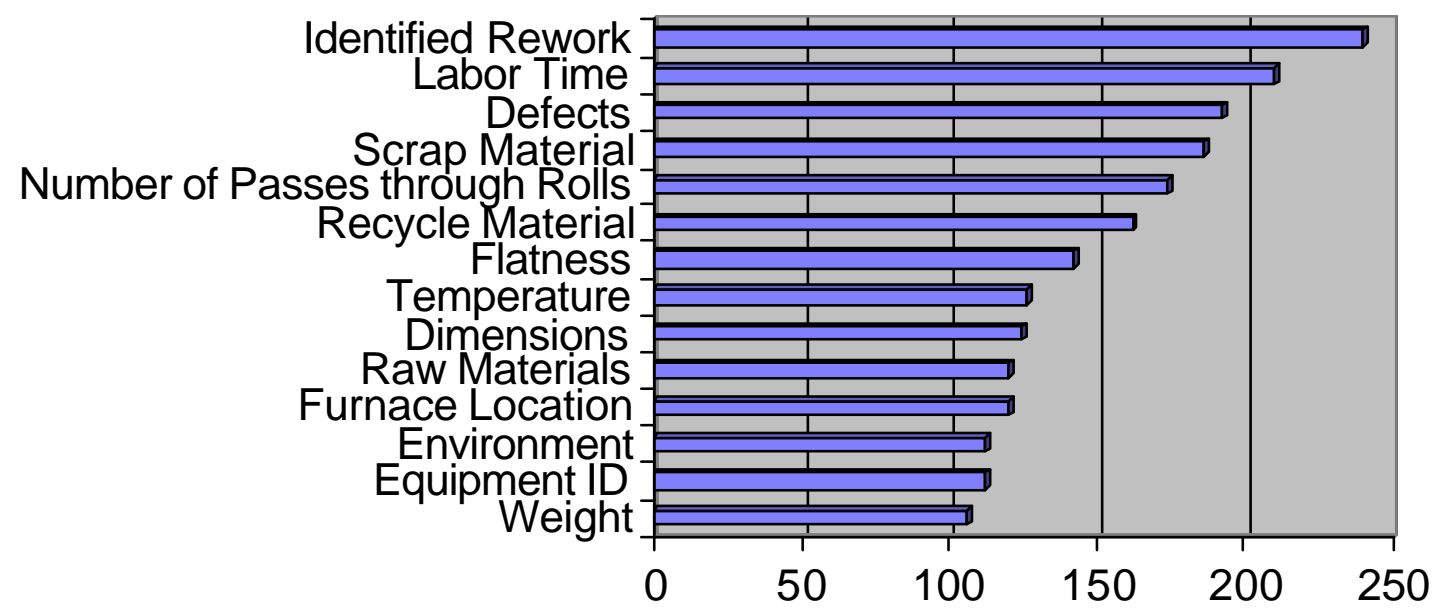

Figure 48. Pareto chart of key manufacturing parameters.

\section{Manufacturing Variation Source Identification}

A cause and effect analysis was performed to further deduce where the variation is coming from in the cell manufacturing baseline process. Using a fishbone diagram, baseline process variation was brainstormed under the main categories of measurement error, manufacturing variation, materials and manufacturing process and is presented in Figure 49. For example one source of variation could be due to different operators. If the operators have not had the proper training or if they are interpreting a procedure differently, they may make a wrong measurement and not even be aware of it. So by tracking which operator made the parts it would be possible to determine if there was a recurring problem. Based on the results of this fishbone in combination with the ranked factors in the Pareto chart, the entire cell fabrication process was examined and data collection opportunities were identified and documented. 


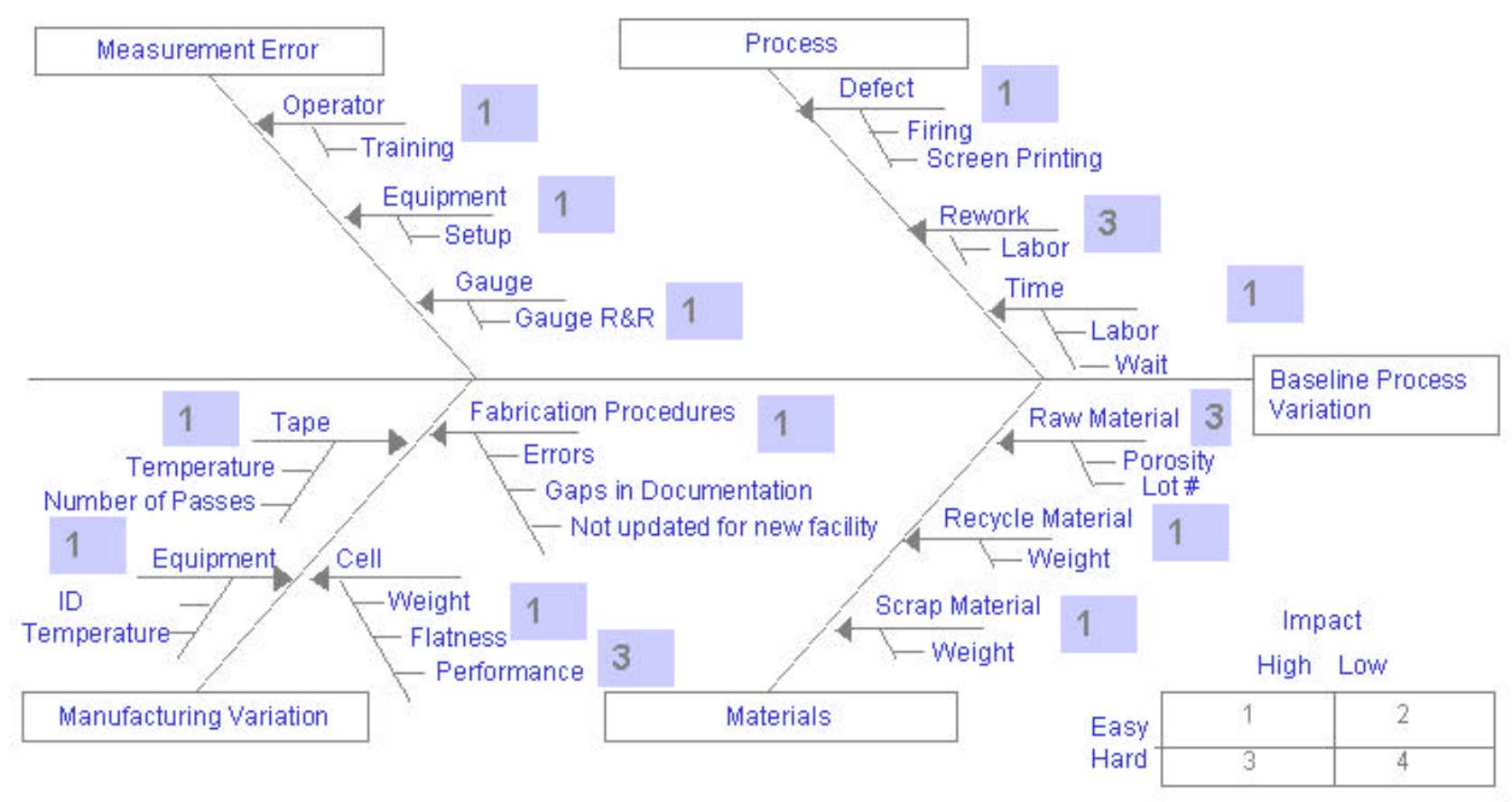

Figure 49. Fishbone of the baseline process variation in SOFC manufacturing. Impact was assigned based on expert judgment, and was used to guide prioritization of areas to be investigated.

\section{Manufacturing Data Collection}

A data collection plan was then created for the list of manufacturing parameters that were appropriate for each step. Previously, the manufacturing data that was collected was limited to paper copies. In the past data was collected for the following steps as follows: anode 1 batch sheet (weight recorded), anode 2 batch sheet (weight recorded), electrolyte batch sheet (weight recorded), cathode paste batch sheet (weight and lot numbers were recorded), and firing log sheets (furnace number, furnace position, and firing schedule was recorded). As was evident from the list of manufacturing parameters listed in Figure 49 above, additional data needed to be track. In addition, this was an opportunity to examine digitization of this process by determining where, how and what type of data to record.

Data collection was grouped into the following categories: calcining, anode 1 , anode 2, electrolyte, bilayer, bilayer firing, cathode screen printing, and cathode firing. Within these categories a number of manufacturing process steps may occur but they are tracked under the broader category for simplicity. For example under the category bilayer, three rolling steps occur. Part of a data collection sheet is presented in Figure 50 for reference.

DE-AC26-00NT40705 


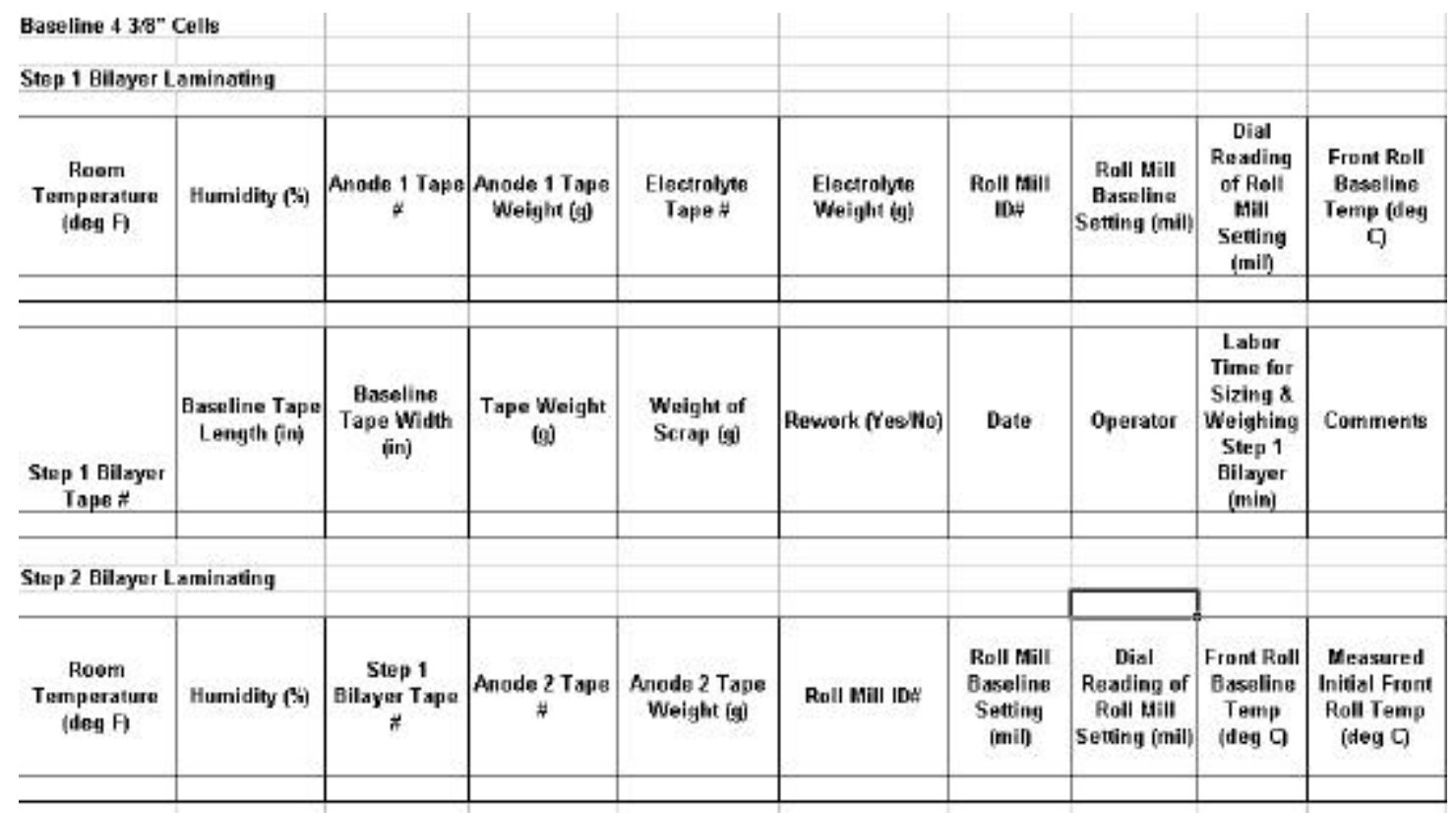

Figure 50. A small section of the data sheet collected on bilayer tape manufacturing.

Within the data sheets numerous pieces of data were collected. In order to give an insight into how much and what types of data was collected for each of the categories, a summary is presented in Table 14. Common to all sheets were places to record things such as rework, date, operator, labor time, temperature and humidity. 
Table 14. Description of Data Categories and the Amount and Types of Data Recorded.

\begin{tabular}{|c|c|c|}
\hline Manufacturing Step & $\begin{array}{l}\text { Number of required } \\
\text { factors }\end{array}$ & Key types of data \\
\hline Calcining & 27 & $\begin{array}{l}\text { Lot number, weight, firing } \\
\text { schedule, furnace id }\end{array}$ \\
\hline Anode 1 & 196 & $\begin{array}{l}\text { Lot number, weight, wet mill } \\
\text { time, mixing temperature, } \\
\text { number of passes through the } \\
\text { rolls, tape temperature, roll } \\
\text { temperature, tape thickness, } \\
\text { trimmings weight }\end{array}$ \\
\hline Anode 2 & 235 & $\begin{array}{l}\text { Lot number, weight, wet mill } \\
\text { time, mixing temperature, } \\
\text { number of passes through the } \\
\text { rolls, tape temperature, roll } \\
\text { temperature, tape thickness, } \\
\text { trimmings weight }\end{array}$ \\
\hline Electrolyte & 166 & $\begin{array}{l}\text { Lot number, weight, mixing } \\
\text { temperature, number of } \\
\text { passes through the rolls, tape } \\
\text { temperature, roll temperature, } \\
\text { tape thickness, trimmings } \\
\text { weight }\end{array}$ \\
\hline Bilayer Laminating & 128 & $\begin{array}{l}\text { Weight, number of passes } \\
\text { through the rolls, tape } \\
\text { temperature, roll temperature, } \\
\text { tape thickness, trimmings } \\
\text { weight }\end{array}$ \\
\hline Bilayer Firing & 30 & $\begin{array}{l}\text { Furnace ID, furnace position, } \\
\text { firing profile, cell flatness }\end{array}$ \\
\hline Cathode Screen Printing & 27 & $\begin{array}{l}\text { Weight, number of layers, } \\
\text { paste waste }\end{array}$ \\
\hline Cathode Firing & 21 & $\begin{array}{l}\text { Furnace ID, furnace position, } \\
\text { firing profile, cell flatness }\end{array}$ \\
\hline
\end{tabular}

It was determined that data would be collected on the fabrication of 126 cells in order to understand the manufacturing process capability and to identify variation. This number enabled 14 bilayer batches to be tracked.

\section{Cell Yield Analysis}

Review of the data on the 126 cells, enabled some calculations to be performed with respect to process yield. The process steps that were considered 
were bilayer tape, bilayer firing, cathode screen printing and cathode firing. It was determined that in the first pass through the entire calendering portion that only $29 \%$ of the material does not have to go through a recycling step. With the addition of more labor to recycle the material the bilayer tape yield has the potential to increase to $90 \%$. Similarly, the total process yield increases by approximately a factor of 3 when the trimmings material is recycled. As the anode 1, anode 2, electrolyte, and bilayer tapes are being made there are trimmings associated with cutting the pieces to the correct sizes. For example, when a round cell is cut out of a square piece of bilayer tape $22 \%$ of the tape becomes trimmings and would be available for recycle. Other opportunities for recycled material come from defects that occur in the rolling process, such as a tape that folds back on itself or where there are visible tears in the electrolyte. These results are summarized in Table 15 below.

Table 15. Manufacturing Yields for Tape Calendared SOFC's.

\begin{tabular}{|l|c|c|}
\hline \multicolumn{1}{|c|}{ Process Step } & Average Yield First Pass & $\begin{array}{c}\text { Average Yield with } \\
\text { Recycled Material }\end{array}$ \\
\hline Bilayer Tape & $29 \%$ & $90 \%$ \\
\hline Bilayer Firing & $66 \%$ & $66 \%$ \\
\hline Screen Printing & $90 \%$ & $90 \%$ \\
\hline Cathode Firing & $98 \%$ & $98 \%$ \\
\hline Total & $17 \%$ & $52 \%$ \\
\hline
\end{tabular}

One area that can be significantly improved with respect to yield is bilayer firing where the average yield between furnaces was $66 \%$. In an effort to understand furnace-to-furnace variation on firing yields, bilayers were fired in 7 different furnaces. Bilayer layers were fired with mixed results. The range of firing yields was from $0 \%$ to $100 \%$ where as few as 3 cells were fired per furnace and up to 20 cells per furnace depending on the furnace capacity. Table 16 presents firing results of the 7 different furnaces used for this study. 
Table 16. Firing Yields of 4 inch Bilayers in 7 Different Furnaces.

\begin{tabular}{|c|c|c|c|c|}
\hline Furnace \# & $\begin{array}{c}\text { Furnace Size } \\
\text { (inch) }\end{array}$ & Bilayers/Run & $\begin{array}{c}\text { Total Number } \\
\text { of Bilayers } \\
\text { Fired }\end{array}$ & Total Yield (\%) \\
\hline G-1 & 15 & 20 & 20 & 100 \\
\hline G-1 & 15 & 18 & 18 & 83.33 \\
\hline H-2 & 9 & 3 & 15 & 40 \\
\hline H-3 & 9 & 3 & 15 & 86.67 \\
\hline H-4 & 9 & 3 & 3 & 33.33 \\
\hline H-5 & 9 & 3 & 3 & 33.33 \\
\hline H-6 & 9 & 3 & 3 & 0 \\
\hline H-9 & 12 & 3 & 9 & 88.89 \\
\hline H-9 & 12 & 6 & 6 & 33.33 \\
\hline
\end{tabular}

For cells fired in furnaces $\mathrm{H}-2$ through $\mathrm{H}-9$ the overall firing yield was only $48 \%$. Some observations included that furnace $\mathrm{H}-9$ had a yield of $88.89 \%$ with 3 cells/run, but the yield dropped to $33.33 \%$ with double the number of cells in the same furnace. The drop in yield may be due to the larger amount of binder burnout in the 6-cell run compared to 3-cell run. Larger volume of binder burnout may cause or aggravate issues like non-uniform binder removal and steep thermal gradients in the furnace that in turn may lead to cell cracking. Yields from furnaces $\mathrm{H}-4, \mathrm{H}-5$, and $\mathrm{H}-6$ were $33.33 \%$ or less. However, during this study only 1 run each was made in these furnaces due to manufacturing constraints. For the same numbers of cells fired in furnaces $\mathrm{H}-2$ and $\mathrm{H}-3$, the much lower yield from furnace $\mathrm{H}-2$ was quite puzzling. Investigation into the firing profiles of furnace $\mathrm{H}-2$ indicated that a hold time during the firing cycle was inadvertently changed from 2 hours to 1 hour. This may have been a contributing factor to the observed low firing yield from furnace $\mathrm{H}-2$. Unfortunately, whether the reduced hold time was exclusively responsible for the low yield has yet to be verified as lack of program schedule did not permit additional experiments on this furnace with the normal hold time.

Cell breakage during the binder burnout seemed to be the dominant failure mechanism where 17 failures due to binder burnout versus 6 failures due to other mechanisms. Breakage during the binder burnout stage is identifiable through visual observation of the sintered part. If the part breaks in the early stages of firing, i.e. the binder burnout stage, there will be large gaps between the fractured pieces due to the fact that little densification has occurred at the low temperatures and the broken parts now shrink independently, thus the fractured pieces become smaller and gaps form between the pieces. In contrast if a part fractures later in the 
cycle the majority of the shrinkage has occurred and the fractured parts will be close together.

For cells fired in furnace $\mathrm{G}-1$ the results were much more encouraging. On the first run $100 \%$ yield was achieved with 20 bilayers and $83.33 \%$ yield in the second run with 18 bilayers. The results from the firing of cells in furnace G-1 were interesting as the yields were very high even with the large number of cells in the run. However, one key difference was that furnace G-1 had silicon carbide ( $\mathrm{SiC}$ ) as kiln furniture as opposed to alumina furniture used in the other furnaces. SiC has a much higher thermal conductivity compared to that of alumina, this reduces the thermal gradients in the furnace during the critical stages in firing cycle. Another important difference between furnace G-1 and the other furnaces is that the firing cycle incorporated forced air convection. This feature could aid in uniform binder burnout and may help to improve the thermal profile in the furnace. The fact that the cells fired in furnace G-1 had high yield indicate that the use of $\mathrm{SiC}$ kiln furniture and forced air convection needs to be examined further for future incorporation into the other furnaces.

Furnace-to-furnace variation results in widely differing yields as well as the differences in kiln furniture and forced air convection were significant. Bilayer firing will be an area of future focus in order to increase the overall process yield. This project has brought to light some potential ways to improve firing yields and increasing manufacturing through put.

\section{Variation Around Process Target}

Another major item that was investigated was whether or not the parts were within specification at different steps in the manufacturing process. For example the bilayer tape thickness specification for this study was $17 \mathrm{mil} \pm 1$ mil. Based on the manufacturing of 126 cells, 118 bilayer cell tapes were manufactured and measured for bilayer thickness with a caliper gage in the middle of the tape. It was found that the mean tape thickness was 18.1 mil with a standard deviation of 0.6 mil and a range of 17 mil to 19.5 mil. Figure 51 shows the data graphically and presents some of the descriptive statistics for the thickness of the bilayer tape. It is clear that variation exists and that the specification needs to be further investigated. It should be noted that the non continuous appearance of the data in Figure 51 is due the measurement gauge, which has a resolution of 0.5 mil, thus the thickness measurements fall into discrete buckets at 0.5 mil increments. Now that the data on these cells has been collected it will be possible to start tracking the performance of the cells and correlating the results to the manufacturing data. 
Descriptive Statistics
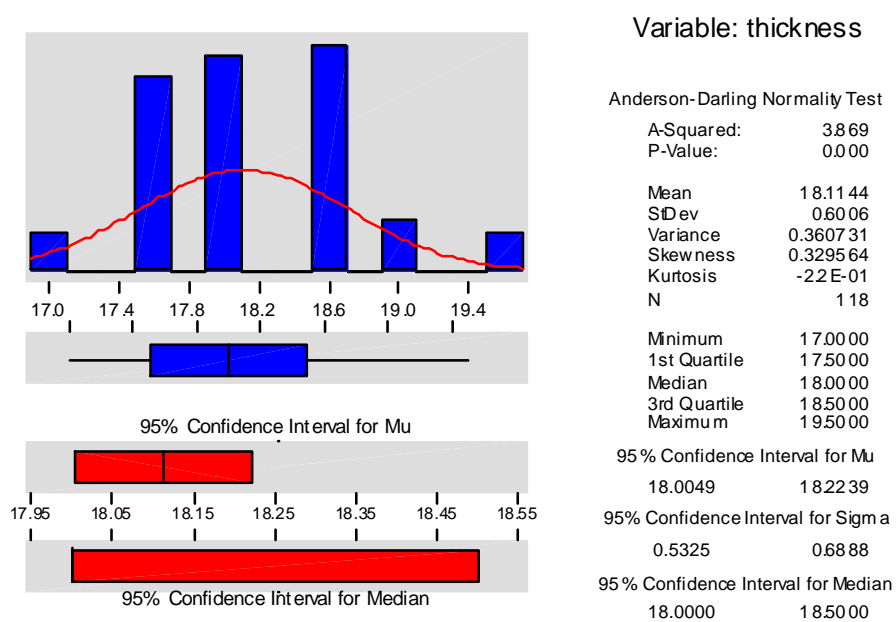

Figure 51. Descriptive statistics of bilayer tape thickness for 118 bilayer cell tapes that remained from the manufacture of 126 cells.

Similarly, bilayer tape weight for the remaining 118 bilayer tape cells were compared. There was no specification called out previously in the manufacturing process for bilayer tape weight, but in an effort to track process yield weight measurements were added above the standard manufacturing data. Figure 52 shows that the mean weight was 24.66 grams with a standard deviation of 0.79 and a range of 23.17 grams to 26.55 grams. This data can be used to help create a specification for bilayer tape weight in the future if it is determined that this is a valuable parameter to track. 
Descriptive Statistics

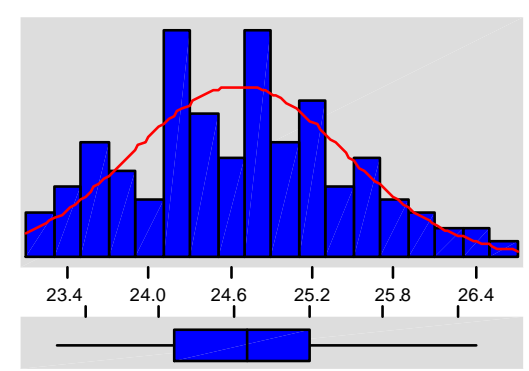

95\% Confidence Int enval for Mu

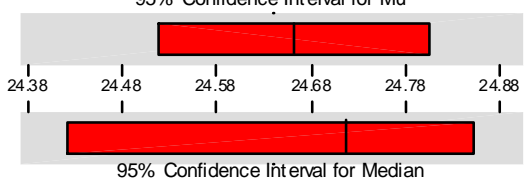

Variable: weight

Anderson-Darling Normality Test

$\begin{array}{ll}\text { A-Squared: } & 0.308 \\ \text { P-Value: } & 0.556\end{array}$

Mean 24.6608

StDev $\quad 0.7852$

Variance $\quad 0.616571$

Skewness $\quad 0.177748$

$\begin{array}{lr}\text { Kurtosis } & -5.1 \mathrm{E}-01 \\ \mathrm{~N} & 118\end{array}$

Minimum -23.1700

1st Quartile $\quad 24.1200$

Median 24.7150

3rd Quartile $\quad 252000$

$95 \%$ Confidence Interval for $\mathrm{Mu}$

$24.5176 \quad 24.8039$

$95 \%$ Confidence Interval for Sigm a

$0.6962 \quad 0.9005$

$95 \%$ Confidence Interval for Median

Figure 52. Descriptive statistics on the bilayer cell tape weight based on 118 bilayer cell tapes that remained from the manufacture of 126 cells.

Another area of interest is flatness of the solid oxide fuel cells. During bilayer firing and cathode firing there is potential that the cell will bow as well as have edge ripples form. It is believed that the amounts of bow and edge ripple are inherent to the specific bilayer configuration/composition, thus significant variation in this may indicate special cause process variation. This non-uniformity in cell bowing can lead to the breakage of the cell once it is in a fuel cell stack under load. All of the tapes were cut in the same manner, a machined punch of a the desired diameter, is placed on the tape and an even load is applied by a hydraulic press. All of the cut edges were inspected for defects, tears or incomplete cuts. For this study a new piece of equipment, a non-contact single laser measurement device was used to measure the part flatness. The cell is place on the laser table and the laser scans the cell according to the selected automated program and determines the flatness measurement where flatness is defined as the maximum height above the flat surface of the table. A run chart of the first thirty fired bilayers is presented below in Figure 53. The approximate mean of the flatness is 55 mil with a standard deviation of 9 mil. The data does not indicate any trends and when examined for correlations with bilayer thickness and bilayer weight none were found. However, it does support that the lack of flatness is something that is inherent to the manufacturing process in its current state. 
Run Chart for Fired Bilayer Flatness

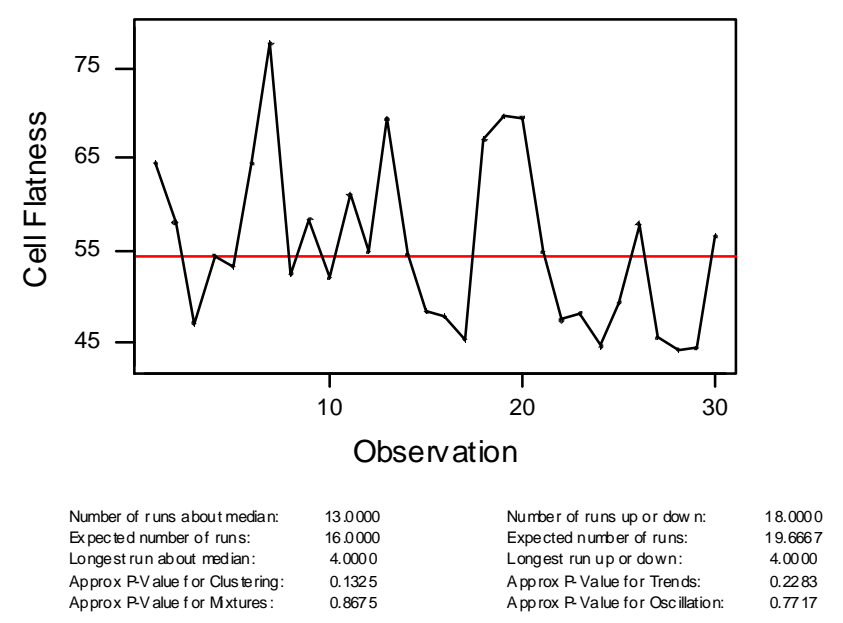

Figure 53. Flatness run chart for the first 30 fired bilayers. The red line denotes the mean flatness.

\section{Manufacturing Process Analysis}

Other data that was recorded which was identified as important included the amount of rework, labor time, and defect tracking. Each of these topics is discussed in more detail below.

Rework was classified as anything that went outside the baseline manufacturing process or had to be redone such as screen printing a fired bilayer and removing the cathode material immediately and redoing the screen print. In this study it was found that the amount of rework was relatively low. In a few areas, such as anode 2 tape calendering, it was found that all the parts needed to go through an additional rolling step. Since all of the parts were found to need more rolling the baseline procedure was modified.

Labor and wait (clock) time were also tracked giving an understanding of which areas take the most time and where improvements could be made with the most significant gains. Significant reductions in labor time should also occur as new manufacturing equipment is brought on line such as a larger roll mill that will allow larger pieces of tape to be rolled. Wait time was not seen to have a significant impact on cell variability.

Visual defects were also noted and 8 parts were rejected in the tape phase based on folded tape and tears in the electrolyte layer. Other observable features on the bilayers, such as color variation, spots, and surface roughness, are not well understood at this point as more correlations with performance need to be made in 
order to determine if the observed features are defects. As a result of this study, however, potential defects were noted so when these cells are tested the manufacturing parameter database can be referenced to see if there are any correlations.

To date a substantial amount of manufacturing data has been captured for the fabrication effort of 126 cells. The data collection categories worked well enabling an understanding of the amount of scrap material, trimmings for recycle, and labor time to name a few for each of the manufacturing process steps. As was noted by the first pass yields, more work is required to improve the yields throughout the different steps in the manufacturing process. Also, a focus on recycling the material is important in order to attain the greater overall yields, which is where scrap material is brought back into the fabrication process at appropriate points. Implementation of this would require modifications to the baseline cell process to accommodate the additions, which were not done during this program. More work is also recommended to understand the best methods for incorporating the recycled material back into future manufactured cells. In addition, parts specifications need to re-evaluated once the manufactured cells are performance tested. It might be possible to correlate high or low performance with one of the manufacturing parameters that were recorded in the database and enable improved specification limits to be implemented.

\subsubsection{Non-Destructive Evaluation (NDE)}

Non-destructive evaluation (NDE) techniques provide a means to monitor the development and propagation of defects in a material or product throughout manufacturing without damaging the part. A wide variety of non-destructive testing techniques are available for inspection of materials, and must be chosen based on specific application needs and constraints. This section summarizes the capabilities of various NDE techniques in imaging and detecting non-uniformities in solid oxide fuel cells (SOFC).

The underlying purpose for doing an inspection is to find defects in the material, such as density gradients, voids, inclusions, and delamination that may compromise quality or degrade performance. In this manner, the inspection techniques aim to extract the same type of information regarding the physical structure and integrity of the object under inspection. However, these techniques utilize and measure different physical properties in order to ascertain the structural soundness, and this impacts the range of validity, time to measure a specimen, quality of data and ease of interpretation.

For the specific case of SOFC inspection, three modalities were chosen to image and characterize structural defects and density variations within SOFC materials. These were infrared imaging (IR), ultrasonic imaging (UT), and digital radiography (DR). In all cases the specimen under inspection is radiated with 
energy, and the response of the object to this energy is measured and used to extract information about the structural properties. IR uses a burst of light to radiate the object and the time evolution of the relaxation of the heat flow in the surface of the sample is measured. UT uses acoustic waves to probe the sample and the echo from the sample is used to reconstruct an image. Both IR and UT can be used to identify cracks, voids, and delamination within the tapes and fired bilayers and cells. Radiography measures the transmission of X-rays through a sample. Xrays are preferentially absorbed for high $\mathrm{Z}$, high-density materials and this can be used to determine the distribution of materials within an object. Because the different modalities probe different physical attributes of the object, they provide similar yet complementary information.

\section{Multiple NDE Techniques Comparaison}

In the first part of the investigation several different cell samples, in various stages of the manufacturing process, were imaged using infrared (IR), ultrasonic (UT), and digital radiography (X-ray) techniques. The samples included unfired anode, electrolyte and bilayer tape as well as 1", 4", and 8" diameter fired bilayers including some with cathode.

Tapes samples of unfired tapes, in various stages of processing, were imaged using X-ray digital radiography. Results are shown in Figure 54, again in reverse video where white is low density. Sample TN4719 electrolyte tape, which is white in appearance, had the lowest density of the three tapes. It is noteworthy that it was imaged with an exposure that was a factor of 5 less than in all the other samples and is presented in the left panel of Figure 54. Sample TN4758, a baseline bilayer tape, consisting of an electrolyte layer, an anode 1 layer, and an anode 2 layer, showed much more contrast in the processing lines, as well as a high-density region, which had a Gaussian-like profile at the bottom of the tape. The image is seen in the center panel of Figure 54. Finally tape number TN4782 anode 2 tape was found to be the most uniform, however, a uniform density increase was evident at the top of the tape (See right panel of Figure 54). In all three samples, there seemed to be evidence of various types of non-uniformities. Localized material depletion or voids that show up as white spots are most likely air bubbles that did not escape the mixture and caused local density reductions. Highdensity regions that were both continuous (i.e. correlated with tape calendering marks on the material) and those that exhibited microstructure or graininess, much like that seen in sample NDE-3 (See Figure 58) were evident. Such microstructures and voids were observed in the radiograph even though no outwardly visible indications were present. 

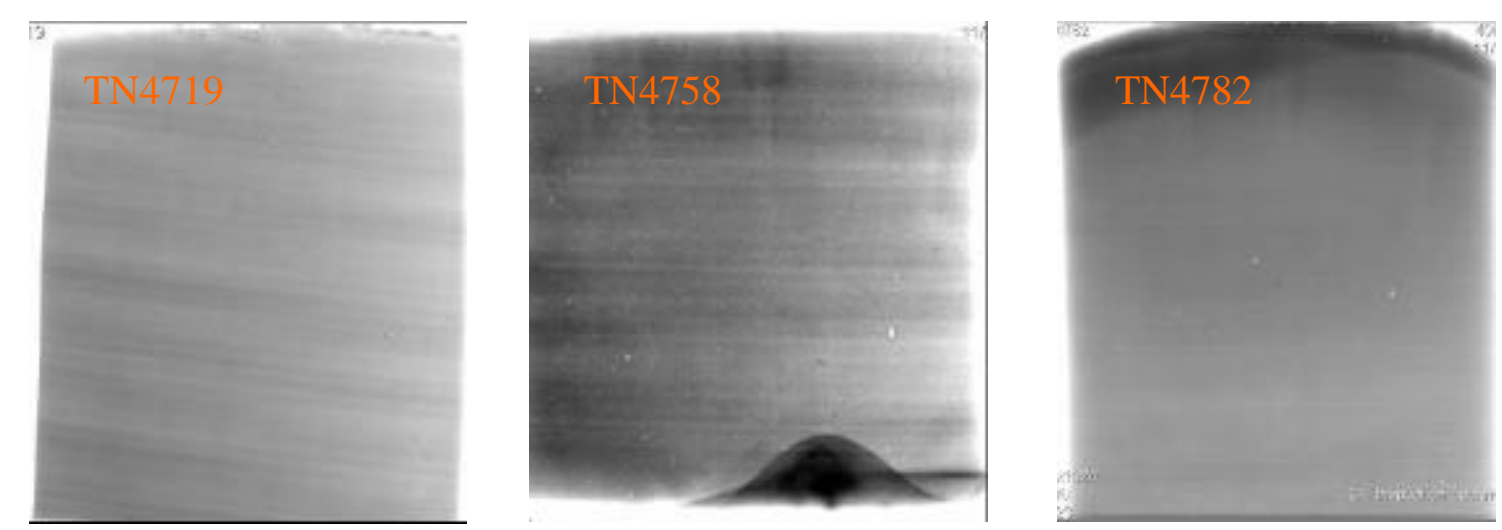

Figure 54 X-ray digital radiography of three tapes in various stages of processing, TN4719 = electrolyte tape, TN 4758 = bilayer tape (electrolyte, anode 1 , and anode 2) with the electrolyte surface up, and TN4782 = anode 2 tape. The electrolyte tape and anode 2 tapes are representative of the tapes used to fabrication the bilayer tape shown.

\section{Fired Bilayer}

In addition to providing more information on visually observed flaws, the NDE techniques can be used to observe more subtle variations in structure/composition. Figure 55 shows SOFC sample (NDE-9) imaged with IR and X-ray. The thermal diffusivity pattern measured appears to be different when comparing the front and back surfaces in the IR images (left panel). The regions, rendered in blue in the IR image, have a lower thermal diffusivity than the rest of the cell. The lower thermal diffusivity implies either a greater thickness or non-connectivity (i.e. porosity) of the cell, both of which have the effect of degrading the thermal conductivity of the cell. The legend on the right hand side of the IR image can be used to estimate the thickness of the sample if the variation in thermal diffusivity is attributable only to a thickness variation in the sample. The $\mathrm{X}$-ray image confirms density variation over the cell, even though there are no visible indications of an asymmetry on either the front or back surfaces. This effect may be attributable to a chemical non-uniformity in the disk, such as a nickel or zirconium rich area. Note that white shading in the radiograph again indicates higher density than black. 

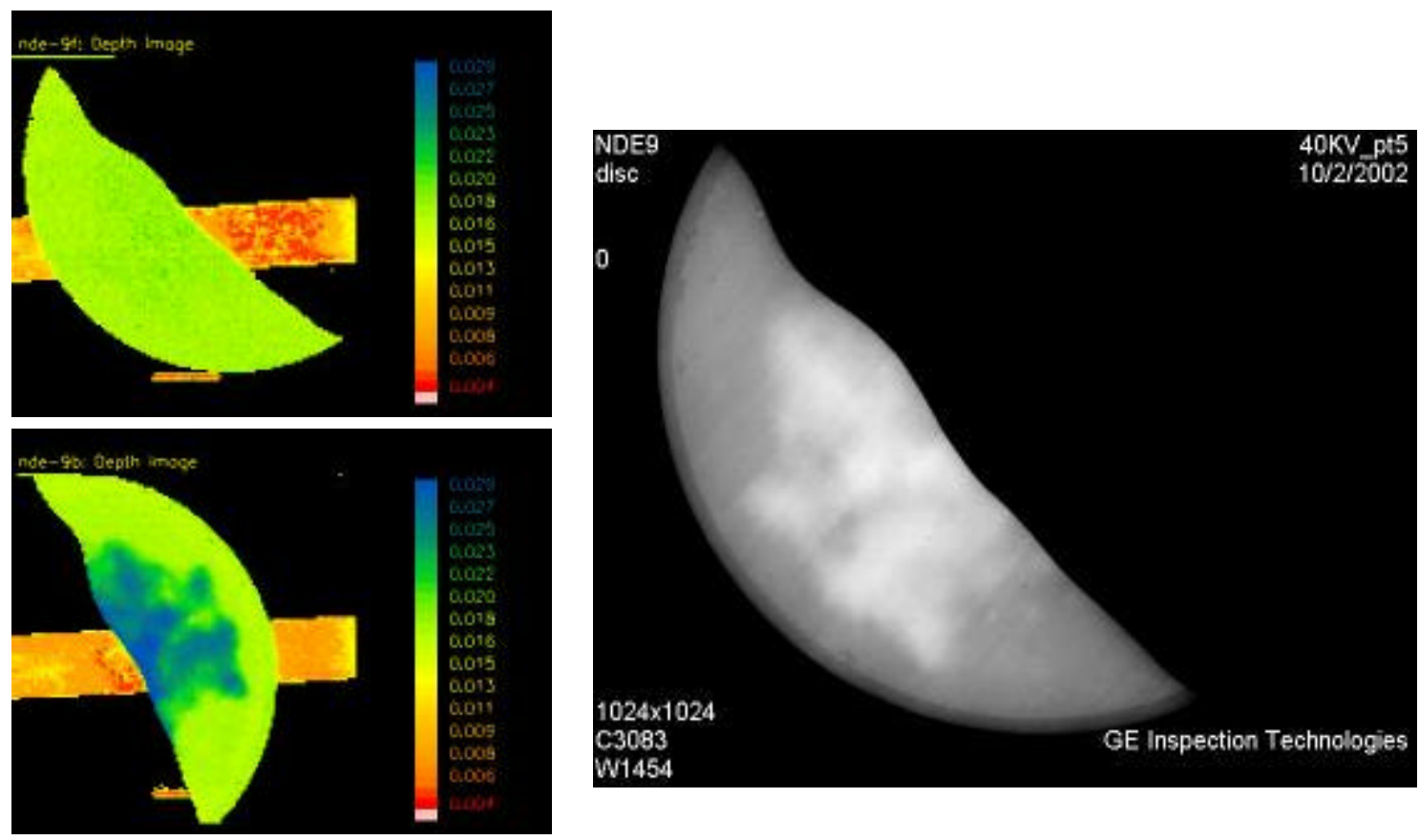

Figure 55. IR and X-ray images of the sintered bilayer sample NDE-9 are shown. The upper left panel is an IR image of the front surface whereas the lower left panel is the back surface. The X-ray image is shown in the right panel. Note: this cell was broken and only half of the cell is seen in the image and the sample was imaged with the electrolyte surface up.

Another comparison between IR and X-ray imaging is seen in Figure 56 where images of sample NDE-5 is shown. Here the sample appears to have a very uniform thermal diffusivity across the disk. $k$. The small cyclone pattern about the center of the disk is an artifact of the light reflected during the pulsed illumination. Evidence of structure in the cell is visible in the X-ray images where broad striations, most likely due to tape calendar processing during manufacture exist. There is also an apparent variation in density throughout the disk. $k$. This can be uniquely ascribed to density since a variation in thickness is ruled out by the IR image. 

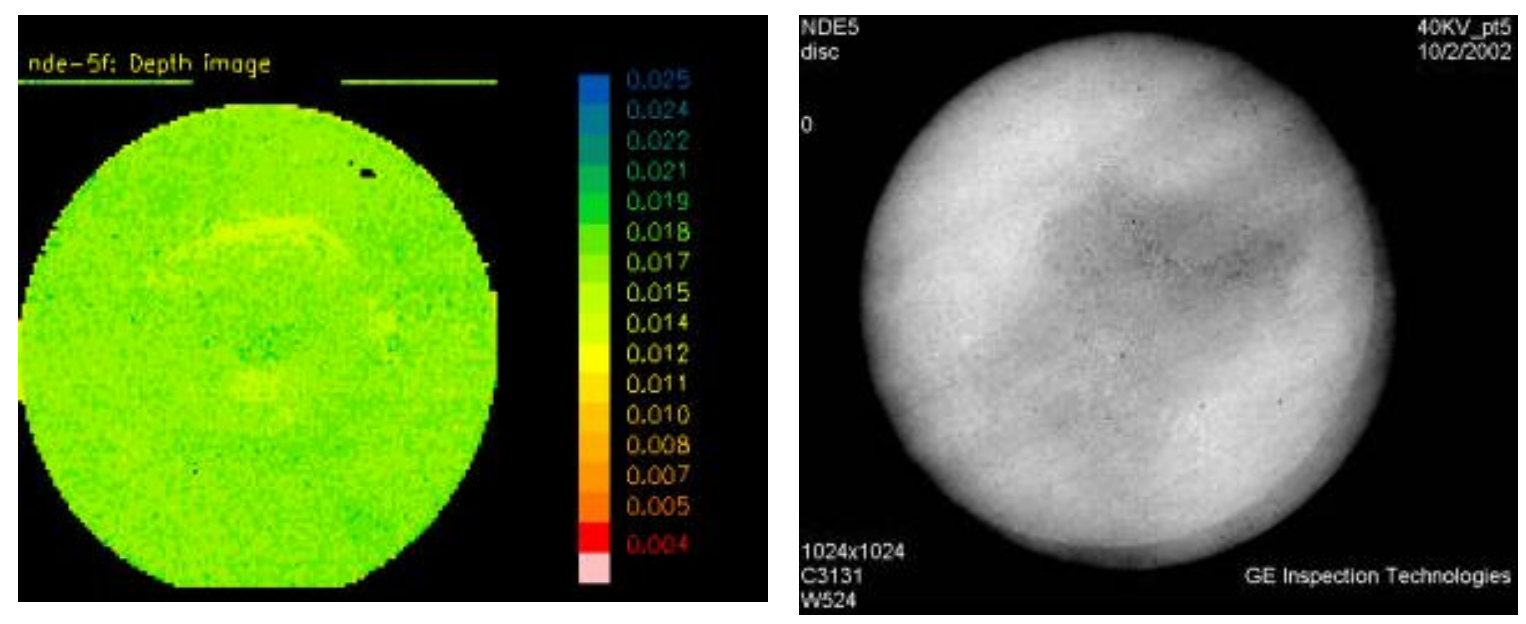

Figure 56. SOFC sample NDE-5 is shown under IR (left) and X-ray (right).

In order to investigate the possibility of thickness variations and obtain an absolute calibration for the IR thickness measurement, sample NDE-5 was measured with a light gauge to determine the shape and surface flatness of the disk. k. Results are shown in Figure 57. Scanning across a single diameter of the disk, it is observed that the disk is not flat. In fact it is bowed with a maximum excursion at the center of the disk of $0.30 \mathrm{~mm}(12 \mathrm{mil})$. The non-uniformities in the surface smoothness are further revealed by the structure seen on the overall shape profile. The amplitude of this structure is the order of $0.05-0.10 \mathrm{~mm}(2-4 \mathrm{mil})$. A similar profile with slightly less surface roughness was extracted upon examination of another sample (NDE-9). 


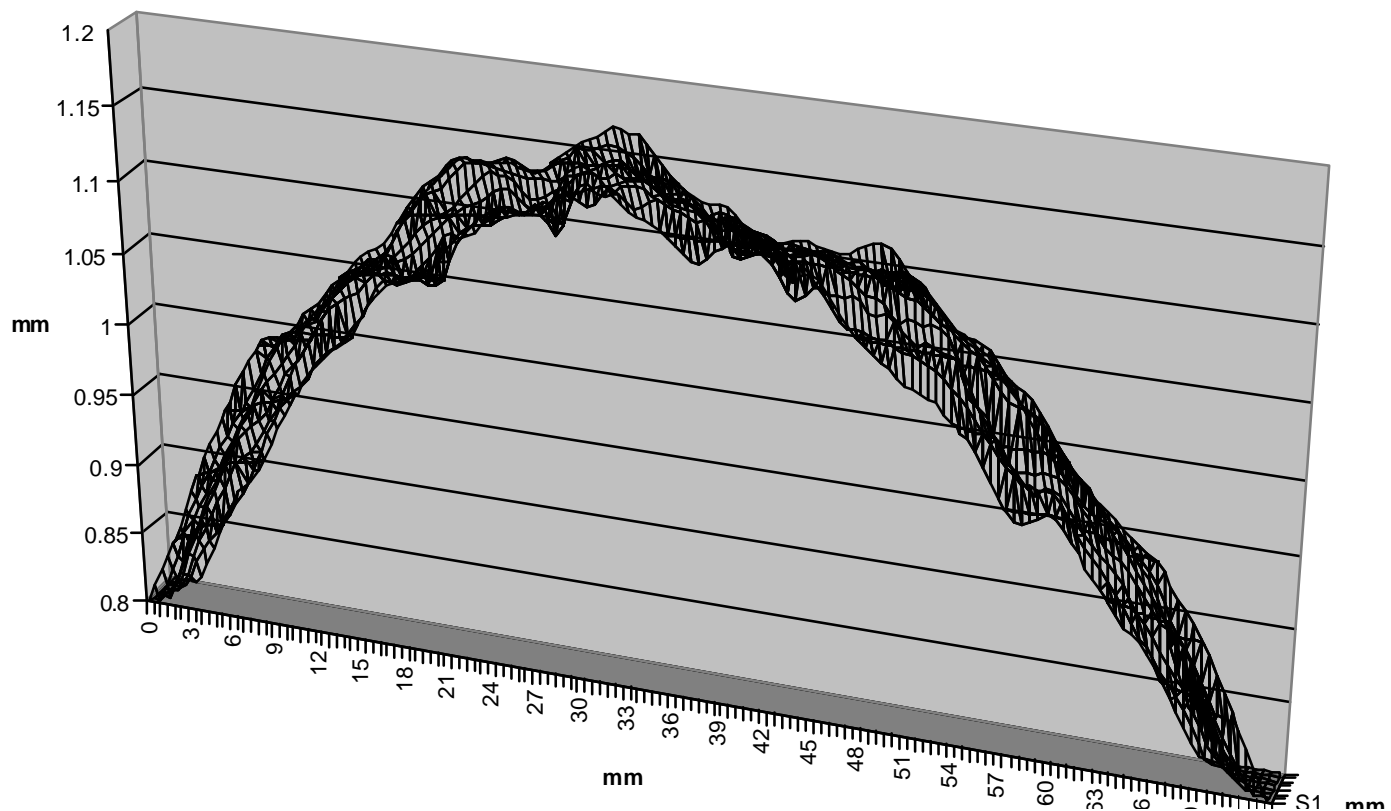

Figure 57: The flatness and surface smoothness of the sample NDE-5 is shown as a function of the position on a diameter.

Local density variations with a definite grain structure have also been identified. Of particular interest was that of SOFC sample NDE-3. An X-ray image at a magnification of $1 x$ is shown in left panel of Figure 58. Note that this image is in reverse video as compared to the previous radiographs. A small, high-density (i.e. black) spot was identified in the central region of the disk. k. No obvious outward visual indications were present. The region was isolated and magnified by a geometric X-ray projection method and a distinct graininess was identified in the region. The graininess is consistent with insufficient pulverization of a high-density material incorporated into the bulk of the material (i.e. Ni). Also seen clearly are the low-density microstructures of voids, as seen by the white dots. 


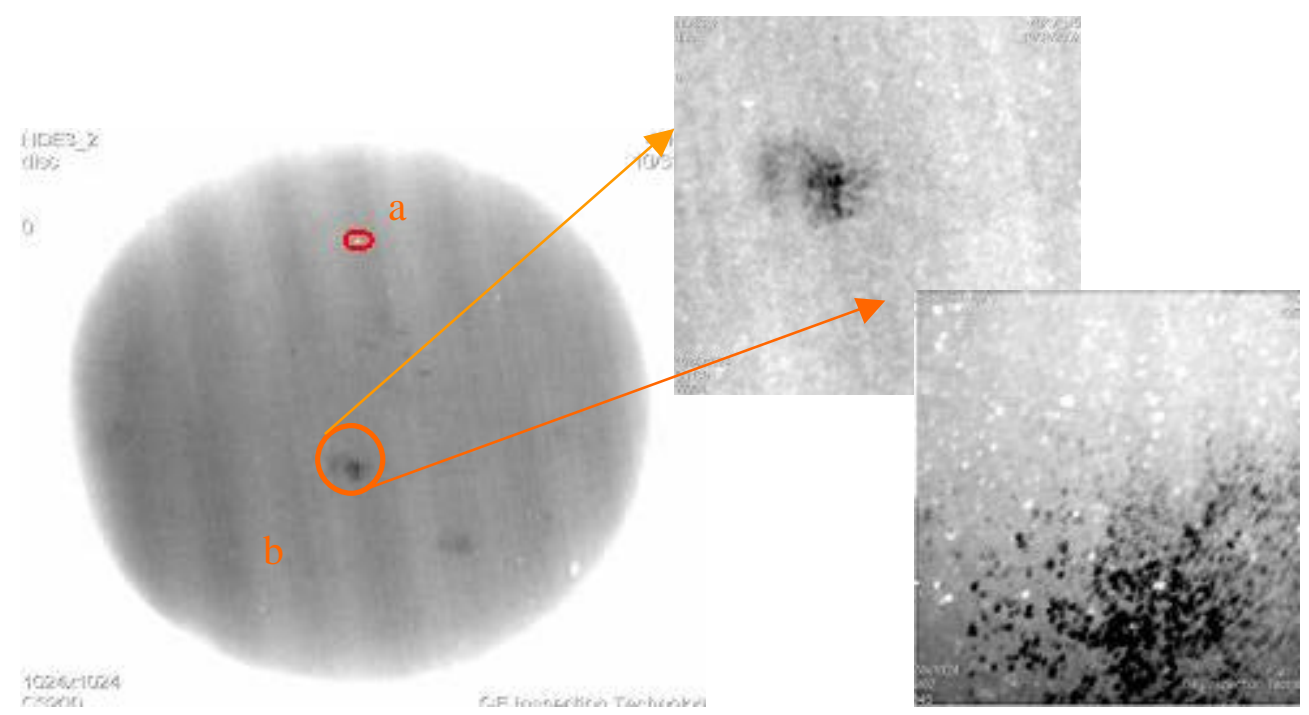

Figure 58 X-ray images of the SOFC plate (NDE-3) are shown in reverse video (i.e. white is low density, and black indicates high density). The right panels where taken at higher magnification.

This particular sample was inspected with UT methods to extract further structural information and is shown in Figure 59. The ultrasonic image has a smaller pixel size $(60 \mu \mathrm{m})$ compared the radiographs $(200 \mu \mathrm{m})$. Both surface skimming (left panel) and reverberation (right panel) images were acquired (See Figure 59). These measurements revealed features similar to those seen in the radiograph (See Figure 58). Striation or rolling marks are seen in both images however the reverberation image is able to identify isolated point like structures along the striations. Both UT imaging methods also show a high-density region at the center of the disk, consistent with the results from X-ray.
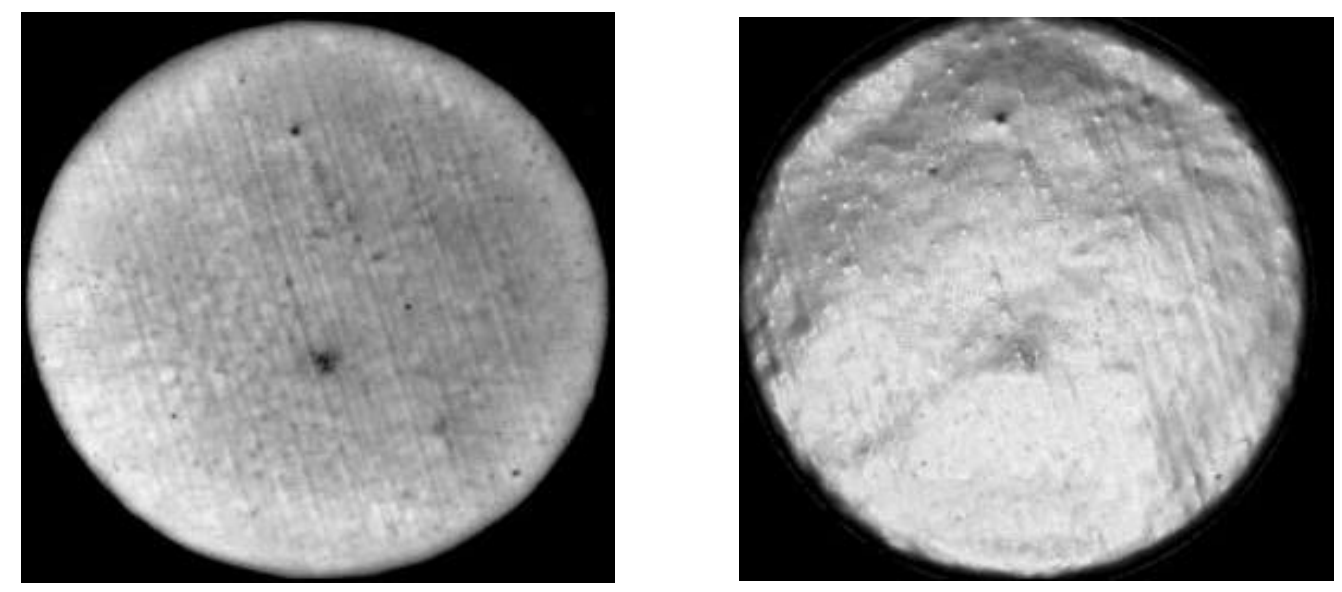

Figure 59. Two ultra-sonic images of sample NDE-3 are shown in the panels above. The left panel shows a surface wave image while the right panel shows an impulse reverberation image. 
In order to determine the characteristics of this high-density blemish in specimen NDE-3, the sample was sectioned for an energy dispersive X-ray fluorescence (EDX) analysis. Results are shown in Figure 60 where the defect can be seen with high detail in the porous anode material. The defect was found to be approximately $120 \mu \mathrm{m}$ below the surface of the cell, which is beyond where X-ray fluorescence (XRF) techniques are expected to work and it explains the poor sensitivity of initial XRF measurements. The defect is also seen to have a spatial extent on the order to 50-75 $\mu \mathrm{m}$, and 20-30 $\mu \mathrm{m}$ in depth. Significant macroscopic structure exists in the defect when compared to the nominal anode tape. Energy dispersive x-ray spectra were acquired in the areas labeled 1, 2, 3 and 4. Based on the peaks that were acquired from the different areas, the defect region was nickel poor and zirconia rich relative to the surrounding "normal" anode material. In addition calcium and sulfur contamination was also observed.

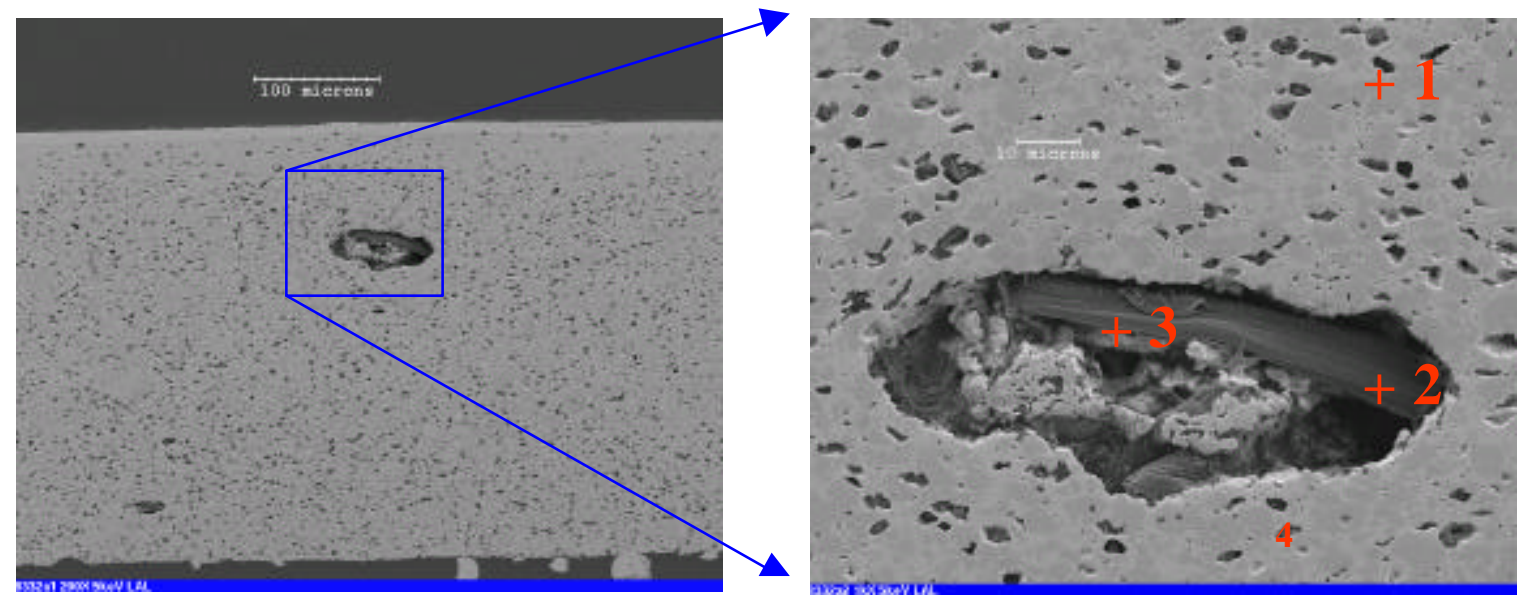

Figure 60. SEM image is of the defect cross - section with a higher magnification image shown on the right.

Figure 61 shows the same SOFC sample (NDE-7) imaged by IR (left panel) and Xray (right panel) with the same orientation in both images. The legend gives the approximate thickness in inches as inferred from the thermal diffusivity measurements. This can be correlated with the highlighted region of the X-ray radiograph in the right panel that shows a fragmented surface in the same location. Darker shading in the radiograph means lower density and/or less material. The cell appears to be quite uniform in the IR image except for two regions at the top and bottom of the cell. Note that the black spots in the upper right extremities of the disk are due to dead pixels in the imaging camera rather than structural defects in the plate. The X-ray image is a map of the cell in terms of the X-ray transparency. The radiograph shows a discontinuous density profile, which is identified with mud cracking or flaking of the deposited cathode. Taking the information together, the increased thermal diffusivity of the blue regions is due to a decreased density of 
materials because of mud cracking and flaking of cathode material, rather than nonuniformities in the chemical properties in the material.
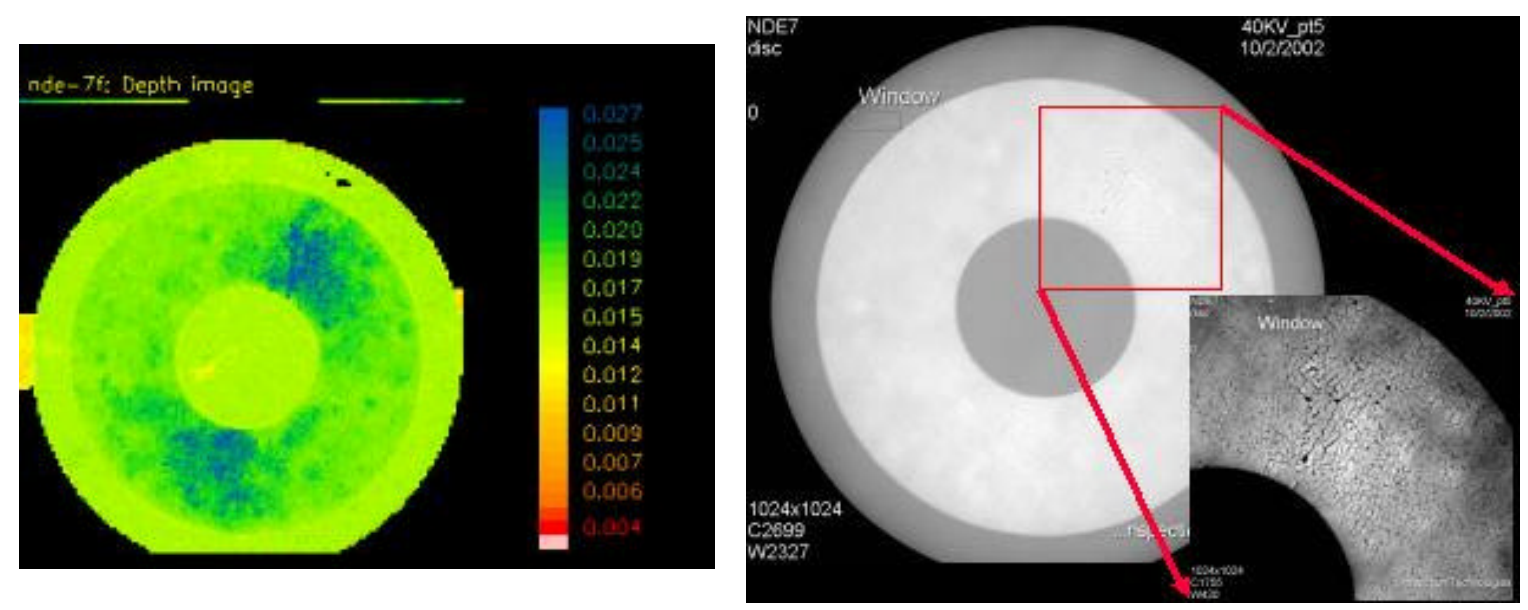

Figure 61. Two images of SOFC (NDE-7) are shown. The left panel is an IR-image and the right panel is an X-ray radiograph.

The three methods used in investigating the SOFC samples have provided unique and complementary information that can be used to build a consistent picture of defects and microstructures. A summary of the examined cells and the identified flaws are presented in Table 17. In terms of acquisition performance, the radiographs are acquired in an average time of 6 seconds per frame. Furthermore, real time scanning and acquisition can be done, if necessary. This technique has potential for quick inspections of materials at different stages of fuel cell manufacture or where inspections of long perimeter regions, such as seals, are required. In contrast, the UT images are more difficult to acquire as they require about an hour to attain and are necessarily taken under water, which compromises flexibility, however, the level of detail is slightly enhanced over the other NDE techniques. The IR method is intermediate in time requirements and is sensitive to surface properties of the SOFC's, however; ambiguity exists whether the variation is coming from lack of homogeneity and/or thickness. Currently, it is believed that of the three techniques explored, radiography is the best screening technique for general inspection characteristics because of the large area coverage, speed of acquisition and sensitivity to density variations. Therefore, this method was chosen to follow the same SOFC cells through the manufacturing process to determine where and when the flaws were developing. 
Table 17. Summary of Cell Examined by NDE

\begin{tabular}{|c|c|c|c|}
\hline Sample & Process Step & $\begin{array}{l}\text { Inspection } \\
\text { Modality }\end{array}$ & Identified Flaw \\
\hline NDE1 & Sintered bilayer & X-ray & \multirow{2}{*}{$\begin{array}{l}\text { Pitting and depletion of material in localized } \\
\text { region as well as high density concentrations } \\
\text { of materials }\end{array}$} \\
\hline NDE2 & Sintered bilayer & X-ray & \\
\hline NDE3 & Sintered bilayer & X-ray, UT & $\begin{array}{l}\text { Strongly attenuating central region of } \mathrm{Zr} \text { rich } \\
\text { deposits } 120 \mu \mathrm{m} \text { from the surface } \\
\text { corresponding to } 20-30 \% \text { of total disk } \\
\text { thickness }\end{array}$ \\
\hline NDE4 & Sintered bilayer & IR, X-ray & $\begin{array}{l}\text { Central and edge regions had depleted } \\
\text { density }\end{array}$ \\
\hline NDE5 & Sintered bilayer & IR, X-ray & $\begin{array}{l}\text { Central and edge regions had depleted } \\
\text { density }\end{array}$ \\
\hline NDE6 & Sintered bilayer & X-ray & Uniform \\
\hline NDE7 & Cell with fired cathode & IR, X-ray & Large Scale porosity and cracking in cathode \\
\hline NDE8 & Cell with fired cathode & IR, X-ray & $\begin{array}{l}\text { Porosity and large crack in cathode and } \\
\text { anode substrate }\end{array}$ \\
\hline NDE9 & $\begin{array}{l}\text { Cell with unfired } \\
\text { cathode }\end{array}$ & IR, X-ray & $\begin{array}{l}\text { Surface density in-homogeneity visible with } \\
\text { IR. X-ray confirms density variation in central } \\
\text { region }\end{array}$ \\
\hline NDE10 & Sintered bilayer & X-ray, UT & $\begin{array}{l}\text { Surface roughness and pitting. Some high } \\
\text { density material concentrations }\end{array}$ \\
\hline NDE11 & Sintered bilayer & X-ray, UT & $\begin{array}{l}\text { Inhomogeneous around edges with } \\
\text { concentrations of high density material at } \\
\text { edges }\end{array}$ \\
\hline NDE12 & Sintered bilayer & X-ray, UT & $\begin{array}{l}\text { Strongly inhomogeneous through structure of } \\
\text { cell. Many high density concentration of high } \\
\text { density material throughout cell, but } \\
\text { concentrated at edges }\end{array}$ \\
\hline NDE13 & Cell with fired cathode & X-ray & $\begin{array}{l}\text { Cracked substrate. Strong non-uniformity and } \\
\text { asymmetry in cathode deposition }\end{array}$ \\
\hline $\begin{array}{l}\text { NDEA } \\
(4758)\end{array}$ & Bilayer Tape & X-ray & $\begin{array}{l}\text { Asymmetric distribution of material from left to } \\
\text { right. Gaussian lip showing high } \\
\text { concentration of material. Numerous large } \\
\text { voids. }\end{array}$ \\
\hline $\begin{array}{l}\text { NDEB } \\
(4719)\end{array}$ & Electrolyte Tape & X-ray & $\begin{array}{l}\text { Strong structural roll marks with numerous } \\
\text { large voids. }\end{array}$ \\
\hline $\begin{array}{l}\text { NDEC } \\
(4782)\end{array}$ & Anode Tape & X-ray & $\begin{array}{l}\text { Uniform with } 3 \text { small and localized defects; } 2 \\
\text { low density, } 1 \text { high density }\end{array}$ \\
\hline
\end{tabular}




\section{Monitoring of Manufacture Defects}

Once X-ray was selected as the best technique for future studies, nine additional 4 inch diameter baseline cells (See Table 18) were evaluated as they went the various stages of manufacture. All the potential flaws were identified at each step and tracked sequentially at multiple stages in the manufacturing process: a) bilayer tape b) fired bilayer c) unfired cathode and d) fired cathode. Performance tests of the completed cells that survived the manufacturing process were performed in an effort to correlate the identified defects with the performance of the SOFC's.

\section{Bilayer Tape}

The nine samples were taken from two separate tapes (TN4854 \& TN4863), cut into 4" diameter samples, and were imaged with X-rays after each processing step. The imaging occurred at approximately $50 \mathrm{kV}$ with a total exposure time of 5$11 \mathrm{~mA} \cdot \mathrm{s}$. Both real time and static digital radiography was used with comparable results between the two methods. As with the previous study, a detector pixel size of $200 \mu \mathrm{m}$ was used, as was the geometric magnification of unity. Figure 62 shows a typical image of bilayer tape NDE-S2 with aluminum calibration standards on the left side of the image.
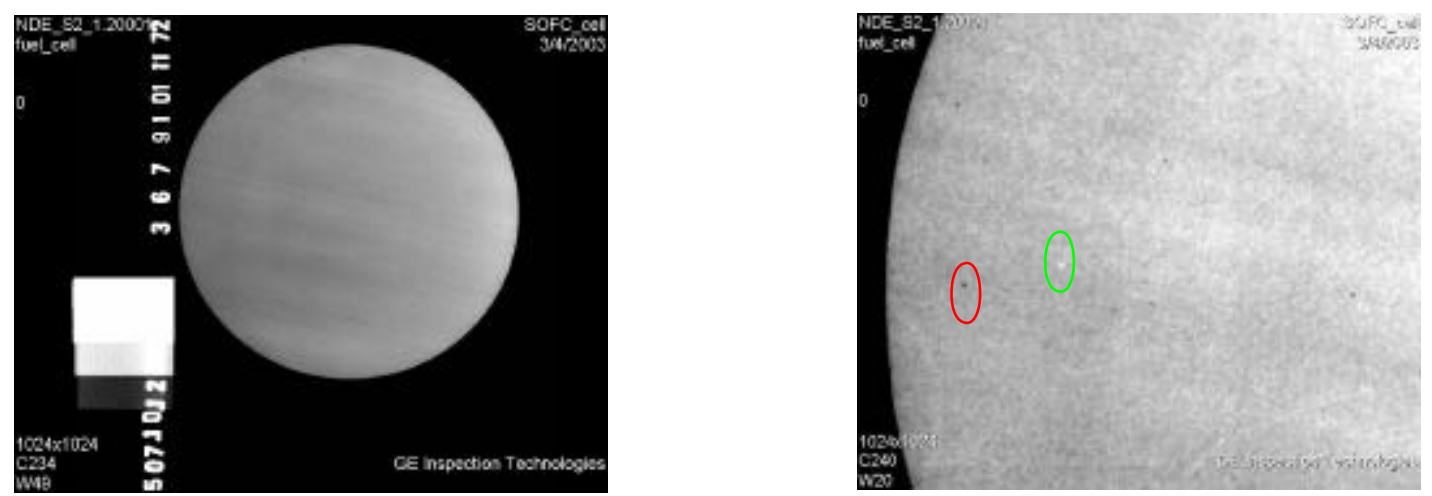

Figure 62. X-ray radiograph of bilayer tape (NDE-S2) with the calibration standards in the left side of the frame (left). The right panel shows a enlarged region of the cell (NDE-S2) illustrating defects or non-uniformities at the $600 \mu \mathrm{m}$ (15 mil) level. Black points, (circled in red) identify voids, while white points (circled in green), indicates regions of high density.

Striation marks previously identified with tape calendering in the processing phase are visible in all the samples. Defects or in-homogeneities that appear in the samples, other than the striations are small in dimension and are strongly localized. 
There is evidence of both high and low-density structures. However, in neither case does the density difference exceed $4 \%$ of the nominal plate density.

Figure 63 shows sample NDE-S5 bilayer tape that has undergone similar production steps, as did NDE-S2. However during packaging, it was pressed with a box, which produced strong compression markings on the surface. The compression shows a systematically smaller gray scale count when compared to the nominal structure of the cell, as well as other cells.

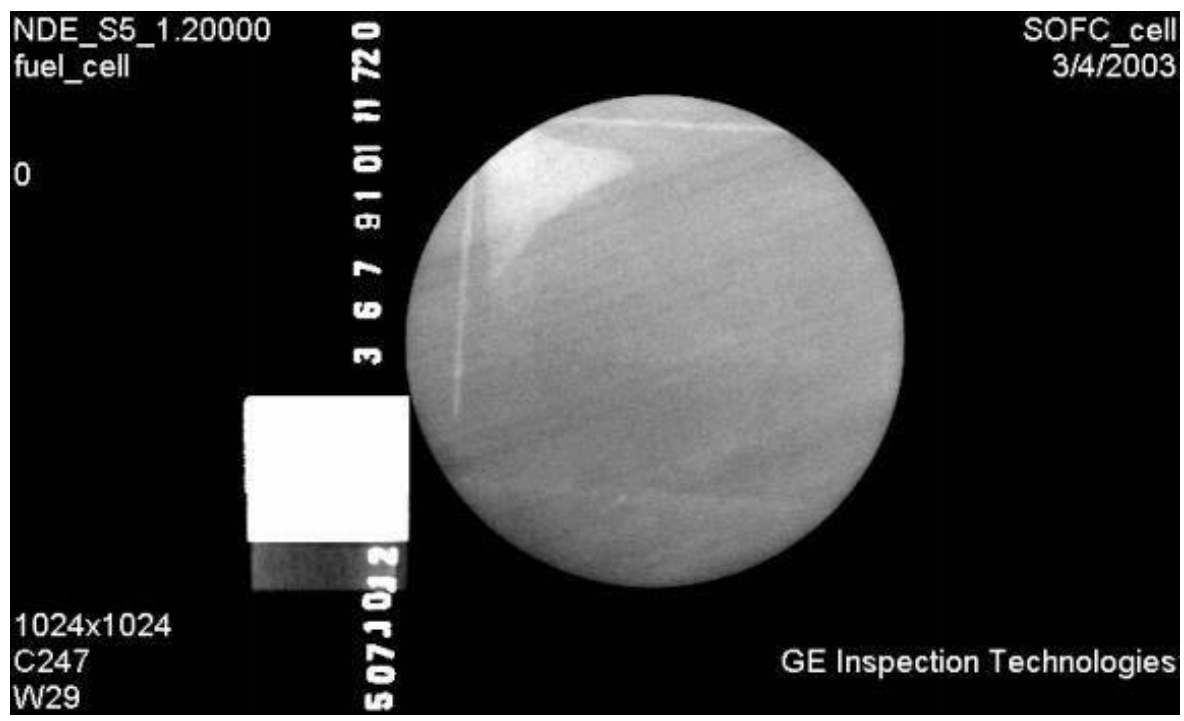

Figure 63. X-ray radiograph of bilayer tape (NDE-S5) with the aluminum calibration standards in the left side of the frame.

Fired Bilayer

The bilayer tapes were then fired and re-imaged. Figure 64 shows the cells NDE-S2 (left) and NDE-S5 after the firing of the bilayer tapes was complete. 

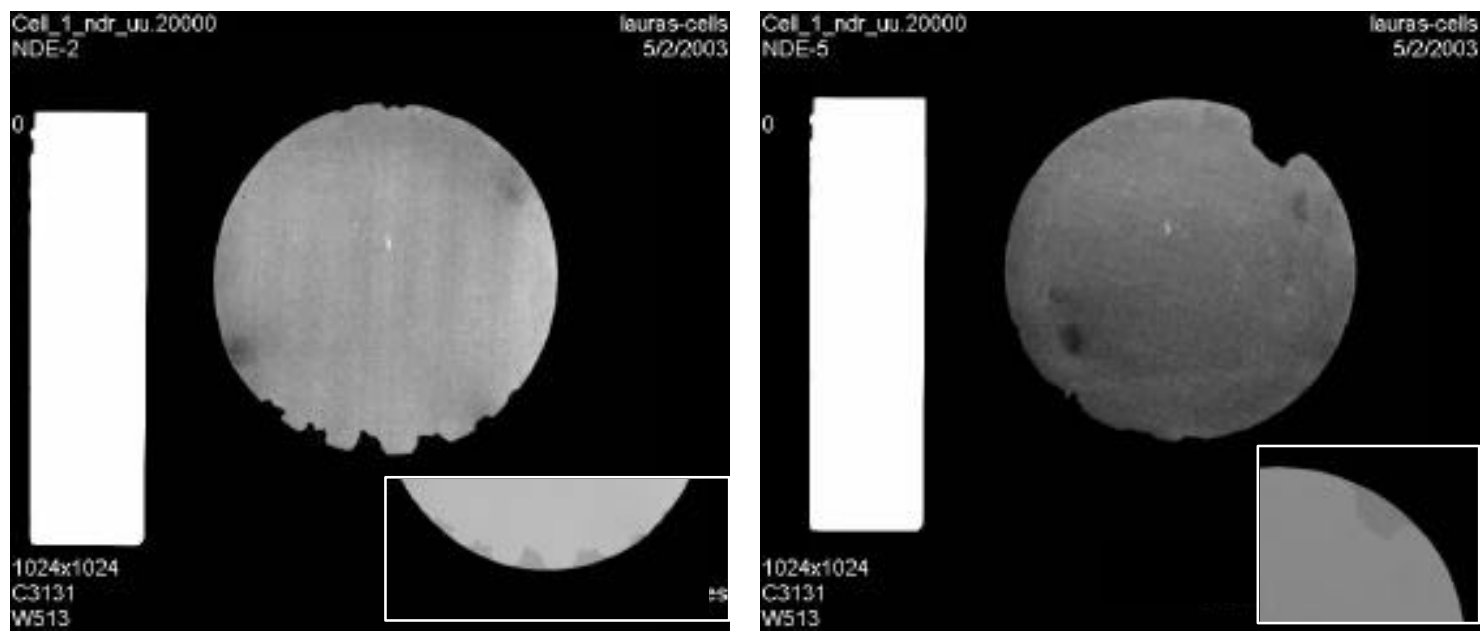

Figure 64. X-ray radiographs of bilayers NDE-S2 (left) and NDE-S5 (right) after sintering. Both images are shown rendered in the identical gray scale. Shown on the inset of each image is a re-normalized gray scale image of the apparent "missing" edges of the bilayers.

There is very little change in the character of the defects as both the striations and surface structure of the bilayers are identical to that before the firing. Note the compression marks in sample NDE-S5 are still visible as darker shades, although they do not seem to be as pronounced as before the firing (as in Figure 63). Several noticeable differences are apparent after the firing of the bilayers. First there are small sections around the edges of both bilayers that appear to be missing. This is not due to a limitation of the detector technology, but rather, reflects the compromise one has to make in rendering a gray scale image. The detector has a full 14 bit dynamic range, whereas the human eye has difficulty discerning more than 7-8 bits (i.e. 128-256 distinct) shades of gray. As such, a choice must be made in rendering an image for evaluation purposes. Either the full scope of the image with very limited detail (i.e. wide latitude) can be shown, or certain regions of the image must be compromised to show greater or complete detail in another region of the image. Wider latitude rendering of the same identical image reveals the material in these regions. This is illustrated in the inset of the left and right panels of Figure 64. However, less detail in the rest of the bilayer such as the loss the striation and rolling marks, as well as the compression defects that are visible in the narrow latitude main image, is visible. The significance of the regions that seem to be absent in the narrow latitude image is that less material is present in these regions. Visible inspection of the bilayers confirms that the electrolyte layer, usually present over the œmplete bilayer is missing in regions that correlate very closely with the images in Figure 64 (see Figure 67 for a photograph of this effect). 


\section{Cathode}

The cells were then processed to deposit the cathode material on the substrate. This was done over an annular region that is shown approximately by the red circles in the left panel of Figure 65. The cells were then again imaged with $\mathrm{X}$-rays. This time care was taken to image the cathode material to look for surface or structural defects that could be correlated with the underlying structure of the substrate. The right panel of Figure 65 shows the image with a gray scale that is optimized to show the details of the cathode. Note that as with the previous images, the white shading indicates regions of higher density. The cathode thickness varied by about $20 \%$. Since this level of variation was not evident before the deposition, it implies that the bulk of the observed variation is due to inhomogeneities in the cathode layer. Some variation in the cathode thickness is expected, however, because the fired bilayers are not completely flat. Therefore, when the cathode is screen printed on the surface of the bilayer, as much cathode material as possible is deposited as the squeegee sweeps across the screen. This leads to a variation in cathode thickness.
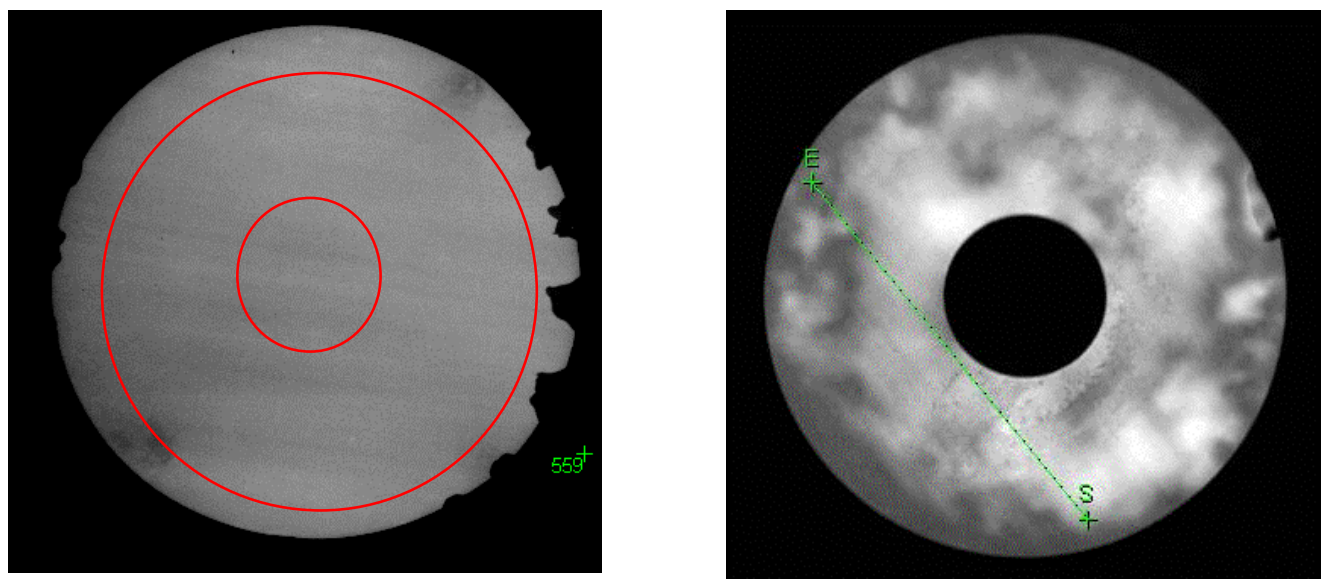

Figure 65. X-ray radiographs of NDE-S2 before (left) and after (right) cathode application. Two circles creating an annulus have been drawn on the fired bilayer image to give an approximate indication of where the cathode was deposited.

Beyond the variation in the thickness and/or material homogeneity in the cathode material, a significant amount of macroscopic pitting was also observed. This was something that translated into mud cracking of the cathode material after it was fired. This is best illustrated by the before (left) and after (right) cathode firing of sample NDE-S2 which is shown in Figure 66. The firing also served to amplify the appearance and structure of seemingly minor surface blemishes that were identified in the unfired cathodes. 

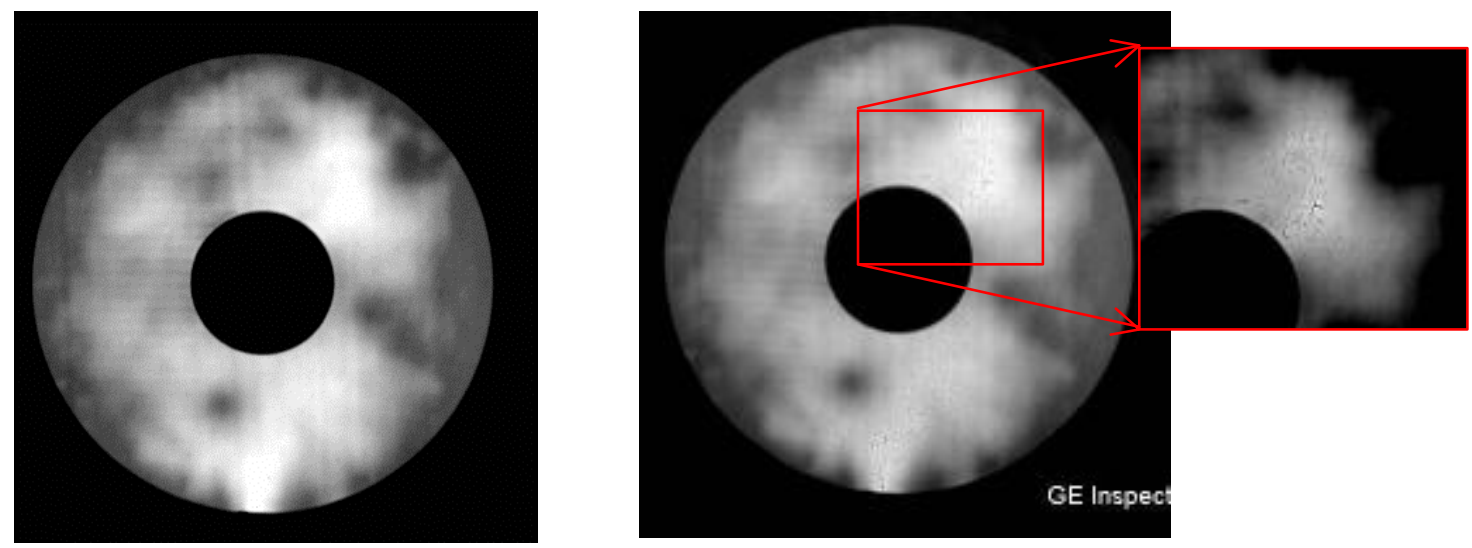

Figure 66. X-ray images of sample NDE-S2 before (left) and after (right) cathode firing.

Figure 67 show a digital photograph and an X-ray of the cell NDE-S5. The gray scale in the X-ray is optimized in order to see the bilayer. The higher density cathode is seen as a white annulus. Beyond the mud crack in the cell, there are also strong indications of erosion and pitting within the cathode material as well. Note the electrolyte layer that spalled off the substrate at the top of the cell (blue circle). The red arrow denotes the position of the crack. $k$. The right panel of Figure 67 shows a wide latitude radiograph of the sample. The red circle indicates a region where the electrolyte layer has spalled. This can be used to orientate the cell when comparing to previous images like that shown in Figure 64. Examples from both NDE-S2 and NDE-S5 are shown in Figure 68. While the blemishes can indeed be identified by careful scrutiny with the naked eye, radiography identifies these regions without any ambiguity. Furthermore, the digital images allow quantitative analysis to be done on these structures to determine their dimensions and depth of penetration. An example of this capability is shown for sample NDES2, where the plot in the center of Figure 68 illustrates the transmitted X-ray flux as a function of the pixel position denoted by the green line marked S-E. The intensity of the X-rays penetrating the position at the crack is an indication that the crack reaches a depth of nearly half of the cathode layer. 

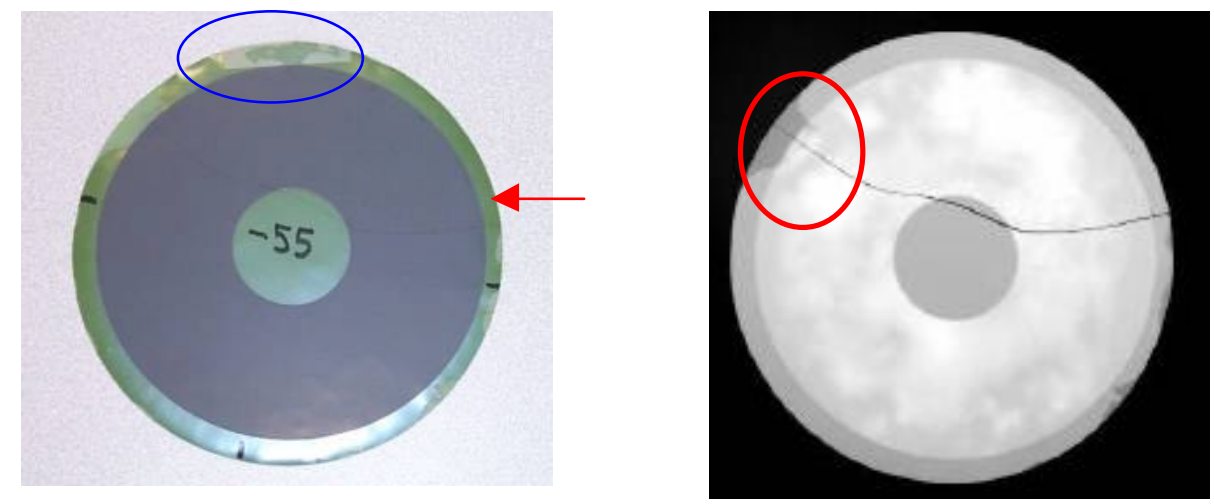

Figure 67. Photograph and wide latitude $X$-ray radiograph (right) of the sample NDE-S5 after the cathode has been fired.
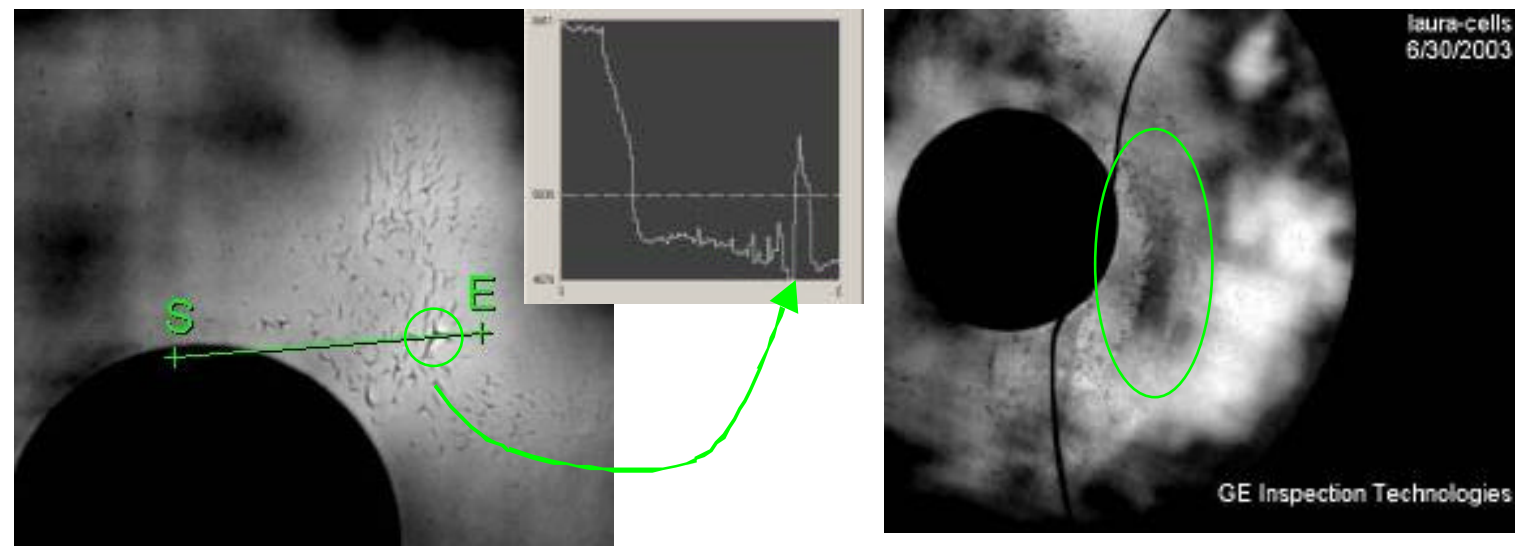

Figure 68. Radiographs of samples NDE-S2 (left) and NDE-S5 (right) are shown above.

Of the nine SOFC cells that went through NDE X-ray examination at each sequential step in the manufacturing process 4 were broken during the process leaving only 5 cells that could be tested. Three (S4, S7, and S9) of these five cells were performance tested in a single cell module.

The 3 cells were tested according to the same procedure, in the same test stand and with the same test operator. Polarization curves were taken for fixed flow, $50 \%$ fuel utilization, $60 \%$ fuel utilization, $70 \%$ fuel utilization, and an attempt was made at $80 \%$ fuel utilization. In general, cell S4 had the best performance and S9 had the worst performance with cell S7 performing in about the middle.

Figure 69 shows a fixed flow polarization curve for all 3 cells. This curve was taken with $64 \%$ hydrogen and the balance nitrogen with 2.5 times the amount of air. Cell S4 had a peak power density of approximately $0.38 \mathrm{~W} / \mathrm{cm} 2$ that was significantly higher than the other cells S7 and S9. 
Polarization Data Grouped for 3 Cells

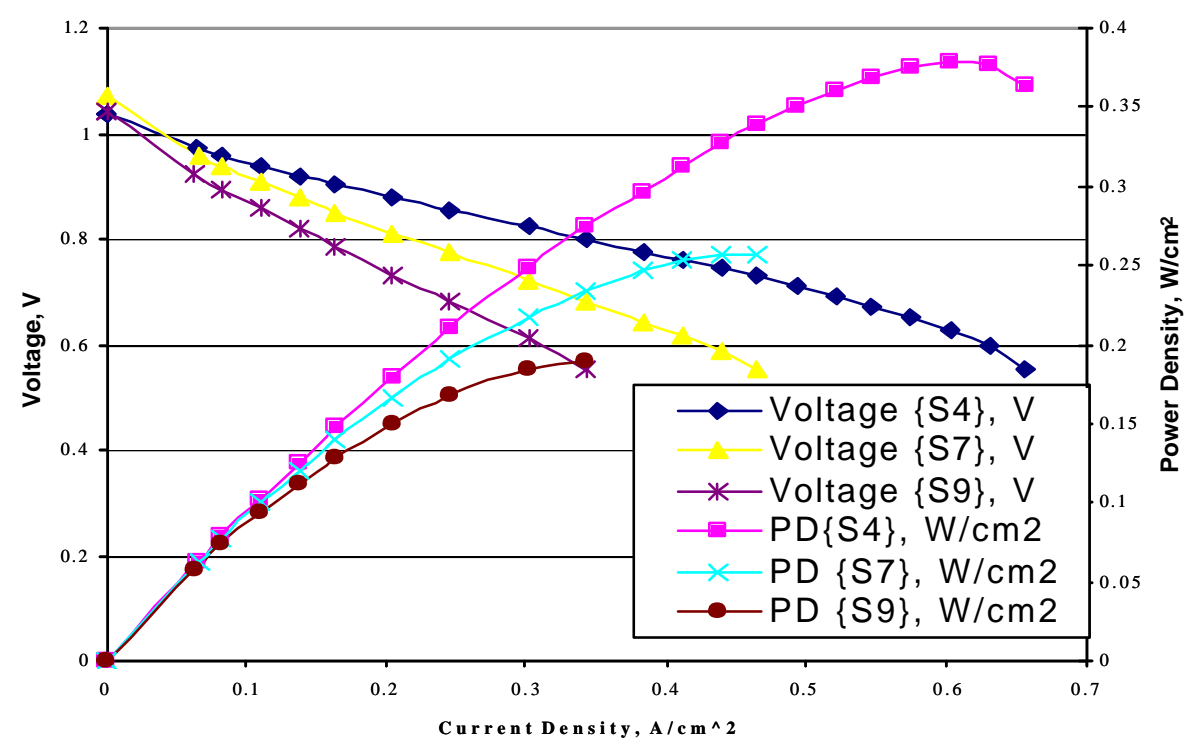

Figure 69. Fixed flow polarization curve for NDE cells S4, S7 and S9. Tests were performed with $64 \%$ hydrogen and balance nitrogen for fuel and at $800^{\circ} \mathrm{C}$.

Polarization curves were also taken at different fuel utilizations for the 3 cells. Figure 70 shows that the more data points were possible to take on S4 due to its performance over the other two cells. However, none of the cells were able to reach $80 \%$ fuel utilization and cell S9 was also not able to do $70 \%$ fuel utilization. 
Fuel Utilization-Voltage Data for 3 Cells

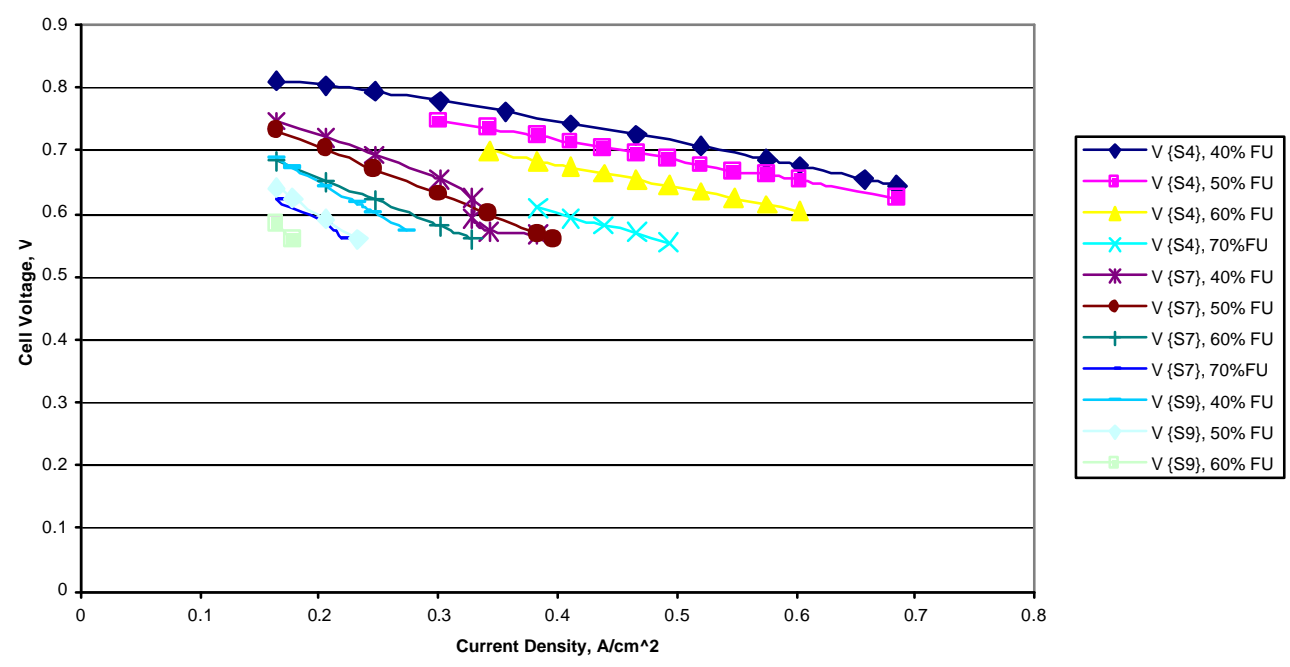

Figure 70. Polarization curves for 3 NDE cells S4, S7 and S9 under fixed fuel utilizations. All data was taken at $800^{\circ} \mathrm{C}$ under $64 \%$ hydrogen balance nitrogen for fuel and $20 \%$ air utilization.

Reviewing the NDE data and the identified flaws, an effort was made to correlate the performance with the observed defects. Cell S9 that had the lowest performance did have a human hair in the tape as well as a noted surface scratch in the bilayer tape. It was also observed that there was significant pitting in the fired bilayer with many low density defect areas in that cell. Cell S7 had an observed air bubble in the bilayer tape and an observed low density region in the central part of the cell. It also had significant pitting in the cathode as well as asymmetric cathode deposition. Cell S4 had some pinholes in the anode material and low density region after firing as well. The cathode material was asymmetrically distributed. The testing of these cells by themselves is inconclusive, more cells with observed defects need to be tested to make true correlations of the defects with performance.

In summary, several non-destructive imaging modalities including IR, UT, and X-ray, were evaluated for their capabilities in defect recognition in SOFC materials in various stages of manufacture. Using radiography, nine SOFC cells were followed through sequential stages of manufacture, from the bilayer tapes all the way to the fired cathodes on the bilayer substrate. Many different inhomogeneities were identified, characterized and cataloged. A summary of the flaws that were identified for the cells are listed in Table 18. The short acquisition time and high image fidelity showed that digital radiography was very well suited to screening, cataloging, and monitoring surface and structural defects that occur throughout the manufacturing phases of SOFC components. The level of detail has shown to be sufficient to identify defects and density in-homogeneities at the level 
of $200 \mu \mathrm{m}$ in a tape or cell. Furthermore, the digital data enables fast quantitative estimates of material thickness and scales of the in-homogeneities.

Table 18. Summary of Cells and Identified Flaws

\begin{tabular}{|c|c|c|c|}
\hline Sample & Final Process Step & $\begin{array}{l}\text { Inspection } \\
\text { Modality }\end{array}$ & Identified Flaw \\
\hline NDE-S1 & Bilayer Tape & X-ray & $\begin{array}{l}3 \text { air bubbles in tape; Uniform with slight } \\
\text { asymmetry in thickness from left to right }\end{array}$ \\
\hline NDE-S2 & Fired Cathode & X-ray & $\begin{array}{l}1 \text { small defect in tape; Two high density } \\
\text { regions near edge of anode. Flaking on cell } \\
\text { edges after firing anode. Asymmetric } \\
\text { deposition in cathode layer. }\end{array}$ \\
\hline NDE-S3 & Bilayer Tape & X-ray & $\begin{array}{l}\text { Triangular piece missing in tape; Non uniform } \\
\text { low density defects in central region of cell } \\
\text { (Cracked anode). }\end{array}$ \\
\hline NDE-S4 & Fired Cathode & X-ray & $\begin{array}{l}\text { White streak in tape; Pinholes } 800 \mu \mathrm{m} \text { wide } \\
\text { visible in anode. Central low density defect } \\
\text { after firing. Asymmetric cathode thickness } \\
\text { map. }\end{array}$ \\
\hline NDE-S5 & Fired Cathode & X-ray & $\begin{array}{l}\text { Stuck to box memory, } 3 \text { air bubbles, and } \\
\text { surface scratch in tape; Compression defect } \\
\text { with slightly higher density visible in anode. } \\
\text { Flaking on cell edges after firing anode. } \\
\text { Strong pitting in cathode was evident. } \\
\text { Asymmetric cathode thickness. Evidence of } \\
\text { substrate crack after firing. }\end{array}$ \\
\hline NDE-S6 & Fired Cathode & $X$-ray & $\begin{array}{l}7 \text { air bubble and dark streak in tape; Non } \\
\text { uniformities visible as both high and low } \\
\text { density point structures in anode. } \\
\text { Concentration of broad high density structure } \\
\text { in central region. Depletion of material } \\
\text { around edges. Strongly asymmetric cathode } \\
\text { deposition. }\end{array}$ \\
\hline NDE-S7 & Fired Cathode & X-ray & $\begin{array}{l}1 \text { air bubble and dark streak in tape; Uniform } \\
\text { except for central low density defect in anode. } \\
\text { Strong pitting in cathode was evident. } \\
\text { Strongly asymmetric cathode deposition. }\end{array}$ \\
\hline NDE-S8 & Bilayer Tape & $X$-ray & $\begin{array}{l}2 \text { dark streaks in tape; Pinholes visible in } \\
\text { central region of anode. }\end{array}$ \\
\hline NDE-S9 & Fired Cathode & X-ray & $\begin{array}{l}2 \text { white spots, human hair, and surface } \\
\text { scratch in tape. Pitting gives rise to multitude } \\
\text { of low density defects in anode. }\end{array}$ \\
\hline
\end{tabular}




\subsubsection{Interconnect Fabrication Process}

Earlier, in Table 24, the potential process capability gaps that could exist between component fabrication and assembly operations were identified. This section describes these potential processes and gaps for interconnect fabrication and describes the work done in establishing analytical and experimental means to determine these manufacturing process capabilities, requirements and gaps, and the data generated in the following areas.

(1) Formability of metallic interconnects and current collectors

(2) Flatness of metallic interconnects and current collectors

(3) Methods to assemble metallic interconnects, cell support sheet

Detailed process capability assessments were conducted using the following approaches:

Paper studies:

- Survey of industrial mass production lines: Consumer appliances and high performance heat exchangers

- Consultation with industrial experts

Analytical:

- Stack and component level stress analyses

- Finite element simulations

Experimental:

- Component level fabrication and testing

- Fabrication of prototype interconnect components

- Assembly of prototype interconnect components

- Testing of interconnect components

In addition to theoretical and experimental determination of process capability, a sheet metal interconnect was manufactured by manufacturing methods similar to those intended for use in a mass production environment. The interconnect pan was stamped, and assembled by laser welding. A glass-sealed tape calendered cell was tested for performance using this interconnect. The results are summarized under the section titled performance testing.

\subsubsection{Formability of sheet metal interconnects}

It is widely accepted that sheet metal stamping is one of the lowest cost methods to mass-produce SOFC interconnects. The types and dimensions of features that may be desired to be formed using sheet metal stamping will be 
determined by the functional requirements of the interconnect, such as flow distribution, current collection and cell mechanical support. However, the ductility and formability of the metal used will place limits on the dimensions of the features that can be stamped in it. The mechanical properties that are critical for determination of feature formability limits through finite element simulations are:

- Young's modulus

- Poisson's ratio

- Yield strength

- Plastic strain hardening exponent

- Plastic strain ratio

- Maximum uniform plastic elongation $\left(e_{u n i f}\right)$

- Forming limit curves

\section{Sheet tension experiments}

A commercially available ferritic stainless steel alloy was chosen as the candidate material for experiments and analysis. Rolled sheets of thickness 0.0255 " and 0.005 " were available for testing. Uniaxial tensile testing was done to determine elastic-plastic properties. For each thickness, 3 samples were tested along the rolling direction, and 3 along the transverse direction. The specimens were prepared by water jet cutting in the case of the thicker stock, and wire electrodischarge machining in the case of the thinner stock. Typical stress strains for rolling and transverse directions are shown in Figure 71. The results are summarized in Table 19.

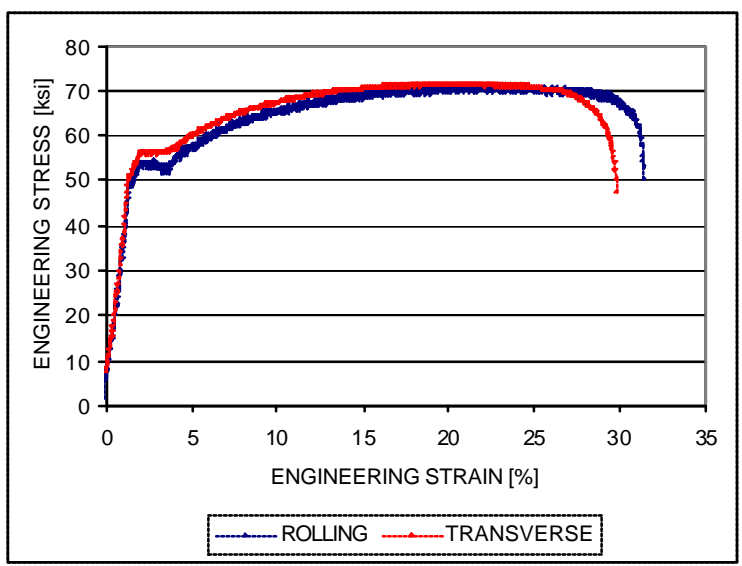

Figure 71 . Engineering stress strain curves from 0.025 " thick stainless sheets. 
Table 19. Summary of Tensile Tests on Stainless Steel Sheets.

\begin{tabular}{|c|c|c|c|}
\hline Sample & $s_{y}(k s i)$ & $e_{\text {unif }}(\%)$ & $N$ \\
\hline Rolling & 51.8 & 20.24 & 0.24 \\
\hline Transverse & 54.1 & 18.64 & 0.22 \\
\hline
\end{tabular}

\section{Forming limit curves}

When sheet metal is being stamped, it is undergoing in-plane biaxial stretching at each location. The deformation state at each location in the blank can be represented in terms of the major and minor strains, i.e. principal strains. The forming limit curve (FLC) of a material is a graph of the allowable amounts of major and minor strains during sheet forming and provides information about how much a particular metal can be stretched before necking or fracture occurs. The necking strains are obtained under a variety of biaxial forming conditions so that most of the practical stamping conditions are duplicated. It is used by die designers, metallurgists, and other engineers as both a design and diagnostic tool.

Forming limit curves for 0.0255 " thick stainless steel were generated by Hitchcock Manthey LLC, Inc. (Troy, NY). Forty-four samples as per the dimensions in Figure 72 were prepared by waterjet cutting. Samples before testing are shown in Figure 73. A $2 \mathrm{~mm}$ square grid pattern was applied to each of these samples by electrochemical etching. Each of these samples was then formed by using a $100 \mathrm{~mm}$ diameter hemispherical punch close to the point of failure. Surface strains near the necked regions are measured. Grids that have not undergone necking or failure are used to identify safe strains. Necked and safe data points are collected and are compiled by the ASAME (Automated Strain Analysis and Measurement Environment) program and used to produce the forming limit curve - the curve which is located above all safe strains and below all near necking strains. 

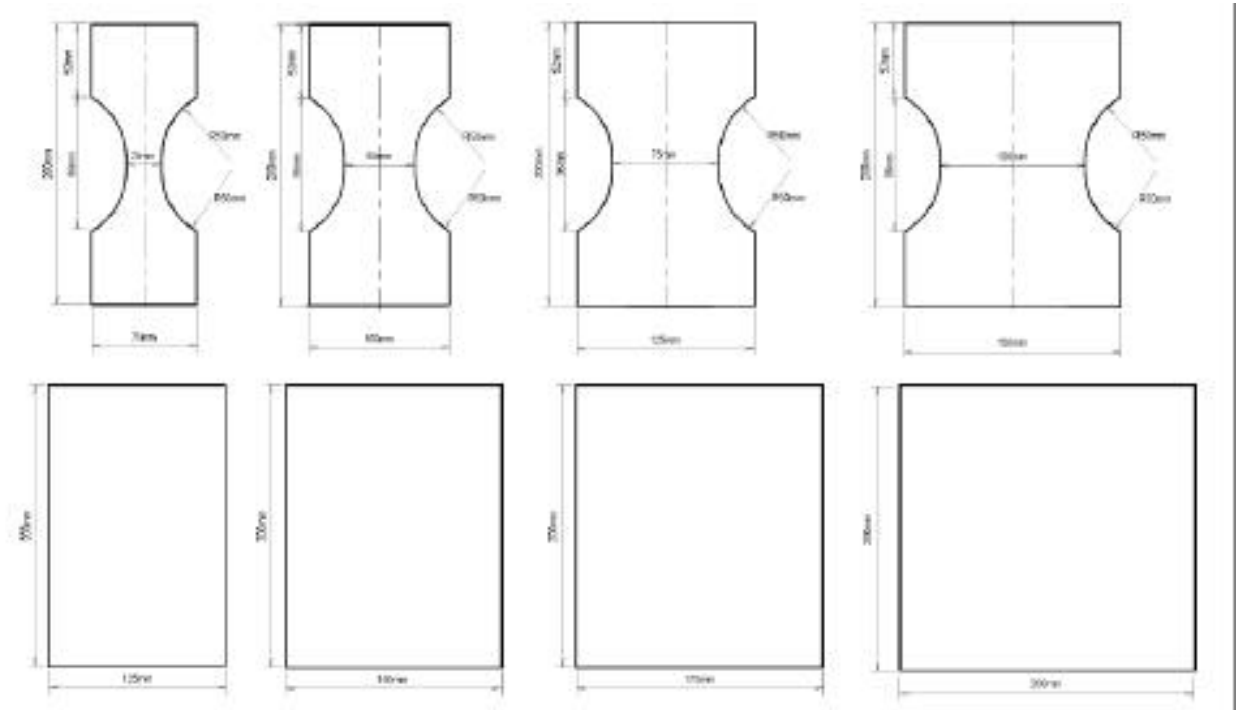

Figure 72. Sample dimensions used for forming limit curve generation.

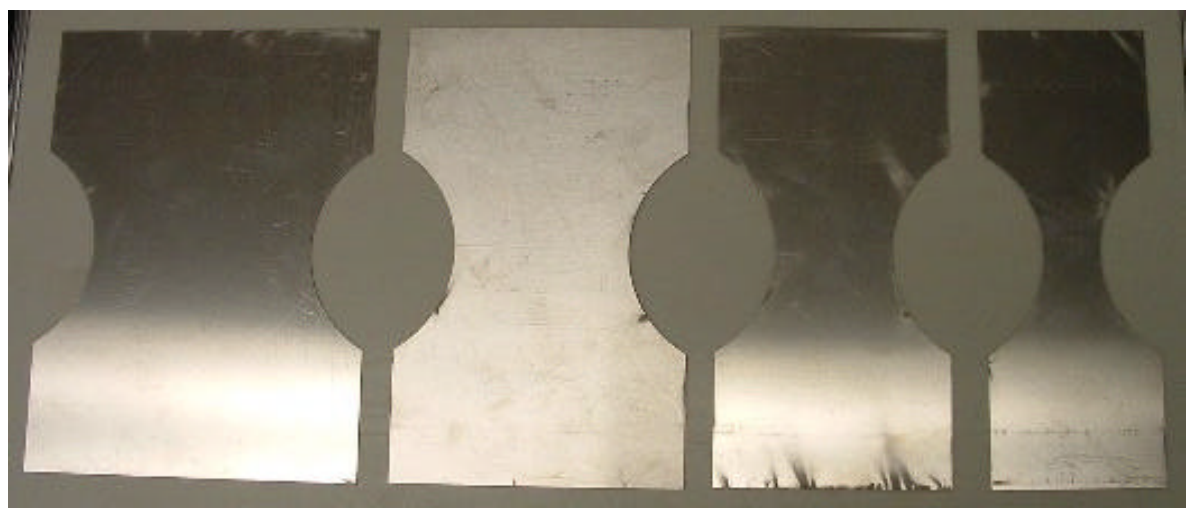

Figure 73. Samples prior to testing.

Figure 74 below is a summary of all the strain measurements conducted during the 44 tests. The strain values at which necking or failure was observed are shown in green. The forming limit line for necking lies just below this set of points. A second line is drawn below the necking limit line considering a safety factor of 8$10 \%$ major strain units. While failure doesn't occur for strains in marginal zone, by definition, normal process variations will drift the process and cause periodic failures at this site. 


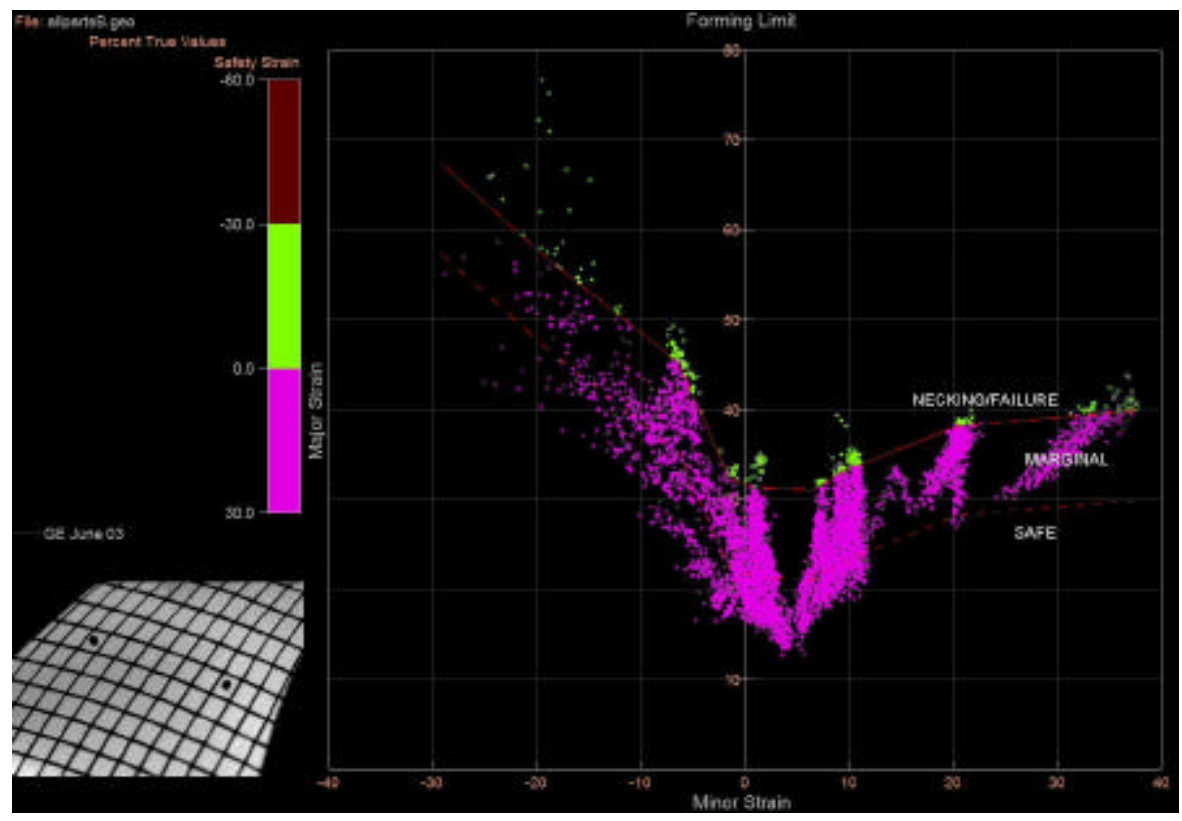

Figure 74. Limiting strains measured on $0.025 "$ thick stainless steel.

The forming limit curve for 0.025 " thick stock was then translated to forming limit curves for thicknesses of 0.005 " and 0.010 " using a shift factor FLD calculated using standardized procedures for stainless steels. The graph shown in Figure 75 below shows the variation (shift) of forming deformation limit $\left(F L D_{0}\right)$ with sheet thickness and yield strength for constant values of strain hardening exponent (n). 


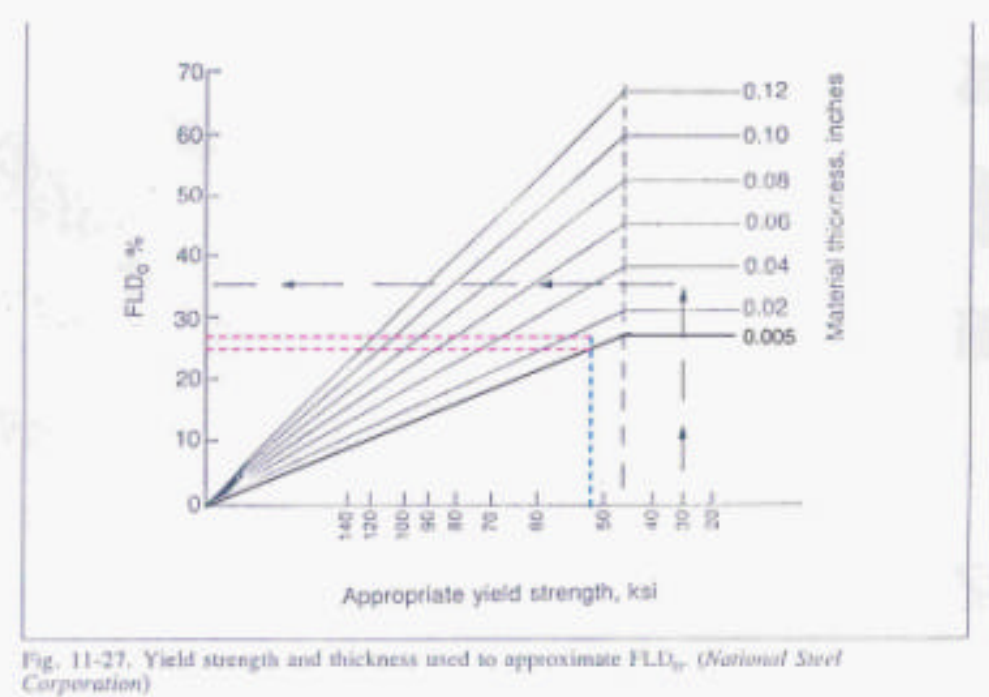

Figure 75. Method to shift forming limit curves between various sheet thicknesses.

Figure 76 (a), (b) and (c) provide the forming limit curves for all three thicknesses that were used in simulations. The allowable strains decrease with material thickness.
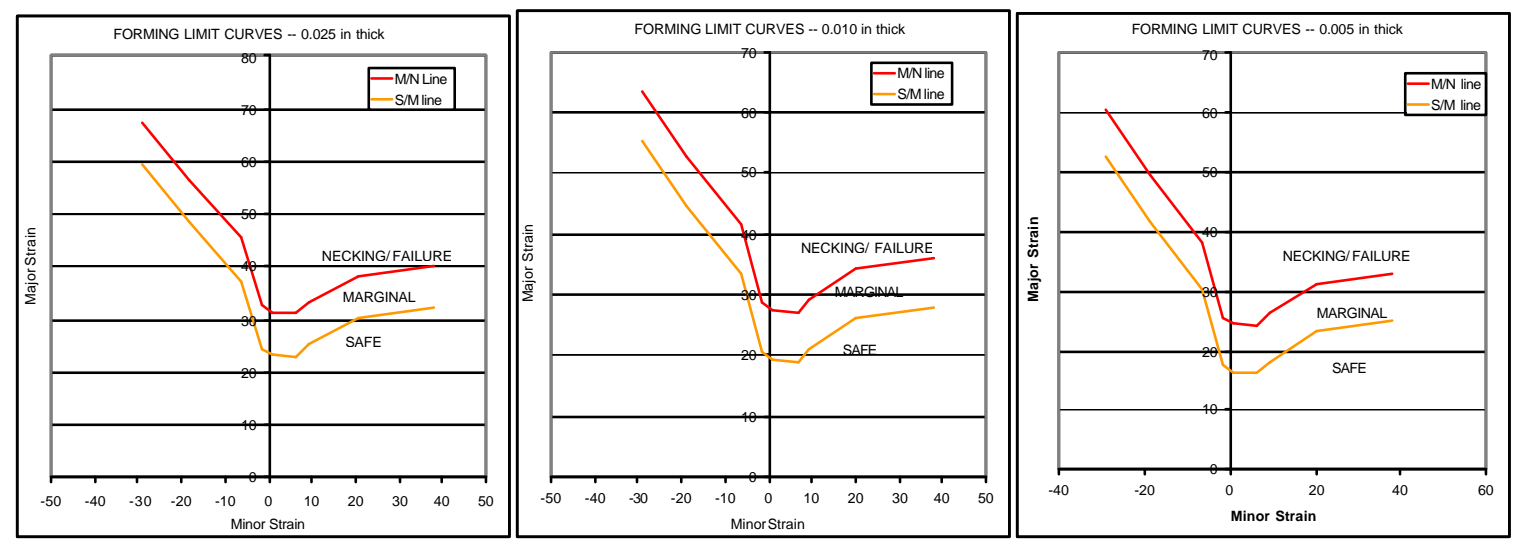

Figure 76. Forming limit curves for (a) 0.025 " thick stock; (b) 0.010 " thick stock; (c) 0.005 " thick stock.

\section{Finite element analysis of typical interconnect features}

Some of the typical features that may be required in an SOFC interconnect are shown in Figure 77 and Figure 78 . Figure 77 describes the typical corner shapes that may be encountered in the designs. In the present work, finite element DE-AC26-00NT40705 
analyses have been performed using ABAQUS and LS-DYNA packages to determine relations between $R_{\text {ROOT, }} R_{\text {OUTSIDE, }} R_{\text {INSIDE, draw depth and sheet }}$ thickness.

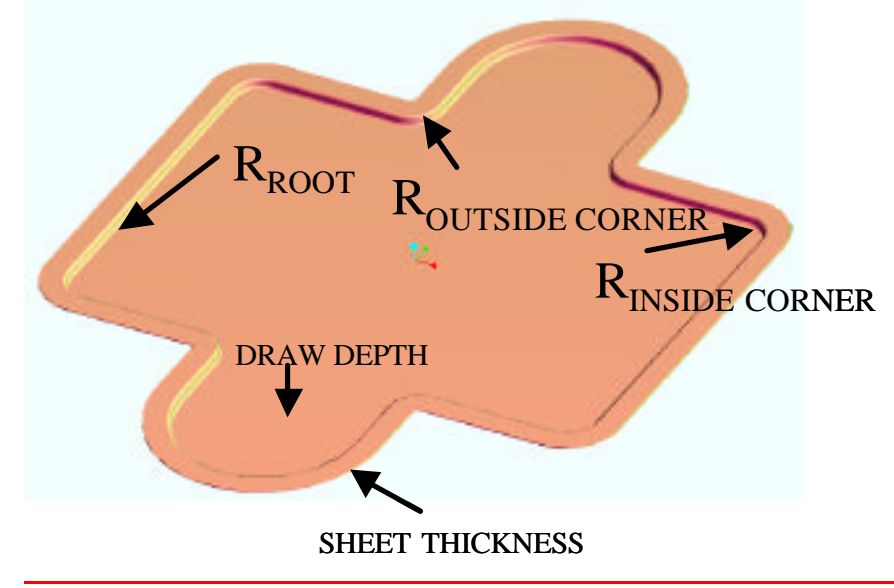

Figure 77. Typical corner dimensions that may pose limits on stamped interconnect design.

In Figure 78 are indicated some of the typical flow guide features. The surfaces of these features also function as current collectors from the fuel cell. Analysis will be performed on these features in the future as design details get defined through performance analysis.
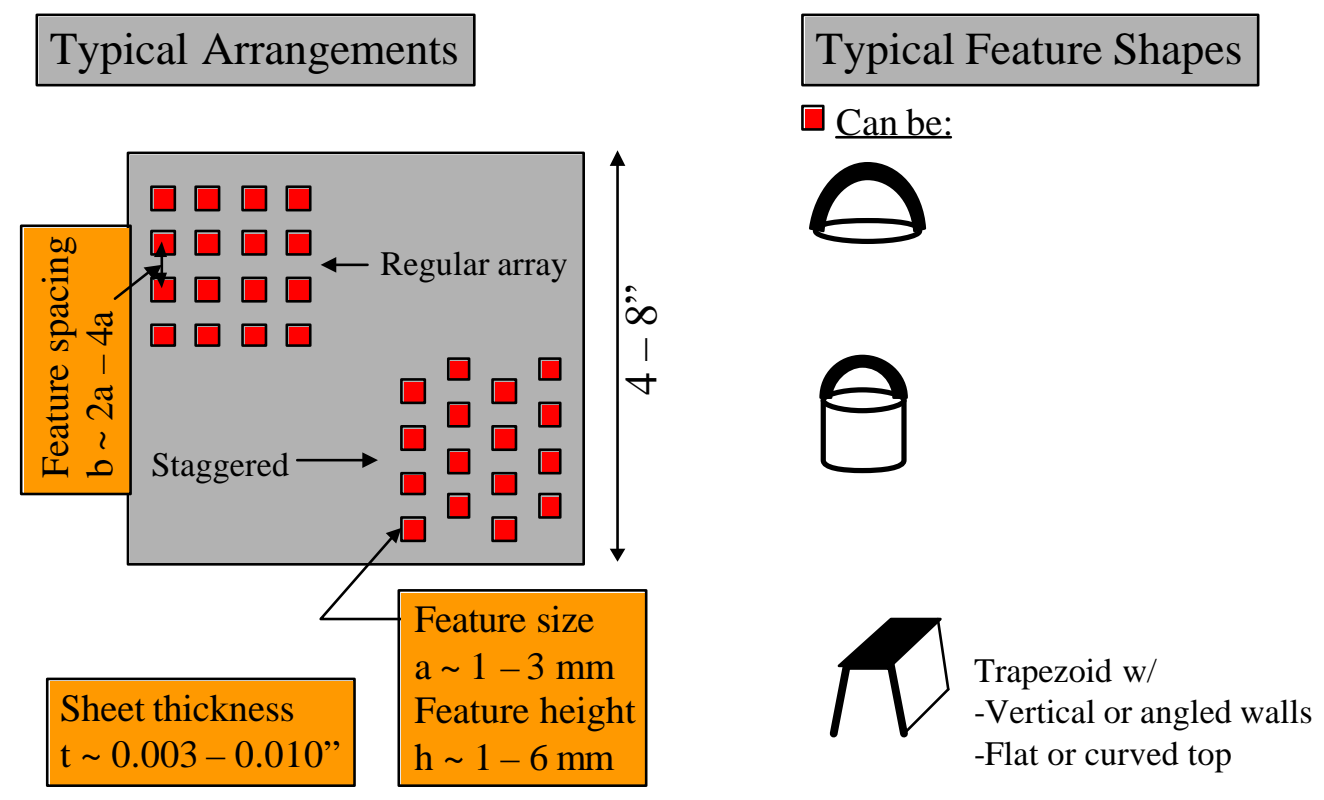

Figure 78. Flow/current collector features that may be stamped in sheet metal interconnects. 
Simulations were conducted for sheets of three thicknesses -0.005 ", 0.010 " and $0.025 "$. RROOT limits were determined using a full factorial DOE (design of experiments) of 2-D axisymmetric simulations in ABAQUS/Standard package. The DOE points are listed in Table 20. Figure 79 shows typical strain contours from the simulations.

Table 20. DOE for $\mathrm{R}_{\mathrm{ROOT}}$ Determination.

\begin{tabular}{|c|c|}
\hline Thickness (inches) & $\mathbf{R}_{\text {ROOT }}$ Thickness \\
\hline 0.005 & 1 \\
\hline 0.010 & 2 \\
\hline 0.025 & 4 \\
\hline
\end{tabular}
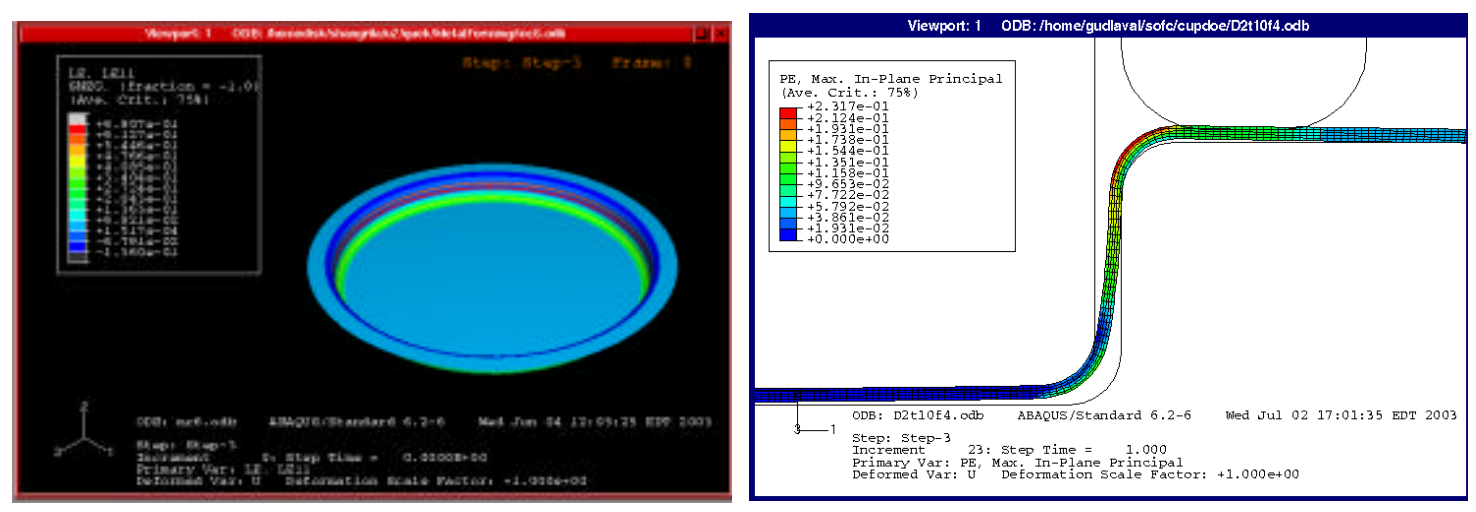

Figure 79. Axisymmetric finite element simulations for determination of $\mathrm{R}_{\mathrm{ROOT}}$

The safe strain limits under uniaxial tension as dictated by the forming limit curves in Figure 76 are approximately $16 \%$ for 0.005 " thickness, $19 \%$ for 0.010 " thickness and $24 \%$ for 0.025 " thickness. Figure 80 shows the major strains predicted for various root radii at draw depths of $1 \mathrm{~mm}$ and $2 \mathrm{~mm}$. The results indicate that for thinner stock of 0.005 " and 0.010 ", R ROOT of at least 4 times thickness is required to achieve $1-2 \mathrm{~mm}$ draw depth. Thicker stock experiences smaller strains at the same draw depths. 

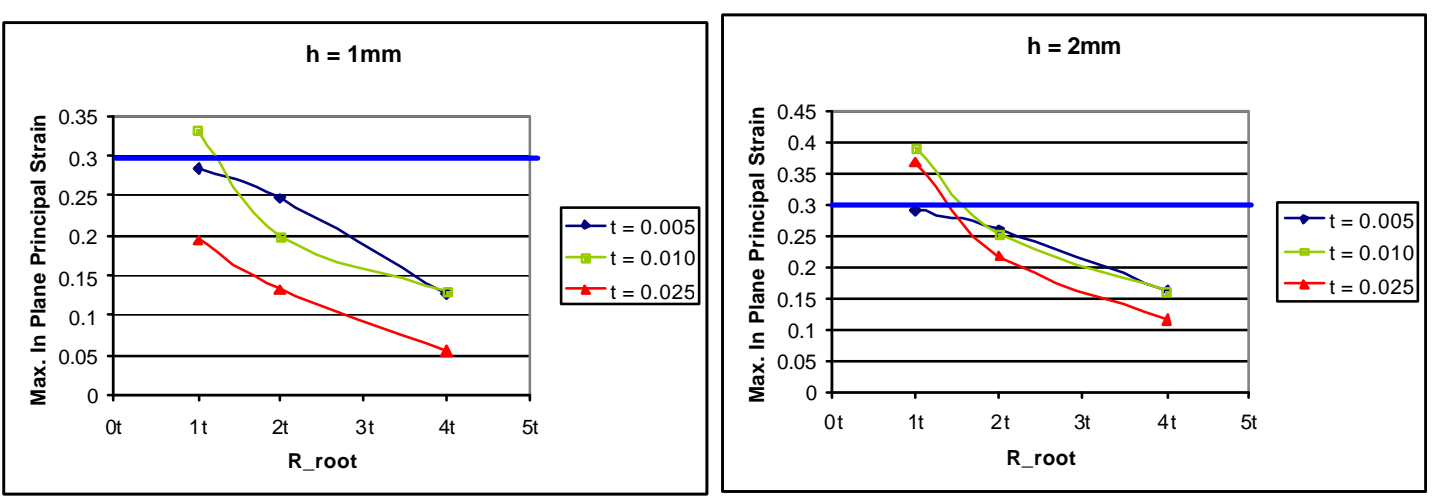

Figure 80. Calculated major strains for (a) draw depth of $1 \mathrm{~mm}$ and (b) draw depth of $2 \mathrm{~mm}$.

The next set of simulations was performed to calculate the maximum allowable draw depth for various inside and outside corner radii, as indicated in Figure 77 . Here, $\mathrm{R}_{\mathrm{ROOT}}=6^{*}$ thickness was used in order to avoid limitations due to that dimension. The DOE for inside/outside corner limits is given in Table 21.

Table 21. Inside/Outside Corner Radius DOE

\begin{tabular}{|c|c|c|c|c|}
\hline Sheat Thickness (t) & Comer radius( Rc) & Wall inclination(Theta degree) & Punch radius(Rp) & Die radius ( Rd) \\
\hline 0.025 & $10 \mathrm{t}$ & 15 & 51 & 61 \\
\hline 0.010 & $10 t$ & 15 & 61 & 61 \\
\hline 0.005 & $30 \mathrm{t}$ & 15 & 더 & 5i \\
\hline 0.005 & $20 \mathrm{t}$ & 15 & 61 & 6 \\
\hline 0.010 & 30t & 15 & 81 & 61 \\
\hline 0.010 & $20 \mathrm{t}$ & 15 & 61 & 61 \\
\hline 0.025 & $20 \mathrm{t}$ & 15 & 61 & 61 \\
\hline 0.005 & $10 \mathrm{t}$ & 15 & ET & $5 t$ \\
\hline 0.025 & $30 \mathrm{t}$ & 15 & 61 & 61 \\
\hline
\end{tabular}

For each DOE simulation point the peak major and minor strains were plotted on the forming limit diagrams. The results are shown in the graphs below. For 0.025" material (Figure 81) the plots show that corner radius of even 10t is acceptable. For 0.010 " thick stainless steel the plots (Figure 82) show that corner radius of at least $30 \mathrm{t}$ is recommended. 

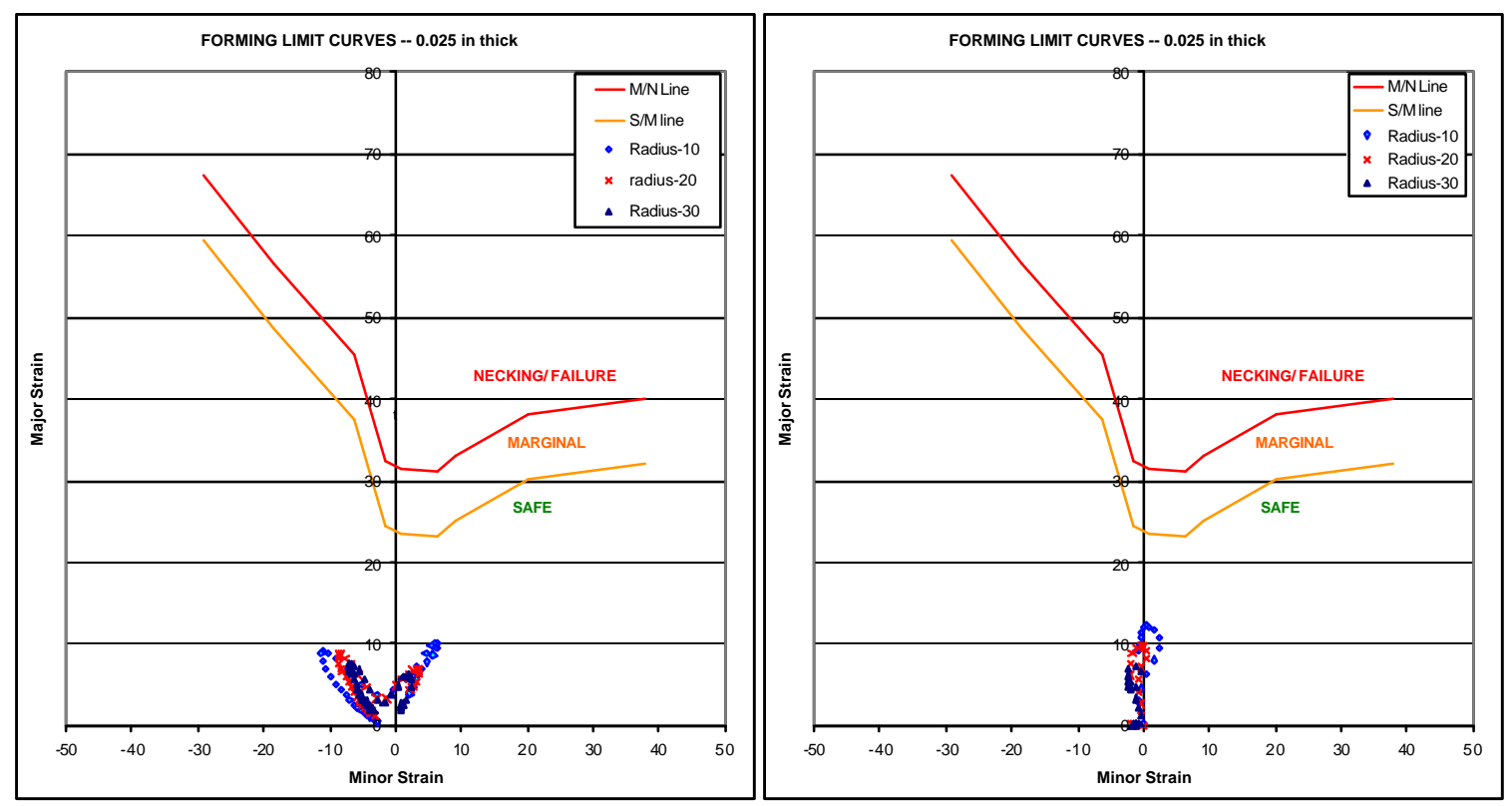

Figure 81. Forming limit diagrams of strains in inside (left) and outside (right) corners for 0.025 " sheet. Draw depth $=0.250$ ".
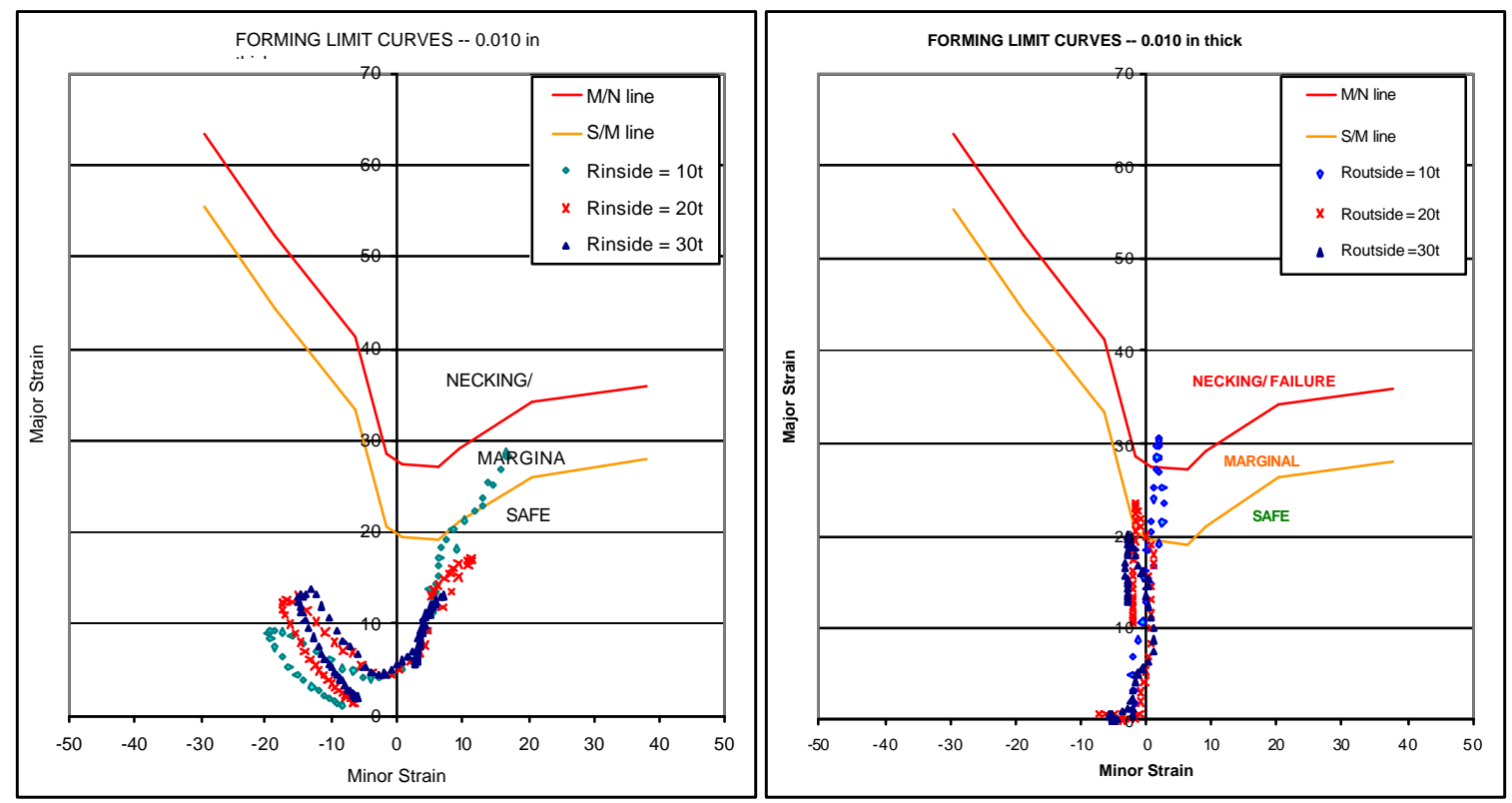

Figure 82. Forming limit diagrams of strains in inside (left) and outside (right) corners for 0.010 " sheet. For Draw depth $=0.250$ ".

The simulations for 0.005 " thick stainless steel showed severe wrinkling at draw depths of much less than 0.200 ". The deformed plot for a corner radius of $10 x$ 
sheet thickness is shown below (Figure 83). The image shows severe wrinkling and even cracking in some regions. From the simulations it was determined that the maximum depth:

at $10 \mathrm{t}$ was $0.074 "$

at $20 \mathrm{t}$ was $0.100 "$

at 30 t was $0.120 "$.

It is hence recommended that careful analysis be performed before designing complex features in 0.005 " thick stainless steel.

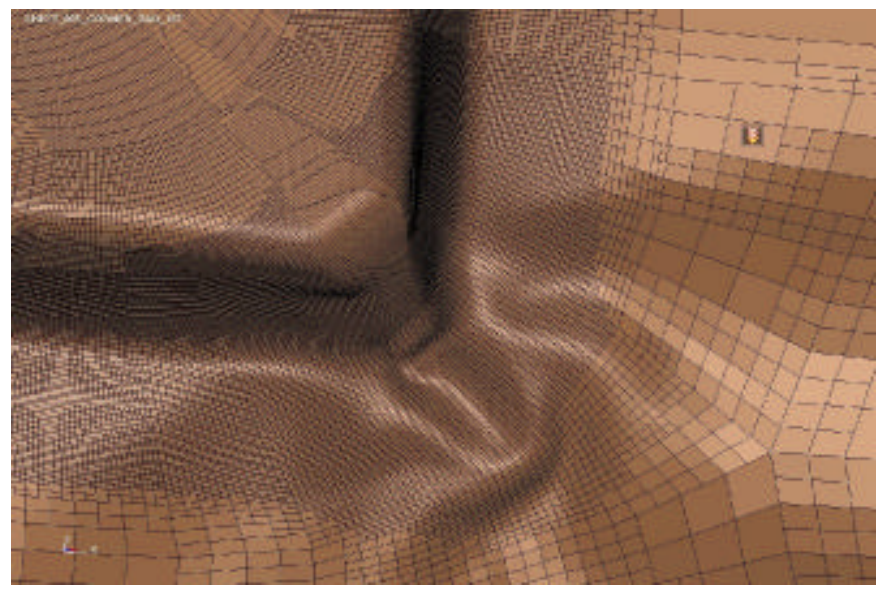

Figure 83. Deformed element plot for forming of 0.005 " thick stock into a corner with radius of $0.050 "$.

A summary of the metal forming analysis work is listed below:

- Formability parameters of a stainless steel materials have been determined experimentally. Maximum uniaxial strain with uniform elongation is approximately $19 \%$.

- For draw depths of 0.079 " or more, minimum punch fillet radius ("RROOT") of at least $4 \mathrm{t}$ (4 times thickness) is recommended. For material thinner than 0.010 ", fillet radius of $6 t-10 t$ is recommended

- Results of in-plane corner radius simulations for a draw depth of 0.250 " recommend the following minimum radii:

- Sheet thickness $=5$ mil $\Rightarrow>$ Minimum in-plane radius $=$ unable to determine. Draw depths were limited to 0.100 " with an in-plane radius that is greater 0.100 "

- Sheet thickness $=10$ mil $\Rightarrow>$ Minimum in-plane radius $=0.300 "$ 
- Sheet thickness $=25$ mil $\Rightarrow>$ Minimum in-plane radius $=0.250 "$

\section{Experimental Test Vehicles}

Two types of experimental test vehicles were designed and fabricated to ascertain and demonstrate process capabilities. These were a 1.5" diameter stamped "cup" (shown in Figure 84 and Figure 85) and a 6" diameter prototype interconnect (shown in Figure 86). The designs and goals of each of these are outlined below.

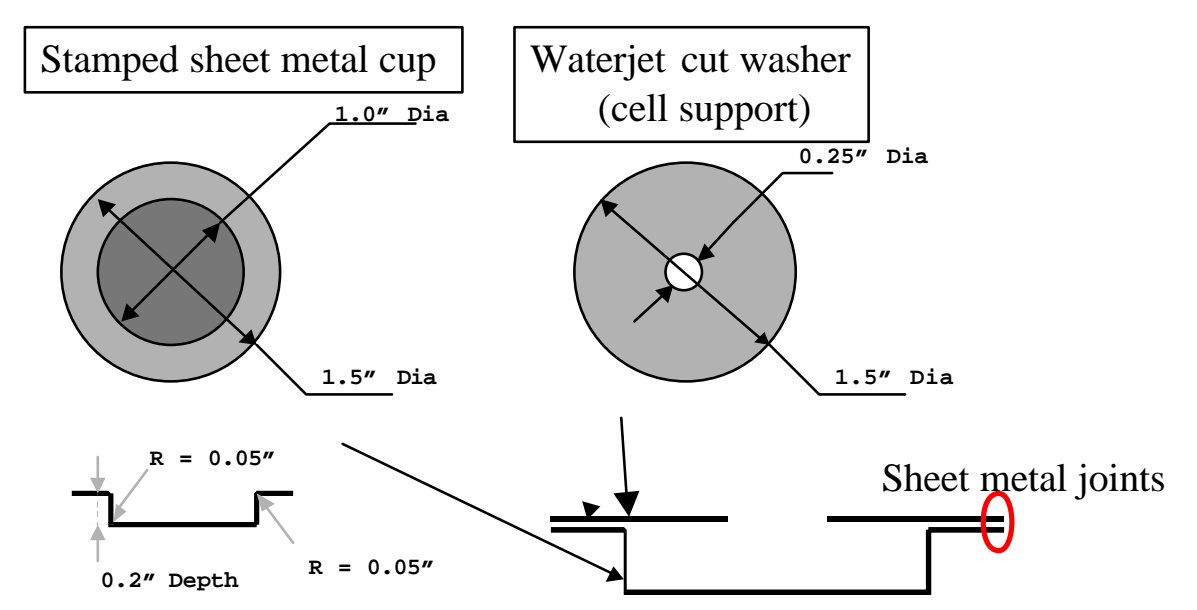

Figure 84 . Schematic of the 1.5" stamped cup test vehicle.

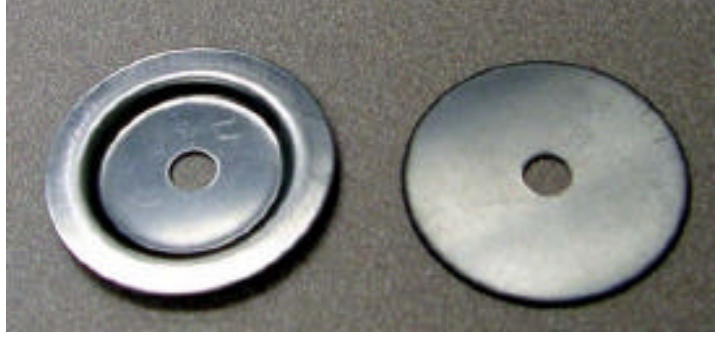

Figure 85. Photograph of a 1.5 " stamped cup test vehicle, 0.025 " thick metal sheet.

The applications of this test vehicle were:

- Determination of stamping flatness variability

- Demonstration of sheet metal joining processes

- Determination of interactions of sheet metal joining and cell sealing 
The manufacturing experiences from the 1.5" stamped cup and analyses were used in the construction of a 6 " prototype interconnect that was then used to conduct electrochemical testing on 4" circular tape calendared cells. The components are shown below:

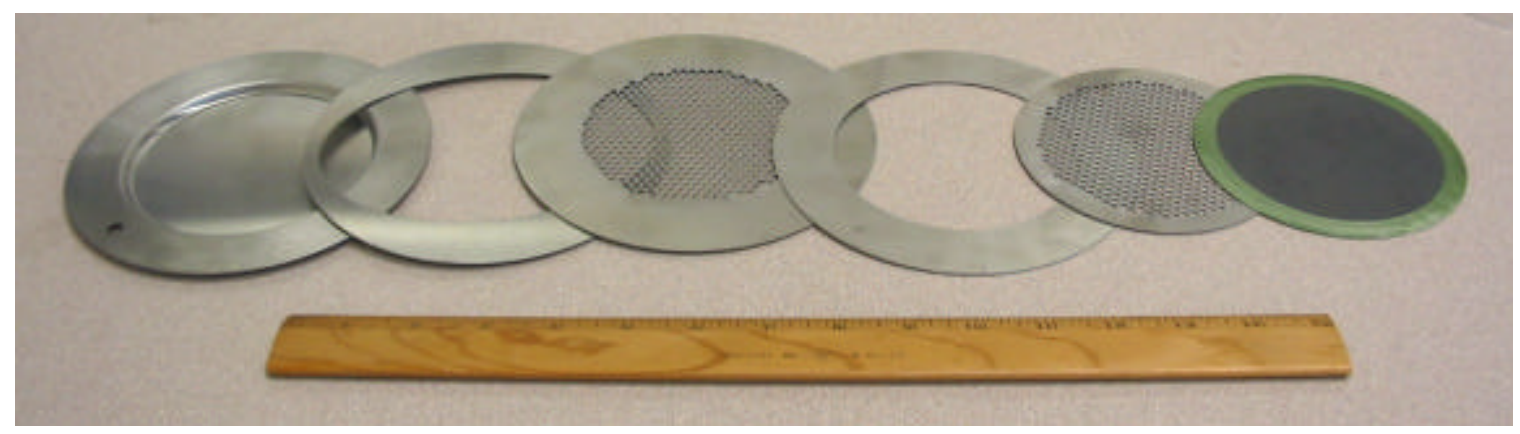

Figure 86. Components of 6 " test vehicle, from left to right: Stamped interconnect "pan"; manifold spacer sheet; anode current collector perforated sheet; cathode current collector support sheet; cathode current collector perforated sheet; 4" tape calendared cell

\subsubsection{Flatness and Variability in Sheet Metal Interconnects}

The interconnect mates with the cell in at least two regions where uniform contact is critical. One is in the active area, where the interconnect collects current from the cell electrodes. The other is around the perimeter of the cell, where an appropriate sealant is applied to bond the cell to the cell support portion of the interconnect. Lack of flatness may arise due to the following reasons:

- Variation in material thickness: For sheet thicknesses $>0.020$ ", expect variation of up to +0.003 "

- Elastic spring back: When a sheet is stamped, part of its deformation is elastic; the recovery of this portion of deformation is called springback

- Tool and die wear

- Tool - blank friction

- Material hardness state 
Lack of flatness may be either local, or global, as shown in the figure below.

(a)

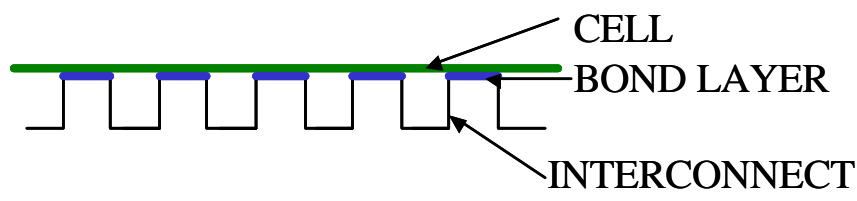

(b)

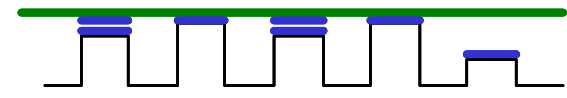

(c)

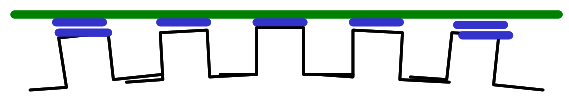

Figure 87. Schematic representation of interconnect non-flatness. (a) Ideal situation; cell and interconnect are flat. (b) Local non-uniformity in current collector surface (c) Global curvature in current collector. Contact resistance varies with bond paste thickness and contact pressure.

\section{Flatness of Current Collection Region}

The current collector - electrode interface is a contact between rigid surfaces. A paste-like, initially compliant, sinterable bonding layer is typically applied to fill the gaps between the rigid mating surfaces. In order to assess manufacturing capability of stamping repeating contact features in a current collector, a prototype array of dimples was stamped in a $115 \mathrm{~mm}$ square sheet of 0.005 " thick stainless steel. The dimples were $3.5 \mathrm{~mm}$ in diameter, and the spacing between them was $4 \mathrm{~mm}$. The depth of each dimple was approximately $0.5 \mathrm{~mm}$. Figure 88 below shows a photograph of the dimpled sheet. The main observation was that the residual stresses of stamping resulted in significant warpage of the sheet. The difference in height between the center and the corners was as much as $3 \mathrm{~mm}$. 


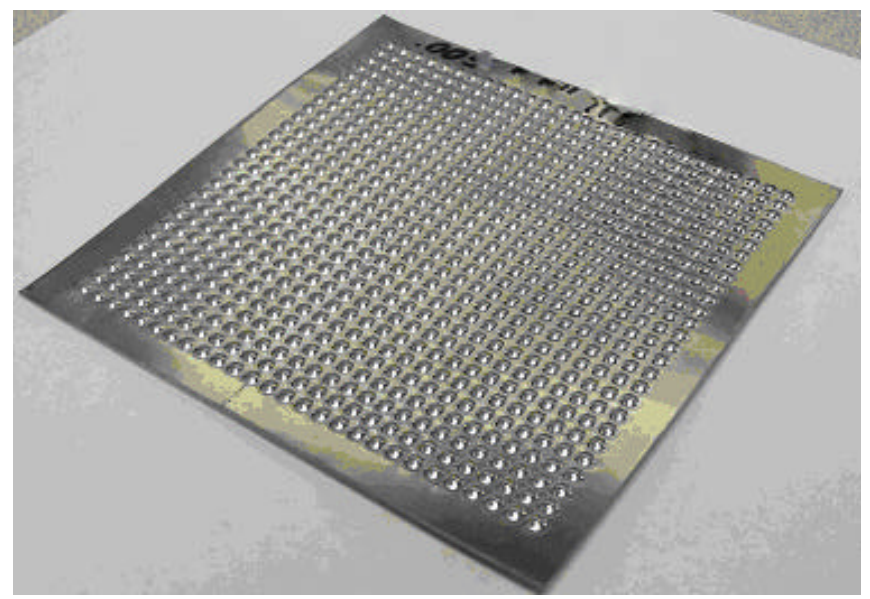

Figure 88. $115 \mathrm{~mm}(4.53 ")$ square sheet of $0.127 \mathrm{~mm}(0.005 ")$ thick stainless steel sheet was stamped with an array of dimples. Dimple diameter $=3.5 \mathrm{~mm}$ $(0.138 ") ;$ spacing $=4 \mathrm{~mm}(0.154 ") ;$ height $=0.5 \mathrm{~mm}$ (0.197")

Flatness measurements were also performed on the 6" test vehicle, just after stamping and after metal joining (brazing, laser welding). Analysis of variance techniques were used to isolate lack of flatness due to spring back (which can be mitigated by appropriate die design), and lack of flatness due to other variations (material thickness, properties, die friction, etc.). The regions measured are indicated in the figure below:

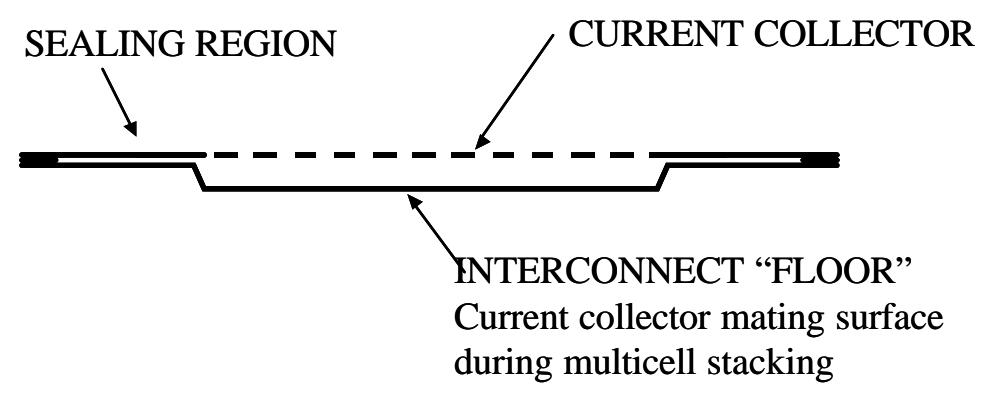

Figure 89. Flatness measurements on prototype interconnect.

Flatness was measured along the diameter of "floor" regions of several 6" interconnects. Shown below in Figure 90 are height profiles measured on four different interconnect samples. 
CURVATURE OF INTERCONNECT "FLOOR" REGIONS

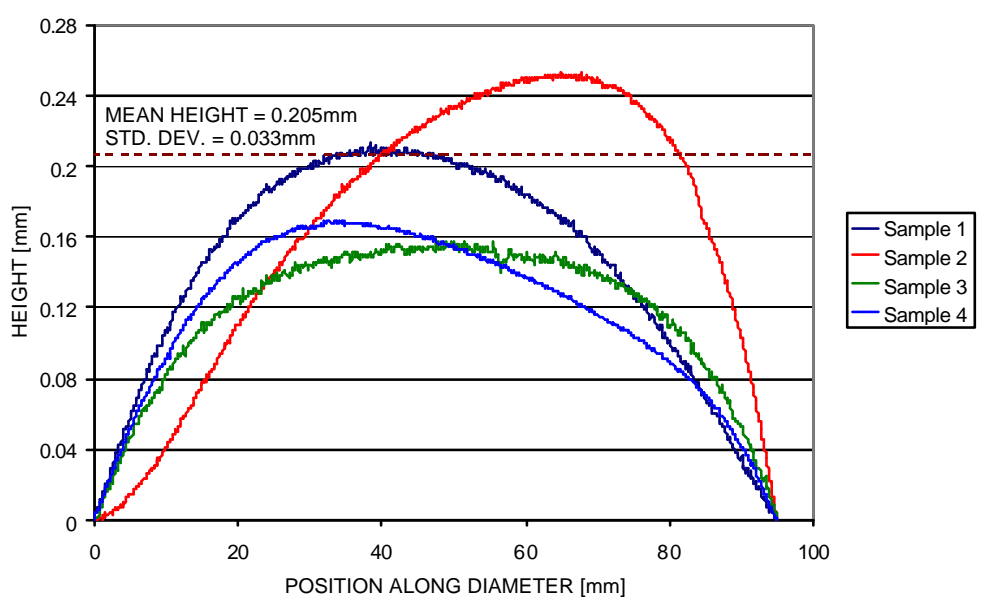

Figure 90. Height profiles for four 6" interconnects.

The variance in spring back in the simple, axisymmetric geometry was found to be $0.033 \mathrm{~mm}$. In a stamped interconnect with a complex array of current collection features, more significant spring back as well as variability may be expected.

\section{Flatness of Seal Seating Region}

Elastic-plastic springback analysis was conducted on the cup drawing simulations shown in Figure 79. For draw depths of 0.200 ", typical levels of spring back of up to 0.004" were predicted for the geometries analyzed (shown in the figure below).

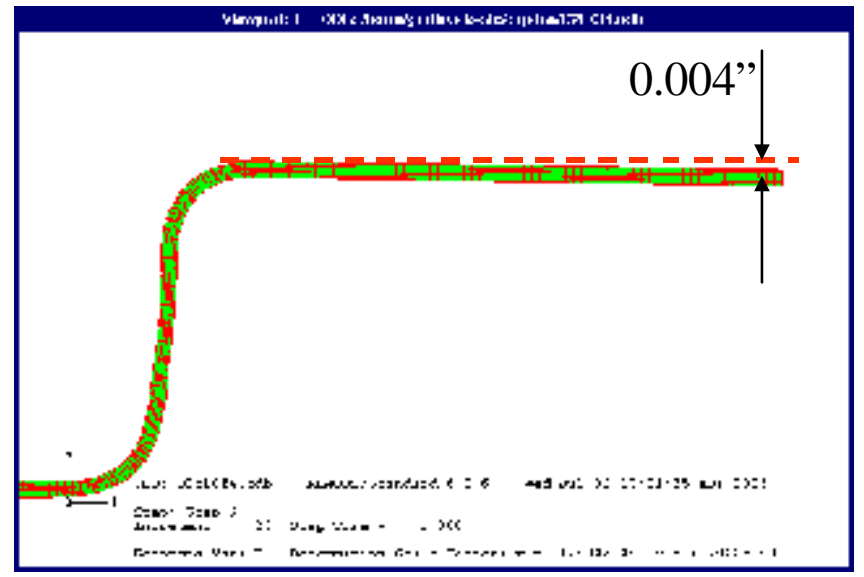

Figure 91. Spring back simulation in cup drawing of a 2" ID cup, to a depth of 0.2 ". 
Flatness measurements of the 1.5" stamped cups (draw depth $=0.200$ ") showed a mean spring back of $0.044 \mathrm{~mm}$. Standard deviation measured from five parts was found to be $0.013 \mathrm{~mm}$. A schematic is shown in the figure below.

\section{$0.044 \mathrm{~mm}(\mathrm{SD} 0.013 \mathrm{~mm})$}

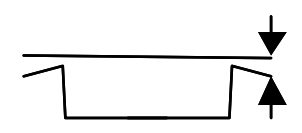

Figure 92. Springback in 1.5 " cups

Flatness measurements on seal regions stamped 6" interconnects showed less than 0.001 " variation in surface height.

The simulations presented here address local elastic springback, which can be at least partially accounted for by appropriate die design. The axisymmetric nature of the 1.5" cups and 6" interconnects allows for easy mitigation of springback. However, in stamping large complex parts global spring back variations of at least 0.010 " -0.020 " over a 6 " distance are expected, as is seen in benchmark capability data from the consumer appliance industry

For geometries with more complex features and sharper in-plane radii such as those shown in Figure 77, more significant spring back is expected. More detailed analyses of specific designs are recommended.

Another source of lack of flatness is thermal deformation during the metal joining processes of interconnect assembly. In the case of the 6" interconnects, significant curvature has been observed on the current collector surface of the cathode interconnect due to improper heat sinking during laser welding.

\subsubsection{Metallic Interconnect Assembly Methods}

This section deals with the various metal joining methods may be used in assembling the subcomponents of metallic interconnects. Survey and testing was geared towards examining several sheet metal joining methods, and several sheet metal joint configurations. Edge and lap weld studies were conducted on 0.005 " and 0.025 " thick stainless steel foils, using laser and e-beam welding techniques. The goals of this study were to provide preliminary answers to the following questions

- What is the heat input for various sheet metal joining processes. This affects

i. Penetration

ii. Distortion 
iii. Joint strength

- What part preparation is required for each process

i. Part cleaning

ii. Clamping: allowable gap between sheets to be welded

iii. Alignment requirements

- What joint quality can be expected

i. Joint strength (depending on stresses applied during operation of fuel cell)

ii. Hermeticity

iii. Effect of thermal cycling

- What is the effect of welding process on the presence of a fuel cell pre-sealed to the interconnect

i. Proximity of fusion zone

ii. Stresses arising from clamping

Also investigated in this effort was the interaction between glass seals used to seal cell to cell support and metal joining processes to attach cell support to the rest of the interconnect. This information is critical to some of the assembly sequences described previously. The various sheet metal microjoining processes considered were:

- Laser welding

- Electron beam welding

- Micro TIG welding

- Plasma-arc welding

- Resistance projection welding

A comparative assessment of these techniques is given in the table below. It must be noted that the ratios indicated in comparison are merely qualitative. Actual values will depend on the actual parameters required to weld similar samples. Some results are reported for certain joining processes listed in Table 22. 
Table 22. Comparitive Assessment of Sheet Metal Joining Processes

\begin{tabular}{|c|c|c|c|c|c|}
\hline & $\begin{array}{c}\text { Laser } \\
\text { welding }\end{array}$ & $\begin{array}{l}\text { E-beam } \\
\text { welding }\end{array}$ & $\begin{array}{c}\text { MicroTIG } \\
\text { welding }\end{array}$ & $\begin{array}{l}\text { Plasma- } \\
\text { Arc } \\
\text { welding }\end{array}$ & $\begin{array}{l}\text { Resistance- } \\
\text { Projection }\end{array}$ \\
\hline $\begin{array}{l}\text { Energy } \\
\text { input }\end{array}$ & $\begin{array}{c}1 x \\
50-100 w\end{array}$ & $\begin{array}{c}<1 x \\
50-100 w\end{array}$ & $\sim 3 \mathrm{X}$ & $\sim 2 \mathrm{x}$ & $<1 x$ \\
\hline $\begin{array}{l}\text { Typical spot } \\
\text { sizes }\end{array}$ & $\begin{array}{c}1 \mathrm{x} \\
0.010 \sim \\
0.020 ”\end{array}$ & $\begin{array}{c}<1 \mathrm{X} \\
0.010 \sim \\
0.020 "\end{array}$ & $\begin{array}{c}\sim 3 \mathrm{x} \\
>0.050 "\end{array}$ & $\begin{array}{c}\sim 2 \mathrm{x} \\
0.010 \sim \\
0.020 "\end{array}$ & - \\
\hline $\begin{array}{l}\text { Penetration } \\
\text { (depth/width } \\
\text { ratio) }\end{array}$ & 1x & $>1 x$ & $<1 x$ & $\sim 1 \mathrm{x}$ & $<1 x$ \\
\hline Feed rates & $1 x$ & $1 \mathrm{x}$ & $<x / 3$ & $<1 x$ & $>1 x$ \\
\hline $\begin{array}{l}\text { Tolerance to } \\
\text { part non- } \\
\text { flatness }\end{array}$ & $\begin{array}{c}\mathbf{1 x} \\
\text { Beam } \\
\text { doesn't } \\
\text { automatically } \\
\text { track target }\end{array}$ & $>1 x$ & $>1 x$ & $>1 x$ & $\begin{array}{c}>>1 \mathrm{x} \\
\text { Mechanical } \\
\text { load is } \\
\text { applied }\end{array}$ \\
\hline Capital cost & $1 x$ & $1 x$ & $<x / 3$ & $<1 x$ & - \\
\hline Maintenance & $1 x$ & $1 x$ & $\mathbf{1 x}$ & $>1 x$ & $<1 x$ \\
\hline
\end{tabular}

Resistance projection welding is a non-beam joining process most useful in lap welding of sheet metal components. Since it does not depend on access of an electrode/beam to the joint target, it is useful in accomplishing blind joints. This is a process wherein a small projection is made in one of the surfaces to be welded, and the two surfaces to be welded are held together under load and high potential difference. A large current flows instantaneously through the limited contact region, thus fusing it and forming a localized weld nugget. Once fusion occurs, the contact region increases, reducing current density, thus terminating further growth of the weld nugget. It is also possible to conduct projection resistance welding at higher contact pressures to obtain a solid-state weld, which has a finer grain size and is thus stronger. The figure below describes typical dimensions involved in projection welding:

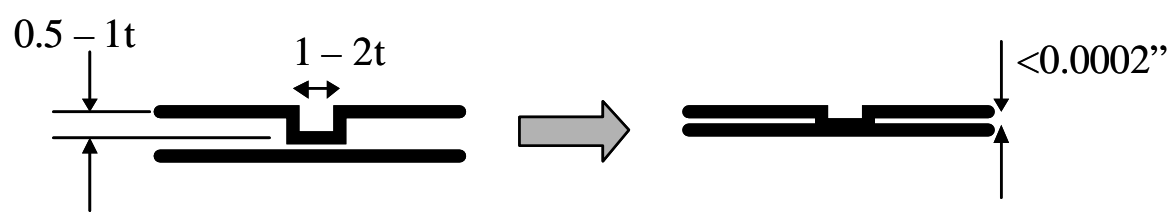

Figure 93. Resistance projection welding process schematic. 
Using the 1.5" stamped cups shown in Figure 84, edge and lap welds were performed using laser and e-beam methods. A summary of weld parameters used is provided in Table 23 below. Sample names in each cell are given according to the process used joint design used. For example, "LE" is a Laser - Edge weld. The prefix T- indicates welds on thin (0.005") stock.

Table 23. Desgin of Experiment on Sheet Metal Weld Configurations

\begin{tabular}{|c|c|c|}
\hline & Laser weld & E-beam weld \\
\hline Edge weld: $0.025 "$ & $\begin{array}{l}\text { Spot size: } 0.008 ” \\
\text { Feed rate: } 1.9 \mathrm{in} / \mathrm{s} \\
\text { Power: } 0.516 \mathrm{~J} / \text { pulse }\end{array}$ & $\begin{array}{l}\text { Spot size: } 0.008 ” \\
\text { Feed rate: } 1.6 \mathrm{in} / \mathrm{s} \\
\text { Power: } 120 \mathrm{kV}\end{array}$ \\
\hline Lap weld: $0.025 "$ & $\begin{array}{l}\text { Spot size: } 0.016 " \\
\text { Feed rate: } 0.55 \mathrm{in} / \mathrm{s} \\
\text { Power: } 4.85 \mathrm{~J} / \mathrm{pulse}\end{array}$ & $\begin{array}{l}\text { Spot size: } 0.008 ” \\
\text { Feed rate: } 1.3 \mathrm{in} / \mathrm{s} \\
\text { Power: } 140 \mathrm{kV}\end{array}$ \\
\hline Edge weld: $0.005^{\prime \prime}$ & $\begin{array}{l}\text { Spot size: } 0.008 ” \\
\text { Feed rate: } 1.9 \mathrm{in} / \mathrm{s} \\
\text { Power: } 0.108 \mathrm{~J} / \text { pulse }\end{array}$ & $\begin{array}{l}\text { Spot size: N/A } \\
\text { Feed rate: N/A } \\
\text { Power: N/A }\end{array}$ \\
\hline
\end{tabular}

Cross sections of each weld were prepared and imaged in order to determine weld depth of penetration. These images are shown in the Figure 94 Figure 101 below.

Laser edge welding (small spot) of two 0.025 " thick sheets as done and a micrograph of a cross section is shown in Figure 94 . A spot size of 0.008 " was used, which resulted in a total fusion zone about 0.008 " deep, with an undercut of about 0.002 ". The width of weld as seen in the micrograph is about 0.014 ". 


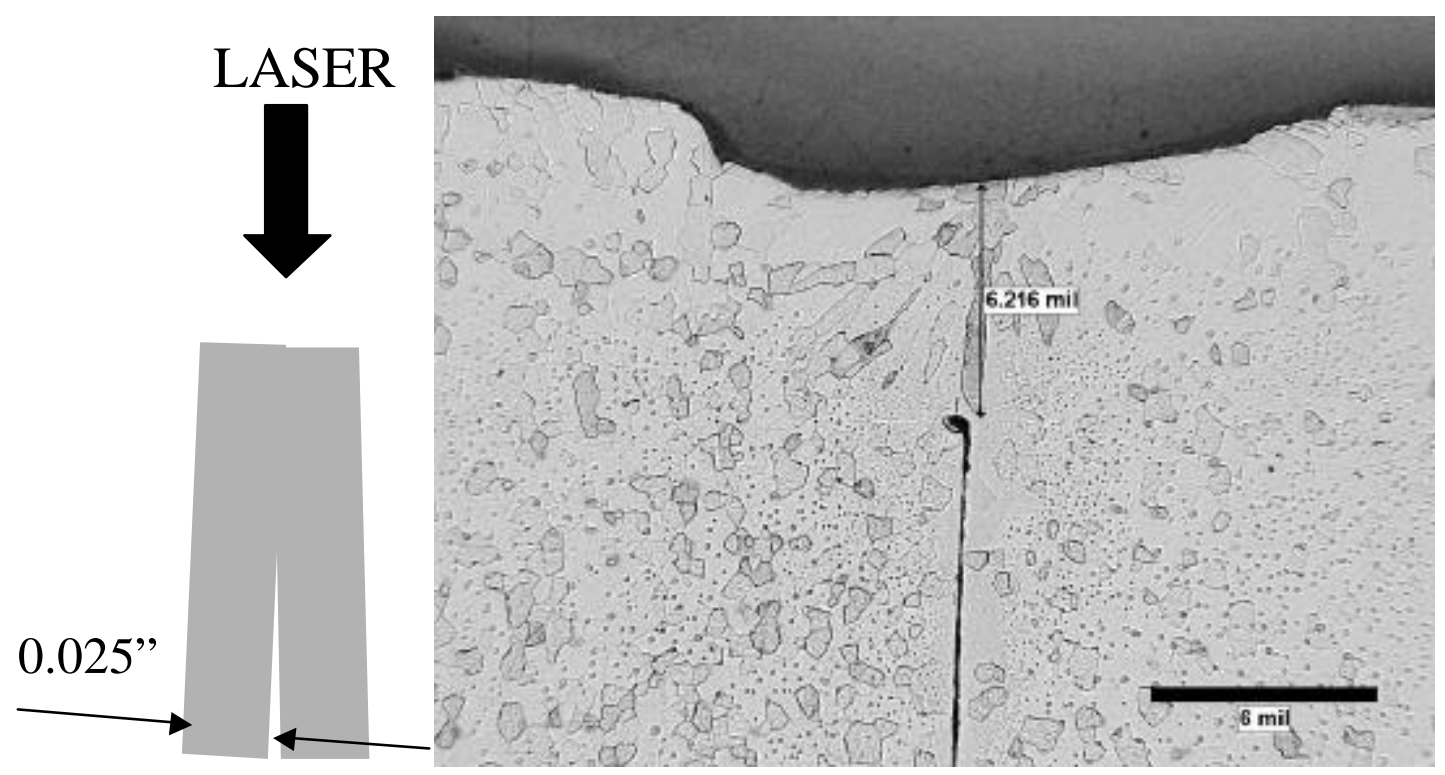

Figure 94. Laser edge weld (small spot) of two 0.025 " thick sheets.

The spot size was increased in order to try and get a deeper weld. The cross section is shown in Figure 95. It is clear that with the larger spot and same laser power, larger weld width is obtained, but penetration has not changed significantly.

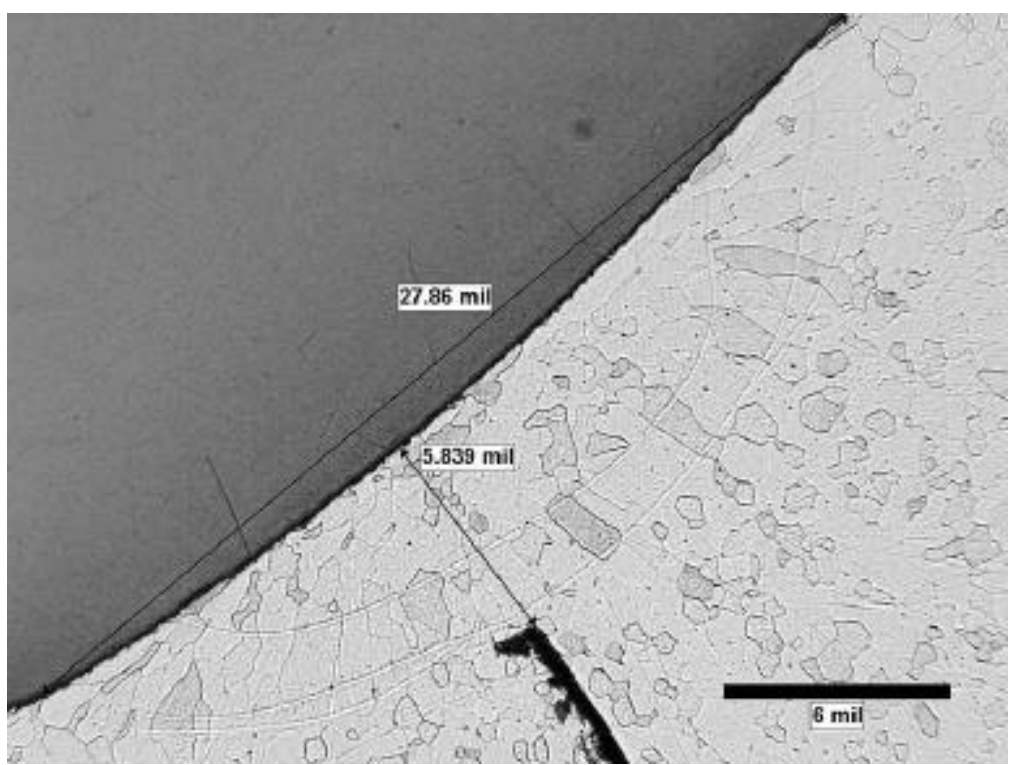

Figure 95. Laser edge weld (large spot).

A laser lap weld of two 0.025 " thick sheets was also done and a micrograph of a cross section is shown in Figure 96. A power of $4.85 \mathrm{~J} /$ pulse had to be used, 
which led to higher penetration and larger weld width. However, full penetration was not achieved because of excessive gap between mating surfaces.

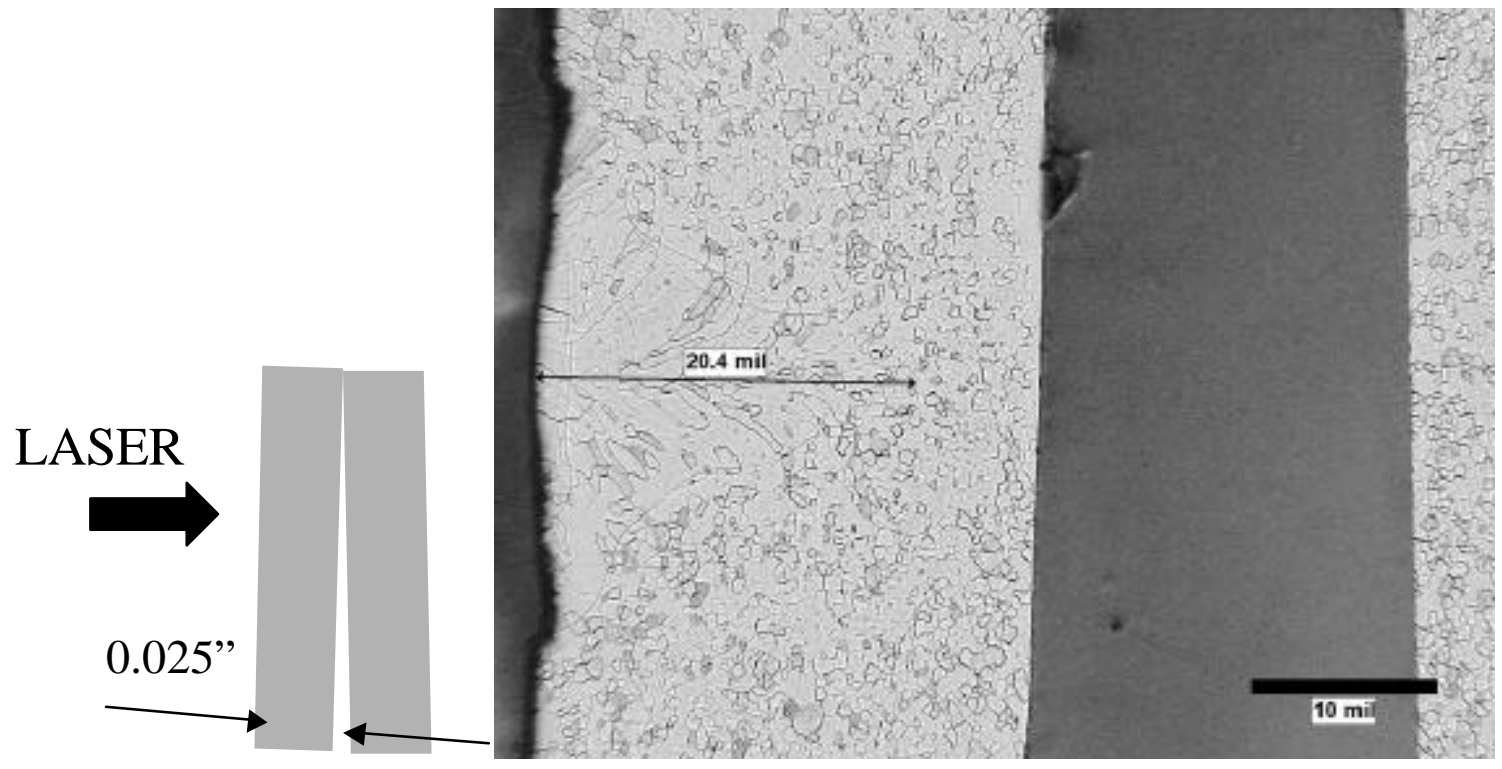

Figure 96. Laser lap weld of two 0.025 " thick sheets.

In another laser lap welded sample with the same power settings, a smaller part gap was present, which helped achieve full penetration. A cross section is shown in Figure 97. The same power setting as in the previous case was used the gap between mating surfaces was much smaller. Further process development is required for achieving reliable lap welds. 


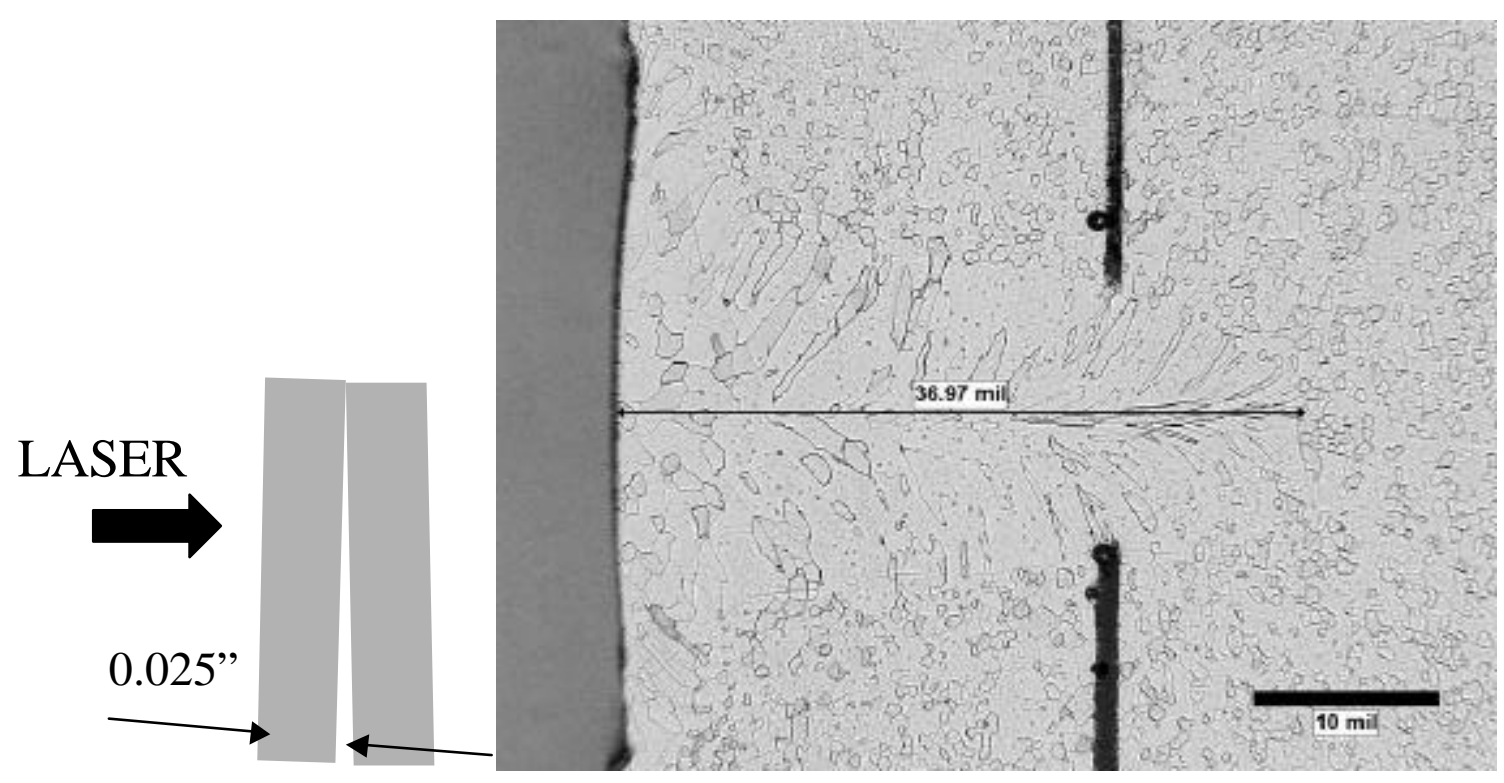

Figure 97. Laser lap weld of two 0.025 " thick sheets that resulted in a full penetration through the first sheet.

Laser edge welding of 0.005 " thick stock was also performed and a cross section if presented in Figure 98. The spot size and feed rate were the same as that used for edge welding of 0.025 " thick sheets whereas the power level was about $20 \%$ only. The fusion zone extends across the full face of the target edge, without generating a notch. 


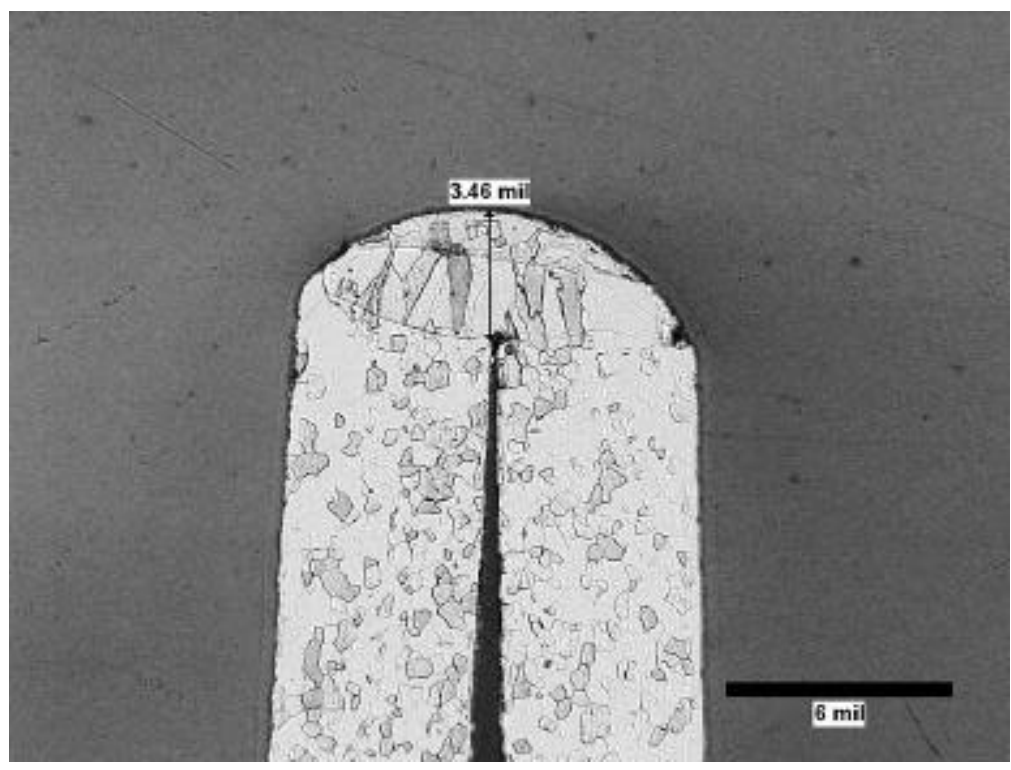

Figure 98. Laser edge weld of 0.005 " thick stock.

E-beam was also used to edge weld 0.025 " thick sheets. A micrograph of this weld is shown in Figure 99 .A pulsed e-beam with a frequency of $3.3 \mathrm{~Hz}$ and average power of about $120 \mathrm{~W}$ was used. The weld width is about the same as that in the case of the laser weld, but deeper penetration was obtained.

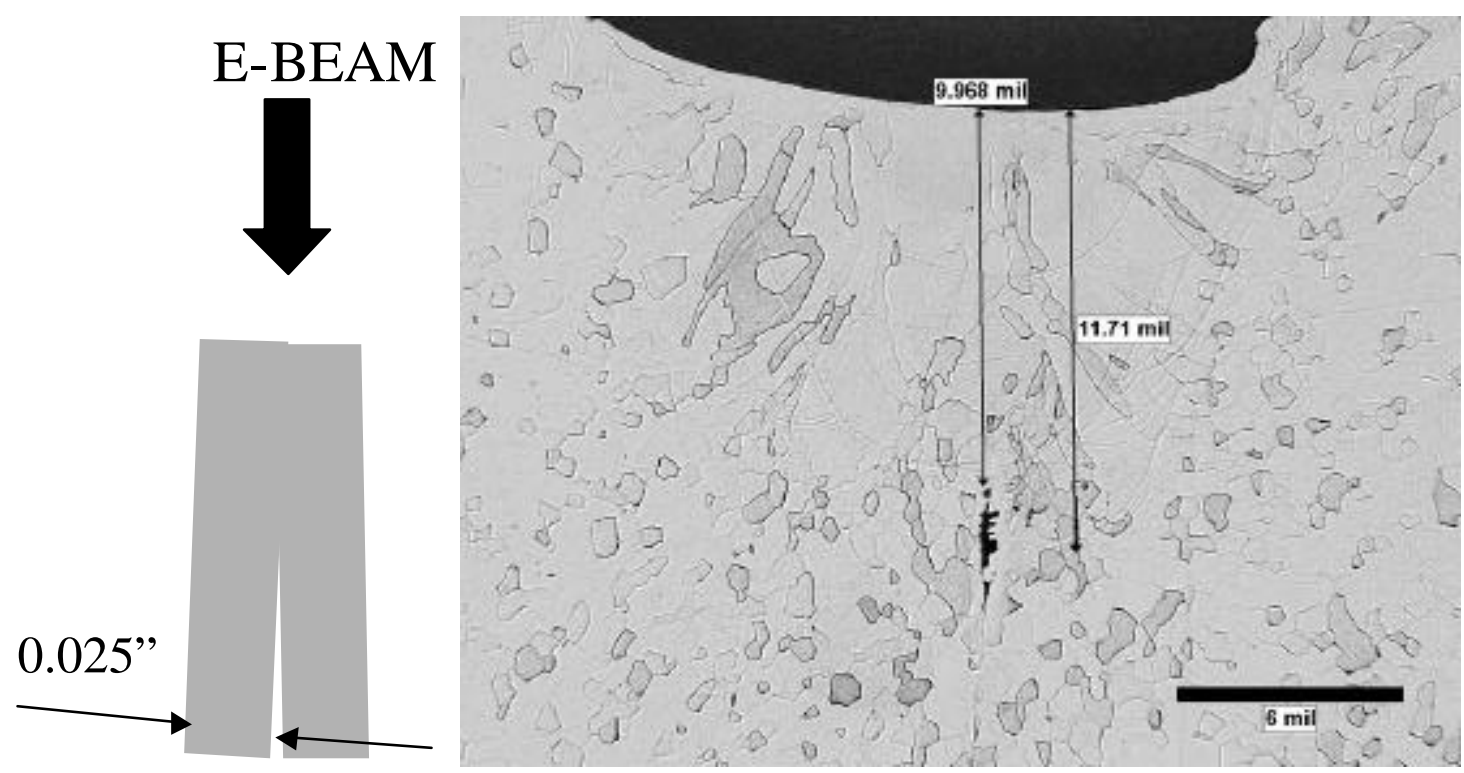

Figure 99. E-beam edge weld of 0.025 " thick sheets. 
E-beam lap weld was done on of 0.025 " thick sheets and the cross section is shown in Figure 100. The power used was 18\% higher than that used in the case of the edge weld. Full penetration through the first sheet was obtained with less than 0.020 " weld width in the top sheet.

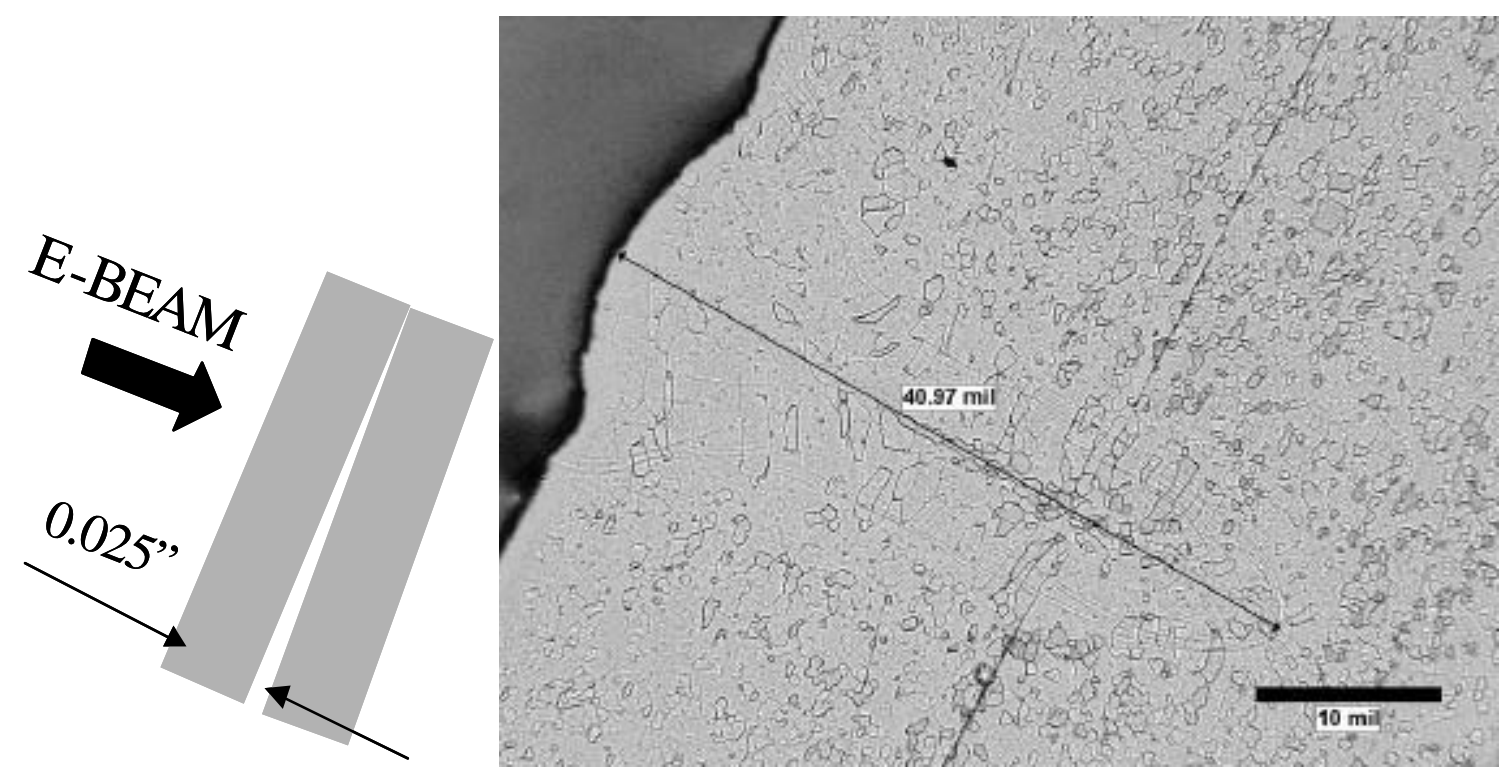

Figure 100. E-beam lap weld of $0.025 "$ thick sheets.

Welding of Interconnect Components in the Presence of Glass Seals

For some of the assembly sequences described previously, it is advantageous to be able to pre-seal the cell to the cell support and then join the cell support to the rest of the interconnect. A limited set of experiments was performed to evaluate this possibility. The test vehicles used involved having 1" button cells pre-sealed (using a glass seal) to the 1.5" test washers, shown in Figure 84, followed by welding these to the 1.5 " stamped cups. The following configurations were tried:

- Laser edge

- E-beam edge

- E-beam lap

Laser edge welding of 0.025 "material with glass sealed cell resulted in seal delamination in 2 of the 4 samples. In the case of the 2 samples that survived, the weld parameters used were: Feed rate $=1.9 \mathrm{in} / \mathrm{s}$; spot size $=0.008$ "; beam energy $=0.516 \mathrm{~J} /$ pulse. A photograph of these samples is shown in Figure 101. 


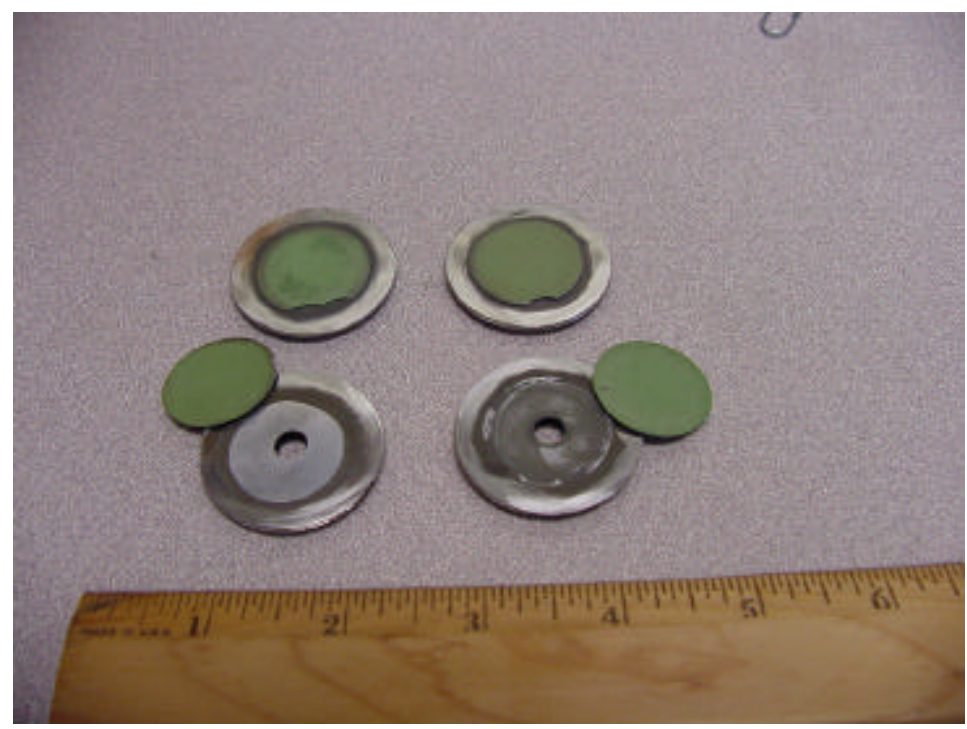

Figure 101. Photograph of samples after laser edge welding of 0.025 " material with glass sealed cell.

A photograph of samples that were E-beam welded is shown in Figure 102. The upper two cells were edge welded, whereas the lower three cells were lap welded. All cells survived without seal delamination. This is confirmed by the fact that for the power settings used in these experiments, the e-beam welds showed deeper penetration for the same weld width than laser welds.

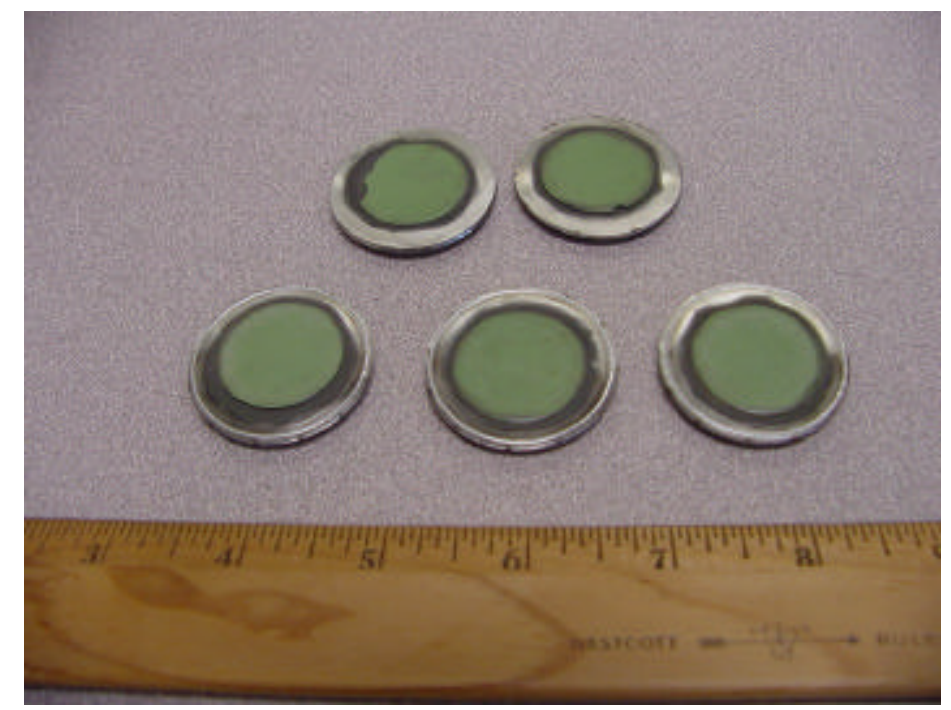

Figure 102. Photograph of samples after E-beam welding of 0.025 " material with glass sealed cell. 
The key observations were:

- The glass seal in the laser-welded test article failed and led to delamination of the cell from the metal. There are two plausible explanations for this:

i. The springback gap (see Figure 92) between the mating edges was large, thus requiring a higher laser power level to accomplish the weld. Excess heat may have caused the seal to delaminate

ii. The forces exerted during clamping of the two parts caused excessive bending of the cell support, thus delaminating the seal

- Cells in some of the other cases showed cracking, but mechanical integrity of the seal was retained. It is not clear if leaks had developed in the glass seal.

\subsubsection{Unitized Cell Module Fabrication}

\subsubsection{Assembly of Unitized Cell Modules}

A typical planar SOFC stack consists of a number of repeating unitized cell modules stacked one on top of another. Each cell module consists of one planar fuel cell, metallic interconnects contacting the anode and cathode to collect current, and means to provide fuel and air to the anode and cathode side respectively. The interconnect of cell modules needs to be designed to perform the following functions:

- Maintain electrical continuity from the cathode of one cell module to the anode of the next

- Maintain electrical insulation between the anode and cathode of the same cell

- Carry fuel and air uniformly to all cell modules, while completely isolating the transport path of one from that of the other

For the current study, a typical cell module was chosen to include the following subcomponents:

(1) Fuel cell: Ceramic trilayer of anode, electrolyte and anode

(2) Anode side interconnect: Consists of the current collector and flow channels, typically stamped from sheet metal

(3) Cathode side interconnect: Consists of current collector and flow channels, typically stamped from sheet metal 
It must be noted that the anode side interconnect and cathode side interconnect may be two opposite sides of the same bipolar interconnect. However, since it is more convenient to consider the fuel cell as the central component of the repeating cell module, these two are shown separately

(4) Cell support: The metallic portion of either the anode side interconnect or cathode side interconnect to which the cell is attached

(5) Seal: Seal between fuel cell and bipolar plate

(6) Anode bond: Means to bond anode current collector with fuel cell anode

(7) Cathode bond: Means to bond cathode current collector with fuel cell cathode

(8) Fuel manifold: Means to carry fuel through stack to various cells

(9) Air manifold: Means to carry air through stack to various cells

Figure 103 is a schematic representation of a typical arrangement these components in a cell module, and of cell modules in a stack. There are several challenges surrounding the assembly of the individual subcomponents into a working stack. The fragility of the ceramic fuel cell owing to its brittleness, the need for high temperature gaseous and electrical isolation, differential thermal expansion of various components, manufacturing variations, incompatibility of some assembly processes with some other components, are just a few. As a result, the process of assembly of a stack from its subcomponents is a nontrivial one. Module design therefore consists of both the designs of individual components, as well as designing the various assembly processes required in the path towards building the stack. 


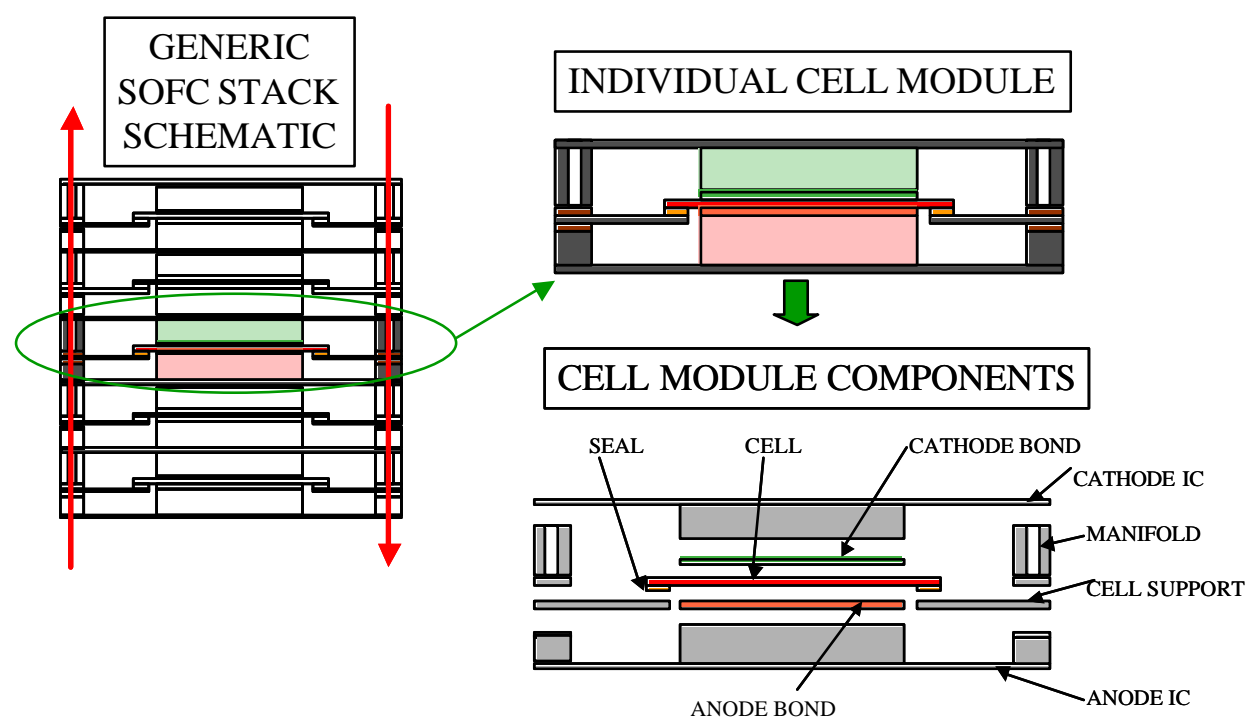

Figure 103. Schematic of planar SOFC stack, cell module, and components.

\section{Design for Assembly}

There are multiple design options for each of these components that effectively address one or more of the challenges. It is therefore effective to consider these various options, and evaluate all practical stack assembly paths under each design choice. Each of these assembly paths will place certain requirements on the manufacturing capability of each component and each assembly process required in building the stack. The challenge before stack designers is one of closing the gap between process capabilities and requirements. In this project some of the process capability issues involved in component fabrication and assembly were addressed.

The set first design options considered here relates to the location of the fuel cell with respect to the cell support. The space defined by the anode side interconnect and the cell support is necessarily a cavity carrying the fuel. One may choose to place the cell "inside" or "outside" this cavity. These configurations can be visualized by thinking of the anode side interconnect and cell support as a shoe box with a opening cut in the lid of the box large enough the expose the surface of the fuel cell, but not large enough for the cell to fall through. For the "outside" configuration the fuel cell is attached to the outside of the lid. While for the "inside" configuration the lid is removed from the box, the fuel cell is then attached to the inside of the lid, and the lid then replaced back on the box. Each option has its own advantages relating to the fabrication of interconnects, location of inter-module insulation and cell sealing. 
The second set of design options considered here relates to the location of the electrical insulation between the cathode side interconnect and anode side interconnect, with respect to the cell support. It is always true that the insulation must also seal at least one or both of the fuel and air streams. Placing the electrical insulation between the cell support and anode side interconnect requires that the entire fuel cavity be sealed by the same electrical insulator. If this is done, cell support will be at the anode electrical potential (V). Placing the insulation between cell support and cathode side interconnect requires that it seal the fuel, and possibly air manifold(s). Under this option, cell support will be at cathode electrical potential.

Figure 104 captures these high-level design options. Next, the various assembly operations that need to be accomplished while building a stack, and the various process options for each must be examined. In Figure 105 below, the exploded view of the cell module in Figure 104 is used here to point out the various assembly operations.

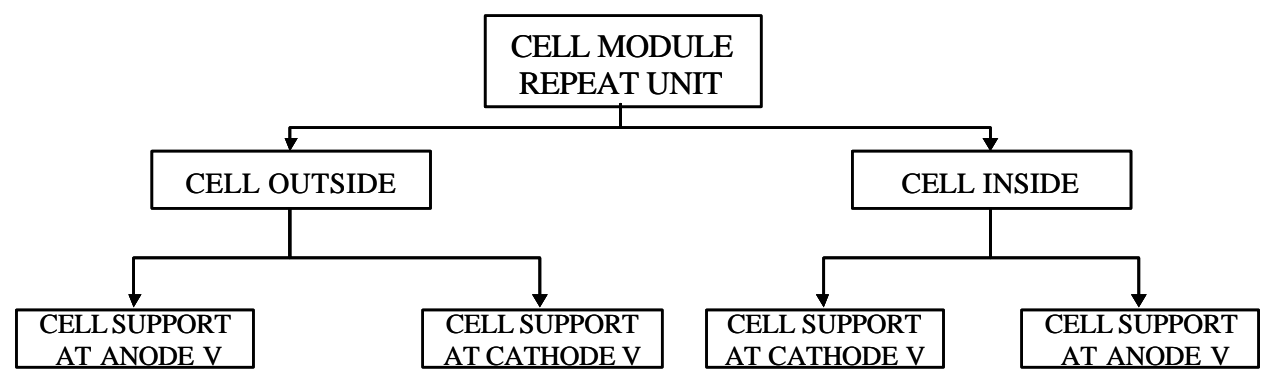

Figure 104. Design choices that govern stack assembly pathways.

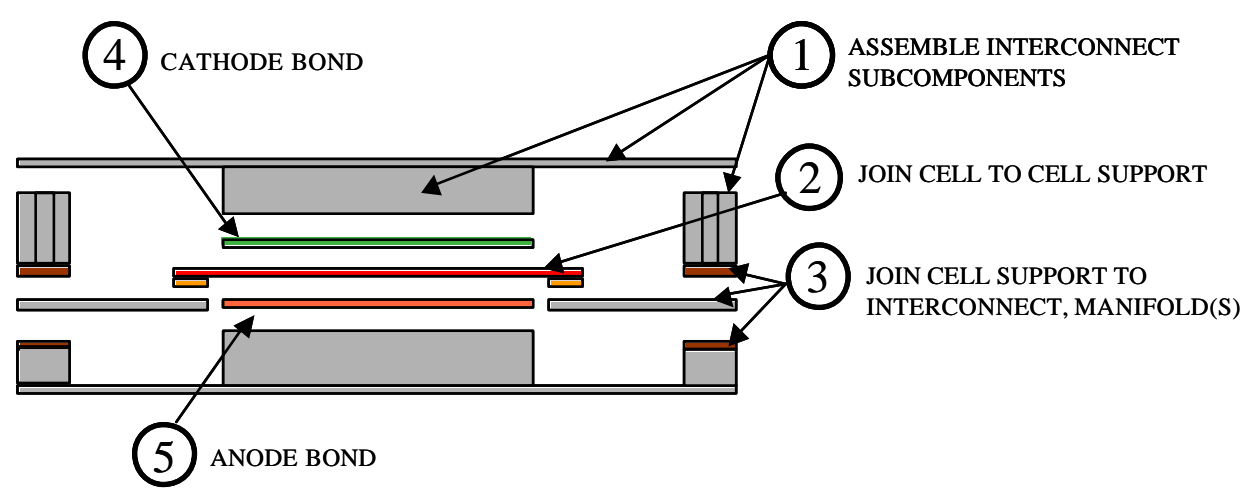

Figure 105. Assembly operations in building a stack. 
Each of these assembly operations either affects, or is affected by the design and manufacture of individual components. A comprehensive matrix of these component-process interactions is presented in Table 24 below. Also listed in this table are some of the process options for each operation that have been considered in this study. As the understanding of stack building technology grows, this list will grow and mature.

Table 24. Interactions Between Components and Assembly Operations

\begin{tabular}{|c|c|c|c|c|c|}
\hline $\begin{array}{r}\text { Assembly } \\
\text { Operations } \\
\end{array}$ & $\begin{array}{c}\text { Assemble IC } \\
\text { subcomponents }\end{array}$ & Cell/Cell support joint & $\begin{array}{c}\text { Join cell } \\
\text { support//C/Manifold }\end{array}$ & Anode bond & Cathode bond \\
\hline $\mathrm{Cc}$ & $\begin{array}{l}\text { " Braze } \\
\text { * Beam weld } \\
\text { " Resistance weld }\end{array}$ & $\begin{array}{l}\text { * Glass seal } \\
\text { × Braze } \\
\text { * Compressive gasket }\end{array}$ & $\begin{array}{l}\text { * Metal braze } \\
\text { * Beam weld } \\
\text { * Resistance weld } \\
\text { * Compressive gasket } \\
\text { * Glass seals }\end{array}$ & ${ }^{*} \mathrm{Ni}$ bond paste & * LSM bond paste \\
\hline Fuel Cell & ${ }^{*}$ Limit IC distortion & $\begin{array}{l}\text { * Cell flatness } \\
{ }^{\star} \text { Cell strength v/s } \\
\text { compressive load } \\
{ }^{\star} \text { Cell braze survival }\end{array}$ & $\begin{array}{l}\text { * Effect on cell when } \\
\text { cell pre-ioined }\end{array}$ & $\begin{array}{l}\text { * Cell flatness } \\
\text { * Bond paste gap filling } \\
\text { capability }\end{array}$ & $\begin{array}{l}\text { * Cell flatness } \\
\text { * Bond paste gap filling } \\
\text { capability }\end{array}$ \\
\hline Anode/Cathode IC & \multirow{2}{*}{\multicolumn{3}{|c|}{$\begin{array}{l}\text { * Subcomponent tolerances, flatness } \\
\text { * Distortion after joining }\end{array}$}} & $\begin{array}{l}\text { * Flatness/tolerance of } \\
\text { IC } \text { v/s bond paste gap } \\
\text { filling capability }\end{array}$ & $\begin{array}{l}\text { * Flatness/tolerance of } \\
\text { IC v/s bond paste gap } \\
\text { filling capability }\end{array}$ \\
\hline Cell Support & & & & & \\
\hline \begin{tabular}{|l|} 
Fuel Manifold \\
Air Manifold \\
\end{tabular} & \multicolumn{3}{|r|}{$\begin{array}{l}\text { "Flatness of mating } \\
\text { surfaces }\end{array}$} & & \\
\hline
\end{tabular}

\section{Stack Assembly Pathways}

Having identified the key process options available for each assembly operation, it is now possible to enlist all possible assembly pathways (sequences) for each of the design choices enlisted in Figure 104. Listed below are a number of possible assembly sequences that could be employed to build stacks from unitized cell modules. In the text below, "closed interconnect" refers to an interconnect to which the cell support has already been attached. Pictorial representations are provided for the initial few sequences in order to amiliarize the reader with the terms.

(A) Cell outside; cell support sheet at anode potential

Sequence \#1: All at once (Figure 106) - all metallic components are fabricated, and then all components are assembled and sealed in a single firing operation 


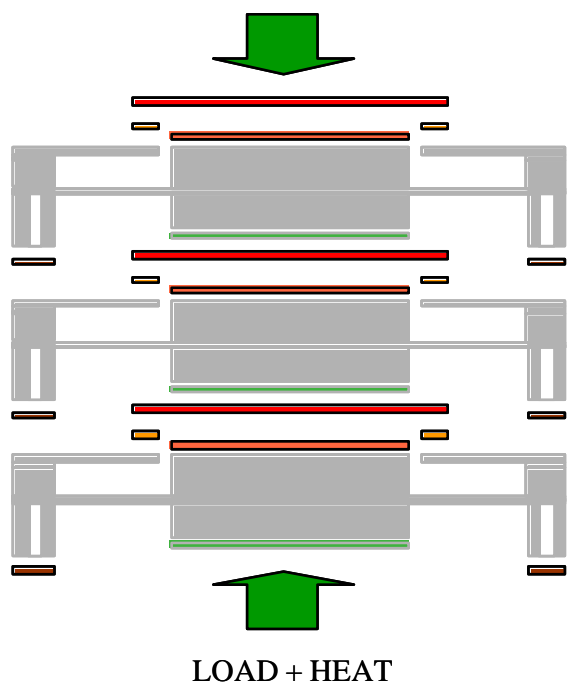

Figure 106. Sequence \#1 All at once-pre-assemble all metallic interconnect components along with cell support.

Sequence \#2a: Closed anode side interconnect - presealed cell (Figure 107) - this case is identical to Sequence \#1 expect that the cell is sealed to the anode side interconnect in a separate operation and then the stack would be assembled and manifold seals made.

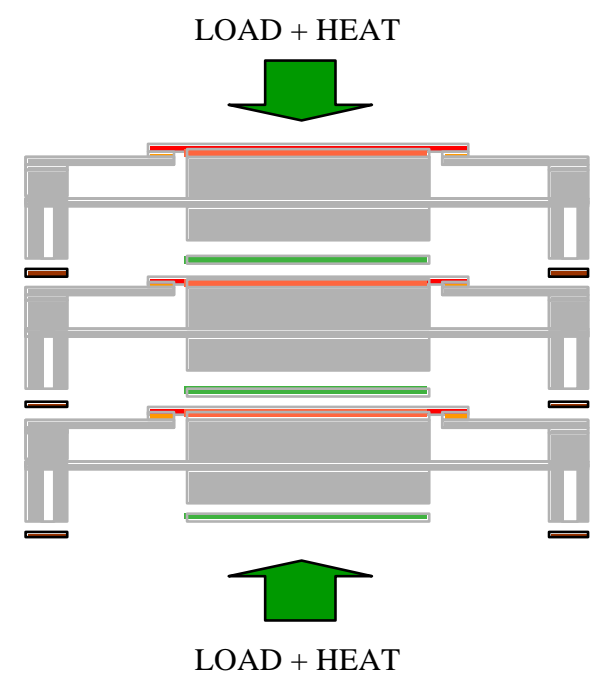

Figure 107. Sequence \#2a: Close anode side interconnect, seal cell before stack, assemble and manifold. 
Sequence \#2b: Preseal cell - close interconnect (Figure 108) - In this case the cell is sealed to the cell support sheet which is then joined to the anode side interconnect. After the cell/cell support and the interconnect are joined the stack is then assembled and the manifold seals made.
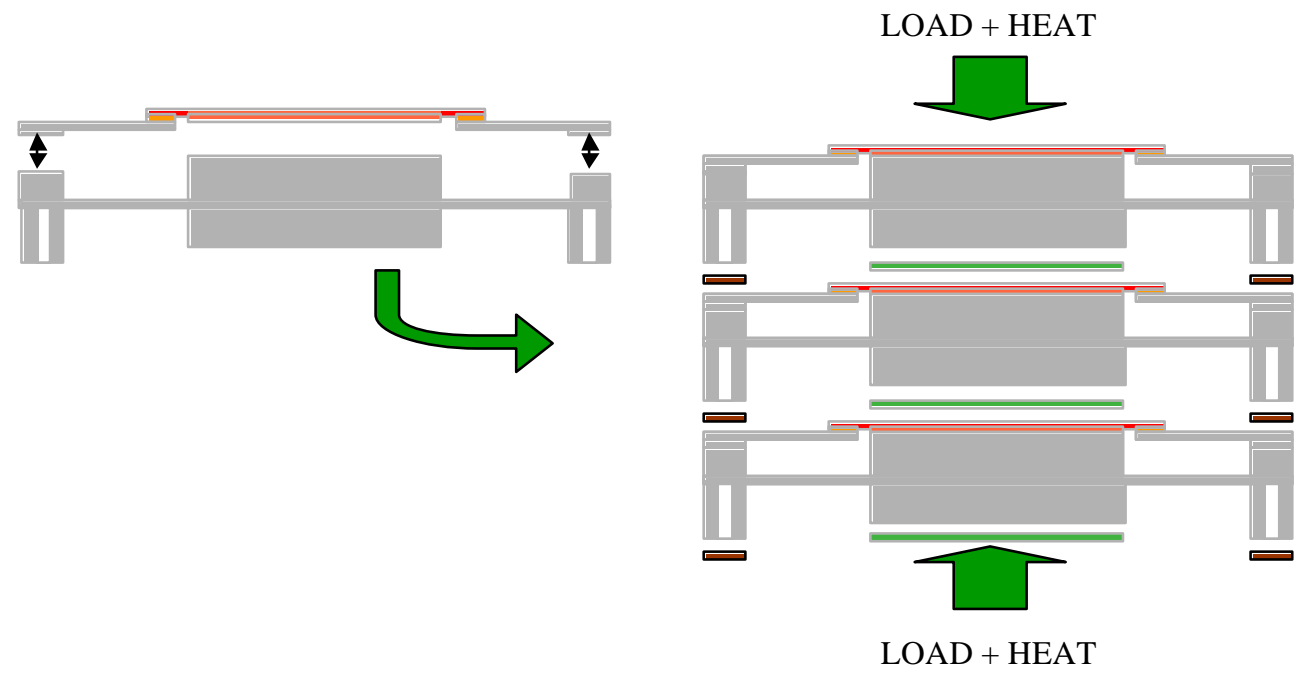

Figure 108. Sequence \#2b: Preseal cell, close interconnect, assemble and manifold.

Sequence \#3: All seals first - In this case the cell and the manifold is first sealed to the cell support sheet. The cell/cell support/manifold assembly is stacked and sealed to the interconnects.

A similar set of sequences is possible for other configurations

(B) Cell outside; cell support at cathode potential

(C) Cell inside; cell support at cathode potential

(D) Cell inside; cell support at anode potential

Each of the sequences above has its own limitations and process restrictions that would need to be considered in adopting an assembly approach, such as sealing operations that require special conditions that are not compatible with other components or may lead to reduced reliability. One example would be brazing of the interconnects, typically brazing is performed in a low por environment, this atmosphere can cause reduction of some cathode materials, therefore an assembly sequence with a brazing step after a cell has been attached would not be feasible. Another example would be an assembly sequence, such as Sequence \#1 (all at 
once), in this sequence all of the seals are made in the same operation, this does not allow for checking of seal quality of individual parts before incorporation into the completed stack, this assembly order would require a very reliable sealing process in order to not create a high rejection rate of completed stacks. Development of this matrix allows the component engineers and stack designers a structure to test stack and component assembly processes against.

\subsubsection{Performance Testing}

The electrochemical performance of a 4" circular tape calendered cell mounted on a 6" sheet metal interconnect was tested. The interconnect was manufactured by stamping 0.025 " thick stainless steel using a custom-made die. It has an outer diameter of 6", and an inner stamped region of diameter 4". The cell support sheet was manufactured by water jet cutting. The cell support sheet and interconnect were joined by laser welding, using the parameters determined in the earlier welding experiments on 1.5" stamped cups. The configuration of parts in the interconnect is shown in an exploded section view below.

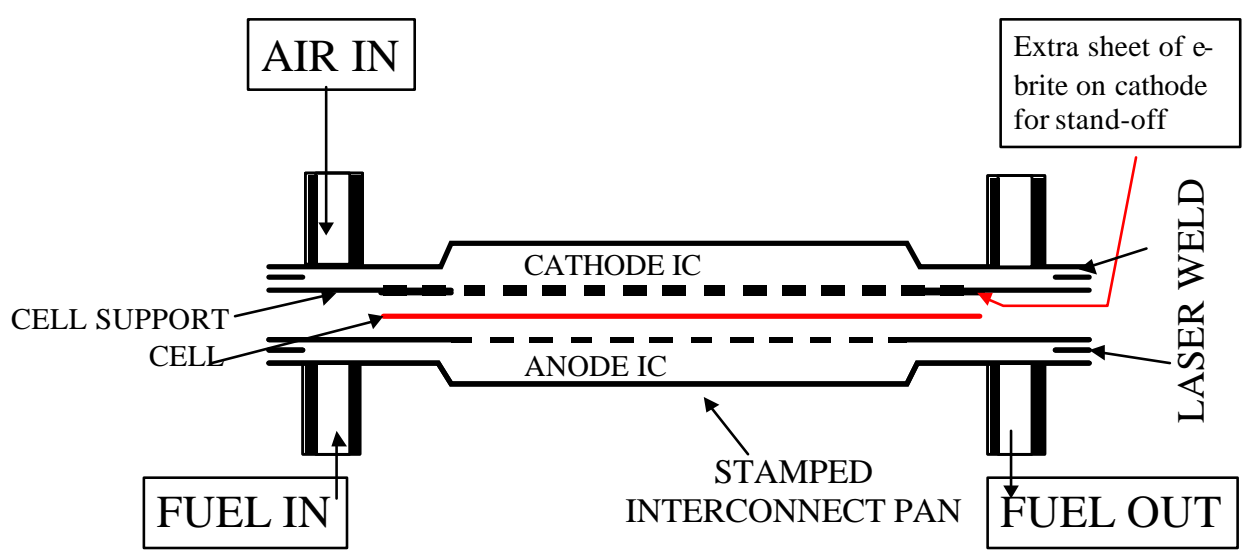

Figure 109. Six inch test vehicle cross-section schematic.

The individual components of the interconnects are shown in Figure 86. Shown in Figure 110 are photographs of the laser welded cathode and anode interconnects. The cathode interconnect has a raised region to contact the cell in order to minimize short circuiting risk between the interconnects. 


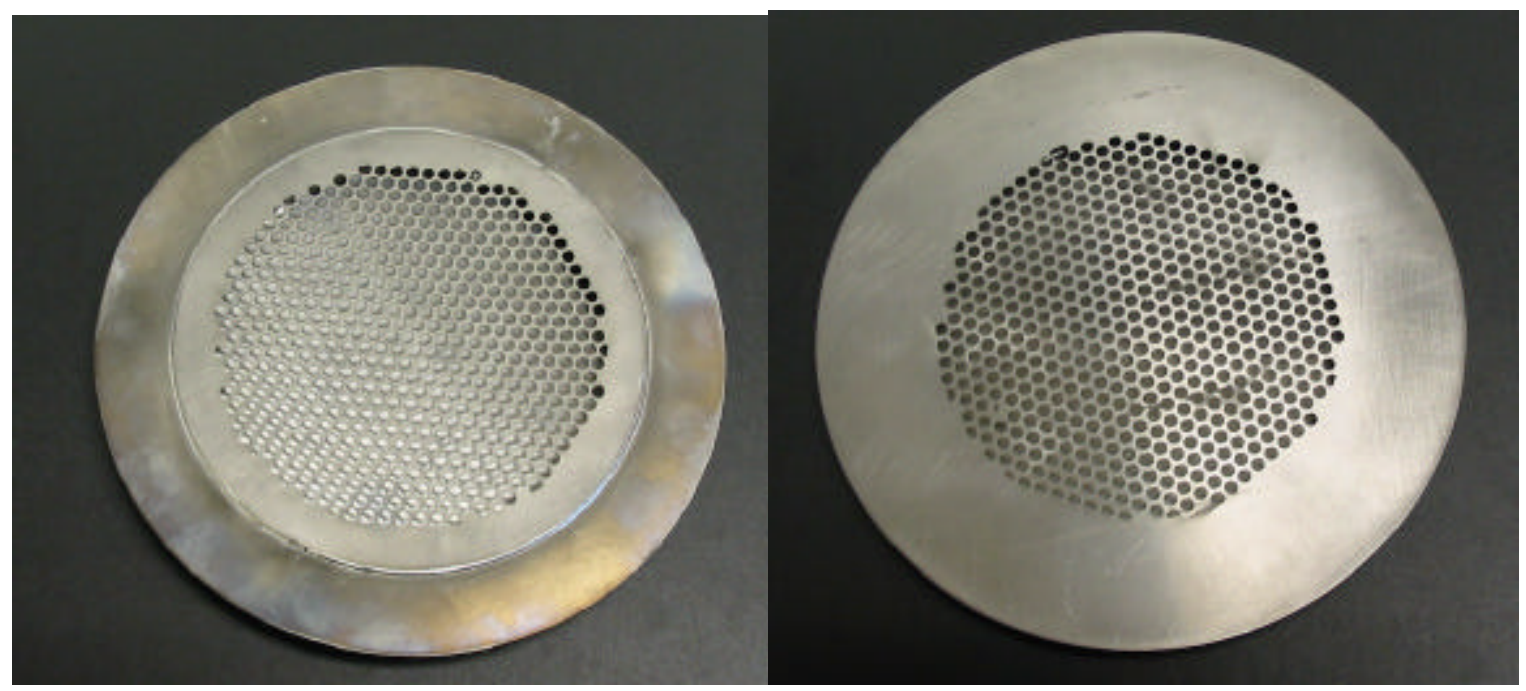

Figure 110. Stamped, laser welded 6" interconnects. Cathode interconnect (left); Anode interconnect (right).

Flatness measurements were performed on the fuel cell, anode cell support and cathode cell support regions. The measurements are shown in Figure 111.

FLATNESS MEASUREMENTS

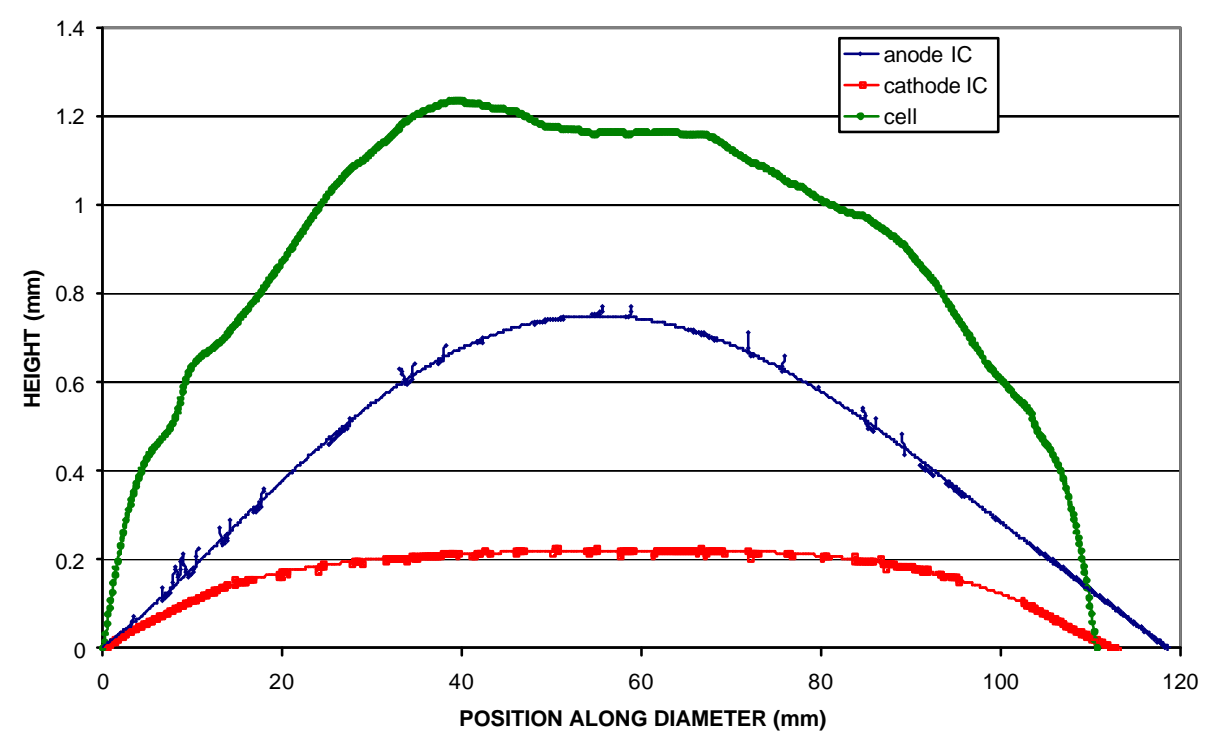

Figure 111. Curvature measurements on cell and interconnects used in test Oly001.

One key observation was regarding the special arrangement of the current collector in the cathode interconnect. In an attempt to physically separate the outermost regions of the two interconnects, the cathode current collector was made by laser welding a smaller circular sheet to a larger annular sheet, as shown in DE-AC26-00NT40705 
Figure 109. This welding operation led to distortion of the cell support sheet, which in turn resulted in the upper surface of the cathode interconnect to be curved by approximately $2 \mathrm{~mm}$ from center to edge.

During assembly of the fuel cell, the cathode bond paste was applied by stencil printing, using a 0.015 " thick stencil. This gave a rapid method to apply a uniform layer of bond paste onto the interconnect.

The performance curves from two module tests, test Oly001 and Oly002, were obtained at $800^{\circ} \mathrm{C}$. The polarization curves from the test are shown in Figure 112 and Figure 113. A peak power density of $215 \mathrm{~mW} / \mathrm{cm}^{2}$ was obtained on test Oly001 and a peak measured power density of $262 \mathrm{~mW} / \mathrm{cm}^{2}$ (extrapolated maximum power density of $292 \mathrm{~mW} / \mathrm{cm}^{2}$ ) for Oly002. The acceptable performance of these tests is a demonstration of low cost interconnect manufacturing methods, viz. sheet metal forming and laser welding.

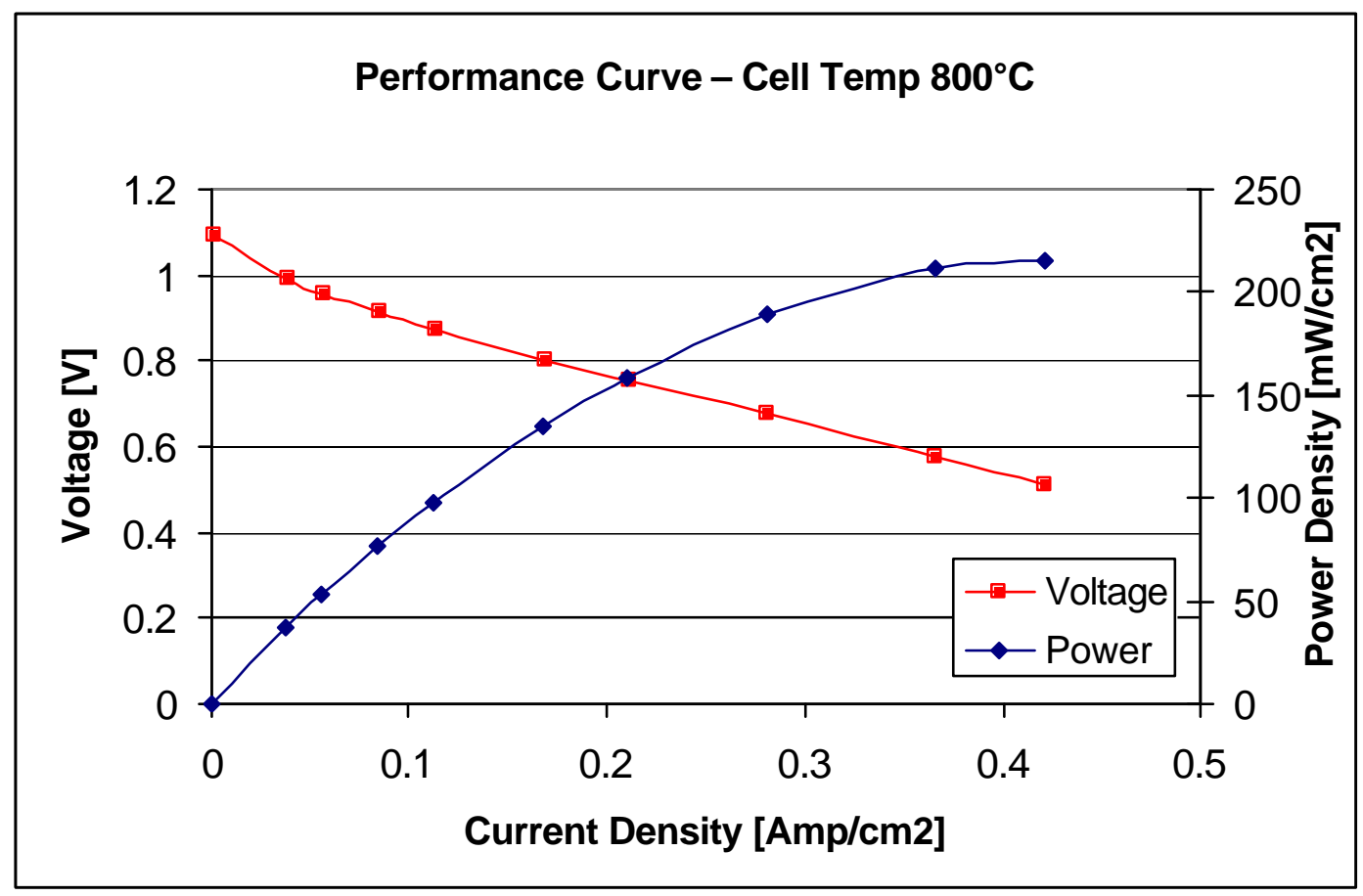

Figure 112. Performance curve from test Oly001. 


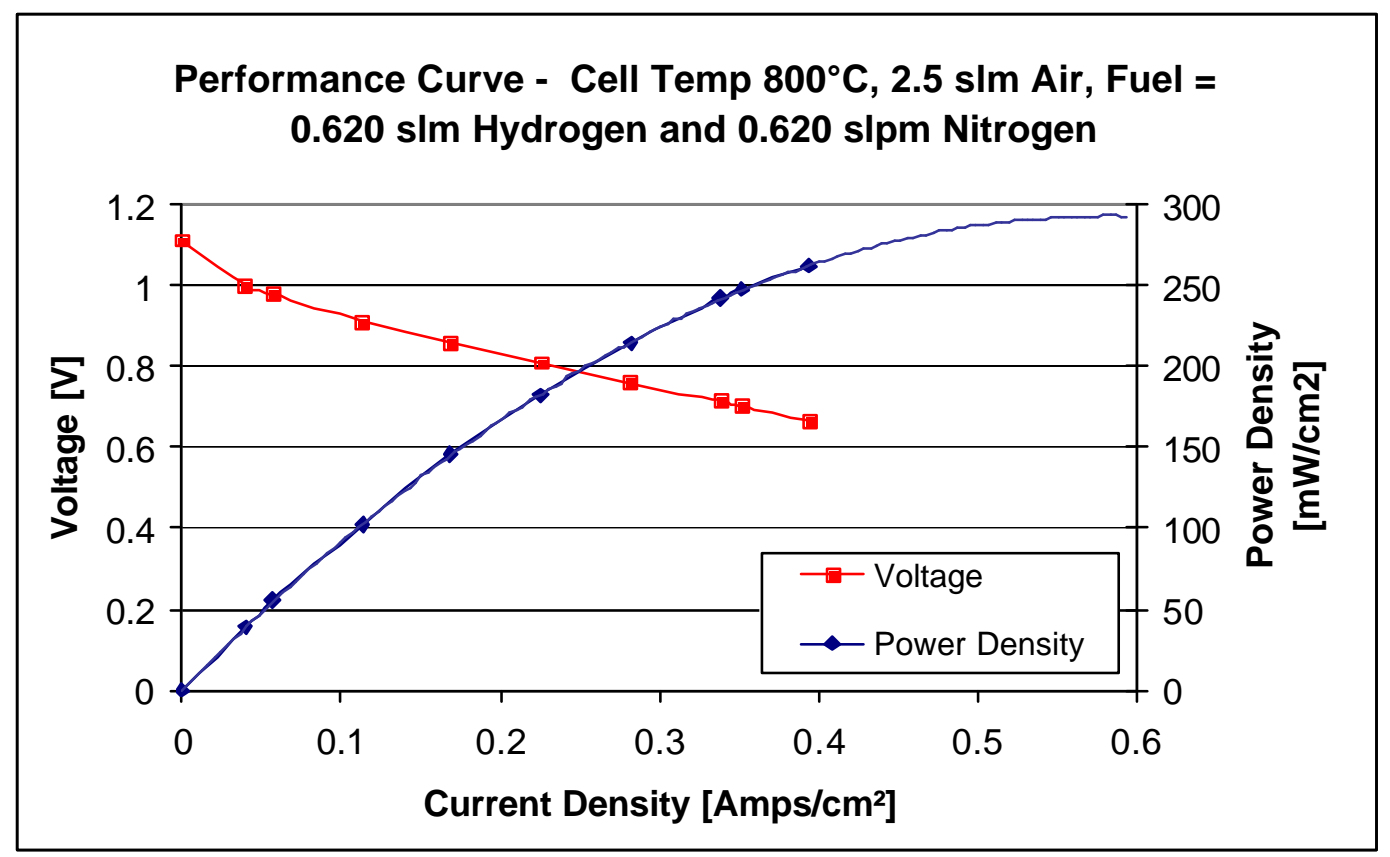

Figure 113. Performance curve from test Oly002.

\section{CONCLUSIONS}

The work done under this program has advanced the understanding and engineering knowledge in a number of areas. The key accomplishments are summarized below:

- Cathode and anode improvements, such as modifications to powder morphologies and compositions, processing improvements and formulation changes, have lead to significantly improved SOFC performance especially in the 650 to $700^{\circ} \mathrm{C}$ range

- Cell power density increased from $0.243 \mathrm{~W} / \mathrm{cm}^{2}$ to $0.892 \mathrm{~W} / \mathrm{cm}^{2}$ for $650^{\circ} \mathrm{C}$ operation. This performance was world leading at the time of reporting.

- Cells were operated at $85 \%$ fuel utilization

- Cells were fabricated that exhibited a $3 x$ improvement in flexure strength, while maintaining a peak power density of $0.914 \mathrm{~W} / \mathrm{cm}^{2}$.

- Flow fields designs for unitized cells were analyzed and optimized for improved flow uniformity across the active area

- $70 \%$ fuel utilization with at a power density of greater than $0.2 \mathrm{~W} / \mathrm{cm}^{2}$ was demonstrated on a unitized cell operating on dilute hydrogen $(64 \%)$ 
- Several NDE techniques for flaw detection in multilayer cells were evaluated; digital radiography was selected for further evaluation

- Manufacturing baseline process maps were created

- Baseline process capability data gathered

- Tools for gather and analyzing capability data developed

- The process maps have been used to identity key areas for improvements

- Developed forming models and investigated advanced joining methods, such as laser, e-beam and micro TIG welding, for fabricating complex interconnect structures

Based on the work done on this program, the following areas would be recommended for further investigation:

- Continued improvement to cathode and anode performance, especially in the area of microstructure engineering for improved lower temperature operation

- Development and refinement of NDE techniques (digital radiography and others) for improved cell reliability.

- Uses results gathered from the baseline process analysis work to develop and investigate methods/approaches to improve sintering yield and bilayer tape first pass

- Metal forming and joining approaches investigated on more complex components for SOFC stacks and evaluated performance in further electrochemical tests

- Use of the flow distribution improvement to develop stack designs for highefficiency and high-performance operation

\section{REFERENCES}

' Adams, et al., J. Am. Ceram. Soc., 80 [4] 903-908 (1997). 